\title{
Determining organic vapor cartridge breakthrough characteristics of JP-8 during aircraft fuel tank entry operations
}

Kevin W. Culp

West Virginia University

Follow this and additional works at: https://researchrepository.wvu.edu/etd

\section{Recommended Citation}

Culp, Kevin W., "Determining organic vapor cartridge breakthrough characteristics of JP-8 during aircraft fuel tank entry operations" (2000). Graduate Theses, Dissertations, and Problem Reports. 1002.

https://researchrepository.wvu.edu/etd/1002

This Thesis is protected by copyright and/or related rights. It has been brought to you by the The Research Repository @ WVU with permission from the rights-holder(s). You are free to use this Thesis in any way that is permitted by the copyright and related rights legislation that applies to your use. For other uses you must obtain permission from the rights-holder(s) directly, unless additional rights are indicated by a Creative Commons license in the record and/ or on the work itself. This Thesis has been accepted for inclusion in WVU Graduate Theses, Dissertations, and Problem Reports collection by an authorized administrator of The Research Repository @ WVU. For more information, please contact researchrepository@mail.wvu.edu. 


\title{
DETERMINING ORGANIC VAPOR CARTRIDGE BREAKTHROUGH CHARACTERISTICS OF JP-8 DURING AIRCRAFT FUEL TANK ENTRY OPERATIONS
}

\author{
by \\ Kevin W. Culp \\ Thesis submitted to the \\ College of Engineering and Mineral Resources at \\ West Virginia University \\ in partial fulfillment of the requirements for the \\ degree of \\ Master of Science \\ in \\ Occupational Hygiene and Safety \\ Warren R. Myers, Ph.D., Chair \\ Paul A. Jensen, Ph.D. \\ Dianne L. McMullin, Ph.D. \\ Department of Industrial and \\ Management Systems Engineering \\ Morgantown, WV \\ 2000
}

Keywords: Respirator, JP-8, fuel, cartridge, breakthrough 


\author{
ABSTRACT \\ DETERMINING ORGANIC VAPOR \\ CARTRIDGE BREAKTHROUGH \\ CHARACTERISTICS OF JP-8 DURING \\ AIRCRAFT FUEL TANK ENTRY \\ OPERATIONS \\ by Kevin W. Culp
}

This study assessed the service life of organic vapor cartridges exposed to Jet Propulsion Type 8 fuel vapor. Two experiments were conducted that involved exposing 45 cartridges to three challenge concentrations $(300,600$, and 1200 parts per million) of fuel vapor and two relative humidity levels (50 and 80 percent). The impact on service life of (1) high relative humidity conditions and (2) prior static exposure to fuel vapor were evaluated.

This study concluded that the 80 percent relative humidity test condition had a statistically significant effect on breakthrough time versus the 50 percent relative humidity condition, reducing service life by as much as 60 percent at the lowest challenge concentration tested. However, this effect was not statistically significant at the highest concentration. Prior exposure to fuel vapor also had a statistically significant impact on service life, but the shift in breakthrough time was minimal and would have a minor impact on cartridge change-out schedule planning. 


\section{ACKNOWLEDGMENTS}

I'd like to extend a very warm "thank you" to all the wonderful people who contributed to the success of this research. Dr. Paul Jensen, Dr. Warren Myers, and Dr. Dianne McMullin spent countless hours tutoring, guiding, and supporting me, graciously donating their time and resources to the project and to me personally. Gary Fletcher and Kurt Van de Stowe were exceptionally instrumental in helping me understand the "ins and outs" of cartridge testing, and were very accommodating of my initial breakthrough testing efforts in their facilities. Sherman Adams, the most talented glassblower in the world, helped to design and create specialized glassware that was a key part of the vapor generation process. Dr. John Zondlo's creative ideas for vapor generation techniques were golden. Dr. Ernie Moyer, Dr. Steve Berardinelli, Steve Martin, Thomas Jefferson, Lee Hall, Bill Hoffman, Dr. Wakif Iskander, Dr. Gary Winn, Maj Les Smith, SSgt Doug Fritts, Jim Dalton, Diana Schwera, and Laszlo Bejo each provided invaluable technical and physical resource contributions to this project. My wife June never ceases to amaze me with her ability to catch manuscript errors; she spent countless hours reviewing and editing my work. Even more critical was the encouragement June and our little girl, Sarah, gave to me throughout the entire degree program. But most importantly, I want to thank God giving me the desire and ability to learn and for the people He has blessed me with. 


\section{TABLE OF CONTENTS}

LIST OF FIGURES................................................................................................................................................. iv

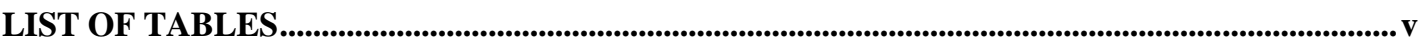

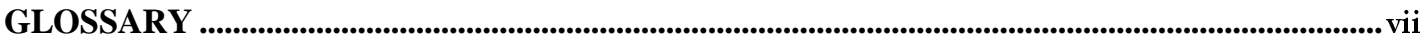

CHAPTER 1. INTRODUCTION ..............................................................................................

1.1. USE OF JET PROPULSION TYPE 8 (JP-8) JET FUEL IN THE U.S. AIR FORCE......................................... 1

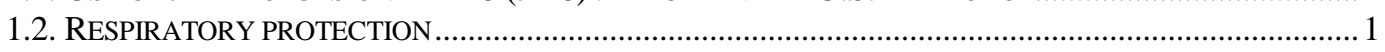

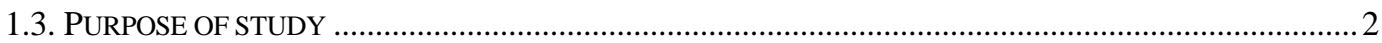

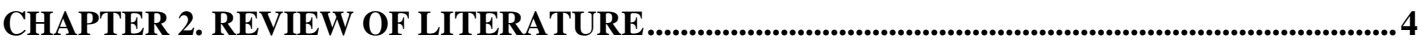

2.1. HISTORY AND PREDOMINANCE OF JP-8 JET FUEL ..............................................................

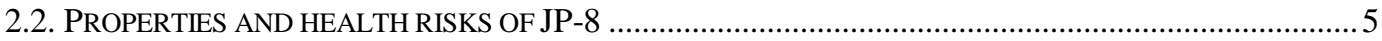

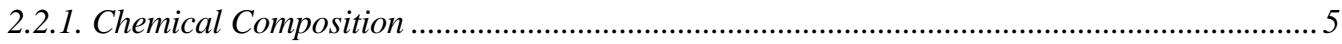

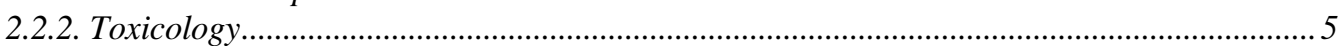

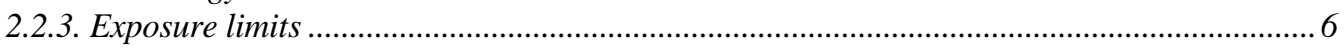

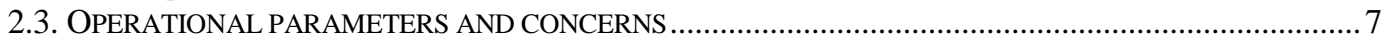

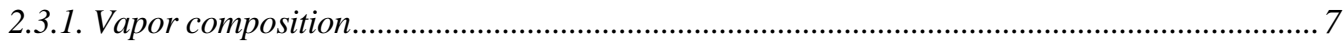

2.3.2. Exposure monitoring data ............................................................................................... 10

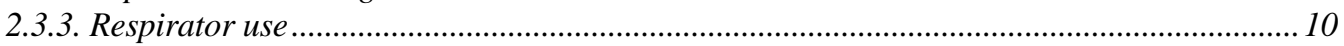

2.3.4. Breakthrough testing parameters vs. the workplace environment .......................................11

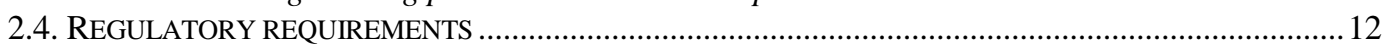

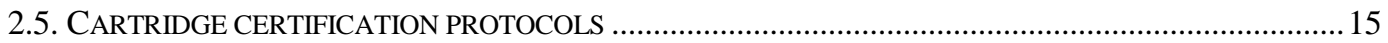

2.5.1. National Institute for Occupational Safety and Health (NIOSH) ....................................... 15

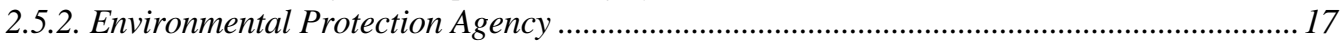

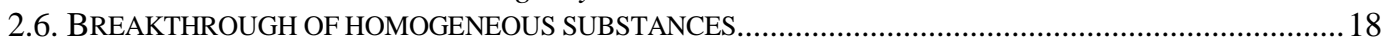

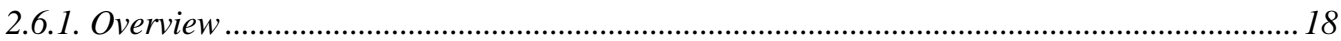

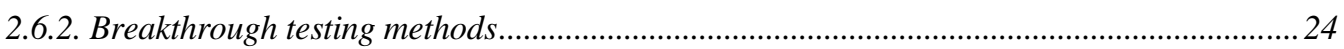

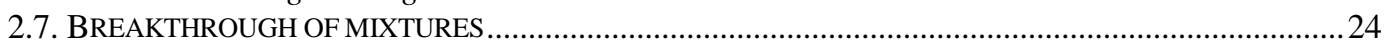

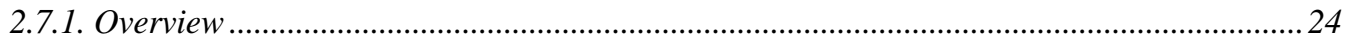

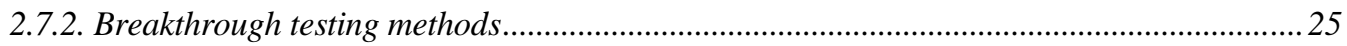

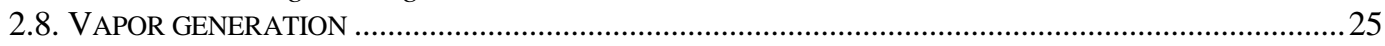

CHAPTER 3. METHODS AND MATERIALS .........................................................................28

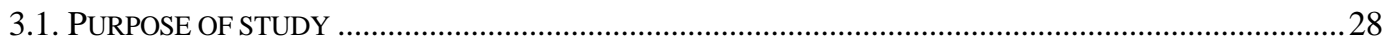

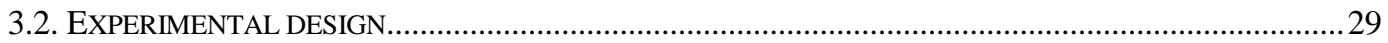

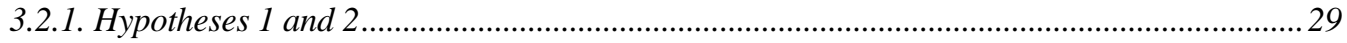

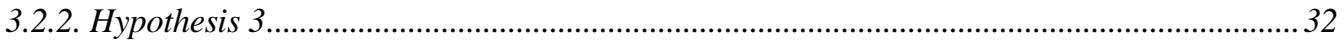

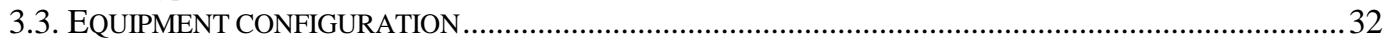

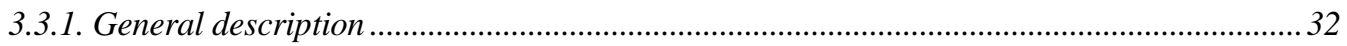

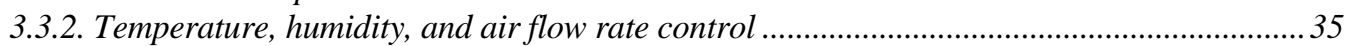

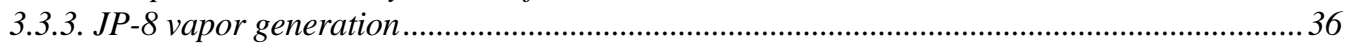

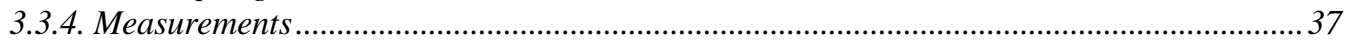

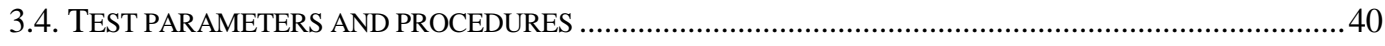

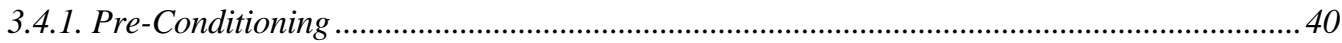




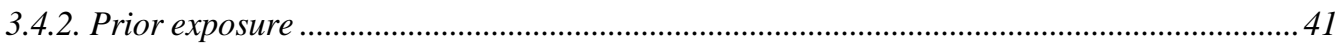

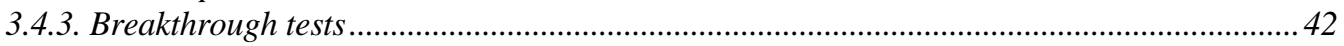

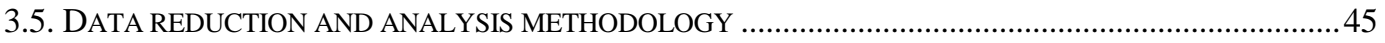

CHAPTER 4. RESULTS ..................................................................................................................................48

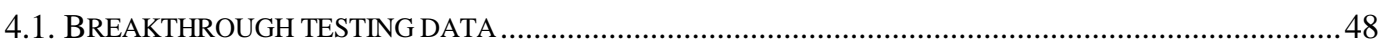

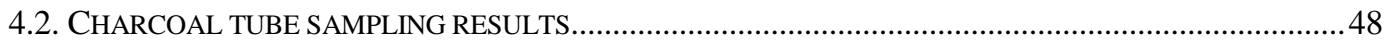

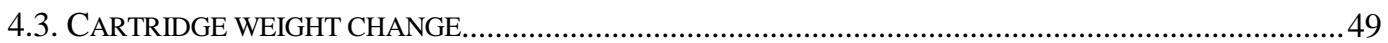

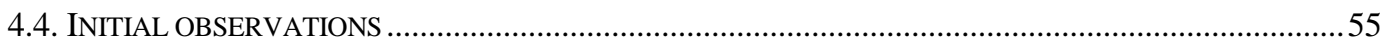

4.4.1. Effects of relative humidity and prior exposure (null hypotheses 1 and 2).........................55

4.4.2. Relationships between breakthrough concentration and time (null hypothesis 3)...............56

CHAPTER 5. ANALYSIS AND DISCUSSION .........................................................................59

5.1. EFFECT OF RELATIVE HUMIDITY AND CHALLENGE CONCENTRATION ON BREAKTHROUGH TIME

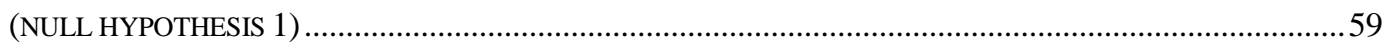

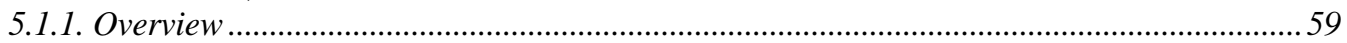

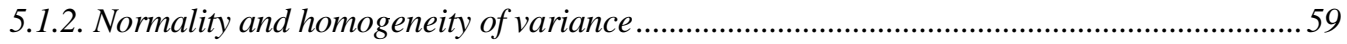

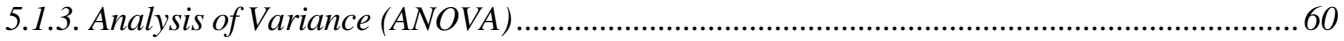

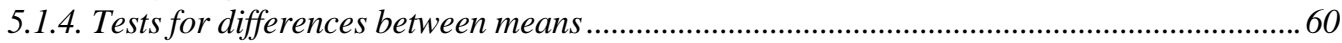

5.2. EFFECTS OF PRIOR EXPOSURE AND CHALLENGE CONCENTRATION (NULL HYPOTHESIS 2) ..............61

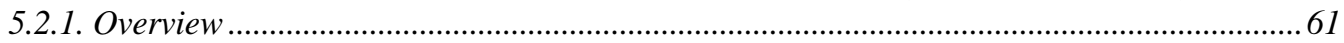

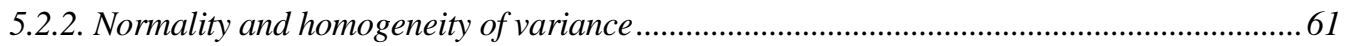

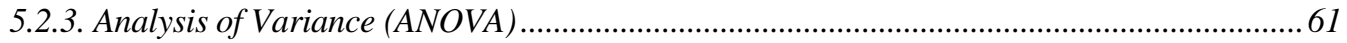

5.2.4. Tests for differences between means ...............................................................................6 62

5.3. ANALYSIS OF BREAKTHROUGH CONCENTRATION VS. BREAKTHROUGH TIME (NULL HYPOTHESIS 3)

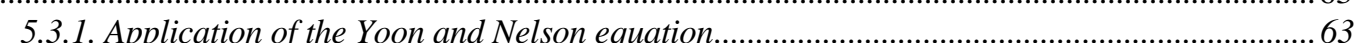

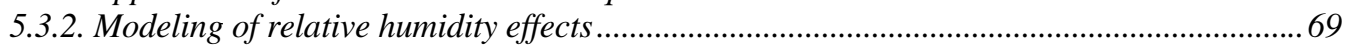

5.4. DEVELOPMENT OF CARTRIDGE SERVICE LIFE GUIDELINES ………………………....................... 71

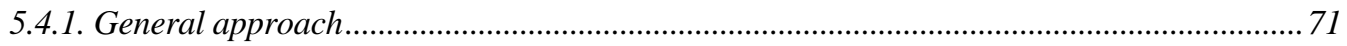

5.4.2. Predicting breakthrough times for the 50 percent relative humidity condition...................... 72

5.4.3. Predicting breakthrough times for the 80 percent relative humidity condition (no prior

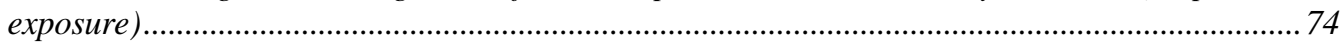

5.4.4. Predicting breakthrough times for the 80 percent relative humidity condition (with prior

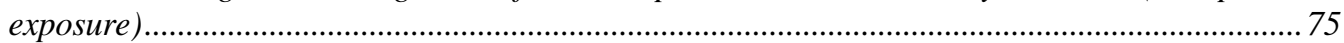

CHAPTER 6. CONCLUSIONS AND RECOMMENDATIONS.............................................................76

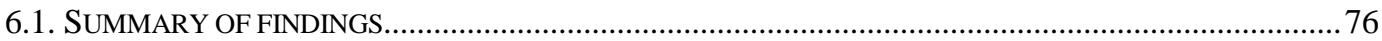

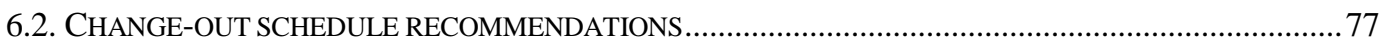

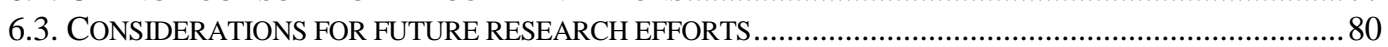

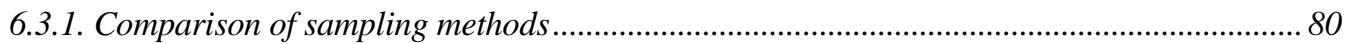

6.3.2. Compositional differences between challenge and breakthrough vapors ............................80 80

6.3.3. Changes in breakthrough times resulting from extensive prior exposure to fuel vapor.......81

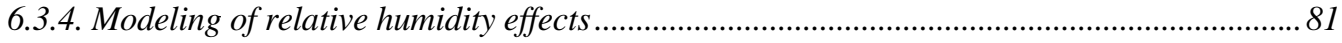

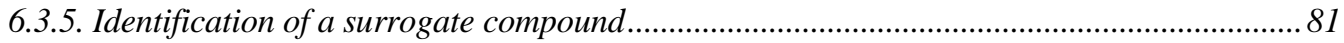

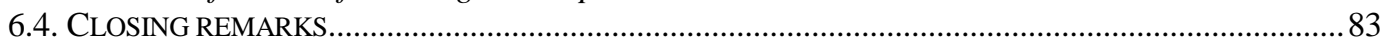


REFERENCES

APPENDICES

APPENDIX A: MEASURED BREAKTHROUGH CONCENTRATION ON OUTLET SIDE OF CARTRIDGES DURING TESTS

APPENDIX B: MODIFIED NIOSH 1550 METHOD SAMPLING RESULTS APPENDIX C: CARTRIDGE WEIGHT CHANGE SUMMARY APPENDIX D: STATISTICAL ASSESSMENT OF RESULTS - SAS/STAT OUTPUT APPENDIX E: CURVE-FITTING ANALYSIS OF GENERALIZED YOON AND NELSON EQUATION 


\section{LIST OF FIGURES}

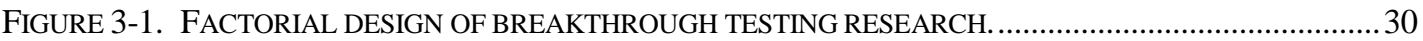

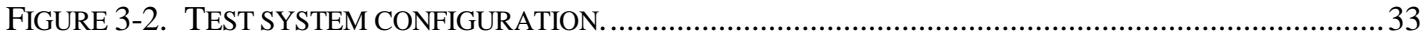

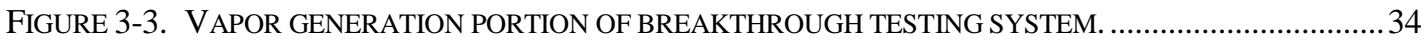

FIGURE 3-4. CUSTOM DISTILLATION HEAD INSERTED INTO TOP OF PACKED COLUMN. .............................37

FIGURE 3-5. CONFIGURATION OF CARTRIDGES INSIDE CHAMBER FOR PRE-CONDITIONING AT 80\%

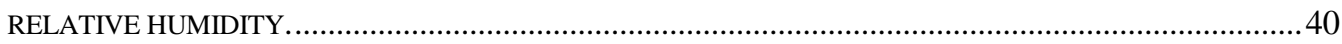

FIGURE 4-1. ESTIMATED MASS OF WATER AND JP-8 FUEL VAPOR FLOWING THROUGH EACH CARTRIDGE PER MINUTE OF BREAKTHROUGH TEST AT $25^{\circ} \mathrm{C}$.

FIGURE 4-2. TOTAL AVERAGE CARTRIDGE WEIGHT GAINS AT 20\% BREAKTHROUGH POINTS FOR EACH TEST CONDITION. (ALL CARTRIDGES WERE PRECONDITIONED FOR 6 HOURS AT 80\% RELATIVE HUMIDITY AND $25^{\circ} \mathrm{C}$.) .

FIGURE 4-3. MEAN BREAKTHROUGH TIME TO 10\% OF JP-8 FUEL VAPOR CHALLENGE CONCENTRATION.

FIGURE 4-4. SCATTER PLOT OF BREAKTHROUGH TIMES FOR 50\% RELATIVE HUMIDITY CONDITION AND NO PRIOR EXPOSURE TO FUEL VAPOR. ALL CARTRIDGES WERE PRECONDITIONED AT $80 \%$ RELATIVE HUMIDITY AND $25^{\circ} \mathrm{C}$ FOR SIX HOURS. PRIOR EXPOSED CARTRIDGES WERE PREVIOUSLY SUBJECTED TO STATIC CONCENTRATIONS OF 1200 PPM FUEL VAPOR FOR EIGHT HOURS AT 80\% RELATIVE HUMIDITY AND $25^{\circ} \mathrm{C}$.

FIGURE 4-5. SCATTER PLOT OF BREAKTHROUGH TIMES FOR 80\% RELATIVE HUMIDITY CONDITION AND NO PRIOR EXPOSURE TO FUEL VAPOR. ALL CARTRIDGES WERE PRECONDITIONED AT $80 \%$ RELATIVE HUMIDITY AND $25^{\circ} \mathrm{C}$ FOR SIX HOURS. PRIOR EXPOSED CARTRIDGES WERE PREVIOUSLY SUBJECTED TO STATIC CONCENTRATIONS OF 1200 PPM FUEL VAPOR FOR EIGHT HOURS AT 80\% RELATIVE HUMIDITY AND $25^{\circ} \mathrm{C}$.

FIGURE 4-6. SCATTER PLOT OF BREAKTHROUGH TIMES FOR 80\% RELATIVE HUMIDITY CONDITION AND PRIOR EXPOSURE TO FUEL VAPOR. ALL CARTRIDGES WERE PRECONDITIONED AT $80 \%$ RELATIVE HUMIDITY AND $25^{\circ} \mathrm{C}$ FOR SIX HOURS. PRIOR EXPOSED CARTRIDGES WERE PREVIOUSLY SUBJECTED TO STATIC CONCENTRATIONS OF 1200 PPM FUEL VAPOR FOR EIGHT HOURS AT 80\% RELATIVE HUMIDITY AND $25^{\circ} \mathrm{C}$.

FIGURE 5-1. SEMI-LOG PLOT OF A GENERALIZED YOON AND NELSON EQUATION AGAINST MEAN BREAKTHROUGH TIMES FOR 50\% RELATIVE HUMIDITY TEST CONDITION. ALL CARTRIDGES WERE PRECONDITIONED AT $80 \%$ RELATIVE HUMIDITY AND $25^{\circ} \mathrm{C}$ FOR SIX HOURS.

FIGURE 5-2. SEMI-LOG PLOT OF A GENERALIZED YOON AND NELSON EQUATION AGAINST MEAN BREAKTHROUGH TIMES FOR 80\% RELATIVE HUMIDITY TEST CONDITION (WITHOUT PRIOR EXPOSURE TO FUEL VAPOR). ALL CARTRIDGES WERE PRECONDITIONED AT 80\% RELATIVE HUMIDITY AND $25^{\circ} \mathrm{C}$ FOR SIX HOURS.

FIGURE 5-3. SEMI-LOG PLOT OF A GENERALIZED YOON AND NELSON EQUATION AGAINST MEAN BREAKTHROUGH TIMES FOR 80\% RELATIVE HUMIDITY TEST CONDITION (WITH PRIOR EXPOSURE TO FUEL VAPOR). ALL CARTRIDGES WERE PRECONDITIONED AT $80 \%$ RELATIVE HUMIDITY AND $25{ }^{\circ} \mathrm{C}$ FOR SIX HOURS. PRIOR EXPOSED CARTRIDGES WERE PREVIOUSLY SUBJECTED TO STATIC CONCENTRATIONS OF 1200 PPM FUEL VAPOR FOR EIGHT HOURS AT 80\% RELATIVE HUMIDITY AND $25{ }^{\circ} \mathrm{C}$.

FIGURE 5-4. GENERALIZED YOON AND NELSON EQUATION FIT TO MEASURED BREAKTHROUGH DATA AT $50 \%$ RELATIVE HUMIDITY, WITHOUT PRIOR EXPOSURE TO FUEL. COEFFICIENTS FOR EQUATION 
WERE DETERMINED INDIVIDUALLY FOR EACH CHALLENGE CONCENTRATION. ALL CARTRIDGES WERE PRECONDITIONED AT $80 \%$ RELATIVE HUMIDITY AND $25^{\circ} \mathrm{C}$ FOR SIX HOURS.

FIGURE 5-5. GENERALIZED YOON AND NELSON EQUATION FIT TO MEASURED BREAKTHROUGH DATA AT 80\% RELATIVE HUMIDITY, WITHOUT PRIOR EXPOSURE TO FUEL. COEFFICIENTS FOR EQUATION WERE DETERMINED INDIVIDUALLY FOR EACH CHALLENGE CONCENTRATION. ALL CARTRIDGES WERE PRECONDITIONED AT $80 \%$ RELATIVE HUMIDITY AND $25^{\circ} \mathrm{C}$ FOR SIX HOURS.

FIGURE 5-6. GENERALIZED YOON AND NELSON EQUATION FIT TO MEASURED BREAKTHROUGH DATA AT $80 \%$ RELATIVE HUMIDITY, WITH PRIOR EXPOSURE TO FUEL. COEFFICIENTS WERE DETERMINED INDIVIDUALLY FOR EACH CHALLENGE CONCENTRATION. ALL CARTRIDGES WERE PRECONDITIONED AT $80 \%$ RELATIVE HUMIDITY AND $25^{\circ} \mathrm{C}$ FOR SIX HOURS. PRIOR EXPOSED CARTRIDGES WERE PREVIOUSLY SUBJECTED TO STATIC CONCENTRATIONS OF 1200 PPM FUEL VAPOR FOR EIGHT HOURS AT $80 \%$ RELATIVE HUMIDITY AND $25^{\circ} \mathrm{C}$.

FIGURE 5-7. RATIO BETWEEN BREAKTHROUGH TIMES FOR 80 PERCENT AND 50 PERCENT RELATIVE HUMIDITY CONDITIONS (WITHOUT PRIOR EXPOSURE TO FUEL VAPOR), WITH LINEAR REGRESSION FIT. DATA POINTS REPRESENT THE CALCULATED MEAN BREAKTHROUGH TIME RATIOS. ALL CARTRIDGES WERE PRECONDITIONED AT 80\% RELATIVE HUMIDITY AND $25^{\circ} \mathrm{C}$ FOR SIX HOURS....70

FIGURE 5-8. STRAIGHT-LINE APPROXIMATION OF CARTRIDGE BREAKTHROUGH TIMES BASED ON $95 \%$ LCL ESTIMATES (50 PERCENT RELATIVE HUMIDITY, NO PRIOR EXPOSURE). ALL CARTRIDGES WERE PRECONDITIONED AT $80 \%$ RELATIVE HUMIDITY AND $25^{\circ} \mathrm{C}$ FOR SIX HOURS AND WERE TESTED WITH AN AIR FLOW RATE OF 32 LPM THROUGH EACH CARTRIDGE.

FIGURE 5-9. STRAIGHT-LINE APPROXIMATION OF CARTRIDGE BREAKTHROUGH TIMES BASED ON $95 \%$ LCL ESTIMATES (80 PERCENT RELATIVE HUMIDITY, NO PRIOR EXPOSURE). ALL CARTRIDGES WERE PRECONDITIONED AT $80 \%$ RELATIVE HUMIDITY AND $25^{\circ} \mathrm{C}$ FOR SIX HOURS AND WERE TESTED WITH AN AIR FLOW RATE OF 32 LPM THROUGH EACH CARTRIDGE. 


\section{LIST OF TABLES}

TABLE 2-1. GENERAL CHEMICAL COMPOSITION OF LIQUID JP-8 FUEL. ${ }^{2}$ .5

TABLE 2-2. MAJOR COMPONENTS OF JP-8 JET FUEL VAPOR AT THE LOWER TEMPERATURE LIMIT OF FLAMMABILITY (LTLF). ${ }^{8}$

TABle 2-3. ChangeS IN VALUE OF S ACROSS THE BREAKTHROUGH CURVE.

TABLE 2-4. APPROXIMATE RATIO OF WATER MOLECULES TO FUEL VAPOR MOLECULES IN A FIXED VOLUME OF AIR FOR 50 AND 80 PERCENT RELATIVE HUMIDITY LEVELS, AT 300 AND 1200 PARTS PER MILLION OF FUEL VAPOR.

TABLE 3-1. SYSTEM PARAMETER SETTINGS FOR CARTRIDGE PRE-CONDITIONING WITH 32 LITERS PER MINUTE OF AIR AT $25^{\circ} \mathrm{C}$ AND 80 PERCENT RELATIVE HUMIDITY. TEMPERATURE AND RELATIVE HUMIDITY SETTINGS ARE EXPRESSED AS APPROXIMATE RANGES OF SETTING PAIRS (A AND B), SINCE AMBIENT LABORATORY TEMPERATURE CONDITIONS AFFECTED THE TEMPERATURE BEING DELIVERED TO THE RESPIRATOR TESTING CHAMBER. PERIODIC ADJUSTMENTS WERE MADE TO ACHIEVE A MONITORED TEMPERATURE OF $25^{\circ} \mathrm{C}$ AND RELATIVE HUMIDITY LEVEL OF 80 PERCENT WITHIN THE CHAMBER.

TABLE 3-2. SYSTEM PARAMETER SETTINGS DURING PRIOR EXPOSURE OF CARTRIDGES TO $25^{\circ} \mathrm{C}$ AIR AT 80\% RELATIVE HUMIDITY AND 1200 PPM JP-8 VAPOR. TEMPERATURE AND RELATIVE HUMIDITY SETTINGS ARE EXPRESSED AS APPROXIMATE RANGES OF SETTING PAIRS (A AND B), SINCE AMBIENT LABORATORY TEMPERATURE CONDITIONS AFFECTED THE TEMPERATURE BEING DELIVERED TO THE RESPIRATOR TESTING CHAMBER. PERIODIC ADJUSTMENTS WERE MADE TO ACHIEVE A MONITORED TEMPERATURE OF $25^{\circ} \mathrm{C}$ AND RELATIVE HUMIDITY LEVEL OF 80 PERCENT WITHIN THE CHAMBER.42

TABLE 3-3. SYSTEM CONFIGURATION SETTINGS USED DURING CARTRIDGE BREAKTHROUGH TESTING. TEMPERATURE AND RELATIVE HUMIDITY SETTINGS ARE EXPRESSED AS APPROXIMATE RANGES OF SETTING PAIRS (A \& B, AND C \& D), SINCE AMBIENT LABORATORY TEMPERATURE CONDITIONS AFFECTED THE TEMPERATURE BEING DELIVERED TO THE RESPIRATOR CHAMBER. PERIODIC ADJUSTMENTS WERE MADE TO ACHIEVE A MONITORED TEMPERATURE OF $25^{\circ} \mathrm{C}$ AND RELATIVE HUMIDITY LEVEL OF 50 OR 80 PERCENT WITHIN THE RESPIRATOR TESTING CHAMBER.

TABLE 4-1. SUMMARY TABLE OF CHARCOAL TUBE SAMPLING RESULTS, COMPARING TARGET CONCENTRATION (MEASURED WITH FOXBORO TVA-1000B PORTABLE FLAME IONIZATION DETECTOR) TO VALUES MEASURED VIA MODIFIED NIOSH 1550 SAMPLING METHOD....

TABLE 4-2. SUMMARY OF TOTAL MEAN CARTRIDGE WEIGHT GAINS (IN GRAMS) FOR EACH TREATMENT CONDITION

TABLE 4-3. MASS FLOWING THROUGH THE CARTRIDGE PER MINUTE AT TESTED CONDITIONS OF CHALLENGE CONCENTRATION AND RELATIVE HUMIDITY, WITH AIR FLOW RATE SET AT 32 LPM. .50

TABLE 4-4. SUMMARY TABLE OF TIME (IN MINUTES) TO VARIOUS BREAKTHROUGH CONCENTRATIONS FOR 50 PERCENT RELATIVE HUMIDITY (NO PRIOR EXPOSURE) TEST CONDITION. ALL CARTRIDGES WERE PRECONDITIONED AT $25^{\circ} \mathrm{C}$ AND 80 PERCENT RELATIVE HUMIDITY FOR SIX HOURS AT AN AIR FLOW RATE OF 32 LPM, AND WERE TESTED AT $25^{\circ} \mathrm{C}$ AND A FLOW RATE OF 32 LPM.

TABLE 4-5. SUMMARY TABLE OF TIME (IN MINUTES) TO VARIOUS BREAKTHROUGH CONCENTRATIONS FOR 80 PERCENT RELATIVE HUMIDITY (NO PRIOR EXPOSURE) TEST CONDITION. ALL CARTRIDGES WERE PRECONDITIONED AT $25^{\circ} \mathrm{C}$ AND 80 PERCENT RELATIVE HUMIDITY FOR SIX HOURS AT AN AIR FLOW RATE OF 32 LPM, AND WERE TESTED AT $25^{\circ} \mathrm{C}$ AND A FLOW RATE OF 32 LPM..... .53

TABLE 4-6. SUMMARY TABLE OF TIME (IN MINUTES) TO VARIOUS BREAKTHROUGH CONCENTRATIONS FOR 80 PERCENT RELATIVE HUMIDITY (WITH PRIOR EXPOSURE) TEST CONDITION. ALL CARTRIDGES WERE PRECONDITIONED AT $25^{\circ} \mathrm{C}$ AND 80 PERCENT RELATIVE HUMIDITY FOR SIX HOURS AT AN AIR FLOW RATE OF 32 LPM, FOLLOWED BY STATIC EXPOSURE TO 1200 PPM OF FUEL VAPOR AND 80 
PERCENT RELATIVE HUMIDITY AT $25{ }^{\circ} \mathrm{C}$ FOR EIGHT HOURS. THEY WERE THEN TESTED AT $25{ }^{\circ} \mathrm{C}$ AND A FLOW RATE OF 32 LPM.

TABLE 5-1. ANALYSIS OF VARIANCE (ANOVA) FOR RELATIVE HUMIDITY AND CONCENTRATION TREATMENTS.

TABLE 5-2. ANALYSIS OF VARIANCE (ANOVA) FOR PRIOR EXPOSURE AND CONCENTRATION TREATMENTS.

TABLE 5-3. CURVE-FIT PARAMETERS FOR GENERALIZED YOON AND NELSON EQUATION.

TABLE 5-4. RATIO BETWEEN 80 PERCENT (WITH NO PRIOR EXPOSURE TO FUEL) AND 50 PERCENT RELATIVE HUMIDITY BREAKTHROUGH TIMES FOR FIXED CONCENTRATIONS AND BREAKTHROUGH POINTS.

TABLE 5-5. SIMPLIFIED ESTIMATES OF CARTRIDGE SERVICE LIFE AT SELECTED ACTION LEVEL FOR 50\% RELATIVE HUMIDITY EXPOSURE AND ROOM TEMPERATURE CONDITIONS. IN MOST CASES, THE SELECTED ACTION LEVEL WILL BE $1 / 2$ THE OEL OR TLV (7 OR 25 PPM).

TABLE 5-6. SIMPLIFIED ESTIMATES OF CARTRIDGE SERVICE LIFE AT A SELECTED ACTION LEVEL FOR 80\% RELATIVE HUMIDITY EXPOSURE AND ROOM TEMPERATURE CONDITIONS. IN MOST CASES, THE SELECTED ACTION LEVEL WILL BE $1 / 2$ THE OEL OR TLV (7 OR 25 PPM).

TABLE 6-1(A) THROUGH (C). ESTIMATED CARTRIDGE SERVICE LIFE FOR PAIRS OF $3 \mathrm{M}^{\mathrm{TM}} 7251$ ORGANIC VAPOR CARTRIDGES DURING ACTIVE EXPOSURE TO JP-8 JET FUEL. ESTIMATES ARE BASED ON THE SERVICE LIFE TESTED UNDER LABORATORY CONDITIONS WITH 32 LPM AIRFLOW THROUGH EACH CARTRIDGE (EQUIVALENT TO 64 LPM AIRFLOW THROUGH EACH SET OF CARTRIDGES) AT (A) 300 PPM, (B) 600 PPM, AND (C) 1200 PPM CHALLENGE CONCENTRATIONS. ALL CARTRIDGES WERE PRECONDITIONED AT 80 PERCENT RELATIVE HUMIDITY AND $25^{\circ} \mathrm{C}$ FOR SIX HOURS.

TABLE 6-2. SUMMARY OF WOOD MODEL EQUATION PARAMETERS AND ESTIMATED BREAKTHROUGH TIMES (TO 10 PERCENT OF THE CHALLENGE CONCENTRATION) FOR MAJOR COMPONENTS OF JP-8 FUEL VAPOR. CALCULATIONS ARE FOR A 300 PPM CHALLENGE CONCENTRATION (0.228 TORR) UNDER DRY CONDITIONS WITH NO CARTRIDGE PRECONDITIONING, AND THE SATURATION PARTIAL PRESSURES $\left(\rho_{\mathrm{SAT}}\right)$ LISTED ARE FOR EACH SUBSTANCE IN PURE FORM.

TABLE 6-3. PARAMETERS FOR APPLYING THE WOOD MODEL EQUATION TO MAJOR COMPONENTS OF JP-8 JET FUEL. 


\section{GLOSSARY}

ACGIH. American Conference of Governmental Industrial Hygienists, a professional organization devoted to the administrative and technical aspects of occupational and environmental health.

AFOSH. Air Force Occupational Safety and Health program. By Executive Order 12196, the Department of Defense is responsible for establishing a Safety and Health program that meets or exceeds federal OSHA guidelines. The AFOSH program is the Air Force's implementation of that requirement.

Air Purifying Respirator (APR). A device that allows a worker to breathe ambient air that has been cleaned of hazardous substances. Cartridges or canisters remove the substances through a variety of mechanisms. With organic vapor cartridges, adsorption of the vapors is the primary mechanism used.

Breakthrough. Permeation of a hazardous substance through a respirator cartridge or canister. Breakthrough is typically defined as a fixed concentration or a percentage of the challenge concentration being drawn (or pushed) through the cartridge or canister.

CFR. The Code of Federal Regulations (CFR) is a codification of general and permanent rules (regulations) that have been previously published in the Federal Register. The CFR, which is compiled by the Office of the Federal Register, is divided into 50 titles, which cover broad areas subject to Federal regulation.

Challenge concentration.. The amount of vapor present in the air stream being fed through a respirator cartridge or canister. This is usually defined in terms of parts per million (ppm) or milligrams per cubic meter $\left(\mathrm{mg} / \mathrm{m}^{3}\right)$.

Committee on Toxicology (COT). A group within the National Research Council's National Academy of Sciences that is tasked with assessing toxicity associated with hazardous substances.

IERA. Institute for Environmental, Safety, and Occupational Health Risk Analysis. IERA is a U.S. Air Force institution headquartered at Brooks Air Force Base in San Antonio, Texas, providing occupational health and environmental risk support to the Air Force community. 
Immediately Dangerous to Life or Health (IDLH). A concentration of a harmful substance in air that poses a threat which would be likely to cause death or immediate or delayed permanent adverse health effects or prevent escape from such an environment.

Jet Propellant Type 8 (JP-8). A type of aviation fuel frequently used in military jet aircraft, similar in composition to Jet-A fuel used in the commercial aviation industry.

LPM. Liters per minute.

$\mathrm{mg} / \mathrm{m}^{3}$. Milligrams of a substance per cubic meter of air, an expression of vapor concentration in mass per unit volume. For JP-8 jet fuel, one $\mathrm{mg} / \mathrm{m}^{3}$ is approximately equivalent to 0.14 parts per million (ppm).

National Institute for Occupational Safety and Health (NIOSH). A national organization within the U.S. Centers for Disease Control and Prevention that conducts health and safety research, recommends standards, and regulates certification of respiratory protection equipment.

NRC. National Research Council.

Occupational Exposure Limit (OEL). The U.S. Air Force limit for airborne concentrations of a substance for a specific period of time. The term OEL includes all time-weighted averages (OEL-TWA)s, short-term exposure limits (OEL-STELs), and ceilings that apply to a substance. OELs apply to occupational exposures for each individual worker for a single 8-hour work shift, and must be adjusted for longer shifts.

OSHA. Occupational Safety and Health Administration.

Parts per million (ppm). An expression of vapor concentration in air. For JP-8 jet fuel, which has an approximate molecular weight of 170 milligrams (mg), a commonlyaccepted conversion factor is about $0.14 \mathrm{ppm}$ for each milligram per cubic meter $\left(\mathrm{mg} / \mathrm{m}^{3}\right)$.

Permissible Exposure Limit (PEL). A maximum allowable concentration of a substance in air, established by OSHA as a legal standard. PELs are 8-hour exposure limits for an individual worker over a 40-hour work week.

Preconditioning. A procedure which involves passing temperature- and humiditycontrolled air through a cartridge in an attempt to simulate static, shelf exposure to fixed levels of humidity and temperature over an extended period of time. In this study, each cartridge was preconditioned by passing 32 liters per minute of air at $25^{\circ} \mathrm{C}$ and 80 percent relative humidity through it for a duration of 6 hours. 
Prior exposure. A simulation of workplace static exposure of an organic cartridge's face to high levels of fuel vapor and relative humidity. For this study, prior exposure refers to exposing a cartridge's face to air containing 1200 parts per million (ppm) of fuel vapor and 80 percent relative humidity for an 8 -hour duration.

Recommended Exposure Limit (REL). A maximum 10-hour Time-Weighted Average Concentration over a 40-hour work week, set by the National Institute for Occupational Safety and Health (NIOSH). It is intended to be a recommended guideline and is not legally enforceable.

Respirator. A protective device that is designed to provide a safe breathing atmosphere free from harmful concentrations of hazardous substances.

Service Life. The length of time a cartridge may be used to prevent respiratory exposure to a vapor. (Also see "breakthrough".)

Technical Order (T.O.). A document that provides maintenance guidance to U.S. Air Force employees. T.O. 1-1-3 is the primary document referenced during repair of aircraft fuel systems.

Threshold Limit Value $\left(\mathbf{T L V}^{\circledR}\right)$. An exposure guideline set by the American Conference of Governmental Industrial Hygienists (ACGIH) under which most people can work consistently for 8 hours per day over a 40-hour work week with no harmful effects.

USAF. United States Air Force.

WVU. West Virginia University, in Morgantown, West Virginia. 
Chapter 1. INTRODUCTION

\subsection{Use of Jet Propulsion Type 8 (JP-8) jet fuel in the U.S. Air Force}

Throughout the United States, both in the military and in the aviation industry, kerosene-based jet

fuels are commonly used as propulsion sources. Activities that require personnel to work around such fuels often expose individuals to vapors that may exceed applicable occupational exposure limits. When engineering and administrative controls cannot adequately maintain levels below these limits, respiratory protection is employed to ensure employees are breathing fresh air sources.

In the United States Air Force (USAF), JP-8 jet fuel is the predominant fuel source for numerous aircraft. Military personnel are frequently exposed to JP-8 vapors when entering aircraft fuel tanks to conduct repairs, during ground refueling activities, storage tank cleaning and maintenance, and other activities where liquid JP-8 may volatilize and produce vapors in a worker's breathing zone. Similar exposures occur in civilian and commercial aviation industry, where similar fuels are used (e.g. Jet-A fuel).

\subsection{Respiratory protection}

Respirators containing organic vapor cartridges are sometimes used to control airborne exposures to fuel vapors. The cartridges use a carbon-based material which adsorbs vapor (aqueous and organic compounds) present in the air stream. As the cartridge is exposed over time, it eventually becomes saturated to the extent that it can no longer adsorb and remove these compounds from the air stream. When this occurs, organic vapors begin to pass through the cartridge.

Consequently, the worker is exposed to an increasing concentration of vapors, which may exceed the applicable Occupational Exposure Limit (OEL) and place the worker at risk. When the concentration of vapors reaches a predetermined value or percentage of the upstream concentration, breakthrough has occurred. 
Recent regulations established by the Occupational Safety and Health Administration (OSHA) in Title 29, Code of Federal Regulations (CFR) Part 1910.134 require employers to establish changeout schedules when air purifying respirators are worn to control exposures below the applicable Permissible Exposure Limit (PEL). Warning properties such as odor or irritation may no longer be used as the sole basis for changing cartridges, although they can be used in conjunction with the established change-out schedule.

Unfortunately, many employers do not have access to quantifiable breakthrough data to help them establish effective change-out schedules. Furthermore, most of the data that do exist were based on breakthrough times for single-component substances. Mathematical models that predict breakthrough for single-component substances have limited applicability to substances containing numerous compounds, such as JP-8, a complex mixture of over 300 organic compounds.

Within the USAF, organic vapor cartridges are used to control exposures to JP-8 vapors under two configurations: (1) as a primary means of vapor control (dynamic air flow through the cartridge); and (2) as a back-up, escape only provision, employed only when a supplied airline system fails to provide adequate flow of air. The first configuration is not used frequently in the USAF, but is more often used in the commercial aviation industry. The second configuration is commonly used in the USAF, particularly during worker entry into aircraft fuel tanks. It is important to note that in the second configuration, the worker is not actively breathing through the cartridge, since a Grade D breathing air source is provided. However, the face of the cartridge is exposed to the ambient level of fuel vapor, since the cartridge will become the default source of breathing air to the user should the supplied air system fail.

\subsection{Purpose of study}

Since there is limited breakthrough data for the use of organic vapor cartridges in controlling worker exposure to environments consisting of complex fuel mixtures such as JP-8, it would be valuable to the USAF and to the aviation industry to address the following: 
- How long will a cartridge last when actively used at known concentrations of JP-8 fuel vapor?

- Will relative humidity impact the service life of a cartridge?

- Does static exposure of a cartridge to JP-8 fuel vapor reduce its ability to perform under dynamic conditions, thereby limiting the active service life?

The purpose of this study is to address these identified areas of concern through the use of controlled experimental procedures and methodology to simulate static and dynamic exposure of organic vapor cartridges to known concentrations of JP-8 fuel vapor and conditions of temperature and relative humidity. 


\section{Chapter 2. REVIEW OF LITERATURE}

\subsection{History and predominance of JP-8 jet fuel}

Prior to World War II, most of the jet engines used throughout the world used kerosene as a fuel source. ${ }^{1}$ The development of high-speed jet aircraft in the late 1940s and early 1950s promulgated research into new aviation fuels that would perform better under high altitude conditions. Various attempts at using different distillation cuts of crude oil eventually led to production of JP4 , a wide-cut fuel composed of a gasoline/kerosene mixture with a flash point near $-10^{\circ} \mathrm{F}$. In the mid-1950s, JP-4 was adopted for widespread use in the Air Force and soon became the fuel of choice for use in many of the Air Force's jet engines. ${ }^{1}$

Shortly thereafter, the Navy began to use JP-5, a high flash point kerosene that had a minimum flash point of $140^{\circ} \mathrm{F}$ and was therefore, for safety reasons, more compatible with shipboard use. Experience with both types of fuels in combat during the Vietnam War demonstrated that Air Force aircraft using JP-4 fuel experienced higher combat losses than U.S. Navy aircraft, and a much higher probability of a crash fire than with JP-5. Furthermore, accident rates for groundbased handling of kerosene-based fuels were found to be significantly lower than for wide-cut fuels such as JP-4. ${ }^{1}$

JP-8 was developed to provide a safer kerosene-based fuel that would be readily available and have a freezing point acceptable to the Air Force $\left(-47^{\circ} \mathrm{F}\right)$. The Air Force began converting from JP-4 to JP-8 in 1979, and completed the conversion by 1994. JP-8 use rapidly became widespread, even being used in the U.S. Army's ground vehicles and equipment, as well as its airplanes and helicopters. JP-8 is now the dominant fuel for use on the battlefield, with the primary exception being the Navy's continued reliance on JP-5 for shipboard use. 


\subsection{Properties and health risks of JP-8}

\subsubsection{Chemical Composition}

The chemical composition of JP-8 fuel is very similar to Jet-A fuel used in the commercial sector. It is refined from crude or shale oil to a mixture of $\mathrm{C}_{8}$ through $\mathrm{C}_{17}$ hydrocarbons. Table 2-1 contains a summary of the general composition of liquid JP-8 fuel. ${ }^{2}$ The actual composition may vary slightly depending on the source and manufacturer of the product.

Table 2-1. General chemical composition of liquid JP-8 fuel. ${ }^{2}$

\begin{tabular}{ll}
\hline Component & $\%$ by volume \\
\hline $\mathrm{C}_{8}$ to $\mathrm{C}_{9}$ aliphatic hydrocarbons & $9 \%$ \\
$\mathrm{C}_{10}$ to $\mathrm{C}_{14}$ aliphatic hydrocarbons & $66 \%$ \\
$\mathrm{C}_{15}$ to $\mathrm{C}_{17}$ aliphatic hydrocarbons & $7 \%$ \\
Aromatic hydrocarbons, typical of cracked gasoline and kerosene (includes & \\
benzene, alkyl benzenes, toluene, xylene, naphthalenes) & $18 \%$ \\
\hline
\end{tabular}

\subsubsection{Toxicology}

An extensive review of military fuels was conducted by the National Research Council's (NRC) Committee on Toxicology (COT) to establish Permissible Exposure Levels (PELs) for use by the military ${ }^{2}$. Their study considered three types of fuels that were similar in composition (JP-5, JP-8, and Diesel Fuel Marine). The COT review of the literature reported the following toxicological effects:

1. Kidney system: Renal toxicity tests conducted in rats and mice of both sexes indicate the primary risk is to the male rat, where kidney lesions result following inhalation of vapors. This result is not believed to be applicable to humans since the lesions are unique to male rats.

2. Central Nervous System (CNS): Studies of workers exposed to fuel vapors indicate acute effects may include dizziness, headaches, nausea, and fatigue. Chronic effects may include neurological symptoms (sleeplessness, depression, headaches, fatigue) and possible impairment of motor skills.

3. Liver: Tests involving rats, mice, dogs, and monkeys that were exposed intermittently to fuel vapors indicated no pathological change except for a small increase in female rat liver weights. 
4. Carcinogenicity: Studies of petroleum workers, which consisted largely of refinery workers and service station attendants, demonstrated an increased risk of cancer. However, these studies were not specific to jet fuel exposures, and much of the impact is attributed to benzene, widely believed to be a carcinogen. ${ }^{3}$ Following their review of this and other epidemiological and toxicological studies, the COT concluded that JP-5 and JP-8 do not pose a carcinogenic risk to humans.

\subsubsection{Exposure limits}

The Occupational Safety and Health Act (OSH Act) of 1970 exempts federal agencies, including the Department of Defense, from adhering to the requirements set by the Occupational Safety and Health Administration (OSHA). However, the Department of Defense is required by Executive Orders 12196 and $12608^{4}$ to maintain a safety and health program that meets, at a minimum, the requirements set forth by OSHA. The USAF has created a set of "Air Force Occupational Safety and Health" (AFOSH) standards as part of its safety and health program.

AFOSH Standard 48-8, "Controlling Exposure to Hazardous Materials," is the Air Force's governing health standard for controlling exposure to chemicals. AFOSH Standard 48-8 requires Air Force personnel to adhere to the most stringent exposure limit of two primary standards: (1) PELs set by OSHA, and (2) Threshold Limit Values (TLVs ${ }^{\circledR}$ ) established by the American Conference of Governmental Industrial Hygienists. ${ }^{6}$ When a standard does not exist for a substance in question, the Air Force Surgeon General (AFMOA/SG) may establish an exposure limit by conducting independent studies, relying upon the professional literature, or using another recommended standard such as the "Recommended Exposure Limits" (RELs) set by the National Institute for Occupational Safety and Health (NIOSH).

For JP-8 jet fuel, neither OSHA nor the ACGIH has adopted an exposure limit. At present, the ACGIH' lists in its "Notice of Intended Changes" an 8-hour TLV ${ }^{\circledR}$ of $100 \mathrm{mg} / \mathrm{m}^{3}$ (over a 40hour working week) for diesel and kerosene, with a skin absorption notation and an A3 carcinogenicity category that identifies it as a confirmed animal carcinogen with unknown 
relevance to humans. However, since this $\operatorname{TLV}^{\circledR}$ has not yet been adopted by the ACGIH, this value is subject to change.

The Air Force has adopted the exposure guidelines given by the Committee on Toxicology. The COT recommended an 8-hour time-weighted average (TWA) PEL of $350 \mathrm{mg} / \mathrm{m}^{3}$ and a Short Term Exposure Limit (STEL) of $1800 \mathrm{mg} / \mathrm{m}^{3}$. Using an average molecular weight of $170 \mathrm{~g} / \mathrm{mol}$, this equates to an 8-hour PEL of approximately $50 \mathrm{ppm}$ and a STEL of $250 \mathrm{ppm}$.

\subsection{Operational parameters and concerns}

\subsubsection{Vapor composition}

Most of the components found in JP-8 are low-volatility, high molecular weight carbon chains containing more than 10 carbons each. Because of their low vapor pressures, these compounds tend to remain in liquid form under room temperature conditions. Therefore, fuel vapor is composed primarily of the more volatile substances in the fuel and does not proportionally parallel the composition of liquid fuel.

The vapor pressure of a volatile substance can be represented by Raoult's Law and Dalton's Laws. $^{7}$ This property of mixtures is described through the following equation:

$$
\mathrm{P}_{\text {total }}=\left(\mathrm{P}_{\mathrm{A}}^{\circ}\right)\left(\mathrm{X}_{\mathrm{A}}\right)+\left(\mathrm{P}_{\mathrm{B}}^{\circ}\right)\left(\mathrm{X}_{\mathrm{B}}\right)+\ldots+\left(\mathrm{P}_{\mathrm{N}}^{\circ}\right)\left(\mathrm{X}_{\mathrm{N}}\right)
$$

where $\mathrm{P}_{\text {total }}=$ Vapor pressure of a solution containing a nonvolatile solute

$\mathrm{P}_{\mathrm{A}}^{\circ}=$ Vapor pressure of the solvent, in pure form

$\mathrm{X}_{\mathrm{A}}=$ Mole fraction of component $\mathrm{A}$

$\mathrm{P}_{\mathrm{B}}^{\circ}=$ Vapor pressure of component $\mathrm{B}$, in pure form

$\mathrm{X}_{\mathrm{B}}=$ Mole fraction of component $\mathrm{B}$

$\mathrm{P}^{\circ}{ }_{\mathrm{N}}=$ Vapor pressure of component $\mathrm{N}$, in pure form

$\mathrm{X}_{\mathrm{N}}=$ Mole fraction of component $\mathrm{N}$

According to this property of mixtures, the vapor pressure of each substance in a mixture would be less than its vapor pressure in pure form. Additionally, the total vapor pressure in a mixture 
would be a mole fraction-weighted average of each component's vapor pressure. Consequently, the high percentage of low-volatility compounds in fuel causes the total vapor pressure to be lower than would be expected if the fuel was composed predominantly of low-volatility substances. Naegeli and Childress analyzed JP-8 fuel vapor composition at the Lower Temperature Limit of Flammability (LTLF), the "temperature at which the lower explosion limit (LEL) exists in dry air under conditions of vapor-liquid equilibrium." 8 The top 10 components of JP-8 fuel found in their studies are listed in Table 2-2. Additionally, they found the average molecular weight of JP-8 vapor at the LTLF to be $114 \mathrm{~g} / \mathrm{mol}$.

Table 2-2. Major components of JP-8 jet fuel vapor at the Lower Temperature Limit of Flammability (LTLF). ${ }^{8}$

\begin{tabular}{lc}
\hline \multicolumn{1}{c}{ Compound in JP-8 jet fuel } & $\begin{array}{c}\text { Vapor concentration } \\
\text { at } \mathbf{3 5 . 6} \mathbf{6}^{\circ} \mathbf{C}(\mathbf{p p m})\end{array}$ \\
\hline Methyl cyclohexane & 803 \\
n-Octane & 498 \\
n-Nonane & 450 \\
m-Xylene & 439 \\
Toluene & 410 \\
Ethyl cyclohexane & 266 \\
cis-1,4-dimethyl cyclohexane & 261 \\
n-Heptane & 252 \\
Cyclohexane & 239 \\
o-Xylene & 235 \\
\hline
\end{tabular}

For purposes of fuel vapor composition categorization, there are three general classifications of activities which can expose Air Force employees to fuel vapors:

- Naturally-ventilated activities. This includes such activities as ground-based aircraft refueling, external servicing of aircraft and storage tanks, and fuel tank entry attendant activities, among others. Activities conducted outside of a confined space where jet fuel is present will often involve exposure to fuel vapors. These activities are usually not controlled with local exhaust ventilation. 
- Ventilated confined space fuel tank entry. Personnel frequently enter aircraft fuel tanks to conduct routine and special cleaning and maintenance. Major maintenance is often conducted after personnel completely drain the tank of all liquid fuel and have purged the tank with fresh air. However, it is often difficult or impractical to completely purge the aircraft of all liquid fuel or vapors in a timely manner, and for some repairs it may be unnecessary. Therefore, some level of fuel vapor is frequently present in the tank. The vapor is controlled by blowing air into and actively extracting it from the tank. When doing work on a flightline, it is standard procedure to use a "blow purge" method which simply forces air into the tank through a flexible duct without using a forced extraction method. ${ }^{9}$

- Foam removal. An activity which has been shown to expose workers to high levels of fuel vapor is one that requires removal of a highly porous polyurethane foam, often present in the tank to prevent movement of the fuel and to minimize explosion and fire risks. Highest exposures have typically been measured ${ }^{10,11,12,13}$ during the initial entry into a tank for the purpose of removing this foam, occasionally reaching levels in excess of $10,000 \mathrm{mg} / \mathrm{m}^{3}$.

The vapor composition to which a worker would be exposed may vary somewhat depending upon the task being accomplished. Raoult's and Dalton's Laws describe vapor composition in a state of equilibrium within an enclosed vessel. These laws may describe the vapor composition anticipated during initial opening of a fuel tank and the subsequent removal of foam saturated with liquid fuel. Under actively ventilated confined space conditions, many of the more volatile, low molecular weight compounds would be expected to have been removed from the worker's breathing zone. Composition of vapors under naturally-ventilated conditions would be expected to fall somewhere between the two extremes.

Before entering, personnel ventilate the fuel tank to reduce the vapor concentrations to safe levels. Air Force fuel cell maintenance procedures are defined in Technical Order (T.O.) 1-1-314, "Inspection and Repair of Aircraft Integral Tanks and Fuel Cells." T.O. 1-1-3 establishes the safe limit for tank entry to be greater than $19.5 \%$ oxygen and less than $10 \%$ of the Lower Explosive 
Limit (LEL). For JP-8, which has an LEL of between 0.6 and 0.9 percent (or 6000 to 9000 $\mathrm{ppm}),{ }^{9}$, this corresponds to a concentration of about $600 \mathrm{ppm}$. In some cases where an aircraft contains explosion suppression and fire-resistant polyurethane foam, personnel are required to remove the foam before conducting repairs. A special safe entry level for these operations has been set at 20\% of the LEL (1200 ppm) during foam removal only. LEL measurements are made using the Bacharach 514M Explosive Meter, which employs a catalytic filament sensor to measure the percentage of the LEL. ${ }^{9}$ Meters are calibrated to methane. Users move the dial to a JP-8 setting when working with JP-8, which corresponds to a conversion factor of approximately 3.0 relative to methane.

When a tank is initially opened, concentrations of fuel vapor frequently exceed safe entry levels. If repairs must be conducted with any fuel remaining in the tank, T.O. 1-1-3 requires personnel to purge the tank before entering. Purging continues throughout the tank entry operation, regardless of the initial vapor concentration.

\subsubsection{Exposure monitoring data}

Monitoring data from Det 1 HSC/OEMI's jet fuel exposure consultation efforts ${ }^{9,13}$ for numerous fuel tank entry sampling efforts throughout 1997 and 1998 revealed concentrations ranging between $3.85 \mathrm{mg} / \mathrm{m}^{3}$ and $10,295 \mathrm{mg} / \mathrm{m}^{3}$ ( $<1 \mathrm{ppm}$ to $1440 \mathrm{ppm}$ ). Mean values were reported to be $267 \mathrm{mg} / \mathrm{m}^{3}$ (38 ppm) for all operations (foam and non-foam), which is below the OEL of 350 $\mathrm{mg} / \mathrm{m}^{3}(50 \mathrm{ppm})$.

\subsubsection{Respirator use}

The majority of Air Force fuel systems maintenance shops use 3M $\mathrm{M}^{\mathrm{TM}}$ EasiAir continuous-flow airline respirators equipped with organic vapor (OV) cartridges. Grade D air is provided as the primary breathing source. Organic vapor cartridges are mounted to the respirator and are used only for escape from the fuel tank in the event the primary air source is terminated. In this configuration, cartridges are passively exposed to organic vapors without actively drawing contaminants through the cartridge. The worker then removes respiratory protection equipment 
and often allows it to sit for a period of time before using it again. In this configuration, use of the respirator is limited to the conditions acceptable for full facepiece air purifying respirators. Continuous flow and full facepiece air purifying respirators such as this one have an Assigned Protection Factor (APF) of 50, designated by NIOSH in its Respirator Decision Logic ${ }^{15}$ reference, and cannot be used in oxygen-deficient or Immediately Dangerous to Life and Health (IDLH) environments.

In some cases, air purifying respirators equipped with organic vapor cartridges may be used for primary protection. In this configuration, the user wears a half-face or full-facepiece respirator without an additional air supply, and draws the entire air source through the cartridges. It is not common practice for Air Force personnel to wear only air purifying respirators during fuel tank entry operations, but they may be used for other operations involving potential exposure to fuel vapor in some situations.

\subsubsection{Breakthrough testing parameters vs. the workplace environment}

Currently, NIOSH conducts organic vapor cartridge certification breakthrough testing using a single contaminant (carbon tetrachloride) at pre-determined parameters defined in $42 \mathrm{CFR}$ 84.207.16 If a cartridge lasts at least 50 minutes during this test when exposed to a challenge concentration of $1000 \mathrm{ppm}$, it passes the certification test.

It is important to recognize that the NIOSH certification process is only designed to ensure organic vapor respirator cartridges meet a minimum breakthrough requirement for carbon tetrachloride. This process is not intended to help the end user establish a cartridge change-out schedule for workplace-specific organic vapors or environmental conditions. It is therefore critical to have available other techniques for estimating the service life of a cartridge under asused conditions.

Manufacturers frequently conduct other testing on cartridges with single component challenge chemicals under a variety of conditions. While much of this data can be used to help estimate a 
cartridge's service life, there are some unique considerations involved in determining the service life of organic cartridges used in a JP-8 vapor environment. These include:

- JP-8 consists of a complex mixture of organic compounds, ranging from the lighter fraction 8-carbon aromatic hydrocarbons to the much less volatile 14-carbon compounds. Singlecompound breakthrough testing may not be an accurate predictor of multiple-compound breakthrough times. Therefore, an understanding of theoretical and actual breakthrough times for JP-8 remain uncertain.

- When used in a back-up configuration, cartridges are passively exposed rather than drawing fuel vapors through the cartridges. Passively exposing a cartridge to organic vapors and allowing it to remain unused on a shelf for a period of time may allow the vapor to diffuse through the cartridge and adversely impact its effective service life during subsequent uses.

\subsection{Regulatory requirements}

The governing regulation for use of respirators in the workplace is the Occupational Safety and Health Administration's (OSHA) Respiratory Protection Standard, 29 Code of Federal Regulations (CFR) 1910.134. ${ }^{17}$

Prior to October 1998, when this portion of the standard was revised, OSHA required users of respirators to define a strategy for identifying when to change out cartridges worn in an air purifying respirator. However, the requirement was not well-defined, and permitted users to rely on warning properties as a primary mechanism for replacing the cartridges if that property could be reliably detected at a concentration lower than the PEL.

The final rule for the new respiratory protection standard changed the requirement in several significant ways. Interpretation of this standard must be made in the context of OSHA Directive CPL 2.0120 and OSHA Instruction CPL 2.103, "Field Inspection Reference Manual (FIRM)," which identify inspection procedures for OSHA compliance officers to follow during enforcement of the Respiratory Protection Standard. According to the standard, when cartridges 
or canisters are used to control gas and vapor exposures, they must either be equipped with an End of Service Life Indicator (ESLI), or be used only with the employer's implementation of a cartridge/canister change-out schedule that ensures they are replaced in adequate time to prevent contaminant breakthrough. Some of OSHA's chemical-specific standards dictate change-out schedule requirements applicable to exposures to those substances only. For example, the standards for acrylonitrile (1910.1045), benzene (1910.1028), and vinyl chloride (1910.1017) specify cartridges be replaced at the end of their service life or the end of each shift, whichever occurs first. The butadiene standard (1910.1051) contains a replacement schedule that is based on the exposure concentration, and includes alternate procedures when additional breakthrough testing data is available. Formaldehyde (1910.1048) requires cartridges to be replaced every 3 hours or at the end of the work shift, whichever occurs first. For all other substances where air purifying respirators are worn to control worker exposures, OSHA requires the employer to establish and implement a change-out schedule. Warning properties such as odor or irritation may not be used as the sole basis for changing cartridges, although they can be used in conjunction with the established change-out schedule. The primary reason for this change is the notion that warning properties are unreliable and are therefore inadequate to indicate sorbent exhaustion has occurred.

The preamble to the final rule for the new standard states that employers are "not required to research and analyze experimental breakthrough data", but "may obtain information from sources who have expertise and knowledge that can help the employer to develop reasonable change schedules.” CPL 2.0120 provides guidance to assist an employer in creating change-out schedules. A brief summary of the guidelines in CPL 2.0120 follows.

- Manufacturer's Objective Data: Cartridge-specific data developed and presented by each manufacturer may be available through distributors, via the manufacturer's Internet web site, or verbally via telephone help line. In some cases, manufacturers have developed computer programs that compute breakthrough times based on known workplace conditions and cartridge characteristics. 
- Experimental Methods: Breakthrough-time data may be determined experimentally in a laboratory using worst-case simulations of workplace conditions. OSHA considers this to be a good approach when compared to other available techniques.

- Mathematical Predictive Modeling: Several types of mathematical equations have been developed based on theoretical assumptions and experimentally-determined breakthrough data. Some mathematical models may require considerable expertise and could involve obtaining proprietary information from each cartridge manufacturer. OSHA believes further development and validation of such models would be of value, and supports further efforts. The "Gerry O. Wood Mathematical Model" is offered as one means for estimating service life. $^{18,35}$

- Analogous Chemical Structures: With this method, the employer compares the chemical of interest against breakthrough characteristics for chemicals of a similar structure. Similarly, a chemical with known characteristics could be justifiably used as a surrogate for a chemical reasonably believed to migrate through the cartridge more slowly, such as a heavier, less volatile compound in the same chemical series. This approach depends significantly on experimental data and expertise. OSHA considers it to be generally less accurate than other methods and advocates its use when better information is unavailable to the employer.

- Workplace Simulations: Currently under development, several methods propose to test breakthrough under actual conditions of use by drawing workplace air through the cartridge at a normal high work level breathing rate and sampling the air stream on the other side of the cartridge to monitor breakthrough. Such a method could supplement an employer's routine air monitoring program and may be able to better account for changing humidity, temperature, and concentration conditions.

- Rules of Thumb: Experimental data may lead to development of rules of thumb for estimating cartridge and canister service life. For example, the American Industrial Hygiene 
Association (AIHA) publication"19 "'The Occupational Environment Evaluation and Control," suggests a method for estimating organic vapor cartridge service life. The method assumes a service life of 8 hours at a normal work rate when the chemical's boiling point is greater than $70{ }^{\circ} \mathrm{C}$ and the concentration is less than $200 \mathrm{ppm}$. The 8-hour breakthrough time is reduced by a number of factors presented in the text, including work rate, concentration, and humidity conditions. OSHA expresses some doubt as to the reliability of this method and advocates its use only in concert with another service life prediction method.

Other requirements of OSHA's Respiratory Protection Standard include establishing a workplacespecific respiratory protection program that address selection and use of respirators, facepiece fittesting and medical monitoring, and training. The standard requires initial fit-testing for all users wearing tight-fitting respirators, and at least annually thereafter, when there is a change in the facepiece, or when the worker's physical condition changes such that the respirator fit could be compromised (e.g. significant weight change). The standard also addresses use of respirators in potentially Immediately Dangerous to Life or Health (IDLH) and oxygen-deficient environments, prohibiting the use of air purifying respirators under those conditions.

Since the USAF is required to maintain a safety and health program at least as stringent as that established by OSHA, the general tenets of the Respiratory Protection Standard apply. AFOSH Standard 48-137, Respiratory Protection Program, ${ }^{20}$ applies these requirements to USAF personnel.

\subsection{Cartridge certification protocols}

\subsubsection{National Institute for Occupational Safety and Health (NIOSH)}

Under its responsibility to test and certify respirators, NIOSH developed requirements for testing chemical vapor cartridges and canisters which are defined in 42 CFR 84.207, "Bench tests: gas and vapor tests: minimum requirements."16 All manufacturers of gas and vapor cartridges must meet these certification requirements before providing a product to the public. 
For organic vapor cartridges, testing must be accomplished at a relative humidity of $50 \pm 5$ percent and a temperature of approximately $25^{\circ} \mathrm{C}$. The challenge vapor is carbon tetrachloride $\left(\mathrm{CCl}_{4}\right)$ at a concentration of $1000 \mathrm{ppm}$; or a lower concentration for organic compounds that produce atmospheres immediately dangerous to life and health at $1000 \mathrm{ppm}$. Breakthrough has occurred when a concentration of $5 \mathrm{ppm}$ is measured exiting the cartridge.

Two types of tests are completed: one on cartridges as received, without equilibration; and one with cartridges that have been equilibrated to known temperature and humidity conditions.

- Non-equilibrated cartridges: After the cartridges are received, they are placed in a sealed bag and tested within 18 hours. If the cartridges are intended to be used individually (one at a time) in a respirator, three are tested at 64 LPM each. If designed to be used in pairs, three pairs of cartridges are tested at 64 LPM (or 32 LPM per cartridge).

\section{- Equilibrated cartridges:}

- Two cartridges (or pairs) are equilibrated by passing room temperature air at 25 percent relative humidity at a flow rate of 25 LPM for 6 hours. Cartridges must be placed in a sealed bag and tested within 18 hours of equilibration. If the cartridges are intended to be used individually (one at a time) in a respirator, they are tested at 64 LPM each. If designed to be used in pairs, they are tested at 64 LPM (or 32 LPM per cartridge).

- Two cartridges (or pairs) are equilibrated by passing room temperature air at 85 percent relative humidity and a flow rate of 25 LPM for 6 hours. Cartridges must be placed in a sealed bag and tested within 18 hours of equilibration. If the cartridges are intended to be used individually (one at a time) in a respirator, they are tested at 64 LPM each. If designed to be used in pairs, they are tested at 64 LPM (or 32 LPM per cartridge). 
The NIOSH criteria requires that cartridges have a minimum tested service life of 50 minutes in order to pass the certification requirements.

\subsubsection{Environmental Protection Agency}

The Environmental Protection Agency (EPA) has developed some interim guidelines in support of Section 5 of the Toxic Substances Control Act (TSCA), which authorizes the EPA to require the use of respiratory protection for workers exposed to gases or vapors of new chemical substances or those submitted as Premanufacture Notifications (PMNs). The EPA requires use of supplied-air respirators for exposure to new volatile chemicals unless a company can show that a NIOSH-approved organic vapor cartridge-type respirator will effectively remove the contaminant from the worker's breathing zone.

The interim recommendations are predominantly based on the Wood and Ackley protocol ${ }^{21}$ for testing organic vapor canisters and cartridges, and on NIOSH's draft decision logic for respirator selection during PMN uses. ${ }^{22}$ The interim recommendations break the testing protocol into two phases. Phase I involves eight different tests that represent the worst case environmental conditions. Phase II, which is only required under certain conditions, addresses the desorption characteristics of the cartridge or canister filters at elevated temperatures by including additional tests under conditions of higher temperature.

An overview of the recommended protocol is included below:

- Conduct an initial screening for service life that is based on predictive modeling. If modeling shows that a predicted service life would be shorter than 20 minutes for the substance, the company should consider an alternative to using an air purifying respirator, such as a supplied-air respirator.

- Document that adsorption of the substance will not result in heats of reaction that yield temperatures more than $20^{\circ} \mathrm{C}$ above the ambient temperature. 
- Perform a minimum of eight tests on the cartridges or canisters of interest at a 50 liter per minute flow rate and a temperature of $25 \pm 2.5^{\circ} \mathrm{C}$, according to the following parameters:

- Two tests each at concentrations of 10 times, 100 times, and 500 times the proposed exposure limit, with a relative humidity held constant at $80 \pm 5$ percent.

- Two tests at 500 times the proposed exposure limit, and a relative humidity held constant at $20 \pm 5$ percent.

- If the cartridge or canister will be used for worker protection at elevated temperatures, defined as $35^{\circ} \mathrm{C}$ or higher, conduct two more series of tests (two replicates for each) at 10 and 500 times the proposed exposure limit, at a temperature of $35 \pm 2.5^{\circ} \mathrm{C}$ and $80 \pm 5$ percent relative humidity.

- Develop change-out schedules according to service life testing results for the worst case conditions, applying a safety factor of $60 \%$ to account for environmental condition variability.

\subsection{Breakthrough of homogeneous substances}

\subsubsection{Overview}

In 1976 Nelson and Correia ${ }^{23}$ published the conclusions of an extensive study describing fundamental breakthrough characteristics of organic vapors through carbon respirator cartridges. This report was the culmination of over 5 years of research in this area. During that series of studies, Nelson et. al. ${ }^{24 \cdot 2526}$ tested cartridge breakthrough for 121 types of vapors at various concentrations, humidity levels, and air flow rates, and provided a review of solvent vapor adsorption properties on activated carbon. The authors also compared theoretical breakthrough times using the adsorption isotherm, Mecklenburg, and Wheeler equations, and attempted to develop a simplified empirical expression for predicting breakthrough to 10 percent of the challenge concentration. 
Additional research by Yoon and Nelson ${ }^{27}$, Moyer28.29, Wood and Moyer ${ }^{30 \cdot 31}$, Wood and Stampfer ${ }^{32}$, and others have further defined the impacts of exposure conditions on breakthrough time and developed additional predictive models for single contaminant breakthrough estimation. One often-used model is presently known as the "modified Wheeler equation".

The original Wheeler equation was initially derived by Wheeler and Robell ${ }^{33}$ to describe catalytic bed poisoning, and was later modified by Jonas and Svirbely ${ }^{34}$ into the following form:

$$
t_{b}=\frac{W_{e}}{C_{0} Q}\left[W-\frac{\rho_{B} Q}{k_{v}} \ln \left[\frac{C_{0}}{C_{x}}\right]\right]
$$

where

$t_{b}=$ breakthrough time in minutes

$W_{e}=$ adsorption capacity in $\mathrm{g} / \mathrm{g}$

$k_{v}=$ adsorption rate constant in minutes $^{-1}$

$W=$ adsorbant weight of carbon in $g$

$\rho_{B}=$ bulk density of the packed bed in $\mathrm{g} / \mathrm{cm}^{3}$

$Q=$ air flow rate in $\mathrm{cm}^{3} / \mathrm{min}$

$C_{o}=$ challenge concentration in $\mathrm{g} / \mathrm{cm}^{3}$

$C_{x}=$ exit concentrations of interest in $\mathrm{g} / \mathrm{cm}^{3}$

While this equation is commonly used to analyze contaminant breakthrough in carbon beds, it is only valid for small exit concentrations (small fractions of the inlet concentration) since it predicts that the exit concentration will increase exponentially. ${ }^{27}$

Yoon and Nelson applied a correction term to this model to account for the reversibility of adsorption of the contaminant as the breakthrough concentration $\left(C_{x}\right)$ increases, ${ }^{27,35}$ as follows: 


$$
t_{b}=\left[\frac{W_{e} W}{C_{0} Q}\right]-\left[\frac{W_{e} \rho_{B}}{k_{v} C_{0}}\right] \ln \left[\frac{C_{0}-C_{x}}{C_{x}}\right]
$$

with variables defined as above.

Wood further defined additional terms in this equation, developing models for $W_{e}$ and $k_{v}$ as shown below:

$$
\begin{gathered}
W_{e}=W_{o} d_{L} \exp \left[-b^{\prime} W_{o} P_{e}^{-1.8} R^{2} T^{2}\left(\ln \left\{\rho / \rho_{\text {sat }}\right\}\right)\right] \\
P_{e}=\left(\frac{n_{D}^{2}-1}{n_{D}^{2}+2}\right) \frac{M_{W}}{d_{L}} \\
1 / k_{V}=\left(\left(1 / V_{L}\right)+0.027\right)\left(I+S / P_{e}\right)
\end{gathered}
$$

where

$W_{o}=$ carbon micropore volume $\left(\mathrm{cm}^{3} / \mathrm{g}\right)$

$d_{L}=$ liquid density of adsorbate $\left(\mathrm{g} / \mathrm{cm}^{3}\right)$

$\mathrm{T}=$ absolute temperature in Kelvin

$\rho=$ partial pressure corresponding to the challenge concentration

$\rho_{\text {sat }}=$ partial pressure (at saturation) of substance

$P_{e}=$ molar polarization (electron cloud displacement or preferential orientation of dipoles)

$\mathrm{R}=$ ideal gas constant of 1.987

$b^{\prime}=3.56 \times 10^{-5}$ (empirically determined)

$M_{W}=$ molecular weight

$n_{D}=$ refractive index

$I=$ calculated constant of $8.25 \times 10^{-4}$. 
$S$ is an empirically-derived coefficient that can be estimated from:

$$
S=0.063-0.0058 \ln \left[\left(C_{0}-C_{x}\right) / C_{x}\right\rfloor
$$

Note that changes in the value of $S$, which ultimately impact $k_{v}$ and modify the slope of the prediction curve, are most significant at the lowest percentages of the breakthrough curve (see Table 2-3). This has a direct relationship on $k_{v}$. Since $k_{v}$ appears in the denominator of the Yoon and Nelson equation, an increase in the value of $S$ will reduce the predicted breakthrough time, $t_{b}$.

Table 2-3. Changes in value of $S$ across the breakthrough curve.

\begin{tabular}{cc}
\hline \% breakthrough & $\mathrm{S}$ \\
\hline 1 & 0.036 \\
5 & 0.046 \\
10 & 0.050 \\
20 & 0.055 \\
30 & 0.058 \\
40 & 0.061 \\
50 & 0.063 \\
\hline
\end{tabular}

The equilibrium adsorption capacity parameter, $W_{e}$, tends to be relatively constant across the breakthrough curve (at a fixed temperature) and is relatively insensitive to the challenge concentration except for substances of extremely low volatility. Note also that $W_{e}$ and $k_{v}$ are not independent of each other, since they share the molar polarization term, $P_{e}$, a constant that is dependent on the polarization characteristics of the challenge substance.

The effects of relative humidity on breakthrough times are currently being studied to better define the response functions. Relative to vapors of most organic compounds, water vapor adsorption by activated carbon is extremely slow. However, at low contaminant concentrations and high humidity levels, the number of water molecules greatly exceeds the number of contaminant molecules, with the water vapor causing a significant reduction in breakthrough time. ${ }^{36}$ For example, $100 \mathrm{ppm}$ of a substance such as methylene chloride (molecular weight $=84.9)$ is equivalent to $2.4 \times 10^{18}$ molecules in 1 Liter of air. The same volume of air humidified at 80 
percent contains approximately $6.1 \times 10^{20}$ water molecules $\left(11.5 \mathrm{mg}^{37}\right)$, over 250 times the number of methylene chloride molecules. For JP-8 fuel, using an approximate molecular weight of 170 $\mathrm{g} / \mathrm{mol}, 300 \mathrm{ppm}$ is equivalent to $7.4 \times 10^{18}$ molecules and $1200 \mathrm{ppm}$ equates to $3.0 \times 10^{19}$ molecules. The relative ratios of water to fuel vapor molecules would be as shown in Table 2-4.

Table 2-4. Approximate ratio of water molecules to fuel vapor molecules in a fixed volume of air for 50 and 80 percent relative humidity levels, at 300 and 1200 parts per million of fuel vapor.

\begin{tabular}{ccc}
\hline Relative humidity level & $\begin{array}{c}\text { Ratio of water to fuel vapor } \\
\text { molecules at } \mathbf{3 0 0} \mathbf{~ p p m} \text { fuel } \\
\text { vapor }\end{array}$ & $\begin{array}{c}\text { Ratio of water to fuel vapor } \\
\text { molecules at 1200 ppm fuel } \\
\text { vapor }\end{array}$ \\
\hline 50 percent & $51: 1$ & $12: 1$ \\
80 percent & $83: 1$ & $20: 1$ \\
\hline
\end{tabular}

One model published by Wood ${ }^{38}$ relates the breakthrough time at a reference relative humidity to a humidity level of interest. The equation takes a general form of the following:

$$
\frac{t_{b}(r e f)}{t_{b}}=K+K^{\prime} R H^{n}
$$

where $t_{b}($ ref $)$ is the breakthrough time at a reference relative humidity, $t_{b}$ is the breakthrough time at the relative humidity level of interest, $K$ and $K^{\prime}$ are constants that depend on the amount of water vapor in the air relative to saturation, and $n$ represents the number of water molecules that fill the charcoal micropores. This model essentially allows prediction of a breakthrough time at any relative humidity when all other key parameters (e.g. temperature, challenge concentration, and percentage of breakthrough) are held constant. Wood states that in his application of this model to initially dry carbon bed tests, the calculated parameters for this equation did not remain constant between the 10 percent and 50 percent of the challenge concentration penetration points. However, he does not address changes in this ratio that may occur throughout the breakthrough curve (with challenge concentration held constant) for preconditioned carbon beds, 
nor does he discuss potential differences in this ratio resulting from changes in the challenge concentration. This model does not describe either of these impacts.

Nelson and Correia ${ }^{23}$ observed during their studies that the typical sigmoidal (s-shaped) breakthrough response curve of breakthrough concentration versus time under dry conditions began to elongate as the relative humidity during test conditions was raised above $65 \%$. This effect is even more pronounced when a cartridge has been pre-conditioned at high humidity levels (65 percent or greater), such that the response becomes nearly linear throughout a large portion of the curve.

It is important to note that these equations help to predict the exit concentration over time when parameters for the cartridge, air flow rate, exposure concentration, and specific compound characteristics are known. While some estimates can be made, most models are limited in their ability to account for the effects of relative humidity, temperature, or mixtures of compounds.

In summary, most of the research in this area has led to the following conclusions:

- Higher exposure concentrations will reduce the breakthrough time for a given contaminant. Breakthrough time is approximately inversely proportional to challenge concentration at the 50 percent breakthrough point, with the complete breakthrough curve exhibiting a sigmoidal shape and following the reaction-kinetic equation principles of mass conservation and firstorder kinetics.

- Breakthrough time is inversely proportional to flow rate.

- Breakthrough time is reduced by between 1 and 10 percent for every $10^{\circ} \mathrm{C}$ increase in temperature above a cartridge's test conditions.

- Activated carbon generally has a greater affinity for less volatile substances. 
- High relative humidity levels during cartridge use reduce service lives when compared to low relative humidity levels. This effect is especially pronounced at relative humidity levels above 65 percent.

- Preconditioning a cartridge at a low relative humidity has a mild impact on its service life, with the test relative humidity having a considerably greater impact than the preconditioning humidity. However, preconditioning at high relative humidity levels will cause a significant reduction in service life.

- Breakthrough times for cartridges tested under pulsating air flow rates are not significantly different from those tested with a steady-state air flow source.

\subsubsection{Breakthrough testing methods}

Methods for testing breakthrough for cartridges exposed to single-component substances typically involve producing a constant flow rate of air at fixed temperature and humidity conditions into a mixing chamber. ${ }^{23}$ In the chamber, a fixed delivery rate of the substance in question is injected and flash-vaporized. The contaminated air is fed into a cartridge testing chamber, where it flows through the cartridge. Relative humidity, temperature, and concentration are monitored at various points through the system to ensure adequate control and to monitor the system parameters. Detection equipment may vary depending upon the substance being monitored. For organic vapors, infrared (IR) detectors or Flame Ionization Detectors (FIDs) are commonly used.

\subsection{Breakthrough of mixtures}

\subsubsection{Overview}

As compared to research published regarding breakthrough data for single-component organic substances, there is a much smaller body of research that has been published to date on organic vapor cartridge service life when exposed to mixtures of two or more substances. Lewis et. al.,39 Grant and Mares, ${ }^{40}$ Myers and Prausnitz, ${ }^{41}$ and Jonas and Sansone ${ }^{42}$ have each studied carbon adsorption characteristics gases and hydrocarbons to a limited degree. 
More recently, Yoon et. al.43י44 tested organic vapor cartridges for mixtures involving acetone and $m$-xylene (binary tests) and various combinations of acetone, cyclohexane, toluene, ethyl acetate, and $m$-xylene (ternary and quaternary tests).

Data from the mixture studies indicate that compounds that are relatively weakly adsorbed by a carbon bed can be displaced by one that has stronger adsorption characteristics. This may, in fact, actually result in a breakthrough concentration for the displaced substance that is greater than its concentration in the challenge mixture. Therefore, the service life of a cartridge becomes highly dependent on the challenge concentration for each component in the mixture, and is measurably influenced as a result of the displacement process. Weakly-adsorbed compounds break through faster than they would as single-component challenges.

Yoon, Nelson, and Lara ${ }^{44}$ have developed a mathematical model that accounts for the rate of adsorption, the capacity of the carbon bed, and the displacement phenomenon that occurs with multi-component substances. Since JP-8 contains over 300 organic compounds, further discussion of their model is beyond the scope of this paper.

\subsubsection{Breakthrough testing methods}

The breakthrough testing methods used for multi-component substances are similar to those used for single-component substances. Methods involve controlled injection and flash volatilization of each component individually into the air stream, allowing them to mix in a chamber before passing through the cartridge.

\subsection{Vapor generation}

In most of the studies reported above, vapor generation of single and multiple contaminants is typically accomplished in a manner similar to that for single component breakthrough testing. A typical vapor generation configuration uses multiple motor-controlled syringes to inject and vaporize a known mass of each contaminant into the air stream. 
The literature does not reflect significant use of other methods for vapor generation in cartridge breakthrough studies. However, inhalation toxicity studies frequently employ other methods. One such method has been employed for producing known and constant concentrations of fuel vapors during toxicity testing of petroleum- and shale-derived fuels at the Toxic Hazards Research Unit, Wright-Patterson Air Force Base, Ohio. The Air Force ${ }^{45}$ used evaporation towers consisting of a 13-inch long, 1-3/4-inch outside diameter glass cylinder. Each of the towers had a 13-turn, 9-inch long spiral embedded in its wall to contain a heating coil and to lengthen the path of vaporization. The top of each tower reduced to a "T" with one arm for vapor exhaust and the other for connecting the input fuel. The bottom was connected to a double "T" constructed of stainless steel tubing, which was used to drain waste fuel and feed carrier air into the system. Vapor effluent was fed into an enclosed dome where animals were exposed to the fuel vapors. Minor corrections in the vapor concentration were accomplished by changing the air flow in each dome. The primary energy of vaporization came from an electrically heated coil wrapped around the tower, with a lesser portion of the energy supplied with the incoming air.

Although not specifically designed for multiple contaminant generation, Potts and Steiner ${ }^{46}$ reported on a device for volatilizing high-boiling liquids without requiring heat input. Their approach uses a multiple plate, high efficiency, countercurrent distillation column that is maintained at a temperature below ambient. They tested two configurations. The first was a relatively simple system that serves well for experiments of short duration where the desired concentration is close to the saturation level in air. However, this system was highly dependent on the temperature of ambient air surrounding the distillation column, so any fluctuations in air temperature could affect the liquid vapor pressure and cause small fluctuations in the generated concentration. Fluctuations would normally occur over a several-hour period, and it was possible to adjust the air flow rates to compensate accordingly and maintain a constant concentration. However, for longer-term studies, the authors designed a second apparatus that uses a temperature-controlled water jacket to maintain a constant temperature within the distillation column. 
According to the authors, one significant advantage of using this system over flash volatilization methods is that in multiple component mixtures, where each component has different vapor pressures, this method would produce a vapor composition that is very similar to that which would be generated from liquid in an open room, as governed by Raoult's Law. Operating the second system for such applications would require a minor modification, allowing for a fresh source of liquid continuously supplied to the top of the column instead of being recirculated. Periodic or continuous emptying of the reservoir would also be necessary. 
Chapter 3. METHODS AND MATERIALS

\subsection{Purpose of study}

The NIOSH protocol for certification of organic vapor cartridges requires the testing of only a single substance, carbon tetrachloride. However, in a work environment, workers are most likely exposed to a different substance, and frequently to multiple substances at the same time. For example, a typical oil-based paint may contain numerous types of solvents (e.g. toluene, xylene, and methyl ethyl ketone), each of which has a different affinity toward carbon and would break through the cartridge at different times.

The OSHA requirement to develop cartridge change-out schedules presents a real dilemma for industry and for the Air Force, since there is a large, undefined number of different chemical combinations to which a worker could be exposed. Cartridge testing already requires considerable resources to assess single chemical breakthrough times. Costs escalate considerably when attempting to address the numerous permutations of multiple chemical exposures possible in the work environment.

To develop change-out schedules for organic vapor cartridges during activities where personnel are exposed to JP-8 jet fuels, the USAF needs to better understand the breakthrough characteristics of the cartridges most commonly used by its employees in an active mode (as primary protective devices) and in a passive mode (as a backup, escape-only provision). Of particular interest is the impact of exposing a cartridge to a static concentration of JP-8 fuel vapor prior to actively drawing air through the cartridge in a dynamic configuration, and the resulting impact on its service life, if any. The emphasis will be placed on cartridges currently in predominant use within the USAF.

Therefore, the focus of this study was to determine those breakthrough times to support development of cartridge change-out schedules during fuel tank entry operations. The hypotheses tested in this study are: 
- 1 st $\mathrm{H}_{0}$ : Preconditioning, followed by subsequent exposure to high levels of relative humidity, will have no significant impact on the breakthrough time of an organic vapor cartridge dynamically exposed to fuel vapor as compared to a cartridge challenged at a low relative humidity level. The alternative hypothesis, $\mathrm{H}_{1}$, states that there is a significant impact on breakthrough time resulting from exposure to high levels of relative humidity.

- 2nd $\mathrm{H}_{0}$ : Prior exposure of a cartridge to a high-level, static concentration of fuel vapor and high level of relative humidity for a full work shift will have no significant impact on its breakthrough time when that cartridge is subsequently used under dynamic flow conditions, relative to cartridges without prior exposure. The alternative hypothesis, $\mathrm{H}_{1}$, states that there would be a significant impact on breakthrough time.

- $3 \mathrm{rd} \mathrm{H}_{0}$ : The breakthrough response characteristics of JP-8 through an organic vapor cartridge cannot be adequately modeled by a generalized form of the Yoon and Nelson equation. The alternative hypothesis, $\mathrm{H}_{1}$, would state that the response function does follow this equation.

\subsection{Experimental design}

\subsubsection{Hypotheses 1 and 2}

To test the first two null hypotheses, two experimental models were established in the form of two by three factorial designs. The first model, which examines the impact of relative humidity and concentration on breakthrough time, uses a 3-level treatment of concentration $(300,600$, and 1200 parts per million of JP-8, equivalent to 2100,4200 , and $8300 \mathrm{mg} / \mathrm{m}^{3}$, respectively) and a 2level treatment of test relative humidity (50 percent and 80 percent). The second model uses a 3level treatment of concentration (same levels as before) and a 2-level "prior exposure" treatment ("yes" or "no") with relative humidity held constant at 80 percent. Five replicates were conducted at each test condition, and the "no prior exposure" treatment at 80 percent relative humidity was shared between the two data sets. All cartridges were preconditioned at 80 percent relative

humidity and a temperature of $25^{\circ} \mathrm{C}$. Pre-exposed cartridges were passively exposed in $25^{\circ} \mathrm{C}$ air 
for 8 hours at 1200 ppm fuel vapor and 80 percent relative humidity. A flow diagram of the cartridge testing procedure is shown in Figure 3-1.

Figure 3-1. Factorial design of breakthrough testing research.

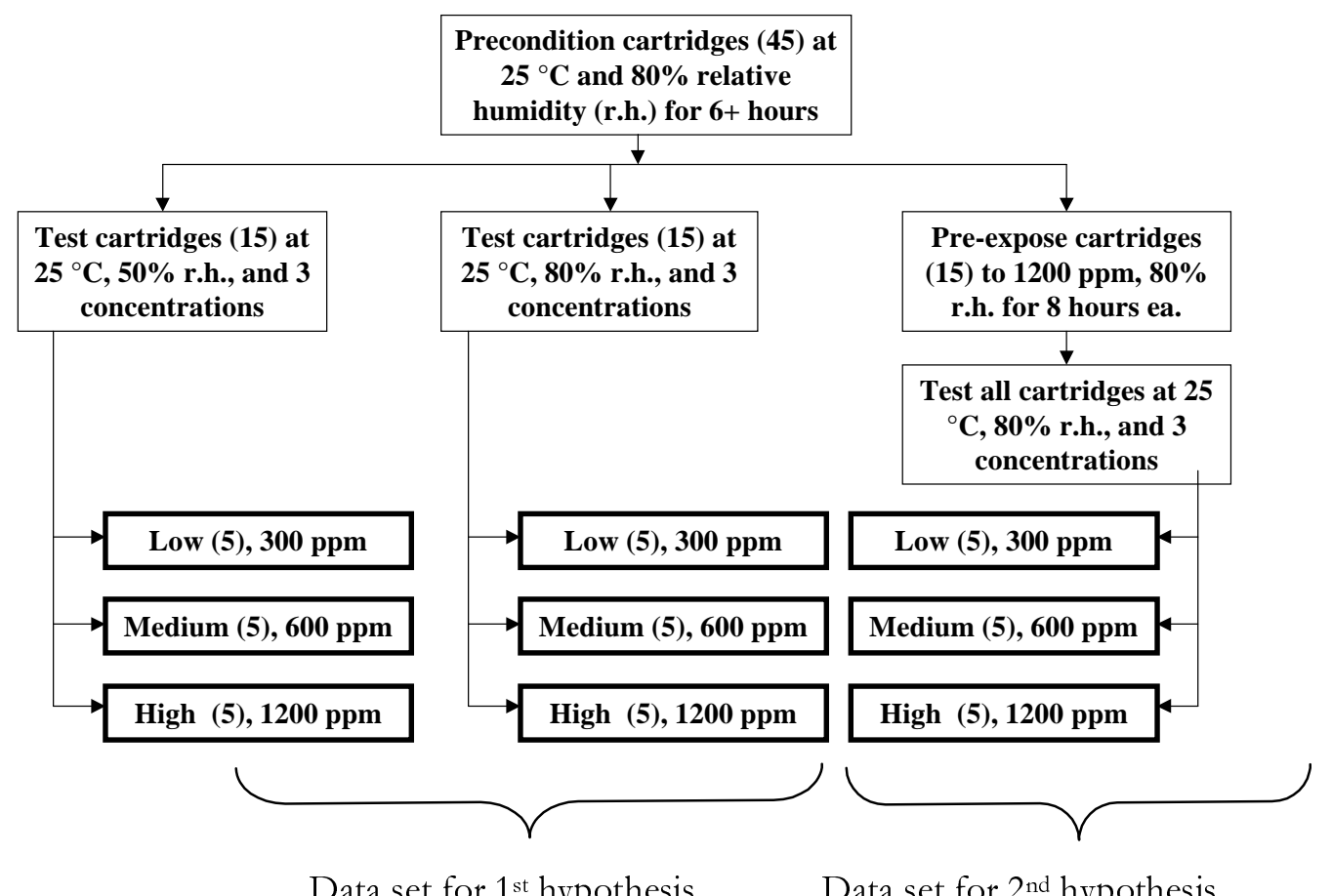

The dependent variable is the breakthrough time to a given fraction of the challenge concentration (e.g. $1 \%, 5 \% 10 \%, 20 \%$ ) or to a fixed level (e.g. the TLV or OEL).

Although the models could have been combined into one $2 \times 2 \times 3$ experimental design (2 levels of relative humidity, 2 levels of prior exposure, and 3 levels of concentration), time constraints limited the number of tests that could be performed. Therefore, the author chose to measure the impact of prior exposure only at the assumed worst-case condition, the higher relative humidity condition of $80 \%$. 
Care was taken throughout the testing to minimize potential systematic error by spacing replicates of each test condition over time throughout the testing period. However, as a result of the amount of time required to achieve system stability before each test, it was impractical to completely randomize the design, and in several instances two or three cartridges were tested under the same environmental conditions in sequence. Analysis of Variance (ANOVA) was still applied to assess the effects of each treatment, recognizing that this design did not meet the strict statistical requirements for using that type of analysis.

For the first null hypothesis, the model statement appears as follows:

$$
\mathrm{Y}_{\mathrm{ijk}}=\mu+\mathrm{R}_{\mathrm{i}}+\mathrm{C}_{\mathrm{j}}+(\mathrm{RC})_{\mathrm{ij}}+\varepsilon_{\mathrm{ijk}}
$$

where

$$
\begin{aligned}
\mathbf{Y}_{\mathrm{ijk}} & =\text { Observation of breakthrough time, in minutes } \\
\boldsymbol{\mu} & =\text { Mean breakthrough time for all cartridges tested at } 80 \% \text { relative humidity, in } \\
& \text { minutes } \\
\mathbf{R}_{\mathbf{i}}= & \text { Test relative humidity }(2 \text { levels: } 50 \% \text { or } 80 \%) \\
\mathbf{C}_{\mathbf{j}}= & \text { Challenge concentration of JP-8 vapor }(3 \text { levels: } 300,600, \text { and } 1200 \mathrm{ppm}) \\
(\mathbf{R C})_{\mathrm{ij}} & =\text { Interaction between relative humidity and challenge concentration } \\
\boldsymbol{\varepsilon}_{\mathrm{ijk}} & =\text { Experimental error }
\end{aligned}
$$

A model statement for the second null hypothesis is shown below:

$$
\mathbf{Y}_{\mathrm{ijk}}=\mu+\mathbf{P}_{\mathrm{i}}+\mathrm{C}_{\mathrm{j}}+(\mathbf{P C})_{\mathrm{ij}}+\varepsilon_{\mathrm{ijk}}
$$

where

$$
\begin{aligned}
\mathbf{Y}_{\mathrm{ijk}} & =\text { Observation of breakthrough time, in minutes } \\
\boldsymbol{\mu} & =\text { Mean breakthrough time for all cartridges tested at } 80 \% \text { relative humidity, in } \\
\mathbf{P}_{\mathrm{i}} & =\text { Pinutes } \\
\mathbf{C}_{\mathrm{j}} & =\text { Challenge concentration of } \mathrm{JP}-8 \text { fuel vapor }(300,600, \text { or } 1200 \mathrm{ppm}) \\
(\mathbf{P C})_{\mathrm{ij}} & =\text { Interaction between prior exposure and challenge concentration treatments } \\
\boldsymbol{\varepsilon}_{\mathrm{ijk}} & =\text { Experimental error }
\end{aligned}
$$




\subsubsection{Hypothesis 3}

The null hypothesis was tested through regression analysis of the breakthrough times vs. challenge concentrations. No additional data collection was necessary.

\subsection{Equipment configuration}

\subsubsection{General description}

The basic approach for conducting the breakthrough studies involved producing a known and controllable concentration of JP-8 vapor, attempting to vaporize the more volatile components while allowing the less volatile compounds to remain in liquid form. The generated air stream/fuel vapor mix was controlled for temperature and humidity conditions, and subsequently fed into a holding chamber where it was pushed through the organic vapor cartridge. Air flow was exhausted into a ventilated fume hood. The general test system configuration is depicted in the block diagram below (Figure 3-2). 
Figure 3-2. Test system configuration.

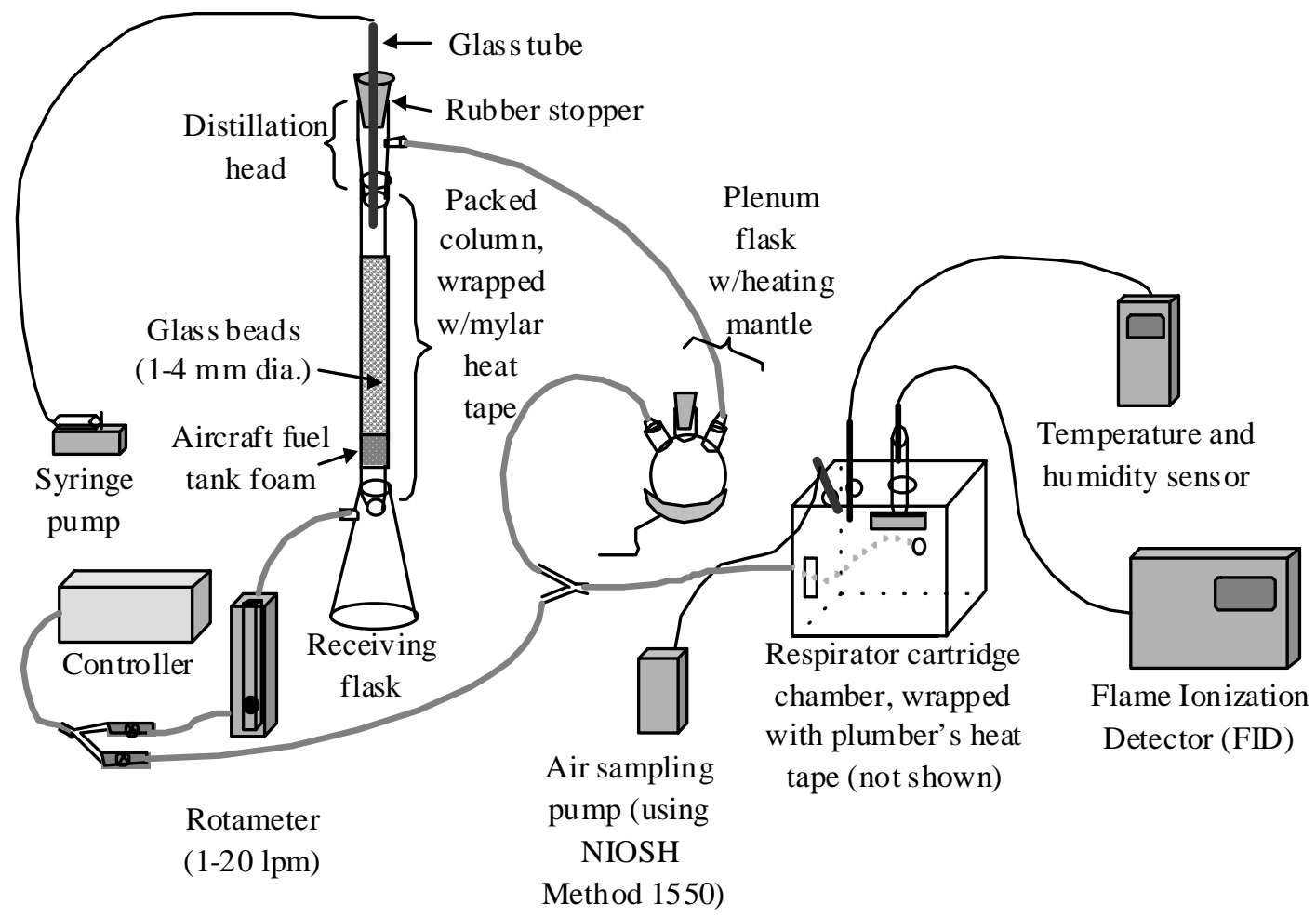


Figure 3-3. Vapor generation portion of breakthrough testing system.

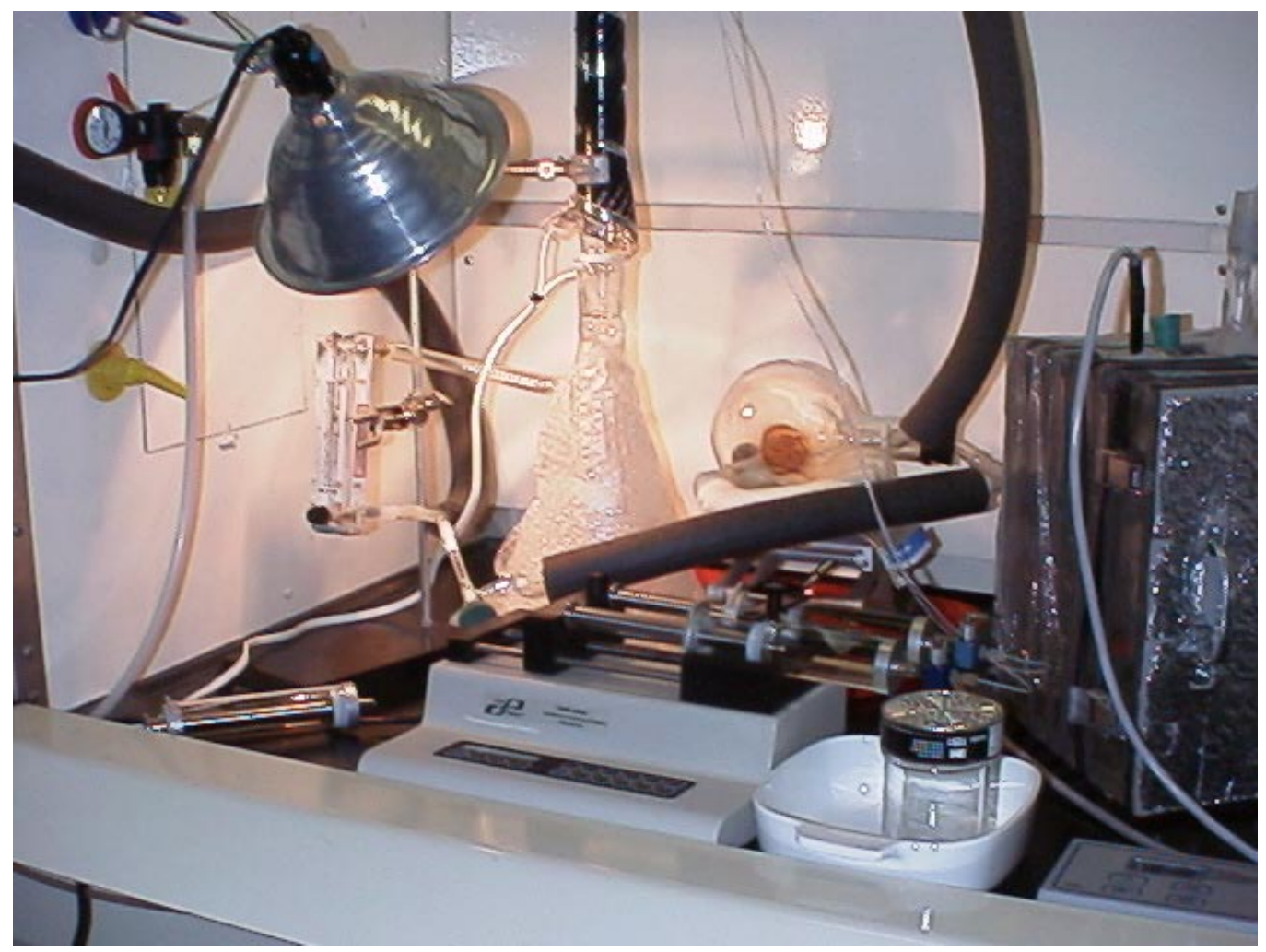

The vapor generation process involved passing air controlled for temperature, humidity, and flow rate through the bottom of a glass packed column filled with glass beads ranging in diameter between $0.1 \mathrm{~cm}$ and $0.4 \mathrm{~cm}$. Jet fuel was injected into the top of the column through a distillation head at a constant flow rate for a given target vapor concentration via a Cole-Parmer 74900 series (S/N 8573) syringe pump (Cole-Parmer Instrument Co., Vernon Hills, IL) equipped with two Hamilton 100-mL Gastight ${ }^{\circledR}$ syringes (part number 1100) with teflon leur locks (Hamilton Company, Reno, NV). Fuel entering the column dispersed across the glass beads, increasing the surface area of the liquid fuel and increasing the efficiency of evaporation. Flow rates of fuel injected into the column were set to 1,2 , and $4 \mathrm{~mL} / \mathrm{min}$ for the 300, 600, and $1200 \mathrm{ppm}$ challenge concentrations, respectively. 
As the air flowed counter-currently through the packed column, the concentration of fuel vapor continued to increase until it passed out of the top of the column through the side of the distillation head. The fuel vapor-enriched air was then fed through polyethylene tubing into a plenum flask, which acted as a liquid trap for any condensing fuel (and doubled as a temperature, humidity, and concentration monitoring point when necessary). Liquid that did not evaporate, e.g. the less volatile components, dripped through the bottom of the column and was collected in an Erlenmeyer flask at its base.

The saturated air then entered into a 28 -liter Plexiglass ${ }^{\circledR}$ chamber. The organic vapor cartridge to be tested was attached to a matching cartridge holder and was immersed into the chamber. Air flowed through the cartridge and exited the other side through a 4-cm inner diameter glass tube.

Adjustments to the fuel vapor concentration entering the chamber were made by mixing the saturated air with fresh air from the air flow controller. A combination of y-splitters and needle valves allow the ratios to be adjusted accordingly to achieve the target challenge concentration of 300, 600, and 1200 ppm.

\subsubsection{Temperature, humidity, and air flow rate control}

A Miller-Nelson controller (Miller-Nelson Research, Inc., Monterey, CA), model no. HCS-301, S/N 97626, was used to provide a constant flow of temperature and humidity controlled air. Heat losses were encountered; therefore, it was necessary to insulate connecting tubing and to add energy at four different locations: (1) a 250-watt infrared heat lamp was placed $25 \mathrm{~cm}$ from the glass needle valve and rotameter to avoid any water vapor condensation within those components; (2) the packed column was wrapped with 1.25 meters of $4 \mathrm{~cm}$-wide Mylar ${ }^{\circledR}$ heat tape (maximum power rating of 20 watts per meter); (3) a heating mantle was placed under the 3-neck plenum flask to minimize the potential for fuel and water vapor condensation (maximum power rating of 270 watts); and (4) 2 meters of plumber's heat tape was wrapped around the respirator

chamber (power rating unknown). The Mylar ${ }^{\circledR}$ heat tape, heating mantle, and plumber's heat tape were each connected to separate variable AC power supplies to enhance controllability at each 
position. A water-jacketed temperature control methodology would have allowed less user intervention and more precision, but at greater expense. The methods used provided adequate temperature stability when monitored and adjusted periodically throughout each testing period.

The chamber temperature was maintained at $25 \pm 1.5^{\circ} \mathrm{C}$ for all tests. Relative humidity was controlled within \pm 2 percent for both the 50 and 80 percent relative humidity test conditions.

\subsubsection{JP-8 vapor generation}

The infusion pump, equipped with two $100 \mathrm{~mL}$ syringes, provided a constant flow rate of fresh fuel into the packed column. Flow rates were between $1.0 \mathrm{~mL} / \mathrm{min}$ and $4.0 \mathrm{~mL} / \mathrm{min}$, depending on the desired concentration in the cartridge testing chamber.

The packed column and head, along with connection joints on the plenum flask and the Erlenmeyer flask, were custom-constructed by the West Virginia University Chemistry Department's resident glassblower. The column was $58 \mathrm{~cm}$ in length and had an inner diameter of $34 \mathrm{~mm}$. It was fitted with a tight-fitting glass joint on the bottom to permit a snug connection with the 3 liter Erlenmeyer flask, which was modified to include a matching joint. The top of the column contained a receiving joint, into which the custom distillation head was inserted. Fuel flowed directly into the top of the packed head via a short glass tube inserted through a rubber stopper. The bottom joint of the packed column, and the joint of the distillation head, were both wrapped with Teflon ${ }^{\circledR}$ tape to ensure no leakage of air, vapor, or liquid occurred and to avoid bonding of the ground glass joints.

The air exited the column through the side of the distillation head and flowed into a 1-liter 3-neck plenum flask. The flask was intended to act as a liquid trap in the event any condensation of fuel or water vapor would result at any time during the initial configuration and active cartridge testing phases, but also added the flexibility to monitor the temperature, humidity, and vapor concentration directly leaving the column and prior to entering the cartridge testing chamber. 
Figure 3-4. Custom distillation head inserted into top of packed column.

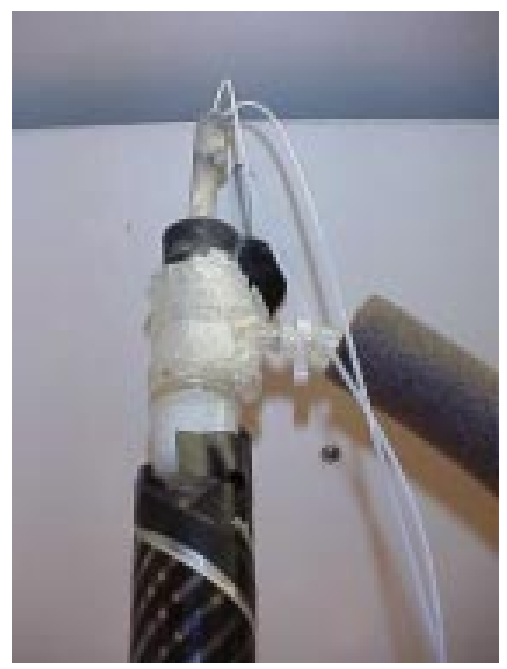

Concentrations of fuel vapor were maintained within \pm 5 percent of the target concentration for all test conditions. If the concentration was found to be outside of this range during any breakthrough test, the test was terminated and the data excluded from analysis.

\subsubsection{Measurements}

\subsubsection{Temperature and relative bumidity}

Temperature and relative humidity levels were monitored inside the cartridge testing chamber with a Digital Hygrometer/Thermometer (Control Company, Friendswood, TX). The probe was inserted to a depth of approximately $5 \mathrm{~cm}$ into the top of the chamber. Calibration of the instrument's response for relative humidity was verified using a saturated lithium chloride salt solution reference method for the low relative humidity calibration point $\left(12.2\right.$ percent at $\left.22{ }^{\circ} \mathrm{C}\right)$, and a saturated sodium chloride salt solution reference method for the high relative humidity level (75.6 percent at $\left.22^{\circ} \mathrm{C}\right)$.

\subsubsection{Fuel vapor monitoring}

Two primary mechanisms were used to measure vapor concentrations within the chamber and on the exit side of the cartridge. Direct reading measurements were taken with a portable Flame 
Ionization Detector (FID), and time-weighted average measurements were taken using coconut shell solid sorbent charcoal tubes.

\section{Flame Ionization Detector}

A Foxboro® TVA-1000B (The Foxboro Company, Foxboro, MA), which is a portable vapor analyzer with a photoionization detector (PID) and FID, was used in the FID monitoring mode to periodically confirm that the challenge concentration inside the chamber had reached the desired steady-state concentration. The same FID was used to monitor breakthrough concentrations. The FID was zeroed by drawing ambient laboratory air through a clean charcoal sampling tube connected to the sampling probe. Calibration was performed using pentane at 7500 ppm (CALGAZTM, from Air Liquide America Corp., Cambridge, MD).

During preliminary testing with this device, several problems and questions were identified concerning the use of this instrument with jet fuel vapors. It was noted that after continuously exposing the instrument to a high level of fuel vapor in the chamber, upon removal from the chamber, the TVA-1000B required in excess of 60 minutes to return to a "zero" reading. Continued testing led to the conclusion that the water trap filter, which was attached to the end of the sampling probe, was adsorbing or absorbing a measurable amount of fuel vapor and desorbing throughout the sampling train during periods of reduced exposure levels. To avoid this problem, an external TSI Portacount ${ }^{\circledR}$ HEPA filter, part number 1602066 (TSI, Inc., St. Paul, $\mathrm{MN}$ ) was added to the tip of the probe and was tested to ensure minimal adsorption occurred. A separate external filter was used at each challenge concentration. However, even with an external filter in place, the instrument still required between 10 and 15 minutes to recover from a highlevel exposure to fuel vapor in the chamber. Therefore, it became necessary to ensure the instrument was allowed adequate time to "re-zero" itself after monitoring the chamber concentration. 


\section{Charcoal Tube Sampling}

NIOSH Method 1550 documents a technique for measuring naphthas, the lighter-fraction components of JP-8 that dominate the composition of fuel vapor near the test temperature conditions. This method uses a $100 \mathrm{mg}$ front / $50 \mathrm{mg}$ back coconut shell charcoal solid sorbent tube with collection flow rates of between 0.01 and 0.2 LPM. It has a working range of 100 to $2000 \mathrm{mg} / \mathrm{m}^{3}$ for a 5 liter air sample. As presented in NIOSH Method 1550, the working range does not adequately cover the higher concentrations measured during this study. Therefore, the author consulted with the NIOSH Method 1550 validation team to determine if using a higher capacity charcoal tube would be an acceptable alteration. The validation team indicated that a 400 mg front / $200 \mathrm{mg}$ back charcoal tube would be acceptable for monitoring higher concentrations, with some modifications to the analysis protocol to account for the additional mass of adsorbate.

The modified NIOSH Method 1550 was used to collect time-weighted average fuel vapor concentrations only within the respirator chamber during breakthrough tests. Sampling was conducted at approximately $30 \mathrm{~mL} / \mathrm{min}$ using an SKC personal sampling pump with a low-flow rate adapter. The pump was calibrated before and after each test with a BIOS International DryCal DC-2 Flow Calibrator (Base S/N B-757) and an accompanying low flow cell, part number DC-1LC, S/N 1131 (BIOS International, Butler, NJ).

\subsubsection{Cartridge weights}

To determine the mass of water vapor and fuel adsorbed by the carbon, each cartridge was weighed upon removal from its packaging, after preconditioning, after prior exposure to fuel vapor (when applicable), and upon completion of its test for breakthrough. Cartridges were weighed using a Mettler AE 163 Electronic Balance, S/N B96156 (Mettler Toledo, Toledo, OH) with a precision of $\pm 0.1 \mathrm{mg}$. 


\subsection{Test parameters and procedures}

\subsubsection{Pre-Conditioning}

All cartridges were preconditioned at $25^{\circ} \mathrm{C}$ and 80 percent relative humidity for a 6-hour period.

32 LPM of air was passed through each cartridge, which were placed (in pairs) within the respirator chamber (Figure 3-5). The air flow tubing from the Miller-Nelson controller fed directly into the respirator chamber at 64 liters per minute. Since the laboratory ambient temperatures were lower than the desired pre-conditioning temperature of $25^{\circ} \mathrm{C}$, the MillerNelson controller was adjusted to compensate for heat loss within the air flow tubing. Air exited the Miller-Nelson controller at approximately $32{ }^{\circ} \mathrm{C}$ and 53 percent relative humidity, which is equivalent to $25^{\circ} \mathrm{C}$ at 80 percent relative humidity.

Figure 3-5. Configuration of cartridges inside chamber for pre-conditioning at $80 \%$ relative humidity.

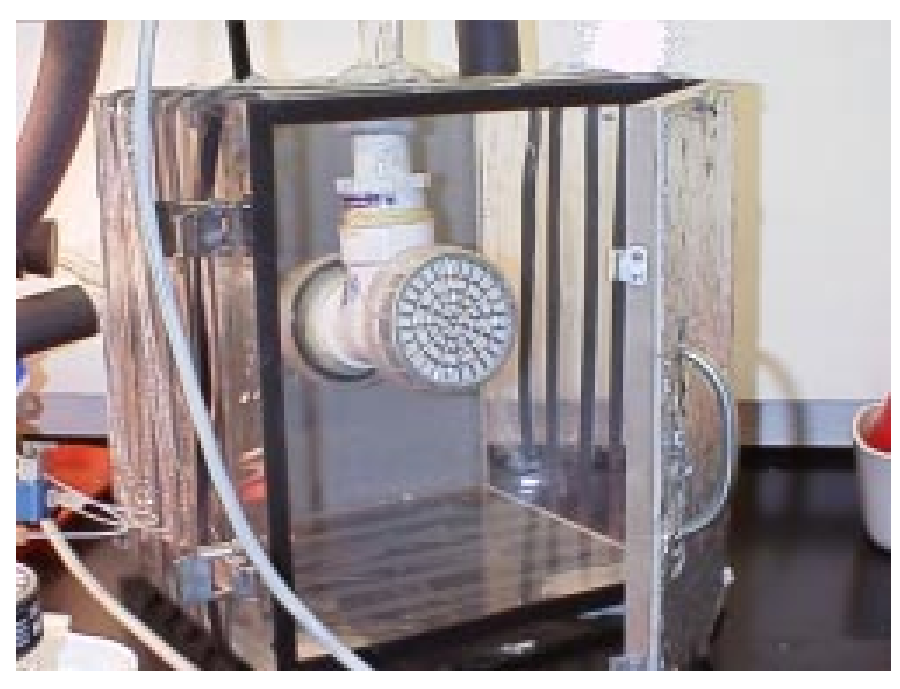


Actual settings for the Miller-Nelson controller were as follows:

Table 3-1. System parameter settings for cartridge pre-conditioning with 32 liters per minute of air at $25{ }^{\circ} \mathrm{C}$ and 80 percent relative humidity. Temperature and relative humidity settings are expressed as approximate ranges of setting pairs $(A$ and $\mathrm{B}$ ), since ambient laboratory temperature conditions affected the temperature being delivered to the respirator testing chamber. Periodic adjustments were made to achieve a monitored temperature of $25{ }^{\circ} \mathrm{C}$ and relative humidity level of 80 percent within the chamber.

\begin{tabular}{lc}
\hline Parameter & Dial setting \\
\hline Miller-Nelson controller flow rate setting & 64.0 \\
Miller-Nelson controller temperature setting & $32.3^{(\mathrm{A})}$ to $40.0^{(\mathrm{B})}$ \\
Miller-Nelson controller relative humidity setting & $47.0^{(\mathrm{A})}$ to $29.0^{(\mathrm{B})}$ \\
\hline
\end{tabular}

Periodic adjustments to the controller temperature and humidity dial positions were made to compensate for changing ambient conditions, particularly during the University's transition from winter to summer HVAC settings. Instead of making major changes to the system temperature and humidity settings, the laboratory ambient temperature was adjusted whenever possible. During a period in which the laboratory air conditioning system was inoperable, testing was postponed until the HVAC system was active again. In all cases, adjustments were made such that pairs of temperature and relative humidity settings yielded a monitored temperature and humidity level of $25^{\circ} \mathrm{C}$ and 80 percent relative humidity within the respirator testing chamber, equivalent to a dew point of $21.3^{\circ} \mathrm{C}$.

After pre-conditioning, each cartridge was placed in a sealed Ziploc ${ }^{\circledR}$ bag to prevent water weight loss until the prior exposure procedure or breakthrough test began. Elapsed time from cartridge pre-conditioning and testing ranged from 6 hours to 72 hours.

\subsubsection{Prior exposure}

Pre-exposed cartridges were first pre-conditioned as described above, and were then placed in a cartridge holder that allowed the cartridge face (inlet) to be exposed to fuel vapor and humidified air in the chamber. Cartridge holders were sealed with hot glue on the reverse side to prevent the 
outlet side of the cartridge from being exposed to chamber air. These cartridges were then placed in groups of three to five cartridges in the chamber and exposed to $25^{\circ} \mathrm{C}$ air at $1200 \mathrm{ppm}$ and 80 percent relative humidity for 8 hours, equivalent to a standard full-shift work exposure.

General parameter settings for each of the control inputs are shown in Table 3-2. Periodic adjustments to the temperature control and relative humidity settings were necessary depending on the changing ambient laboratory temperature conditions and the associated drift in system temperature, humidity, and vapor concentration. In all cases, adjustments were made such that pairs of temperature and relative humidity settings yielded a monitored temperature and humidity level of $25^{\circ} \mathrm{C}$ and 80 percent relative humidity within the respirator testing chamber.

Table 3-2. System parameter settings during prior exposure of cartridges to $25{ }^{\circ} \mathrm{C}$ air at $80 \%$ relative humidity and $1200 \mathrm{ppm}$ JP-8 vapor. Temperature and relative humidity settings are expressed as approximate ranges of setting pairs ( $A$ and $B$ ), since ambient laboratory temperature conditions affected the temperature being delivered to the respirator testing chamber. Periodic adjustments were made to achieve a monitored temperature of 25 ${ }^{\circ} \mathrm{C}$ and relative humidity level of 80 percent within the chamber.

\begin{tabular}{lc}
\hline Parameter & Setting \\
\hline Miller-Nelson controller: flow rate (LPM) & 9.0 \\
Miller-Nelson controller temperature $\left({ }^{\circ} \mathrm{C}\right)$ & $32.3^{(\mathrm{A})}$ to $40.0^{(\mathrm{B})}$ \\
Miller-Nelson controller relative humidity $(\%)$ & $47.0^{(\mathrm{A})}$ to $29.0^{(\mathrm{B})}$ \\
Fuel flow rate into packed column (mL/min) & 1.0 \\
Air flow rate through column (LPM) & 4.7 \\
Column heat tape rheostat voltage (Volts) & 70 \\
Flask heating mantle rheostat voltage (Volts) & 15 \\
Chamber heat tape rheostat voltage (Volts) & 30 \\
\hline
\end{tabular}

After prior exposure, each cartridge was stored in a sealed Ziploc ${ }^{\circledR}$ bag awaiting its breakthrough test. Elapsed time between pre-exposure and testing ranged from 6 to 72 hours.

\subsubsection{Breakthrough tests}

Cartridges were tested at three concentrations (300,600, and $1200 \mathrm{ppm})$ and two test relative humidity levels (50 and 80 percent), requiring six sets of operating parameters (see Table 3-3). 
Achieving these concentrations at equilibrium conditions usually required between one and two hours of warm-up time. During warm-up, each component was allowed to equilibrate to its desired temperature; the packed column became saturated with liquid fuel, ensuring a steady-state liquid flow rate across the glass beads; and the TVA-1000B was given time to recover to zero following measurement of the chamber concentration.

As mentioned previously, some minor adjustments to the temperature control settings and flow rates were necessary, depending on the changing laboratory temperature conditions and the associated drift in system temperature, humidity, and vapor concentration; for this reason, Table 3-3 expresses the temperature and relative humidity dial positions as pairs of settings.

Additionally, the settings indicated on the Miller-Nelson controller indicate approximate air flow feed conditions from the controller itself but do not reflect the actual flow rate through and temperature and relative humidity inside the respirator testing chamber as a result of temperature drops in the system air combined with heat losses throughout the system. To compensate for this, chamber temperature and humidity were continuously verified throughout the duration of each breakthrough test, and air flow through the system was checked periodically by measuring the air flow through an exit port of the respirator chamber with a BIOS International DryCal DC2 Flow Calibrator, base S/N B-757, and an accompanying high flow cell, part number DC-1HC, S/N 1454 (BIOS International, Butler, NJ). 
Table 3-3. System configuration settings used during cartridge breakthrough testing. Temperature and relative humidity settings are expressed as approximate ranges of setting pairs (A \& B, and $C \& D$ ), since ambient laboratory temperature conditions affected the temperature being delivered to the respirator chamber. Periodic adjustments were made to achieve a monitored temperature of $25^{\circ} \mathrm{C}$ and relative humidity level of 50 or 80 percent within the respirator testing chamber.

\begin{tabular}{|c|c|c|c|c|c|c|}
\hline Parameter & $\begin{array}{c}50 \% \text { RH } \\
300 \mathrm{ppm}\end{array}$ & $\begin{array}{l}50 \% \text { RH } \\
600 \mathrm{ppm}\end{array}$ & $\begin{array}{c}50 \% \text { RH } \\
1200 \mathrm{ppm}\end{array}$ & $\begin{array}{c}80 \% \text { RH } \\
300 \text { ppm }\end{array}$ & $\begin{array}{l}80 \% \mathrm{RH} \\
600 \mathrm{ppm}\end{array}$ & $\begin{array}{c}80 \% \mathrm{RH} \\
1200 \mathrm{ppm}\end{array}$ \\
\hline $\begin{array}{l}\text { Miller-Nelson controller: } \\
\text { flow rate (LPM) dial } \\
\text { setting }\end{array}$ & \multicolumn{6}{|c|}{35.1} \\
\hline $\begin{array}{l}\text { Miller-Nelson controller } \\
\text { temperature }\left({ }^{\circ} \mathrm{C}\right) \text { dial } \\
\text { setting }\end{array}$ & \multicolumn{3}{|c|}{$33.0^{(\mathrm{A})}$ to $40.0^{(\mathrm{B})}$} & \multicolumn{3}{|c|}{$33.0^{(\mathrm{C})}$ to $40.0^{(\mathrm{D})}$} \\
\hline $\begin{array}{l}\text { Miller-Nelson controller } \\
\text { relative humidity (\%) } \\
\text { dial setting }\end{array}$ & \multicolumn{3}{|c|}{$27.8^{(\mathrm{A})}$ to $17.1^{(\mathrm{B})}$} & \multicolumn{3}{|c|}{$47.0^{(\mathrm{C})}$ to $29.0^{(\mathrm{D})}$} \\
\hline $\begin{array}{l}\text { Fuel flow rate into } \\
\text { packed column } \\
(\mathrm{mL} / \mathrm{min})\end{array}$ & 1.0 & 2.0 & 4.0 & 1.0 & 2.0 & 4.0 \\
\hline $\begin{array}{l}\text { Air flow rate through } \\
\text { packed column } \\
\text { (LPM) }\end{array}$ & 4.7 & 8.8 & 18.0 & 4.7 & 8.8 & 18.0 \\
\hline $\begin{array}{l}\text { Column heat tape } \\
\text { rheostat voltage } \\
\text { (Volts) }\end{array}$ & \multicolumn{6}{|c|}{70} \\
\hline $\begin{array}{l}\text { Flask heating mantle } \\
\text { rheostat voltage } \\
\text { (Volts) }\end{array}$ & \multicolumn{6}{|c|}{15} \\
\hline $\begin{array}{l}\text { Chamber heat tape } \\
\text { rheostat voltage } \\
\text { (Volts) }\end{array}$ & \multicolumn{6}{|c|}{4} \\
\hline
\end{tabular}

The breakthrough testing followed the general procedures given below:

1. Configure the testing system to the parameters shown in Table 3-3.

2. Zero and calibrate the TVA-1000B to 7500 ppm pentane.

3. After approximately one hour, begin monitoring the chamber temperature, humidity, and concentration. Perform minor adjustments as needed, waiting 10 to 15 minutes after each adjustment to ensure stability has been achieved. 
4. Once the system has reached equilibrium, remove TVA probe from the chamber and allow it to re-zero.

5. Remove cartridge from the Ziploc ${ }^{\circledR}$ bag and place it in the cartridge holder. Open the chamber, put the holder in place, plug the top of the cartridge holder, and seal the chamber opening with rope caulk. Close chamber door and wait 5 to 10 minutes for the chamber to equilibrate.

6. Initiate the breakthrough test by removing the cartridge holder plug. Immediately place TVA-1000B probe inside outlet end of cartridge holder and begin TVA data logging; insert charcoal tube into chamber and start sampling pump; and manually log temperature and humidity.

7. Monitor chamber concentration, temperature, and relative humidity approximately every hour (or sooner when possible) to ensure stability at the desired challenge concentration. If the concentration or other conditions have changed, modify column air flow rate, system temperature settings, and humidity level as necessary. After monitoring the chamber, remove the TVA-1000B sampling probe and allow it to recover to a reading of less than $5 \mathrm{ppm}$ exposed to ambient laboratory air, then continue monitoring and data logging the breakthrough concentration on the outlet end of the cartridge holder.

8. Once the breakthrough concentration reaches 20 percent of the challenge concentration, remove the TVA-1000B probe, terminate data logging, stop sampling pump, remove charcoal tube, and re-plug the cartridge holder.

9. Remove cartridge from the chamber and weigh it. Cartridge may be discarded once testing is completed.

10. At the end of testing, post-calibrate the sampling pump and cap the charcoal tube. Respan and re-zero the TVA-1000B.

\subsection{Data reduction and analysis methodology}

Data-logged breakthrough concentrations in the TVA-1000B were transferred via serial cable into the Foxboro data logging software on an Intel-based PC and were subsequently imported into 
Microsoft Excel ${ }^{\circledR} 97$ spreadsheet software. Microsoft Excel ${ }^{\circledR}$ was then used to restructure logged concentrations data to enable further graphical analysis and to export data sets readable in a PCbased statistical analysis tool, the SAS Institute, Inc.'s SAS/STAT ${ }^{\circledR}$ software. A summary chart was developed to identify various breakthrough times for each test, specifically at the $1 \%, 5 \%$, $10 \%$, and $20 \%$ of challenge concentration points; for the current Air Force 8-hour Occupational Exposure Limit of 50 ppm; and for the proposed ACGIH 8-hour Time-Weighted Average TLV ${ }^{\circledR}$ of $14 \mathrm{ppm}$.

The null hypotheses 1 and 2 (effects of relative humidity and prior exposure) were both tested at the 10 percent of challenge concentration breakthrough time. This percentage value was selected since it is the mid-point of the breakthrough range sampled, and is a concentration that has been frequently tested in the literature. Testing the hypotheses first required assessing the distribution normality of the five data points in each cell, and then determining the homogeneity of variance (HOV) for each cell relative to the other five cells in its data set. Normality of breakthrough times was verified using the SAS/STAT ${ }^{\circledR}$ PROC UNIVARIATE procedure, and homogeneity of breakthrough time variance among cells via Levene's test for equality of variance.

Differences in mean breakthrough times were compared between each cell via Tukey's "Honestly Significant Difference" (HSD) test. The Tukey test facilitates a mean breakthrough time comparison between the six cells in each data set (for a total of 15 comparisons). If the interaction between independent variables was found to be significant, a blocked means comparison was accomplished between the six cells (for a total of 9 comparison tests). The Tukey HSD test controls the experimentwise alpha to a constant by reducing the alpha value used in each cell comparison, thereby minimizing the risk of committing a Type I error (at the risk of allowing the Type II error to increase).

Once normality and homogeneity of variance were established, a General Linearized Model (the SAS/STAT ${ }^{\circledR}$ PROC GLM procedure) provided an assessment of the impact of each treatment 
(relative humidity, prior exposure, and concentration) on the dependent variable (breakthrough time).

Characterizing the relationship between the challenge concentration and breakthrough time was assessed by examining the Yoon and Nelson equation and the Wood model (see Section 2.6.1) and attempting to empirically fit the data sets to a generalized form of these equations. A generalized form of the Yoon and Nelson equation was declared in a curve fitting software package and tested for fit against the mean 1\%,5\%,10\%, and 20\% breakthrough points for each treatment.

Microsoft Excel ${ }^{\circledR}$ and Oakdale Engineering's DataFit software (Oakdale Engineering, Oakdale, PA) were used to provide the graphical analysis and regression tools to assess this relationship.

A form of Wood's relative humidity model (see Section 2.6.1) was compared to the 50 and 80 percent relative humidity (no prior exposure) data sets to examine the relationship between them at each challenge concentration and throughout the duration of the breakthrough curve. The mean breakthrough time for the 1\%,5\%,10\%, and 20\% breakthrough points of the 80 percent relative humidity condition were divided by the equivalent mean breakthrough time of the 50 percent relative humidity condition for each of the three challenge concentrations. This yielded a ratio similar in concept to Wood's relative humidity model. The ratios were then plotted against the breakthrough percentage to identify any trends that result across the breakthrough curve and between challenge concentrations. 
Chapter 4. RESULTS

\subsection{Breakthrough testing data}

Appendix A contains a listing of the concentrations recorded by the TVA-1000B during each cartridge test. A summary of the time required for breakthrough of $1 \%, 5 \%, 10 \%$, and $20 \%$ of the challenge concentration, and the proposed ACGIH TLV ${ }^{\circledR}$ and current Air Force OEL, is presented in Tables 4-4 through 4-6 for each cartridge tested. The tables also include the mean breakthrough times, standard deviations, and the $95^{\text {th }}$ percentile upper and lower confidence limits (2-sided) for each breakthrough point.

\subsection{Charcoal tube sampling results}

Respirator chamber concentrations of fuel vapor were monitored using a modified version of the NIOSH 1550 Sampling Method for naphthas (see Appendix B). Table 4-1 provides a summary of chamber concentrations measured with the modified NIOSH 1550 Sampling Method, and compares these concentrations to the target concentration. The respirator chamber concentration was monitored with the Foxboro TVA-1000B portable FID at the start and end of each test and intermittently throughout to ensure stability within $\pm 5 \%$ of the target concentration.

These results indicate that with the TVA-1000B calibrated to $7500 \mathrm{ppm}$ of pentane gas, a measured concentration of $1 \mathrm{mg} / \mathrm{m}^{3}$ of fuel vapor (via the modified NIOSH 1550 Method) is approximately equivalent to between 0.152 and $0.159 \mathrm{ppm}$ as reported by the TVA-1000B.

The range of concentrations measured at each challenge level is somewhat greater than the $\pm 5 \%$ concentration targeted with the TVA-1000B. At $300 \mathrm{ppm}$, the range spans from $12.6 \%$ below to $22.6 \%$ above the mean; at $600 \mathrm{ppm}$, the range covers $11.2 \%$ below to $9.8 \%$ above the mean concentration; and at $1200 \mathrm{ppm}$, the range covers from $6.0 \%$ below to $12.8 \%$ above the mean concentration. 
Table 4-1. Summary table of charcoal tube sampling results, comparing target concentration (measured with Foxboro TVA1000B Portable Flame Ionization Detector) to values measured via modified NIOSH 1550 Sampling Method.

\begin{tabular}{|c|c|c|c|c|c|}
\hline $\begin{array}{l}\text { Target concentration } \\
\text { (ppm), per TVA-1000B }\end{array}$ & $\begin{array}{c}\text { Mean } \\
(\mathrm{mg} / \mathrm{m} 3)\end{array}$ & $\begin{array}{c}\text { Minimum } \\
\left(\mathrm{mg} / \mathrm{m}^{3}\right)\end{array}$ & $\begin{array}{l}\text { Maximum } \\
\left(\mathrm{mg} / \mathrm{m}^{3}\right)\end{array}$ & $\boldsymbol{\sigma}$ & $\begin{array}{l}\text { Measured ppm } \\
\text { per } \mathrm{mg} / \mathrm{m}^{3}\end{array}$ \\
\hline 300 & 1980 & 1730 & 2170 & 152 & 0.152 \\
\hline 600 & 3780 & 3410 & 4200 & 200 & 0.159 \\
\hline 1200 & 7570 & 7120 & 8540 & 360 & 0.158 \\
\hline
\end{tabular}

Since this method has not been fully validated and compared to TVA-1000B monitoring results, these data will not be used for analysis of cartridge breakthrough times. However, they are available for documentation and possible future analysis.

\subsection{Cartridge weight change}

A table listing the change in cartridge weight resulting from pre-conditioning to 80 percent relative humidity, prior exposure to fuel vapor and high humidity, and the cartridge testing activities is provided in Appendix C. A summary is provided in Table 4-2 below:

Table 4-2. Summary of total mean cartridge weight gains (in grams) for each treatment condition.

\begin{tabular}{cccc}
\hline Concentration & $\mathbf{5 0}$ (no prior) & $\mathbf{8 0}$ (no prior) & $\mathbf{8 0}$ (prior) \\
\hline 300 & 17.3 & 21.0 & 21.3 \\
600 & 19.2 & 25.7 & 25.8 \\
1200 & 23.7 & 27.3 & 27.0 \\
\hline
\end{tabular}

Each cartridge test was terminated when 20 percent of the challenge concentration was measured exiting the cartridge. Therefore, the weight gain would be expected to be greater at the high challenge concentrations, and this was the case. Likewise, the higher relative humidity levels of 80 percent yielded a higher total cartridge weight gain when compared to the 50 percent relative humidity test condition. 
At 50 percent relative humidity and $25^{\circ} \mathrm{C}$, air contains approximately $11.5 \mathrm{mg} / \mathrm{L}$ of water vapor, and contains approximately $18.4 \mathrm{mg} / \mathrm{L}$ at 80 percent relative humidity. ${ }^{37}$ With these data and the sampling data reported in Section 4.2 above, a table of estimated water and fuel vapor mass flowing through each cartridge per minute was constructed (Table 4-3).

Table 4-3. Mass flowing through the cartridge per minute at tested conditions of challenge concentration and relative humidity, with air flow rate set at 32 LPM.

\begin{tabular}{|c|c|c|c|c|}
\hline $\begin{array}{l}\text { Challenge } \\
\text { concentration }\end{array}$ & $\begin{array}{l}50 \% \text { re } \\
\text { humid }\end{array}$ & $\begin{array}{l}\text { ative } \\
y\end{array}$ & $\begin{array}{l}80 \% \text { re } \\
\text { humid }\end{array}$ & \\
\hline 300 ppm & $\begin{array}{l}\text { Water: } \\
\text { JP-8: } \\
\text { Total: }\end{array}$ & $\begin{array}{l}0.37 \mathrm{~g} \\
0.07 \mathrm{~g} \\
0.44 \mathrm{~g}\end{array}$ & $\begin{array}{l}\text { Water: } \\
\text { JP-8: } \\
\text { Total: }\end{array}$ & $\begin{array}{l}0.59 \mathrm{~g} \\
0.07 \mathrm{~g} \\
0.66 \mathrm{~g}\end{array}$ \\
\hline 600 ppm & $\begin{array}{c}\text { Water: } \\
\text { JP-8: } \\
\text { Total: }\end{array}$ & $\begin{array}{l}0.37 \mathrm{~g} \\
0.14 \mathrm{~g} \\
0.51 \mathrm{~g}\end{array}$ & $\begin{array}{l}\text { Water: } \\
\text { JP-8: } \\
\text { Total: }\end{array}$ & $\begin{array}{l}0.59 \mathrm{~g} \\
0.14 \mathrm{~g} \\
0.73 \mathrm{~g}\end{array}$ \\
\hline 1200 ppm & $\begin{array}{r}\text { Water: } \\
\text { JP-8: } \\
\text { Total: }\end{array}$ & $\begin{array}{l}0.37 \mathrm{~g} \\
0.27 \mathrm{~g} \\
0.64 \mathrm{~g}\end{array}$ & $\begin{array}{l}\text { Water: } \\
\text { JP-8: } \\
\text { Total: }\end{array}$ & $\begin{array}{l}0.59 \mathrm{~g} \\
0.27 \mathrm{~g} \\
0.86 \mathrm{~g}\end{array}$ \\
\hline
\end{tabular}

Figure 4-1. Estimated mass of water and JP-8 fuel vapor flowing through each cartridge per minute of breakthrough test at $25^{\circ} \mathrm{C}$.

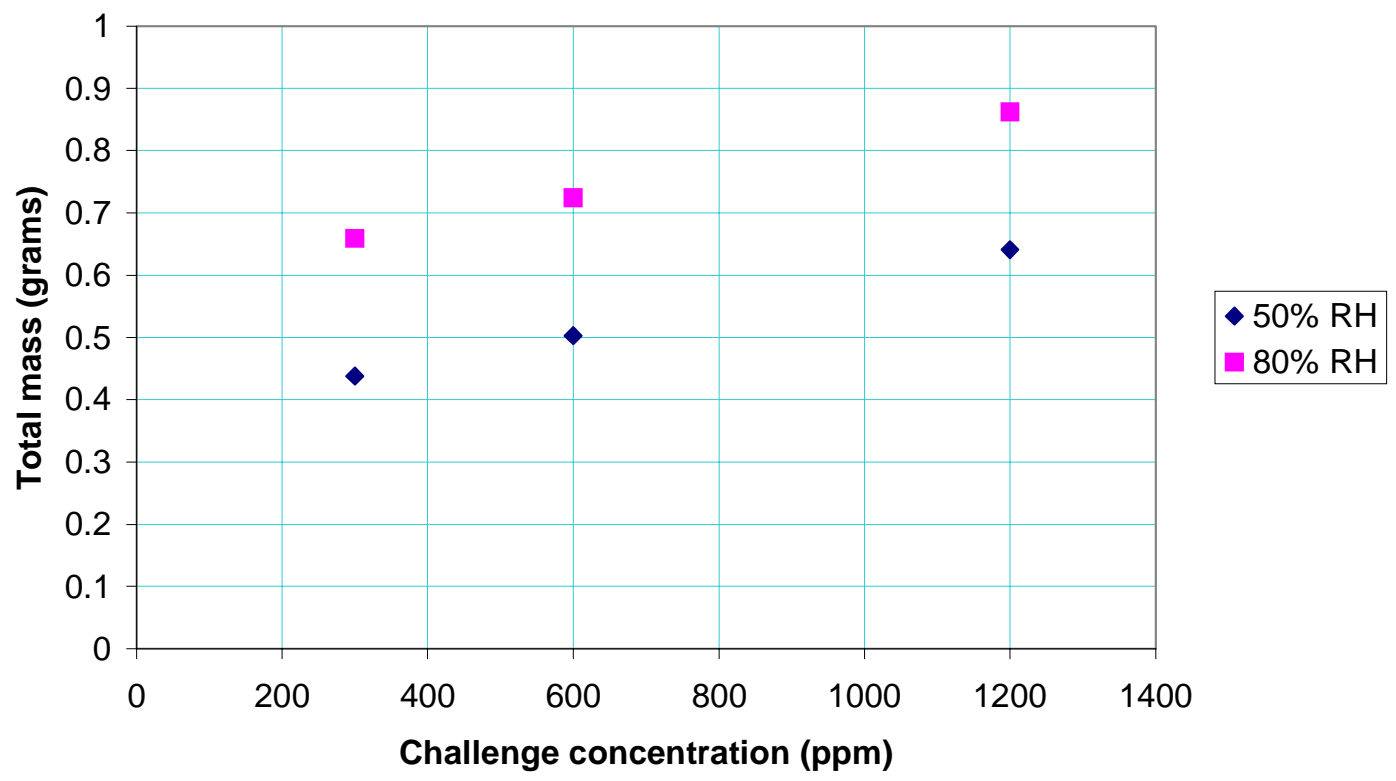


Figure 4-1 shows that based on measured sampling data, as the challenge concentration increases, the mass flow through the cartridge increases with an approximately linear relationship to the challenge concentration, and raising the relative humidity level from 50 percent to 80 percent simply shifts this line upward by a fixed amount.

An examination of total cartridge weight gains also indicates an approximate linear relationship between challenge concentration and weight gain for the 50 percent relative humidity test condition. However, this relationship does not appear to be linear for both 80 percent relative humidity test conditions (Figure 4-2), with the most significant weight change difference occurring between the 300 and 600 ppm challenge concentrations. The reason for this difference is unclear, but could be related to the loss in water weight that may occur as a result of preconditioning cartridges at 80 percent relative humidity and testing them at 50 percent relative humidity.

Figure 4-2. Total average cartridge weight gains at $20 \%$ breakthrough points for each test condition. (All cartridges were preconditioned for 6 hours at $80 \%$ relative humidity and $25^{\circ} \mathrm{C}$.)

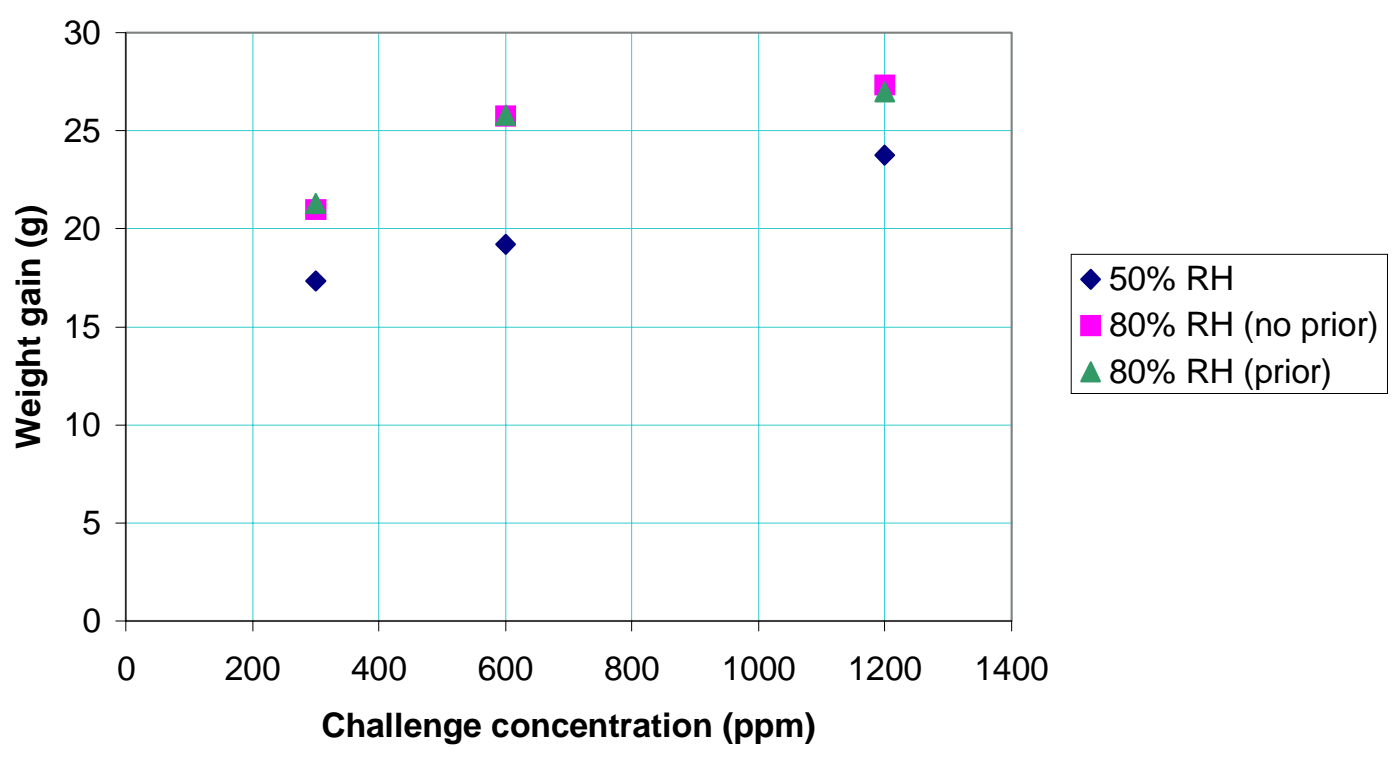


Table 4-4. Summary table of time (in minutes) to various breakthrough concentrations for 50 percent relative humidity (no prior exposure) test condition. All cartridges were preconditioned at $25^{\circ} \mathrm{C}$ and 80 percent relative humidity for six hours at an air flow rate of $32 \mathrm{LPM}$, and were tested at $25^{\circ} \mathrm{C}$ and a flow rate of 32 LPM.

\begin{tabular}{|c|c|c|c|c|c|c|c|}
\hline 300 ppm & $\begin{array}{c}\text { Cartridge } \\
46 \\
49 \\
55 \\
56 \\
74\end{array}$ & $\begin{array}{c}\frac{1 \%}{171} \\
185 \\
- \\
- \\
171\end{array}$ & $\begin{array}{l}\frac{5 \%}{204} \\
206 \\
216 \\
219 \\
226\end{array}$ & $\begin{array}{l}\frac{10 \%}{221} \\
219 \\
229 \\
232 \\
243\end{array}$ & $\begin{array}{l}\frac{\mathbf{2 0} \%}{234} \\
231 \\
242 \\
245 \\
259\end{array}$ & $\begin{array}{l}\frac{T L V}{203} \\
205 \\
214 \\
217 \\
224\end{array}$ & $\begin{array}{c}\text { AF OEL } \\
230 \\
227 \\
238 \\
241 \\
255\end{array}$ \\
\hline & $\begin{array}{c}\text { Mean } \\
\text { StdDev } \\
95 \% \text { LCL } \\
95 \% \text { UCL }\end{array}$ & $\begin{array}{l}176 \\
8.1 \\
147 \\
205\end{array}$ & $\begin{array}{l}214 \\
9.2 \\
200 \\
229\end{array}$ & $\begin{array}{c}229 \\
9.6 \\
214 \\
244\end{array}$ & $\begin{array}{l}242 \\
11.0 \\
225 \\
259\end{array}$ & $\begin{array}{l}213 \\
8.7 \\
199 \\
226\end{array}$ & $\begin{array}{l}238 \\
11.0 \\
221 \\
255\end{array}$ \\
\hline 600 ppm & $\begin{array}{c}\text { Cartridge } \\
31 \\
32 \\
44 \\
63 \\
84\end{array}$ & $\begin{array}{c}\frac{1 \%}{78} \\
75 \\
74 \\
- \\
73\end{array}$ & $\begin{array}{c}5 \% \\
- \\
93 \\
- \\
96 \\
94\end{array}$ & $\begin{array}{l}\frac{10 \%}{108} \\
109 \\
104 \\
110 \\
109\end{array}$ & $\begin{array}{l}\frac{\mathbf{2 0} \%}{124} \\
126 \\
123 \\
128 \\
127\end{array}$ & $\begin{array}{c}\frac{T L V}{87} \\
- \\
- \\
- \\
84\end{array}$ & $\begin{array}{c}\text { AF OEL } \\
102 \\
104 \\
100 \\
106 \\
105\end{array}$ \\
\hline & $\begin{array}{c}\text { Mean } \\
\text { StdDev } \\
95 \% \text { LCL } \\
95 \% \text { UCL }\end{array}$ & $\begin{array}{l}75 \\
2.2 \\
70 \\
80\end{array}$ & $\begin{array}{c}94 \\
1.5 \\
89 \\
100\end{array}$ & $\begin{array}{l}108 \\
2.3 \\
104 \\
112\end{array}$ & $\begin{array}{l}126 \\
2.1 \\
122 \\
129\end{array}$ & $\begin{array}{c}86 \\
2.1 \\
47 \\
124\end{array}$ & $\begin{array}{l}103 \\
2.4 \\
100 \\
107\end{array}$ \\
\hline 1200 ppm & $\begin{array}{c}\text { Cartridge } \\
36 \\
39 \\
54 \\
72 \\
73\end{array}$ & $\begin{array}{l}\frac{1 \%}{41} \\
39 \\
40 \\
39 \\
44\end{array}$ & $\begin{array}{l}\frac{5 \%}{52} \\
48 \\
52 \\
48 \\
55\end{array}$ & $\begin{array}{c}\frac{10 \%}{59} \\
52 \\
57 \\
52 \\
60\end{array}$ & $\begin{array}{c}\frac{20 \%}{67} \\
57 \\
66 \\
59 \\
68\end{array}$ & $\begin{array}{l}\frac{\text { TLV }}{42} \\
40 \\
41 \\
40 \\
45\end{array}$ & $\begin{array}{c}\text { AF OEL } \\
51 \\
47 \\
51 \\
47 \\
54\end{array}$ \\
\hline & $\begin{array}{c}\text { Mean } \\
\text { StdDev } \\
95 \% \text { LCL } \\
95 \% \text { UCL }\end{array}$ & $\begin{array}{l}41 \\
2.1 \\
37 \\
44\end{array}$ & $\begin{array}{l}51 \\
3.0 \\
46 \\
56\end{array}$ & $\begin{array}{l}56 \\
3.8 \\
50 \\
62\end{array}$ & $\begin{array}{l}63 \\
5.0 \\
56 \\
71\end{array}$ & $\begin{array}{l}42 \\
2.1 \\
38 \\
45\end{array}$ & $\begin{array}{l}50 \\
3.0 \\
45 \\
55\end{array}$ \\
\hline
\end{tabular}


Table 4-5. Summary table of time (in minutes) to various breakthrough concentrations for 80 percent relative humidity (no prior exposure) test condition. All cartridges were preconditioned at $25^{\circ} \mathrm{C}$ and 80 percent relative humidity for six hours at an air flow rate of $32 \mathrm{LPM}$, and were tested at $25^{\circ} \mathrm{C}$ and a flow rate of 32 LPM.

\begin{tabular}{|c|c|c|c|c|c|c|c|}
\hline 300 ppm & $\begin{array}{c}\text { Cartridge } \\
35 \\
47 \\
48 \\
64 \\
65\end{array}$ & $\begin{array}{c}\frac{1 \%}{64} \\
- \\
74 \\
70 \\
70\end{array}$ & $\begin{array}{c}\frac{5 \%}{104} \\
98 \\
99 \\
106 \\
105\end{array}$ & $\begin{array}{l}\frac{10 \%}{135} \\
139 \\
138 \\
149 \\
144\end{array}$ & $\begin{array}{l}\frac{20 \%}{190} \\
204 \\
193 \\
214 \\
210\end{array}$ & $\begin{array}{c}\underline{\text { TLV }} \\
- \\
96 \\
96 \\
104 \\
102\end{array}$ & $\begin{array}{c}\text { AF OEL } \\
167 \\
187 \\
177 \\
196 \\
188\end{array}$ \\
\hline & $\begin{array}{c}\text { Mean } \\
\text { StdDev } \\
95 \% \text { LCL } \\
95 \% \text { UCL }\end{array}$ & $\begin{array}{l}70 \\
4.1 \\
61 \\
78\end{array}$ & $\begin{array}{c}102 \\
3.6 \\
97 \\
108\end{array}$ & $\begin{array}{l}141 \\
5.5 \\
132 \\
150\end{array}$ & $\begin{array}{l}202 \\
10.4 \\
186 \\
219\end{array}$ & $\begin{array}{c}100 \\
4.1 \\
91 \\
108\end{array}$ & $\begin{array}{l}183 \\
11.2 \\
165 \\
201\end{array}$ \\
\hline 600 ppm & $\begin{array}{c}\text { Cartridge } \\
34 \\
45 \\
62 \\
70 \\
80\end{array}$ & $\begin{array}{c}\frac{1 \%}{-} \\
- \\
55 \\
50 \\
60\end{array}$ & $\begin{array}{l}\frac{5 \%}{76} \\
67 \\
72 \\
69 \\
78\end{array}$ & $\begin{array}{l}\frac{10 \%}{92} \\
85 \\
93 \\
90 \\
97\end{array}$ & $\begin{array}{l}\frac{20 \%}{116} \\
109 \\
117 \\
112 \\
107\end{array}$ & $\begin{array}{l}\frac{\text { TLV }}{68} \\
57 \\
63 \\
58 \\
68\end{array}$ & $\begin{array}{c}\text { AF OEL } \\
88 \\
79 \\
- \\
83 \\
92\end{array}$ \\
\hline & $\begin{array}{c}\text { Mean } \\
\text { StdDev } \\
95 \% \text { LCL } \\
95 \% \text { UCL }\end{array}$ & $\begin{array}{l}55 \\
5.0 \\
37 \\
73\end{array}$ & $\begin{array}{l}72 \\
4.6 \\
65 \\
80\end{array}$ & $\begin{array}{l}91 \\
4.4 \\
85 \\
98\end{array}$ & $\begin{array}{l}112 \\
4.3 \\
105 \\
119\end{array}$ & $\begin{array}{l}63 \\
5.3 \\
55 \\
71\end{array}$ & $\begin{array}{l}86 \\
5.7 \\
74 \\
97\end{array}$ \\
\hline 1200 ppm & $\begin{array}{c}\text { Cartridge } \\
37 \\
38 \\
71 \\
81 \\
82\end{array}$ & $\begin{array}{l}\frac{1 \%}{34} \\
42 \\
32 \\
34 \\
36\end{array}$ & $\begin{array}{l}\frac{5 \%}{45} \\
51 \\
42 \\
44 \\
45\end{array}$ & $\begin{array}{l}\frac{10 \%}{51} \\
57 \\
47 \\
49 \\
50\end{array}$ & $\begin{array}{c}\frac{20 \%}{60} \\
64 \\
55 \\
56 \\
57\end{array}$ & $\begin{array}{l}\frac{T L V}{35} \\
43 \\
33 \\
35 \\
37\end{array}$ & $\begin{array}{c}\text { AF OEL } \\
44 \\
50 \\
40 \\
43 \\
44\end{array}$ \\
\hline & $\begin{array}{c}\text { Mean } \\
\text { StdDev } \\
95 \% \text { LCL } \\
95 \% \text { UCL }\end{array}$ & $\begin{array}{l}36 \\
3.8 \\
30 \\
42\end{array}$ & $\begin{array}{l}45 \\
3.4 \\
40 \\
51\end{array}$ & $\begin{array}{l}51 \\
3.8 \\
45 \\
57\end{array}$ & $\begin{array}{l}58 \\
3.6 \\
53 \\
64\end{array}$ & $\begin{array}{l}37 \\
3.8 \\
31 \\
43\end{array}$ & $\begin{array}{l}44 \\
3.6 \\
39 \\
50\end{array}$ \\
\hline
\end{tabular}


Table 4-6. Summary table of time (in minutes) to various breakthrough concentrations for 80 percent relative humidity (with prior exposure) test condition. All cartridges were preconditioned at $25^{\circ} \mathrm{C}$ and 80 percent relative humidity for six hours at an air flow rate of 32 LPM, followed by static exposure to $1200 \mathrm{ppm}$ of fuel vapor and 80 percent relative humidity at 25 ${ }^{\circ} \mathrm{C}$ for eight hours. They were then tested at $25^{\circ} \mathrm{C}$ and a flow rate of 32 LPM.

\begin{tabular}{|c|c|c|c|c|c|c|c|}
\hline 300 ppm & $\begin{array}{c}\text { Cartridge } \\
60 \\
61 \\
66 \\
67 \\
75\end{array}$ & $\begin{array}{c}1 \% \\
- \\
- \\
57 \\
- \\
-\end{array}$ & $\begin{array}{c}\frac{5 \%}{102} \\
89 \\
86 \\
93 \\
93\end{array}$ & $\begin{array}{l}\underline{10 \%} \\
136 \\
130 \\
125 \\
132 \\
134\end{array}$ & $\begin{array}{l}\mathbf{2 0 \%} \\
184 \\
190 \\
194 \\
205 \\
175\end{array}$ & $\begin{array}{c}\text { TLV } \\
100 \\
87 \\
- \\
90 \\
90\end{array}$ & $\begin{array}{c}\text { AF OEL } \\
170 \\
172 \\
171 \\
181 \\
159\end{array}$ \\
\hline & $\begin{array}{c}\text { Mean } \\
\text { StdDev } \\
95 \% \text { LCL } \\
95 \% \text { UCL }\end{array}$ & $\begin{array}{c}57 \\
- \\
- \\
-\end{array}$ & $\begin{array}{c}93 \\
6.0 \\
83 \\
102\end{array}$ & $\begin{array}{l}131 \\
4.2 \\
125 \\
138\end{array}$ & $\begin{array}{l}190 \\
11.2 \\
172 \\
207\end{array}$ & $\begin{array}{c}92 \\
5.7 \\
80 \\
104\end{array}$ & $\begin{array}{l}171 \\
7.8 \\
158 \\
183\end{array}$ \\
\hline "600 ppm & $\begin{array}{c}\text { Cartridge } \\
57 \\
58 \\
59 \\
68 \\
69\end{array}$ & $\begin{array}{l}\frac{1 \%}{43} \\
45 \\
41 \\
45 \\
49\end{array}$ & $\begin{array}{l}\frac{5 \%}{59} \\
63 \\
63 \\
63 \\
66\end{array}$ & $\begin{array}{c}10 \% \\
77 \\
84 \\
83 \\
79 \\
85\end{array}$ & $\begin{array}{l}\underline{20 \%} \\
101 \\
111 \\
106 \\
101 \\
110\end{array}$ & $\begin{array}{c}\text { TLV } \\
- \\
- \\
- \\
55 \\
57\end{array}$ & $\begin{array}{c}\text { AF OEL } \\
- \\
78 \\
78 \\
- \\
78\end{array}$ \\
\hline & $\begin{array}{c}\text { Mean } \\
\text { StdDev } \\
95 \% \text { LCL } \\
95 \% \text { UCL }\end{array}$ & $\begin{array}{l}45 \\
3.0 \\
40 \\
49\end{array}$ & $\begin{array}{l}63 \\
2.5 \\
59 \\
67\end{array}$ & $\begin{array}{l}82 \\
3.4 \\
76 \\
87\end{array}$ & $\begin{array}{c}106 \\
4.8 \\
98 \\
113\end{array}$ & $\begin{array}{l}56 \\
1.4 \\
31 \\
81\end{array}$ & $\begin{array}{l}78 \\
0.0 \\
78 \\
78\end{array}$ \\
\hline 1200 ppm & $\begin{array}{c}\text { Cartridge } \\
51 \\
52 \\
76 \\
77 \\
78\end{array}$ & $\begin{array}{c}1 \% \\
- \\
- \\
- \\
- \\
33\end{array}$ & $\begin{array}{l}\frac{5 \%}{41} \\
40 \\
35 \\
34 \\
43\end{array}$ & $\begin{array}{c}\frac{10 \%}{49} \\
48 \\
42 \\
43 \\
48\end{array}$ & $\begin{array}{c}\underline{\mathbf{2 0} \%} \\
59 \\
57 \\
50 \\
52 \\
56\end{array}$ & $\begin{array}{c}\text { TLV } \\
- \\
- \\
- \\
- \\
34\end{array}$ & $\begin{array}{c}\text { AF OEL } \\
- \\
- \\
33 \\
32 \\
41\end{array}$ \\
\hline & $\begin{array}{c}\text { Mean } \\
\text { StdDev } \\
95 \% \text { LCL } \\
95 \% \text { UCL }\end{array}$ & $\begin{array}{c}33 \\
- \\
- \\
-\end{array}$ & $\begin{array}{l}39 \\
3.9 \\
32 \\
45\end{array}$ & $\begin{array}{l}46 \\
3.2 \\
41 \\
51\end{array}$ & $\begin{array}{l}55 \\
3.7 \\
49 \\
61\end{array}$ & $\begin{array}{l}34 \\
- \\
- \\
-\end{array}$ & $\begin{array}{l}35 \\
4.9 \\
18 \\
53\end{array}$ \\
\hline
\end{tabular}




\subsection{Initial observations}

\subsubsection{Effects of relative bumidity and prior exposure (null bypotheses 1 and 2)}

Tables 4-4 and 4-5 form the basis for evaluating the first null hypothesis. A visual examination of these data indicates a strong impact of challenge concentration on breakthrough time, such that a higher challenge concentration results in a considerably shorter time to breakthrough than a lower challenge concentration. It is also evident from the table that there is a reduction in mean breakthrough times when the relative humidity is raised from 50 percent to 80 percent. Another trend that can be seen from this table is that at the high challenge concentration, relative humidity appears to have little impact on the mean breakthrough time yet is more noticeable at lower challenge concentrations. This is indicative of a possible interaction between relative humidity and challenge concentration.

A review of Tables 4-5 and 4-6, which represent the data set used for evaluating the second null hypothesis, provides evidence that challenge concentration has a measurable effect on breakthrough time, with higher concentrations resulting in shorter breakthrough time than lower concentrations. It also appears that prior exposure may slightly reduce breakthrough time.

The impacts of relative humidity and prior exposure can be demonstrated graphically by plotting curves of the mean breakthrough times (at the 10\% breakthrough level) vs. the corresponding challenge concentration for each column (Figure 4-3). 
Figure 4-3. Mean breakthrough time to $10 \%$ of JP-8 fuel vapor challenge concentration.

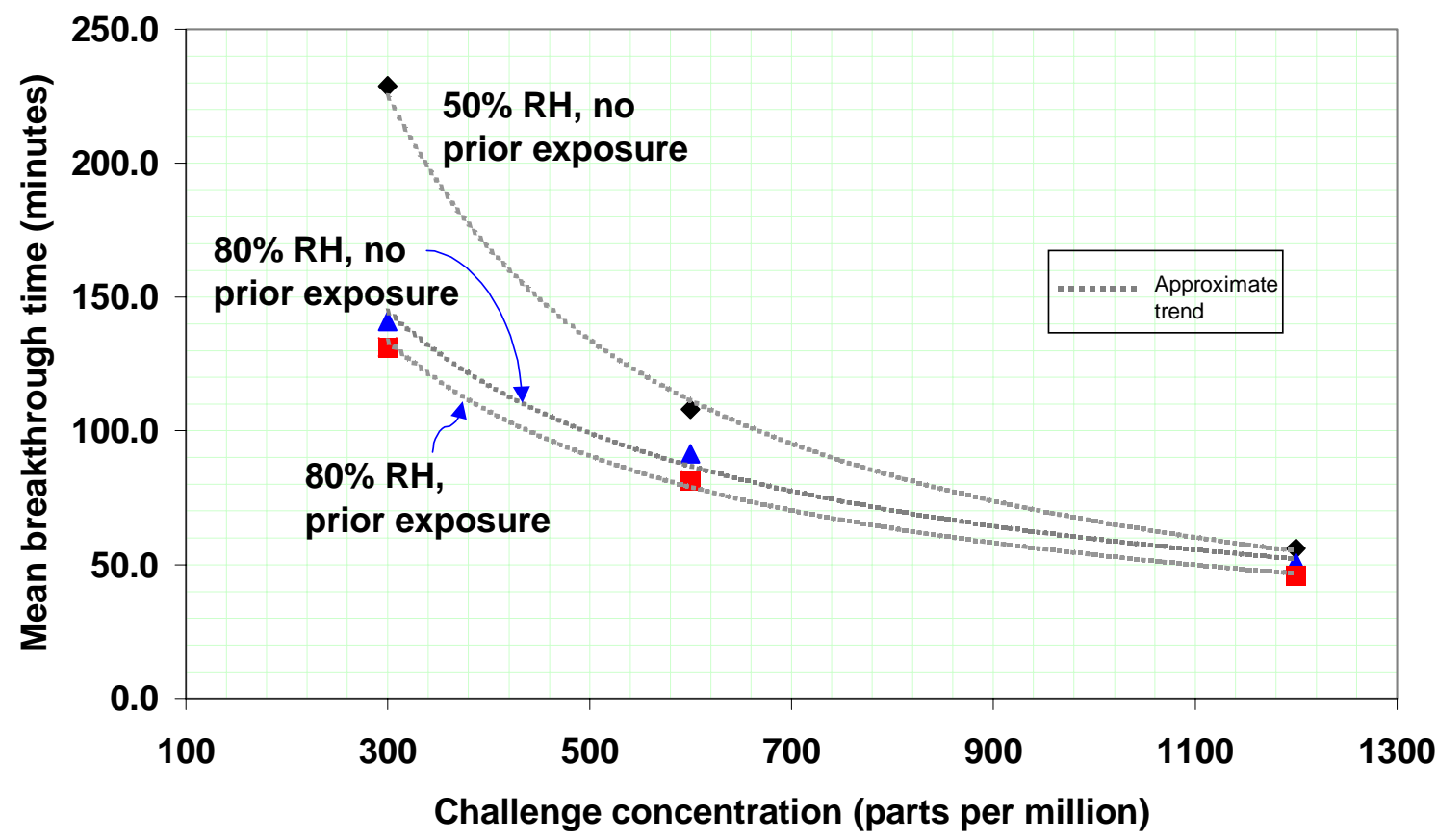

\subsubsection{Relationships between breakthrough concentration and time (null bypothesis 3)}

Independent scatter plots of the breakthrough concentration vs. time to breakthrough were made for each relative humidity and prior exposure treatment. Since there are gaps in the continuity of the data-logged breakthrough concentrations (as a result of intermediate chamber monitoring with the same device), representative points along the breakthrough concentration curve were selected $(1 \%, 5 \%, 10 \%$, and $20 \%$ values of the challenge concentration) where most data points were available for each cartridge. Scatter plots are shown in Figures 4-4 through 4-6.

A cursory examination of Figure 4-4, which shows the response curve at the 50\% relative humidity condition, indicates an apparent non-linearity in the breakthrough concentration with respect to time over the entire range of the curve. This plot appears to resemble the lower 
portion of a typical sigmoidal response curve often reported in the literature for relative humidity test conditions below 65 percent (see section 2.6.1).

However, the 80 percent relative humidity without prior exposure test condition breakthrough response curve (Figure 4-5) appears to lose the clarity of the sigmoidal response curve, appearing to be linear particularly at the lowest challenge concentration of $300 \mathrm{ppm}$. This effect is also apparent for the 80 percent relative humidity with prior exposure test condition (Figure 4-6).

Figure 4-4. Scatter plot of breakthrough times for $50 \%$ relative humidity condition and no prior exposure to fuel vapor. All cartridges were preconditioned at $80 \%$ relative humidity and $25{ }^{\circ} \mathrm{C}$ for six hours. Prior exposed cartridges were previously subjected to static concentrations of $1200 \mathrm{ppm}$ fuel vapor for eight hours at $80 \%$ relative humidity and $25^{\circ} \mathrm{C}$.

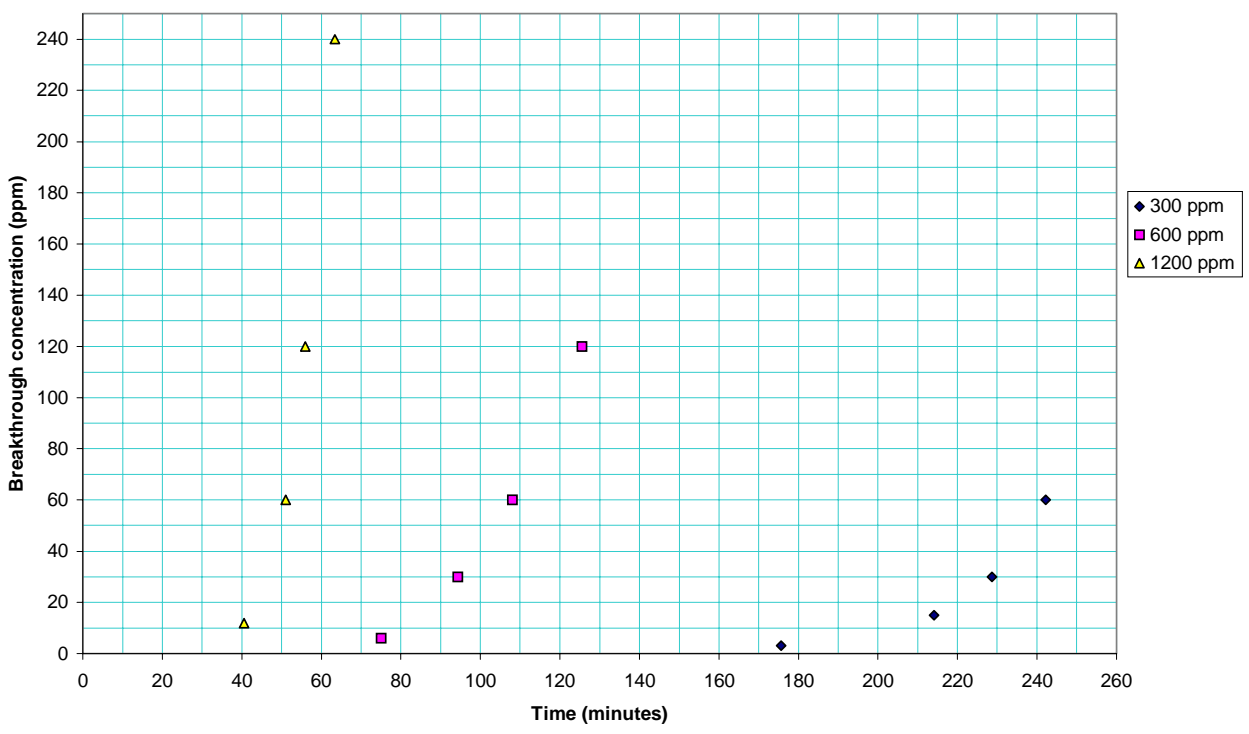


Figure $4-5$. Scatter plot of breakthrough times for $80 \%$ relative humidity condition and no prior exposure to fuel vapor. All cartridges were preconditioned at $80 \%$ relative humidity and $25^{\circ} \mathrm{C}$ for six hours. Prior exposed cartridges were previously subjected to static concentrations of $1200 \mathrm{ppm}$ fuel vapor for eight hours at $80 \%$ relative humidity and $25^{\circ} \mathrm{C}$.

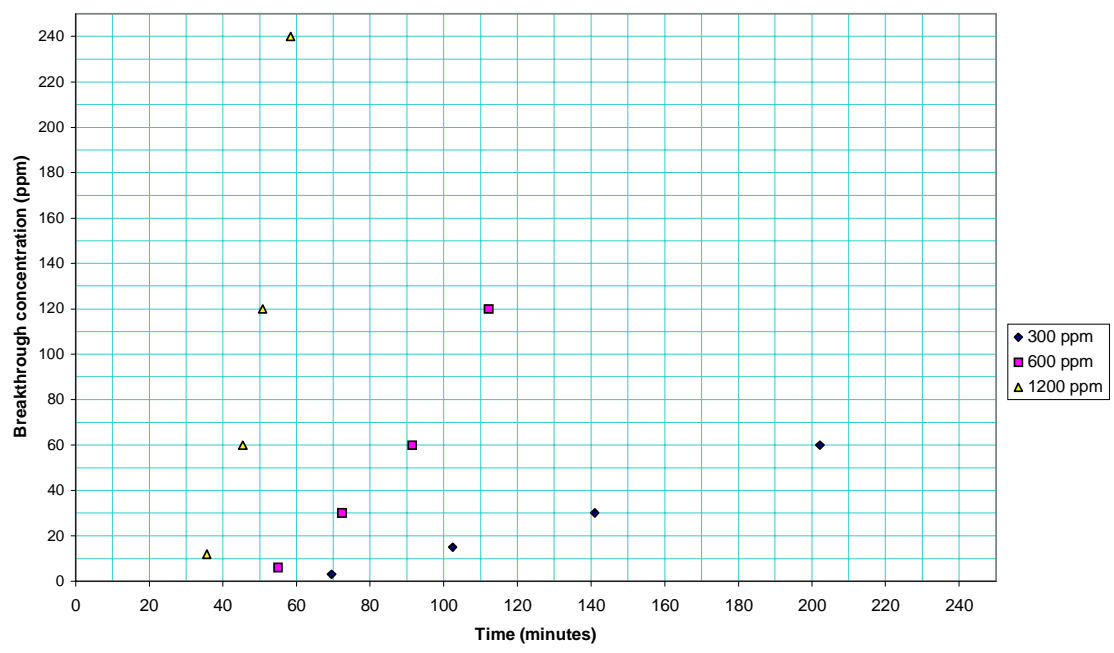

Figure 4-6. Scatter plot of breakthrough times for $80 \%$ relative humidity condition and prior exposure to fuel vapor. All cartridges were preconditioned at $80 \%$ relative humidity and $25^{\circ} \mathrm{C}$ for six hours. Prior exposed cartridges were previously subjected to static concentrations of 1200 ppm fuel vapor for eight hours at $80 \%$ relative humidity and $25^{\circ} \mathrm{C}$.

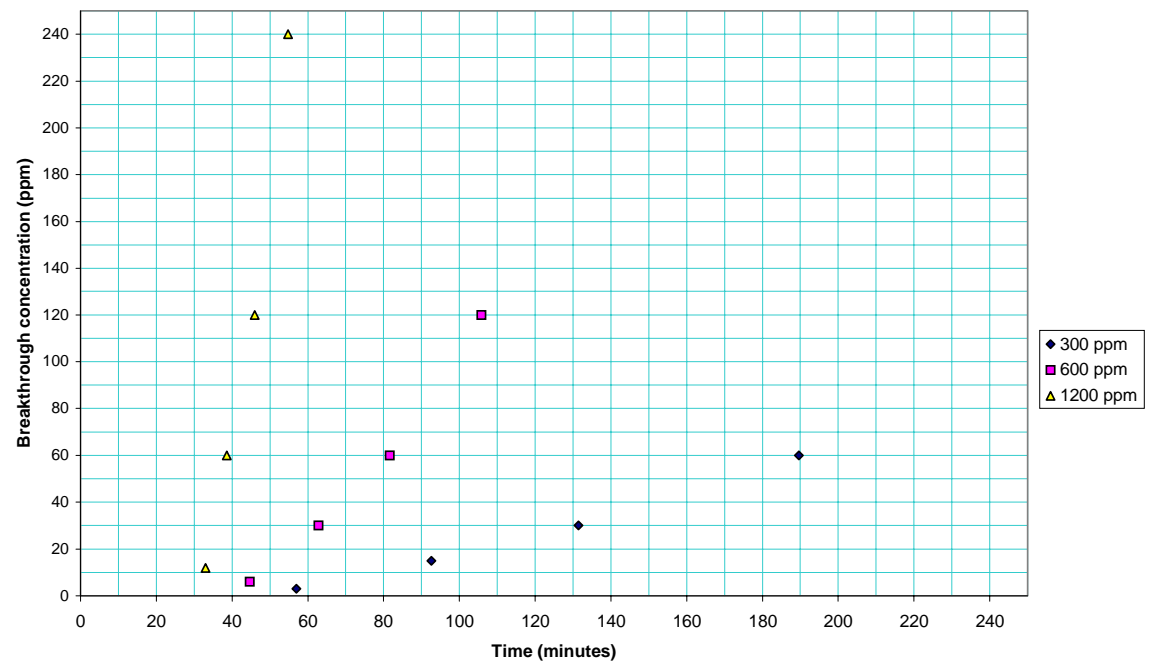


Chapter 5. ANALYSIS AND DISCUSSION

\subsection{Effect of relative humidity and challenge concentration on breakthrough time (null hypothesis 1)}

\subsubsection{Overview}

A 2-sided Analysis of Variance (ANOVA) was conducted to assess the impact of relative humidity and challenge concentration on breakthrough time. The ANOVA was completed for the 10 percent of challenge concentration breakthrough time at each of five data points in all six cells within the matrix. Each cell was tested for normality and homogeneity of variance prior to applying an analysis of variance. The source code and data output for the SAS/STAT ${ }^{\circledR}$ ANOVA and means test analysis routines are included in Appendix D.

\subsubsection{Normality and homogeneity of variance}

It is important to recognize that determining if a five-point data set has a normal distribution is difficult because of the low number of data points. Nevertheless, confirmation of normality lends more credibility to correct application of an ANOVA test.

The PROC UNIVARIATE procedure in SAS/STAT ${ }^{\circledR}$ assesses normality by determining the Shapiro-Wilk statistic, W, which is the "ratio of the best estimator of the variance to the corrected sum of squares estimator of the variance." ${ }^{47}$ A positive normality conclusion requires a large W value (one that is close to the maximum of 1.0) and a large probability (Pr) value (greater than 0.10). In this data set, all cells meet these requirements, so the data within each cell are considered to be normally distributed.

Levene's test for equality of variance was applied to the six cells in this data set. ${ }^{48}$ The calculated F distribution value was 2.4369, which corresponds to an $\alpha$ of 0.06 . When $\alpha$ exceeds 0.10 , the data sets are considered to be homogenous; however, $\alpha>0.05$ is sometimes used as a less stringent criterion. The variances for the cells in this data set would be considered homogenous under the latter criterion. 
While ANOVA assumes that homogeneity of variance and normality are both present in the data set, the $\mathrm{F}$ statistic is considered to be relatively insensitive to violations of these assumptions. ${ }^{49}$ Therefore, this issue will not be addressed further.

\subsubsection{Analysis of V ariance (ANOVA)}

The Analysis of Variance indicates that relative humidity and concentration both had a significant impact on the breakthrough time to $10 \%$ of the challenge concentration $(\mathrm{P}<0.0001$ for each treatment). Additionally, the interaction between relative humidity and concentration was significant $(\mathrm{P}<0.0001)$. A summary of the ANOVA results is presented in Table 5-1.

Table 5-1. Analysis of Variance (ANOVA) for relative humidity and concentration treatments.

\begin{tabular}{lccccc}
\hline $\begin{array}{c}\text { Independent } \\
\text { variable }\end{array}$ & $\begin{array}{c}\text { Degrees of } \\
\text { freedom }\end{array}$ & $\begin{array}{c}\text { Type I Sum of } \\
\text { Squares (SS) }\end{array}$ & $\begin{array}{c}\text { Mean } \\
\text { Square }\end{array}$ & F-Value & $\begin{array}{c}\text { Pr }>\text { F- } \\
\text { Value }\end{array}$ \\
\hline Relative humidity (RH) & 1 & 10010 & 10010 & 340 & $<0.0001$ \\
Concentration (Conc) & 2 & 89000 & 44500 & 1520 & $<0.0001$ \\
RH X Conc (Interaction) & 2 & 10020 & 5010 & 171 & $<0.0001$ \\
\hline
\end{tabular}

\subsubsection{Tests for differences between means}

While the Analysis of Variance showed that relative humidity and concentration both have an overall effect on breakthrough time, it does not reveal at which levels of concentration or relative humidity this impact exists. The Tukey "Honestly Significant Difference" (HSD) test was applied to the cell means at each level of concentration and each level of relative humidity. Since there is evidence of interaction between treatment factors, a blocked approach was used. The Tukey HSD test indicated that there was no difference between the 50 and 80 percent relative humidity test conditions at $1200 \mathrm{ppm}$; all other means were significantly different. In other words, the impact of relative humidity had far less significance at the highest challenge concentration, further evidence of an interaction between relative humidity and concentration. As mentioned previously, this is demonstrated graphically in Figure 4-3, where the breakthrough time curves for 
each relative humidity test condition converge at the high challenge concentration and diverge at the lowest.

\subsection{Effects of prior exposure and challenge concentration (null hypothesis 2)}

\subsubsection{Overview}

A 2-sided ANOVA was conducted to assess the impact of the prior exposure and challenge concentration treatments on breakthrough time. As before, these runs were completed for the 10 percent of challenge concentration breakthrough time at each of five data points in all six cells within the matrix (see Appendix D). The analysis included an assessment of normality and homogeneity of variance prior to conducting the ANOVA.

\subsubsection{Normality and homogeneity of variance}

In this data set, all cells met the normality criteria. Data points are therefore considered to be normally distributed at the 10 percent breakthrough times.

Levene's test for equality of variance was applied to the six cells in this data set. The homogeneity of variance test is met at the $0.10 \alpha$ criterion level.

\subsubsection{Analysis of $V$ ariance (ANOVA)}

The Analysis of Variance indicates that prior exposure to high levels of fuel vapor and relative humidity has a significant impact on the breakthrough time to $10 \%$ of the challenge concentration $(\mathrm{P}<0.0001$ for each treatment). However, the interaction between the prior exposure and concentration treatments were reported as insignificant $(\mathrm{P}=0.33)$. A summary of the ANOVA results is presented in Table $5-2$.

A further assessment of the concentration x prior exposure factor was conducted to determine if the power $(1-\beta)$ was sufficient to confidently conclude that there was no significant interaction

between the factors. Using an $\alpha$ of 0.05 , power was calculated by first determining the $\phi_{\text {effect }}^{2}$ using the general equation below: 


$$
\phi_{\text {effect }}=\sqrt{\frac{(n)\left[\sum\left(\mu-\mu_{i}-\mu_{j}+\mu_{i j}\right)^{2}\right]}{a b \sigma_{\text {error }}^{2}}}
$$

$$
\begin{aligned}
& \text { where } \\
& n=\text { number of observations in each cell } \\
& \mathrm{a}=\text { number of levels in factor } \mathrm{A} \\
& b=\text { number of levels in factor } \mathrm{B} \\
& \mu=\text { population mean } \\
& \mu_{I}, \mu_{j}=\text { means for treatments A and B (respectively) } \\
& \mu_{i j}=\text { mean for the common cell } \\
& \sigma_{\text {ermor }}^{2} \text { is the error variance for the population. }
\end{aligned}
$$

The resulting value of $\phi_{\text {effect }}$ was found to be 0.62 . With $d f_{\text {num }}$ (degrees of freedom in the numerator) of 2 and $d f_{\text {denom }}$ (degrees of freedom in the denominator) of 24 , this equates to a power ${ }^{49}$ of $<0.10$. Therefore, the power of this test was insufficient to conclude there was interaction between the variables.

Table 5-2. Analysis of Variance (ANOVA) for prior exposure and concentration treatments.

\begin{tabular}{lccccc}
\hline $\begin{array}{c}\text { Independent } \\
\text { Variable }\end{array}$ & $\begin{array}{c}\text { Degrees of } \\
\text { freedom }\end{array}$ & $\begin{array}{c}\text { Type I Sum of } \\
\text { Squares (SS) }\end{array}$ & $\begin{array}{c}\text { Mean } \\
\text { Square }\end{array}$ & F-Value & $\begin{array}{c}\text { Pr }>\text { F- } \\
\text { Value }\end{array}$ \\
\hline Prior exposure (Prior) & 1 & 488 & 488 & 28.1 & $<0.0001$ \\
Concentration (Conc) & 2 & 38800 & 19400 & 1120 & $<0.0001$ \\
Prior X Conc (interaction) & 2 & 40.1 & 20.0 & 1.15 & 0.33 \\
\hline
\end{tabular}

\subsubsection{Tests for differences between means}

While the Analysis of Variance showed that prior exposure and concentration both have an overall effect on breakthrough time, it does not reveal at which level of concentration or prior exposure factor this impact exists. The Tukey HSD comparison of means between each of the 
six cells in the matrix revealed there to be a significant difference between all cells except the bottom two, the cartridges tested at a 1200 ppm challenge concentration at both prior exposure levels. In other words, the impact of prior exposure has an insignificant impact at a higher challenge concentration.

\subsection{Analysis of breakthrough concentration vs. breakthrough time (null hypothesis 3 )}

\subsubsection{Application of the Yoon and Nelson equation}

The Yoon and Nelson equation is re-stated as follows:

$$
t_{b}=-\left[\frac{\rho_{B} W_{e}}{C_{0} k_{v}}\right] \ln \left[\frac{C_{0}-C_{x}}{C_{x}}\right]+\left[\frac{W W_{e}}{C_{0} Q}\right]
$$

Recall that as defined in the Wood model, $W_{e}$ changes slightly with the ratio of the challenge substance's vapor pressure to the saturation partial pressure of that substance for most substances. For example, if the average vapor pressure for JP-8 jet fuel is assumed to be 1.47, at a challenge concentration of $300 \mathrm{ppm}$, the ratio $\rho / \rho_{\text {sat }}$ is 0.23 . At $1200 \mathrm{ppm}$, this ratio is 0.91 . Across the range of challenge concentrations tested in this study, per the Wood model, the value of $W_{e}$ will change by the amount given by $(\ln (0.91))^{2} /(\ln (0.23))^{2}=0.004$, or approximately 0.4 percent. It may therefore be treated as a constant.

The $k_{v}$ parameter is affected predominantly by the value of $S$, which changes only slightly when the percentage of breakthrough concentration is above 5 percent. If $k_{v}$ is selected at a mid-point along the tested breakthrough curve (e.g. 10 percent breakthrough), the Yoon and Nelson equation would tend to under-predict the breakthrough time for low breakthrough points (1 and 5 percent) and slightly over-predict at the 20 percent breakthrough point.

Therefore, for the purposes of model comparison and breakthrough prediction, $k_{v}$ and $W_{e}$ will be treated as constants. This allows a simplification of the Yoon and Nelson equation to the following form: 


$$
t_{b}=-A \frac{1}{C_{0}} \ln \left[\frac{C_{0}-C_{x}}{C_{x}}\right]+\frac{B}{C_{0}}
$$

where $A$ and $B$ are curve-fitting constants. This equation is now in the form of $y=-m x+b$, with $x$ defined as:

$$
x=\frac{1}{C_{0}} \ln \left[\frac{C_{0}-C_{x}}{C_{x}}\right]
$$

A semi-log scatter plot of this $x$ value against the mean breakthrough times should, in theory, demonstrate if this relationship is followed. This was accomplished by fitting the Yoon and Nelson equation to each factorial condition in both experiments. Plots are shown in Figures 5-1 through 5-3.

Figure 5-1. Semi-log plot of a generalized Yoon and Nelson equation against mean breakthrough times for $50 \%$ relative humidity test condition. All cartridges were preconditioned at $80 \%$ relative humidity and $25^{\circ} \mathrm{C}$ for six hours.

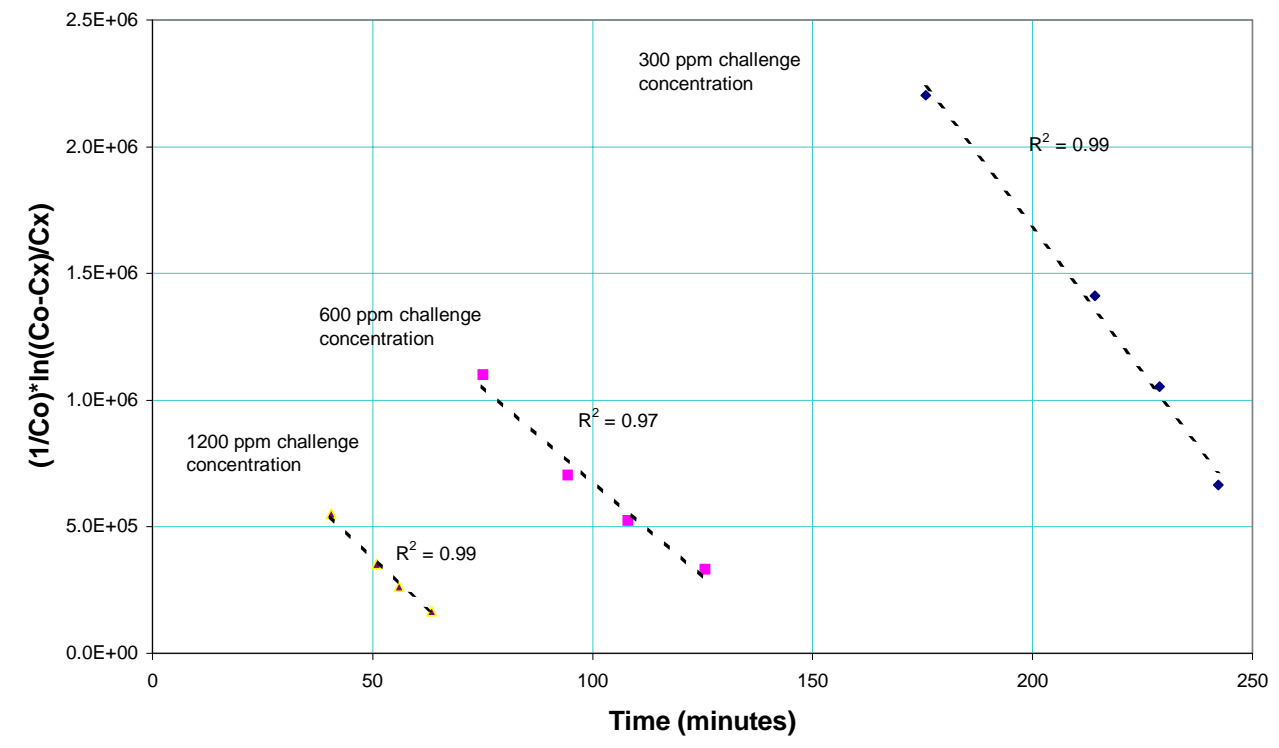


Figure 5-2. Semi-log plot of a generalized Yoon and Nelson equation against mean breakthrough times for $80 \%$ relative humidity test condition (without prior exposure to fuel vapor). All cartridges were preconditioned at $80 \%$ relative humidity and $25^{\circ} \mathrm{C}$ for six hours.

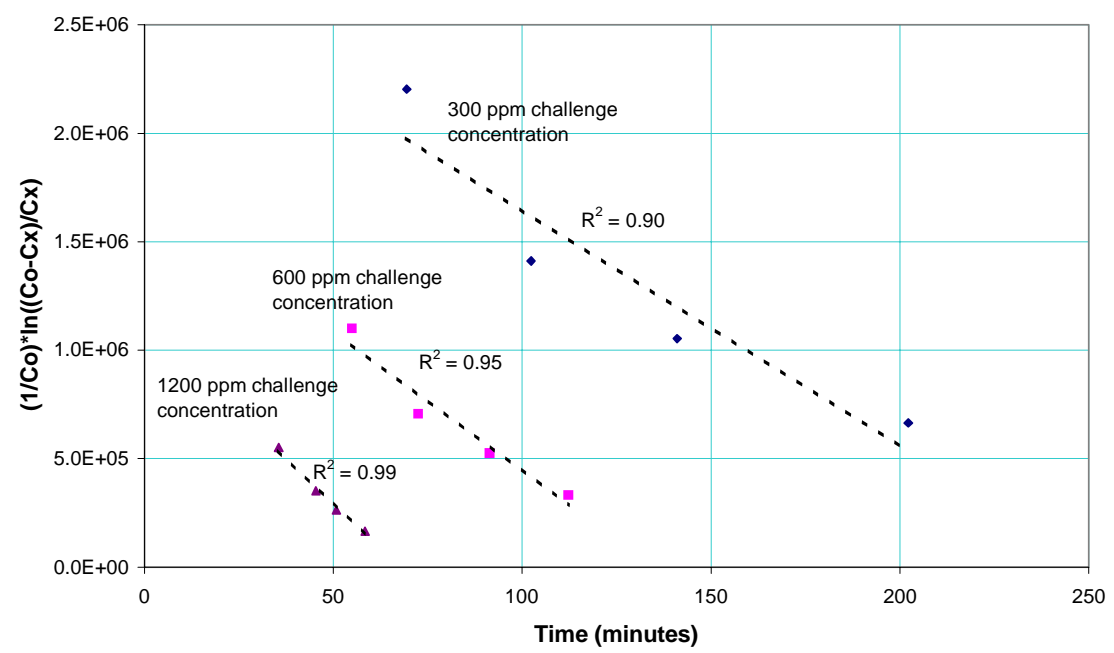

Figure 5-3. Semi-log plot of a generalized Yoon and Nelson equation against mean breakthrough times for $80 \%$ relative humidity test condition (with prior exposure to fuel vapor). All cartridges were preconditioned at $80 \%$ relative humidity and $25{ }^{\circ} \mathrm{C}$ for six hours. Prior exposed cartridges were previously subjected to static concentrations of $1200 \mathrm{ppm}$ fuel vapor for eight hours at $80 \%$ relative humidity and $25^{\circ} \mathrm{C}$.

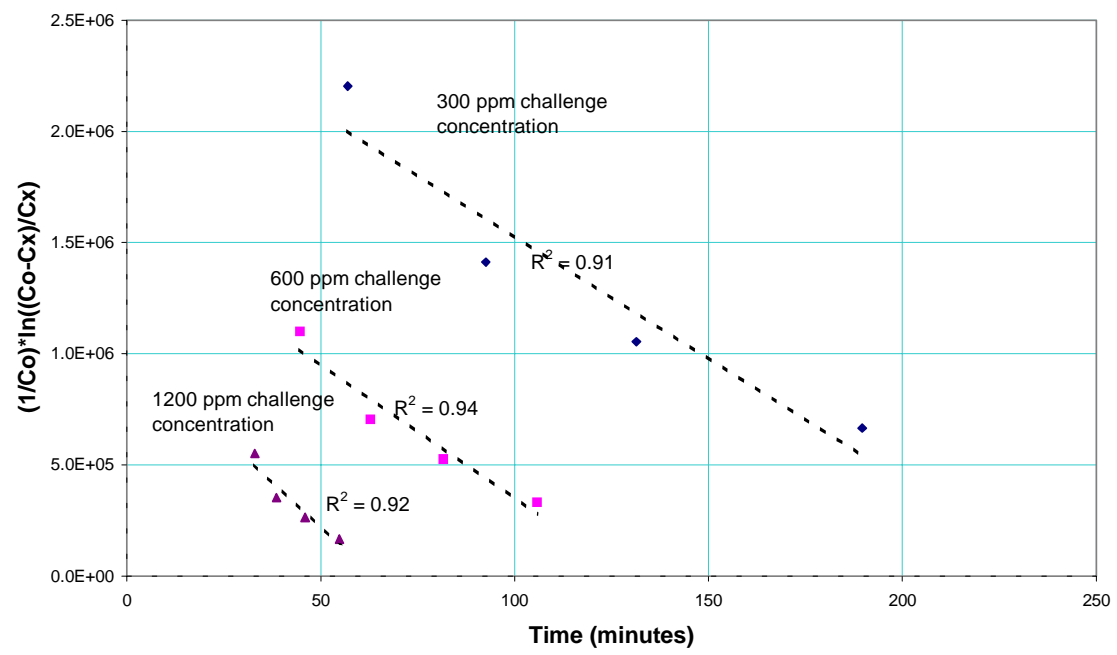


It can be seen from these plots that the 50 percent relative humidity condition appears to follow the form of the Yoon and Nelson equation quite well. Regression squared coefficients $\left(\mathrm{R}^{2}\right)$, which are indicators of the amount of variation in the dependent variable (the Yoon and Nelson equation) that can be accounted for by the independent variable (challenge concentration), ${ }^{49}$ were 0.99 for the 300 and 1200 ppm challenge concentrations and 0.97 for the 600 ppm challenge concentration. However, the fit for both 80 percent relative humidity test conditions was not as good. Visual examination of these charts indicates a possible non-linearity for both 80 percent relative humidity test conditions, which was also evident in the linear plots of breakthrough concentration vs. time presented in Section 4.4.2.

This finding does appear to be consistent with Nelson and Correia's data set where breakthrough curves for carbon cartridges preconditioned and tested at high humidity levels departed from the typical sigmoidal shape and became more linear in nature except for the extreme portions of the breakthrough curve. ${ }^{23}$

Another way of presenting this relationship is to plot the breakthrough time predicted by the generalized Yoon and Nelson equation against the mean breakthrough times as shown in Figures 5-4 to 5-6. To produce these prediction curves, constants A and B were determined individually for each challenge concentration curve using the DataFit curve fitting software tool. The curve fitting was accomplished on the breakthrough times for the $1 \%, 5 \%, 10 \%$, and $20 \%$ of challenge concentration (see Appendix E), and was based on all cartridges tested at each condition. Optimal curve fit parameters are shown in Table 5-3. 
Table 5-3. Curve-fit parameters for generalized Yoon and Nelson equation.

\begin{tabular}{ccccccc}
\hline $\begin{array}{c}\text { Relative } \\
\text { humidity }\end{array}$ & $\begin{array}{c}\text { Prior } \\
\text { exposure }\end{array}$ & $\begin{array}{c}\text { Challenge } \\
\text { concentration }\end{array}$ & A & $\begin{array}{c}\mathbf{9 5 \%} \text { CL } \\
(+/-)\end{array}$ & B & $\begin{array}{c}\mathbf{9 5 \%} \text { CL } \\
(+/-)\end{array}$ \\
\hline 50 & No & 300 & $4.31 \mathrm{E}-05$ & $9.05 \mathrm{E}-06$ & $5.69 \mathrm{E}-04$ & $2.53 \mathrm{E}-05$ \\
& & 600 & $6.49 \mathrm{E}-05$ & $6.45 \mathrm{E}-06$ & $6.02 \mathrm{E}-04$ & $1.88 \mathrm{E}-05$ \\
& & 1200 & $5.82 \mathrm{E}-05$ & $1.17 \mathrm{E}-05$ & $6.02 \mathrm{E}-04$ & $3.52 \mathrm{E}-05$ \\
80 & \multirow{2}{*}{ No } & 300 & $8.44 \mathrm{E}-05$ & $1.60 \mathrm{E}-05$ & $5.02 \mathrm{E}-04$ & $4.66 \mathrm{E}-05$ \\
& & 600 & $7.63 \mathrm{E}-05$ & $1.32 \mathrm{E}-05$ & $5.55 \mathrm{E}-04$ & $3.69 \mathrm{E}-05$ \\
& & 1200 & $5.82 \mathrm{E}-05$ & $1.19 \mathrm{E}-05$ & $5.58 \mathrm{E}-04$ & $3.59 \mathrm{E}-05$ \\
80 & \multirow{2}{*}{ Yes } & 300 & $1.01 \mathrm{E}-04$ & $2.03 \mathrm{E}-05$ & $5.13 \mathrm{E}-04$ & $5.03 \mathrm{E}-05$ \\
& & 600 & $7.74 \mathrm{E}-05$ & $1.14 \mathrm{E}-05$ & $5.23 \mathrm{E}-04$ & $3.43 \mathrm{E}-05$ \\
& & 1200 & $6.76 \mathrm{E}-05$ & $2.11 \mathrm{E}-05$ & $5.38 \mathrm{E}-04$ & $5.24 \mathrm{E}-05$ \\
\hline
\end{tabular}

These plots also confirm that the generalized Yoon and Nelson equation does appear to fit the data well for the 50 percent relative humidity condition. The fit for both 80 percent relative humidity conditions is not as good.

Figure 5-4. Generalized Yoon and Nelson equation fit to measured breakthrough data at $50 \%$ relative humidity, without prior exposure to fuel. Coefficients for equation were determined individually for each challenge concentration. All cartridges were preconditioned at $80 \%$ relative humidity and $25^{\circ} \mathrm{C}$ for six hours.

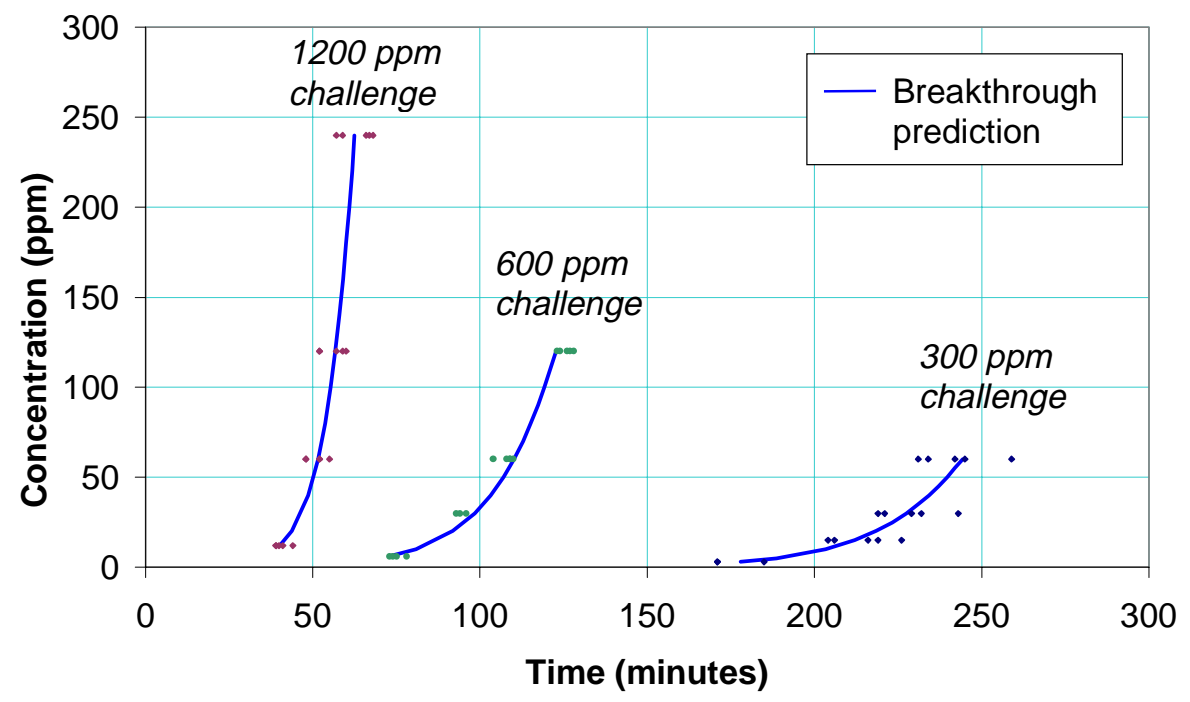


Figure 5-5. Generalized Yoon and Nelson equation fit to measured breakthrough data at $80 \%$ relative humidity, without prior exposure to fuel. Coefficients for equation were determined individually for each challenge concentration. All cartridges were preconditioned at $80 \%$ relative humidity and $25^{\circ} \mathrm{C}$ for six hours.

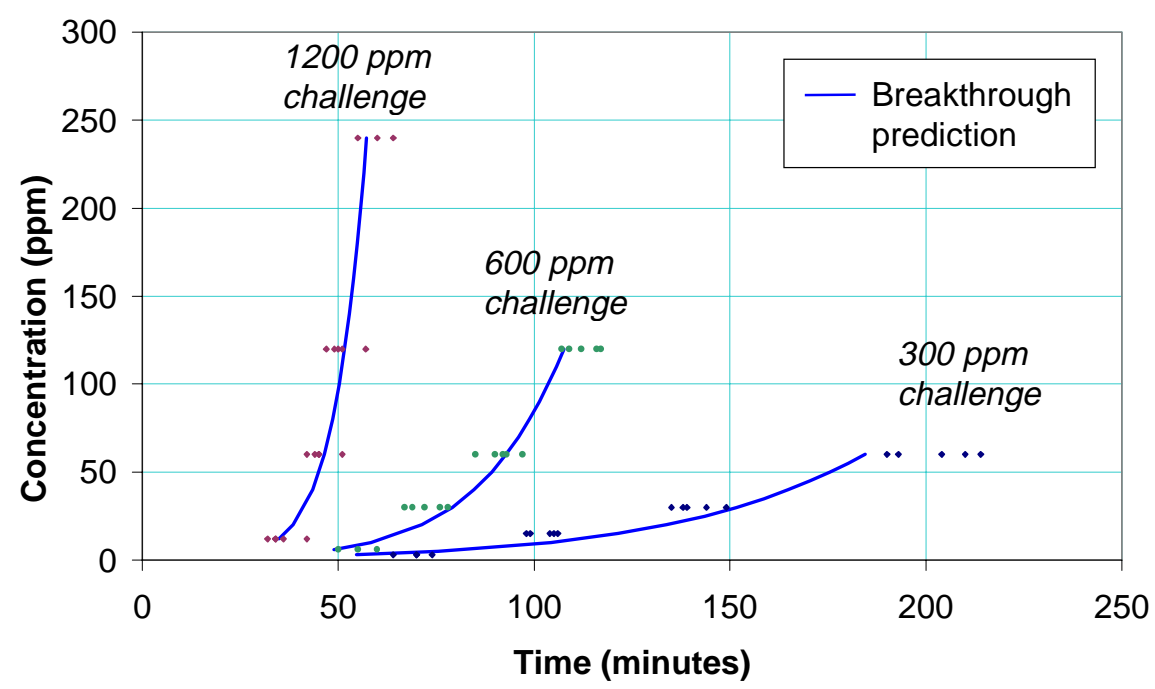

Figure 5-6. Generalized Yoon and Nelson equation fit to measured breakthrough data at $80 \%$ relative humidity, with prior exposure to fuel. Coefficients were determined individually for each challenge concentration. All cartridges were preconditioned at $80 \%$ relative humidity and $25{ }^{\circ} \mathrm{C}$ for six hours. Prior exposed cartridges were previously subjected to static concentrations of $1200 \mathrm{ppm}$ fuel vapor for eight hours at $80 \%$ relative humidity and $25^{\circ} \mathrm{C}$.

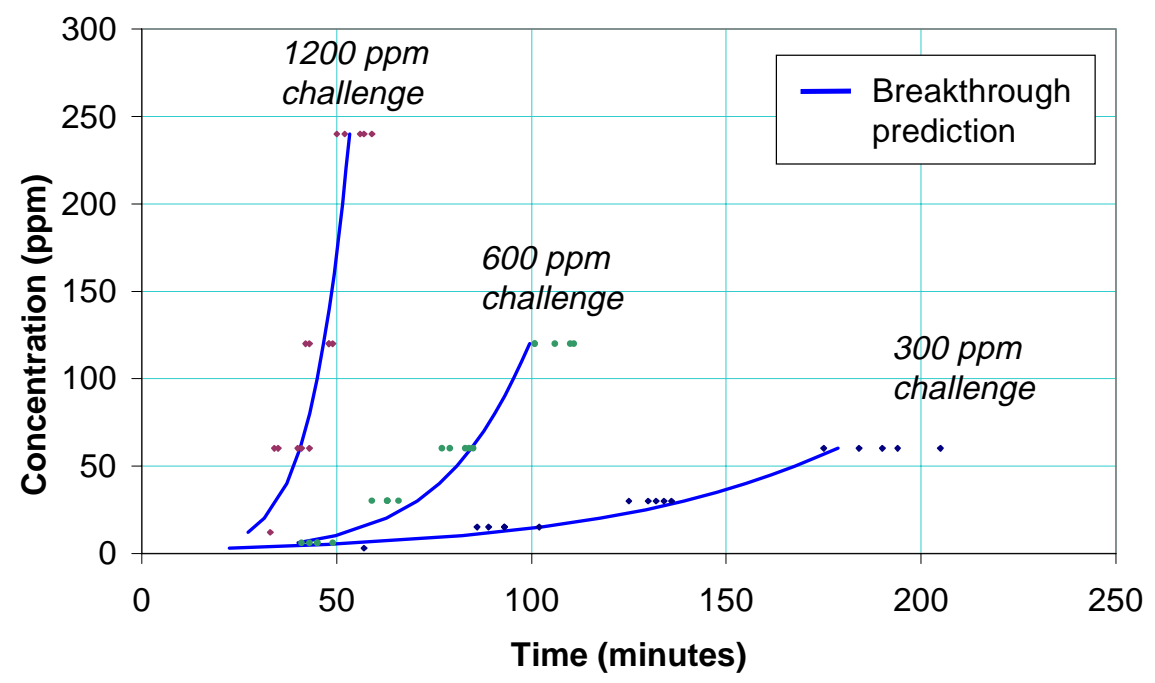




\subsubsection{Modeling of relative humidity effects}

A test of Wood's relative humidity model was conducted by calculating the ratio of breakthrough times for the $80 \%$ and $50 \%$ no prior exposure test conditions, with all other parameters held constant. The result of this comparison is presented in Table 5-4 and Figure 5-7.

Table 5-4. Ratio between 80 percent (with no prior exposure to fuel) and 50 percent relative humidity breakthrough times for fixed concentrations and breakthrough points.

\begin{tabular}{ccccc}
\hline $\begin{array}{c}\text { Challenge } \\
\text { Concentration }\end{array}$ & $\begin{array}{c}\text { Percent } \\
\text { breakthrough }\end{array}$ & Breakthrough time (50\% RH) & $\begin{array}{c}\text { Breakthrough } \\
\text { time }(\mathbf{8 0} \% \mathbf{R H})\end{array}$ & $\begin{array}{c}\text { Ratio } \\
\mathbf{t}_{80} / \mathbf{t}_{50}\end{array}$ \\
\hline 300 & 1 & 176 & 70 & 0.40 \\
300 & 5 & 214 & 102 & 0.48 \\
300 & 10 & 229 & 141 & 0.62 \\
300 & 20 & 242 & 202 & 0.83 \\
600 & 1 & 75 & 55 & 0.73 \\
600 & 5 & 94 & 72 & 0.77 \\
600 & 10 & 108 & 91 & 0.85 \\
600 & 20 & 126 & 112 & 0.89 \\
1200 & 1 & 41 & 36 & 0.88 \\
1200 & 5 & 51 & 45 & 0.89 \\
1200 & 10 & 56 & 51 & 0.91 \\
1200 & 20 & 63 & 58 & 0.92 \\
\hline
\end{tabular}


Figure 5-7. Ratio between breakthrough times for 80 percent and 50 percent relative humidity conditions (without prior exposure to fuel vapor), with linear regression fit. Data points represent the calculated mean breakthrough time ratios. All cartridges were preconditioned at $80 \%$ relative humidity and $25^{\circ} \mathrm{C}$ for six hours.

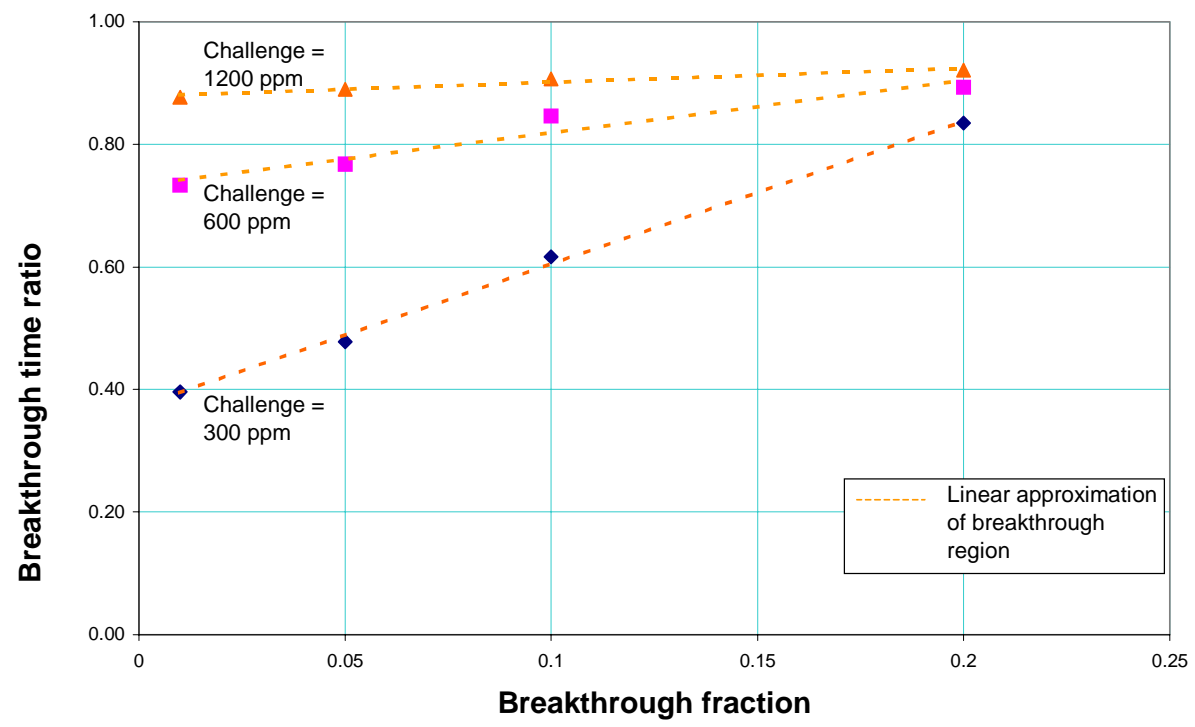

From this information, three observations can be made:

- It appears that at a fixed challenge concentration, the ratio of breakthrough times increases as the breakthrough percentage increases. This effect is quite pronounced at 300 and $600 \mathrm{ppm}$, but is less visible at the highest concentration of $1200 \mathrm{ppm}$.

- At low breakthrough concentrations, the breakthrough time ratio increases as the challenge concentration is raised.

- At high breakthrough concentrations (approaching 20 percent of the challenge concentration), the ratio of breakthrough times for each of the challenge concentrations begin to converge. 
These findings are consistent with the previous conclusion that there exists an interaction between challenge concentration and relative humidity. The reason for the difference in ratios as the challenge concentration changes is most likely explained by the large number of water molecules present in air at high relative humidity levels relative to the number of organic compound molecules in the air stream. The ratio of water to organic compound molecules is much greater at $300 \mathrm{ppm}$ of fuel vapor, allowing the high concentration of water molecules in the 80 percent relative humidity test condition vapor to have a more profound effect than at 1200 ppm of fuel vapor. ${ }^{36}$

The difference in ratios that is apparent from the increase in the breakthrough fraction curve may be a result of the longer carbon bed exposure time, allowing the cartridge more time to reach an equilibrium point between water vapor and the organic compounds in JP-8 jet fuel. ${ }^{38}$ Although not tested during this study, as the breakthrough curve continues beyond the 20 percent point, the ratio would be expected to level off and never completely approach 1.0.

\subsection{Development of cartridge service life guidelines}

\subsubsection{General approach}

Ideally, the optimal method to use in developing service life guidelines would be to fit the Yoon and Nelson equation and the Wood model to the entire data set, empirically derive the applicable constants, and predict exposure under any work environment condition of interest. However, as presented in Section 5.3 above, these equations do not appear to accurately describe the full JP-8 fuel vapor breakthrough data set, so a slightly different (and much simpler) approach was taken to enable development of a breakthrough time table for end-user implementation.

Because of the uncertainty associated with characterizing workplace exposures, it isn't necessary to be able to predict the breakthrough time at any randomly-selected challenge concentration or relative humidity condition. For this reason, a segmented or classification-based approach is appropriate, and the accuracy of a prediction model designed for this purpose must only be good enough to provide adequate worker protection with an adequate safety margin. 
For JP-8 jet fuel, which has an OEL of 50 ppm and a proposed TLV ${ }^{\circledR}$ of 14 ppm, the only portion of the breakthrough curve of real interest to the end user is the region of $25 \mathrm{ppm}$ or below, since cartridges should be changed out at $1 / 2$ of the exposure limit. A straight-line interpolation between the extreme points within this range provided a good approximation of the breakthrough time at any concentration within this range and enabled development of a simple table that can be easily put into use (see Section 6.2). It is important to recognize that the linear models developed in this section only apply to breakthrough concentrations below $30 \mathrm{ppm}$. If applied above that concentration, these equations will incorrectly predict a service life that is longer than the actual service life.

\subsubsection{Predicting breakthrough times for the 50 percent relative bumidity condition}

For the 50 percent relative humidity test condition, measured breakthrough times for each challenge concentration curve were plotted against breakthrough concentration. For the 1200 ppm challenge concentration, this included breakthrough points through 5 percent breakthrough (or $60 \mathrm{ppm}$ ). $30 \mathrm{ppm}$ was selected as the upper end for the 600 and $300 \mathrm{ppm}$ challenge concentrations to allow finer resolution at these levels. The 95\% LCL of the mean was then plotted for each set of cartridges, and a straight line was used to connect the 95\% LCL for the breakthrough point on the lower end to the 95\% LCL on the upper end of each challenge concentration data set. The resulting linear regression equations were then used to interpolate breakthrough times of interest within this region. 
Figure 5-8. Straight-line approximation of cartridge breakthrough times based on $95 \%$ LCL estimates (50 percent relative humidity, no prior exposure). All cartridges were preconditioned at $80 \%$ relative humidity and $25{ }^{\circ} \mathrm{C}$ for six hours and were tested with an air flow rate of 32 LPM through each cartridge.

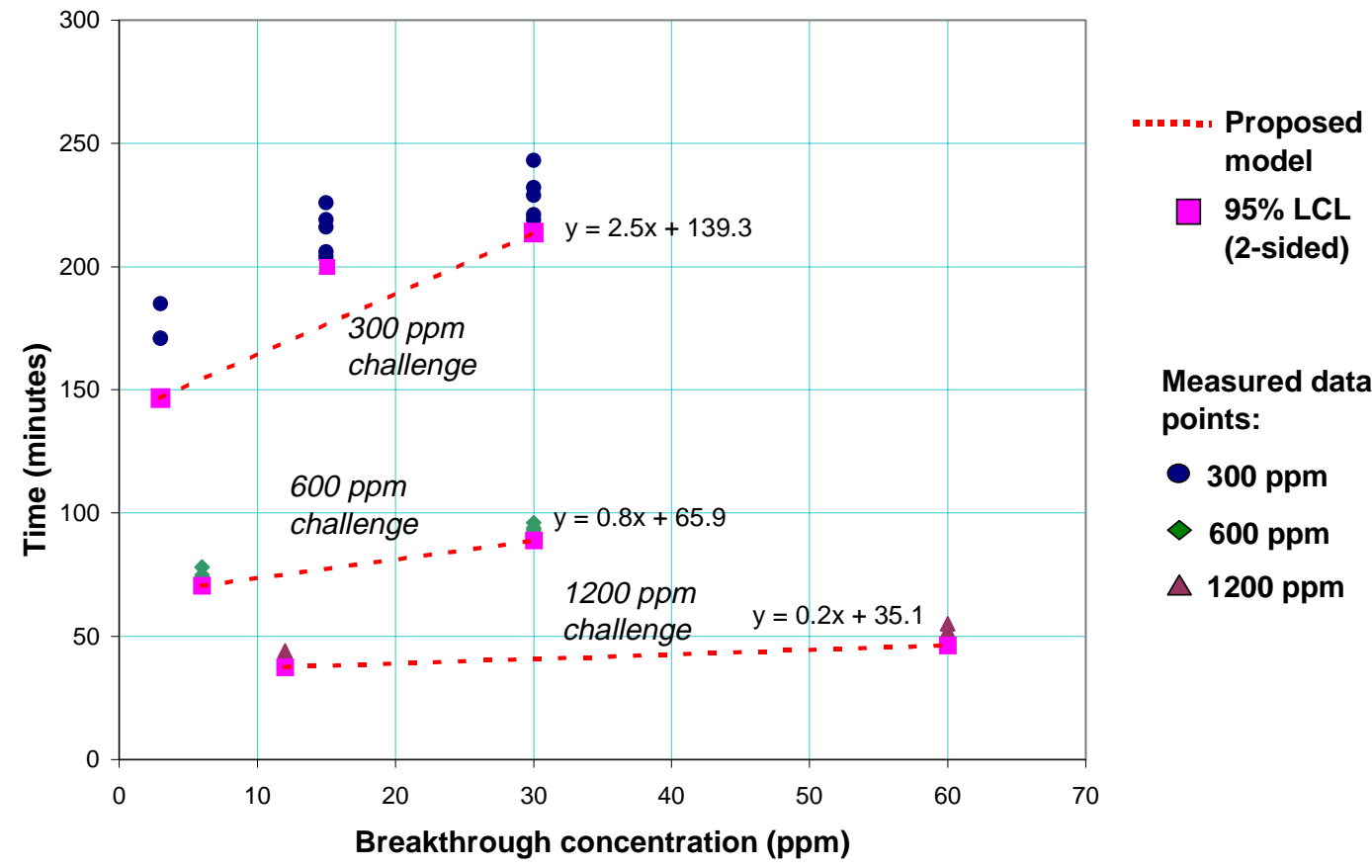

This yields three equations that can be used to estimate breakthrough times for 300,600, and 1200 ppm challenge concentrations. Equations are summarized in Table 5-5.

Table 5-5. Simplified estimates of cartridge service life at selected action level for $50 \%$ relative humidity exposure and room temperature conditions. In most cases, the selected action level will be $1 / 2$ the OEL or TLV (7 or $25 \mathrm{ppm})$.

\begin{tabular}{cc}
\hline $\begin{array}{c}\text { Maximum estimated } \\
\text { worker exposure (ppm) }\end{array}$ & $\begin{array}{c}\text { Estimated breakthrough time (in minutes) } \\
\text { to a desired action level }(\mathbf{A L} \text {, in ppm) }\end{array}$ \\
\hline 300 & Time $=(2.5)(\mathrm{AL})+139$ \\
600 & Time $=(0.8)(\mathrm{AL})+66$ \\
1200 & Time $=(0.2)(\mathrm{AL})+35$ \\
\hline
\end{tabular}


5.4.3. Predicting breakthrough times for the 80 percent relative bumidity condition (no prior exposure)

A similar approach was used for the 80 percent relative humidity (no prior exposure) test condition. Results are presented in Figure 5-9 and Table 5-6.

Figure 5-9. Straight-line approximation of cartridge breakthrough times based on $95 \%$ LCL estimates (80 percent relative humidity, no prior exposure). All cartridges were preconditioned at $80 \%$ relative humidity and $25{ }^{\circ} \mathrm{C}$ for six hours and were tested with an air flow rate of 32 LPM through each cartridge.

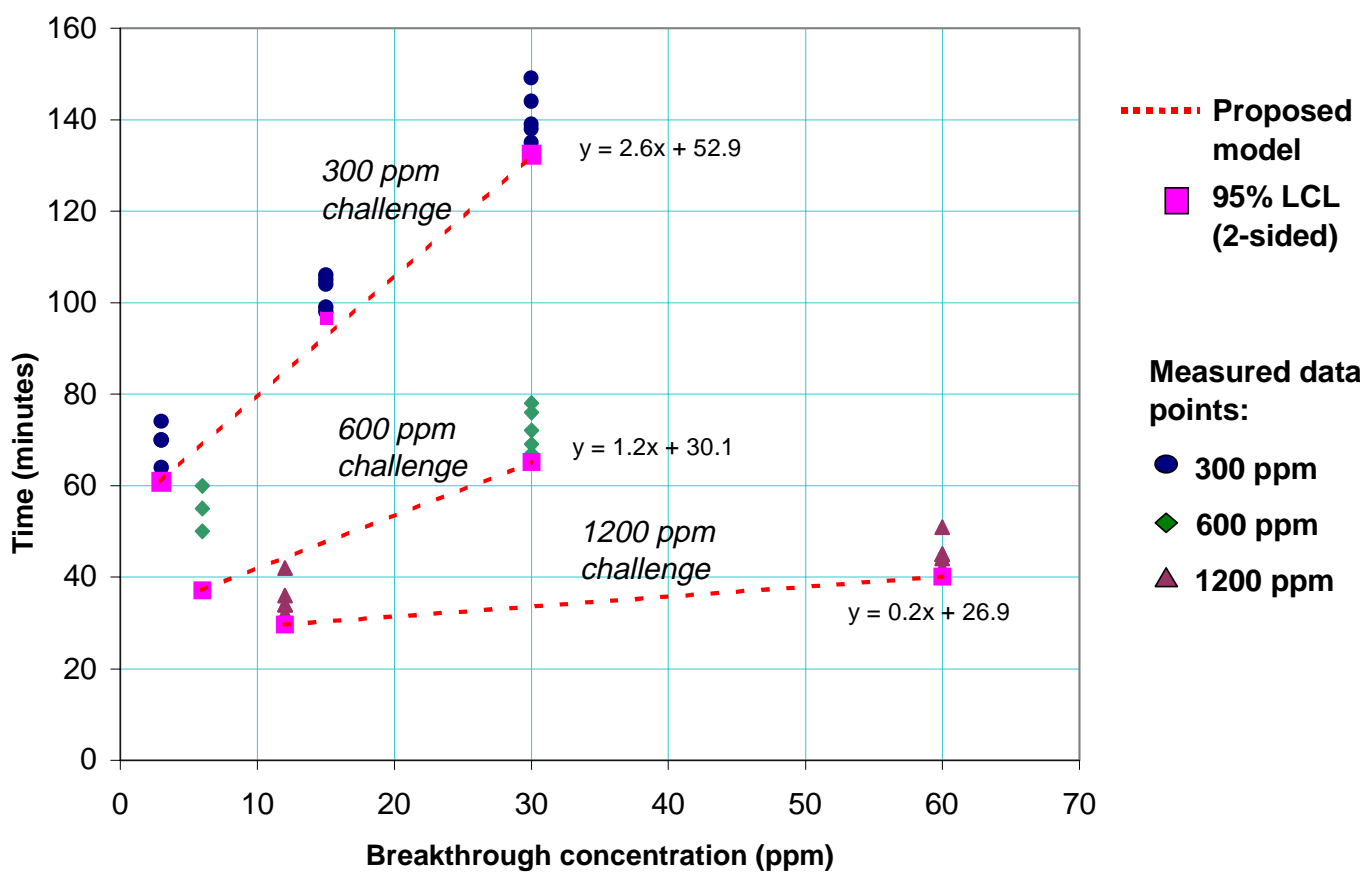

Table 5-6. Simplified estimates of cartridge service life at a selected action level for $80 \%$ relative humidity exposure and room temperature conditions. In most cases, the selected action level will be $1 / 2$ the OEL or TLV (7 or $25 \mathrm{ppm}$ ).

\begin{tabular}{cc}
\hline $\begin{array}{c}\text { Maximum estimated } \\
\text { worker exposure (ppm) }\end{array}$ & $\begin{array}{c}\text { Estimated breakthrough time (in } \\
\text { minutes) } \\
\text { to a desired action level (AL, in ppm) }\end{array}$ \\
\hline 300 & Time $=(2.6)(\mathrm{AL})+53$ \\
600 & Time $=(1.2)(\mathrm{AL})+30$ \\
1200 & Time $=(0.2)(\mathrm{AL})+27$ \\
\hline
\end{tabular}




\subsubsection{Predicting breakthrough times for the 80 percent relative bumidity condition (with prior exposure)}

The Air Force is currently using these cartridges as a back-up provision in the event of an air supply failure, so these cartridges are seldom placed in actual use. Of primary concern is the service life expected from the cartridges if they are needed to aid in escape from an environment containing JP-8 fuel vapor.

The prior exposure test did show a statistically significant reduction in cartridge service life compared to the 80 percent relative humidity without prior exposure condition. However, if the cartridges are only put into active use in a back-up capacity, and are not actively used afterwards, this effect can be ignored. The change is not significant at $1200 \mathrm{ppm}$, and will not impair the service life needed during the 15 minutes or so that may be needed to exit a fuel tank.

Because of the current use conditions, no prediction model will be proposed for determining breakthrough times of cartridges with prior exposure to fuel vapor. However, it is unclear how much of an impact long-term exposure to fuel vapor may have, since this study terminated exposure at 8 hours. Instead, cartridges used in a back-up configuration should be discarded and replaced on a regular schedule. Since data for exposures exceeding 8 hours is currently unavailable, the professional recommendation of this author is to discard cartridges after 8 hours of cumulative static exposure to fuel vapor, or within one week or less of first use. 


\section{Chapter 6. CONCLUSIONS AND RECOMMENDATIONS}

\subsection{Summary of findings}

The research reported in this paper helps to define the service life of the $3 \mathrm{M}^{\mathrm{TM}} 7251$ organic vapor cartridge when exposed to concentrations of JP-8 fuel between 300 and 1200 parts per million (ppm). In doing so, this research led to the following conclusions:

- The test relative humidity has a statistically significant impact on a cartridge's service life for cartridges preconditioned at 80 percent relative humidity. When compared to cartridges actively tested at 50 percent relative humidity, the service lives of cartridges tested at 80 percent relative humidity were significantly reduced at challenge concentrations of 300 and $600 \mathrm{ppm}$, with more than a 50 percent reduction in breakthrough time at $300 \mathrm{ppm}$. The difference between mean breakthrough times at 1200 ppm was not statistically significant when compared using the Tukey HSD means test.

- The interaction between relative humidity and challenge concentration is significant. Much of the current research on the impacts of relative humidity suggest the use of an adjustment factor that accounts for the relative humidity level, but not the interaction between relative humidity and challenge concentration.

- Exposing the face of a cartridge to JP-8 fuel vapor and high humidity over an 8-hour period without actively drawing vapor through it had a statistically significant impact on a cartridge's service life at some challenge concentrations. This effect was most prominent at $300 \mathrm{ppm}$, but was not significant at 1200 ppm. For end-user applications, this difference is moderate and will have a minor impact on the cartridge replacement times selected as part of a changeout schedule.

- The interaction between concentration and prior static exposure of a cartridge's face to fuel vapor and high humidity levels is not significant. 
- The breakthrough response curve for cartridges tested at 50 percent relative humidity can be modeled well by a general form of the Yoon and Nelson equation, with equation parameters determined empirically. This model is useful for predicting a cartridge's service life at the $50 \%$ relative humidity test condition.

- The breakthrough response curve for cartridges tested at 80 percent relative humidity does not appear to follow the shape of the Wood Model equation as well as the 50 percent relative humidity data sets.

- A comparison of breakthrough times between the 80 and 50 percent relative humidity levels (without prior exposure) demonstrates that the ratio does not remain constant throughout the portion of the breakthrough curve tested ( 1 percent to 20 percent breakthrough), nor is the ratio constant at different challenge concentrations.

\subsection{Change-out schedule recommendations}

The data collected during this study would not be as meaningful to the aviation community in general unless it can be used to create a cartridge change-out schedule for workers exposed to JP8 jet fuel. While the equations presented in Section 5.4 are sufficient to estimate cartridge service life at the 50 and 80 percent relative humidity levels, the end user should not be required to calculate breakthrough times. Instead, a change-out table was developed to enable an end-user to quickly determine breakthrough times to $1 / 2$ of the Air Force OEL or the ACGIH's proposed $\mathrm{TLV}^{\circledR}$. For conditions that vary significantly from the tested conditions (e.g. higher temperatures or humidity levels), the 80 percent relative humidity test condition breakthrough times are reduced by an additional 25 percent to provide an extra margin of safety.

The tables should only be applied when a good characterization of the workplace environment and exposures has been accomplished by an individual trained in such techniques. If there is any question regarding applicability of these recommendations, consult a health or safety professional before entering a potentially hazardous environment. Additionally, the breakthrough times 
presented in this table are only applicable to pairs of 3MTM 7251 organic vapor cartridges used in an air purifying respirator.

Application of these tables is a four-step process:

1. Assess the maximum exposure anticipated during the task to be accomplished, and characterize the exposure as high (between 600 and 1200 ppm), medium (between 300 and 600 ppm), or low (less than 300 ppm). If anticipated exposures exceed 1200 ppm, an air purifying respirator should not be used in that environment and these tables do not apply. Determination of concentration should initially be accomplished by a health or safety professional, who may recommend a sampling method for local use by fuel systems repair personnel. One possible method that could be employed by repair personnel is to monitor the concentration with an explosive meter and convert the measured percentage of the Lower Explosive Limit (LEL) to a part per million value. For example, assuming an LEL of between 6000 and $9000 \mathrm{ppm}$, a reading of 10 percent of the LEL would equate to a concentration between $600 \mathrm{ppm}$ and $900 \mathrm{ppm}$ of fuel vapor, which would characterize the exposure as "high". Before using this method, however, some validation work needs to be accomplished to ensure adequate sensitivity, accuracy, and reliability of the selected explosive meter, and to compare its response to other sampling methods (such as the FID used in this study).

2. Characterize the relative humidity level as high ( 80 percent or greater), medium (between 50 and 80 percent), or low (less than 50 percent). If the maintenance procedure is to be accomplished in an environment where the humidity level is not controlled, weather reports may be adequate for estimating the relative humidity level. If conducted indoors, a measurement should be taken with a hygrometer or similar device.

3. Select a breakthrough level of concern. This should be $1 / 2$ of the OEL or the proposed ACGIH TLV ${ }^{\circledR}$, depending on the safety factor desired. 
4. Look up the breakthrough time in the corresponding table, and ensure the cartridge is changed out before that time elapses. Be sure to allow adequate time to exit the environment before the service life expires.

Table 6-1(a) through (c). Estimated cartridge service life for pairs of $3 \mathrm{M}^{\mathrm{TM}} 7251$ organic vapor cartridges during active exposure to JP-8 jet fuel. Estimates are based on the service life tested under laboratory conditions with 32 LPM airflow through each cartridge (equivalent to 64 LPM airflow through each set of cartridges) at (a) $300 \mathrm{ppm}$, (b) $600 \mathrm{ppm}$, and (c) $1200 \mathrm{ppm}$ challenge concentrations. All cartridges were preconditioned at 80 percent relative humidity and $25^{\circ} \mathrm{C}$ for six hours.

\begin{tabular}{|l|c|c|c|}
\hline $\begin{array}{l}\text { (a) Vapor concentration } \\
\text { less than } 300 \text { ppm }\end{array}$ & \multicolumn{3}{|c|}{ Breakthrough time } \\
\hline $\begin{array}{l}\text { Desired change-out } \\
\text { concentration }\end{array}$ & $\begin{array}{c}\text { Below } \mathbf{5 0} \% \\
\text { relative } \\
\text { humidity }\end{array}$ & $\begin{array}{c}\mathbf{5 0 - 8 0 \%} \\
\text { relative } \\
\text { humidity }\end{array}$ & $\begin{array}{c}\text { Above } \mathbf{8 0} \% \text { relative } \\
\text { humidity or temp } \\
\text { above } 85\end{array}$ \\
\hline $7 \mathrm{ppm}(1 / 2$ of proposed TLV
\end{tabular}

\begin{tabular}{|c|c|c|c|}
\hline $\begin{array}{l}\text { (b) Vapor concentration } \\
300 \text { to } 600 \mathrm{ppm}\end{array}$ & \multicolumn{3}{|c|}{ Breakthrough time } \\
\hline $\begin{array}{l}\text { Desired change-out } \\
\text { concentration }\end{array}$ & $\begin{array}{l}\text { Below } 50 \% \\
\text { relative } \\
\text { humidity }\end{array}$ & $\begin{array}{c}50-80 \% \\
\text { relative } \\
\text { humidity }\end{array}$ & $\begin{array}{l}\text { Above } 80 \% \text { relative } \\
\text { humidity or temp } \\
\text { above } 85^{\circ} \mathrm{F}\end{array}$ \\
\hline 7 ppm (1/2 of proposed TLV ${ }^{\circledR}$ ) & $1 \mathrm{hr}$ & $35 \mathrm{~min}$. & 20 min. \\
\hline $25 \mathrm{ppm}(1 / 2$ of USAF OEL) & $1 \frac{1 / 4}{\mathrm{hrs}}$ & $1 \mathrm{hr}$ & 45 min. \\
\hline
\end{tabular}

\begin{tabular}{|c|c|c|c|}
\hline $\begin{array}{l}\text { (c) Vapor concentration } \\
600 \text { to } 1200 \mathrm{ppm}\end{array}$ & \multicolumn{3}{|c|}{ Breakthrough time } \\
\hline $\begin{array}{l}\text { Desired change-out } \\
\text { concentration }\end{array}$ & $\begin{array}{l}\text { Below } 50 \% \\
\text { relative } \\
\text { humidity }\end{array}$ & $\begin{array}{l}50-80 \% \\
\text { relative } \\
\text { humidity }\end{array}$ & $\begin{array}{l}\text { Above } 80 \% \text { relative } \\
\text { humidity or temp } \\
\text { above } 85^{\circ} \mathrm{F}\end{array}$ \\
\hline 7 ppm (1/2 of proposed TLV $\left.{ }^{\circledR}\right)$ & 35 min. & $30 \mathrm{~min}$. & $20 \mathrm{~min}$. \\
\hline $25 \mathrm{ppm}(1 / 2$ of USAF OEL) & $40 \mathrm{~min}$. & $30 \mathrm{~min}$. & $20 \mathrm{~min}$. \\
\hline
\end{tabular}




\subsection{Considerations for future research efforts}

\subsubsection{Comparison of sampling methods}

At present, there have been few controlled, side-by-side comparisons between Flame Ionization Detector (FID) direct sampling and the modified NIOSH 1550 charcoal tube adsorbant sampling methods. A better understanding of the relationship between these methods and the relative merits of each would help establish and more accurately document workplace exposures, cartridge breakthrough times, and comparisons to existing occupational exposure limits. For example, an occupational exposure limit of $350 \mathrm{mg} / \mathrm{m}^{3}$ can be converted to parts per million (ppm) by using the existing conversion factors and published molecular weights for JP-8 jet fuel or kerosene (approximately $170 \mathrm{~g} /$ mole). However, those values are based on the average molecular weight of all components in liquid fuel and not on the vapor composition, which appears to have a much lower average molecular weight of approximately $114 \mathrm{~g} / \mathrm{mol} .{ }^{8}$ Using a part per million conversion factor based on the average molecular weight of the liquid fuel may not accurately represent the actual workplace exposure when compared to the exposure limit.

\subsubsection{Compositional differences between challenge and breakthrough vapors}

According to the current literature regarding breakthrough of substances containing multiple components, the interaction between components is relatively complex. Substances weakly adsorbed in a carbon bed can be displaced by those with stronger adsorption properties, potentially modifying the composition of the vapor breaking through the cartridge.

Consequently, a worker using a respirator for protection against JP-8 may actually be exposed to a subset of substances that is considerably different than the ambient JP-8 vapor when breakthrough begins. Depending on the substances that break through first, and their concentrations, the risks to the worker could be different than if one assumes the compounds breaking through resemble the composition of JP-8. This could be especially important if other 
compounds are present in the work environment, such as methyl ethyl ketone (MEK) solvent that might be used in a fuel tank.

\subsubsection{Changes in breakthrough times resulting from extensive prior exposure to fuel vapor}

This research reported on the change in breakthrough time that results from exposing a cartridge, under static conditions, to high levels of fuel vapor in a controlled, high humidity test environment, and concluded that there does appear to be a slight reduction in breakthrough time after eight hours of exposure. It would be beneficial to understand the impact of repeated cartridge exposure under such conditions, combined with storage of the cartridge over a period of several days or weeks, and the resulting impact on breakthrough times. Modeling of the passive diffusion of fuel vapor that occurs into the carbon and its applicability to existing breakthrough models would be beneficial to the respirator user community.

\subsubsection{Modeling of relative humidity effects}

The current work that is being done to model the effects of relative humidity levels during preconditioning and test conditions should be applied to the data presented in this report in an attempt to identify whether or not JP-8 follows the typical response characteristics predicted by those models. With this information, it will be possible to better predict the impact of other humidity levels, particularly those higher than the $80 \%$ level tested in this study.

\subsubsection{Identification of a surrogate compound}

Since JP-8 fuel is composed of over 300 organic compounds, it would be beneficial to be able to identify a single compound that could be used in future breakthrough testing to represent JP-8 fuel vapor. By doing this, it may be possible to more easily produce controlled concentrations of a challenge vapor and quickly estimate breakthrough response time for any given cartridge.

Identifying a surrogate compound could be accomplished by first determining the breakthrough times for JP-8 through a dry carbon bed, and then estimating $W_{e}$ and $k_{v}$ under dry conditions in a manner similar to that used to curve fit the $50 \%$ relative humidity data to the Yoon and Nelson 
equation in this report. These values could then be compared to $W_{e}$ and $k_{v}$ values calculated through the Wood Model equations for the major components of JP- $8^{8}$ fuel vapor. A list of the applicable properties and parameters for these components is presented in Table 6-2, based on the assumed test values in Table 6-2 and commonly-available chemical property information. ${ }^{37}$

Table 6-2. Summary of Wood Model equation parameters and estimated breakthrough times (to 10 percent of the challenge concentration) for major components of JP-8 fuel vapor. Calculations are for a $300 \mathrm{ppm}$ challenge concentration ( 0.228 torr) under dry conditions with no cartridge preconditioning, and the saturation partial pressures $\left(\rho_{\text {sat }}\right)$ listed are for each substance in pure form.

\begin{tabular}{lccccccccc}
\hline Compound & $\begin{array}{c}\text { Density } \\
(\mathbf{g} / \mathbf{c c})\end{array}$ & $\begin{array}{c}\boldsymbol{\rho} \\
\text { (torr) }\end{array}$ & $\begin{array}{c}\boldsymbol{\rho}_{\text {sat }} \\
\text { (torr) }\end{array}$ & $\begin{array}{c}\mathbf{M W} \\
(\mathbf{g} / \mathbf{m o l})\end{array}$ & $\mathbf{n}_{\mathbf{D}}$ & $\mathbf{P}_{\mathbf{e}}$ & $\begin{array}{c}\mathbf{k}_{\mathbf{v}} \\
\left(\mathbf{m i n}^{-1}\right)\end{array}$ & $\begin{array}{c}\mathbf{W}_{\mathbf{e}} \\
(\mathbf{g} / \mathbf{g})\end{array}$ & $\begin{array}{c}\text { Est. time } \\
(\mathbf{m i n})\end{array}$ \\
\hline Methyl cyclohexane & 0.7694 & 0.228 & 37 & 98.19 & 1.4231 & 32.50 & 2154 & 0.318 & 250 \\
n-Octane & 0.7025 & 0.228 & 10 & 114.2 & 1.3974 & 39.19 & 2424 & 0.363 & 258 \\
n-Nonane & 0.7176 & 0.228 & 3 & 128.3 & 1.4054 & 43.85 & 2592 & 0.406 & 263 \\
m-Xylene & 0.8642 & 0.228 & 9 & 106.2 & 1.4972 & 35.96 & 2299 & 0.440 & 329 \\
Toluene & 0.8669 & 0.228 & 21 & 92.15 & 1.4961 & 31.06 & 2091 & 0.378 & 312 \\
Ethyl cyclohexane & 0.7880 & 0.228 & 13 & 112.2 & 1.4330 & 37.01 & 2340 & 0.392 & 279 \\
cis-1,4-dimethyl cyclohexane & 0.7829 & 0.228 & 18 & 112.2 & 1.4230 & 36.50 & 2320 & 0.376 & 267 \\
n-Heptane & 0.6837 & 0.228 & 46 & 100.2 & 1.3878 & 34.6 & 2242 & 0.286 & 224 \\
Cyclohexane & 0.7785 & 0.228 & 78 & 84.16 & 1.4266 & 27.7 & 1937 & 0.245 & 212 \\
o-Xylene & 0.8802 & 0.228 & 7 & 106.2 & 1.5055 & 35.8 & 2292 & 0.457 & 341 \\
JP-8 Jet Fuel $^{2}$ & 0.8075 & 0.228 & 1.5 & 170 & - & - & - & - & - \\
\hline
\end{tabular}

Table 6-3. Parameters for applying the Wood Model equation to major components of JP-8 jet fuel.

\begin{tabular}{lll}
\hline Parameter & Value & Description \\
\hline$W_{o}$ & 0.597 & Carbon micropore volume $\left(\mathrm{cm}^{3} / \mathrm{g}\right)$, from manufacturer \\
$\mathrm{b}^{\prime}$ & $3.56 \mathrm{E}-05$ & Empirical coefficient \\
$\mathrm{R}$ & 1.987 & Ideal gas constant \\
$\mathrm{T}$ & 298 & Test condition temperature $(\mathrm{K})$ \\
$\mathrm{S}$ & 0.036 & Empirical constant at $1 \%$ breakthrough concentration \\
$\mathrm{V}_{\mathrm{L}}$ & 5.93 & $\begin{array}{l}\text { Linear air flow velocity, } \mathrm{cm} / \mathrm{sec} \text {, based on cross-sectional area of } 90 \\
\mathrm{~cm}^{2} \text { (per manufacturer) }\end{array}$ \\
$\mathrm{I}$ & 0.00083 & Empirical constant \\
$\mathrm{W}$ & 44.5 & Weight of carbon, from manufacturer \\
$\mathrm{Q}$ & 32000 & Air flow rate $\left(\mathrm{cm}^{3} /\right.$ min) \\
$\rho_{B}$ & 0.436 & Bulk density of the packed bed \\
$\mathrm{C}_{\mathrm{o}}$ & 300 & Challenge concentration, in ppm \\
$\mathrm{C}_{\mathrm{x}}$ & 30 & Breakthrough concentration, in ppm (10 percent of challenge) \\
\hline
\end{tabular}




\subsection{Closing remarks}

There is a vast amount of undiscovered knowledge in the respirator research field, and many opportunities to enhance the safety and health conditions for workers using respirators to provide protection from hazardous substances. It is this author's hope that the work presented in this paper will have a positive impact on workers exposed to jet fuel vapors, and that this work may serve as a launching point for further research to answer much of the complexities that remain. 


\section{REFERENCES}

${ }^{1}$ Air Force Research Laboratory (AFRL/PRSF): History of Aviation Fuel Development in the United States (unpublished internal reference).

${ }^{2}$ Committee on Toxicology (COT): Permissible Exposure Levels for Selected Military Fuel Vapors, National Research Council, National Academy Press, Washington DC (1996).

${ }^{3}$ International Agency for Research on Cancer (IARC): IARC Monographs on the Evaluation of Carcinogenic Risks to Humans. Overall Evaluations of Carcinogenicity: An Updating of IARC Monographs Volumes 1 to 42, Supplement 7. IARC, Lyon, France (1987).

${ }^{4}$ Executive Order 12196, February 26, 1980, Occupational Safety and Health Programs for Federal Employees (as amended by Executive Order 12608, September 9, 1987).

${ }^{5}$ Air Force Occupational Safety and Health (AFOSH) Standard 48-8, "Controlling Exposures to Hazardous Materials" (1 Sep 1997).

${ }^{6}$ American Conference of Governmental Industrial Hygienists (ACGIH): Threshold Limit Values for Chemical Substances and Physical Agents / Biological Exposure Indices. ACGIH, Cincinnati, OH (2000).

${ }^{7}$ McMurry, J. and R.C. Fay: Chemistry, Second Edition. Upper Saddle River, Jew Jersey: PrenticeHall, Inc. (1998).

${ }^{8}$ Naegeli, D.W. and K. H. Childress: Lower Explosion Limits and Compositions of Jet Fuel Vapors. Paper no. WSS/CI 98S-66, presented at Western States Section/Combustion Institute, University of California, Berkeley, March 1998.

${ }^{9}$ United States Air Force Human Systems Center (HSC), Det 1 HSC/OEMI: "Consultative Letter, AL-OE-BR-CL-1998-0062, Benzene and Jet Fuel Exposures During Aircraft Fuel Systems Maintenance Operations," Detachment 1 HSC/OEMI, 7 May 1998.

${ }^{10}$ United States Air Force Human Systems Center (HSC), Det 1 HSC/OEMI: Survey Reports 1997-224, 228, 231, and 232 (1997)

${ }^{11}$ United States Air Force Human Systems Center (HSC), Det 1 HSC/OEMI: Survey Reports 1998-001, 024 to 032 (1998)

${ }^{12}$ United States Air Force Human Systems Center (HSC), Det 1 HSC/OEMI: Survey Report 1998-032 - Exposure to Fuel Vapors During Aircraft Fuel Systems Maintenance Operations, Robins ANG, GA (1998)

${ }^{13}$ Carlton, G.N. and L.B. Smith: Exposures to Jet Fuel and Benzene During Aircraft Fuel Tank Repair in the U.S. Air Force. Applied Occupational and Environmental Hygiene, 15(6):485-491 (2000).

${ }^{14}$ United States Air Force Materiel Command (AFMC): Technical Order 1-1-3, "Inspection and Repair of Aircraft Integral Tanks and Fuel Cells", WR-ALC/LKJTC, Robins AFB, GA, 30 Nov 1994; with change 6 dated 23 Jan 98.

${ }^{15}$ National Institute for Occupational Safety and Health (NIOSH), "NIOSH Respirator Decision Logic," DHHS (NIOSH) Publication No. 87-108 (1987). 
${ }^{16}$ National Institute for Occupational Safety and Health (NIOSH): 42 CFR 84.207, "Bench tests: gas and vapor tests: minimum requirements." (1995).

17 Occupational Safety and Health Administration (OSHA): 29 CFR 1910.134, Respiratory Protection. http:/ / www.osha-slc.gov/OshStd data/1910 0134.html (accessed 22 Jan 00).

${ }^{18}$ Occupational Safety and Health Administration (OSHA): The Gerry O. Wood Mathematical Model. http:// wmw.osha-slc.gov/SLTC/respiratory advisor/wood table/wood model/wood model.btml (accessed 17 June 99).

${ }^{19}$ DiNardi, S.R. (ed.): The Occupational Environment - Its Evaluation and Control. Fairfax, VA: AIHA Press (1997).

20 United States Air Force Occupational Safety and Health (AFOSH) Standard 48-137, "Respiratory Protection Program" (1 Nov 98).

${ }^{21}$ Wood, G.O. and Ackley, M.W.: A Testing Protocol for Organic Vapor Respirator Canisters and Cartridges. American Industrial Hygiene Association Journal, 50:651-654 (1989).

${ }^{22}$ Bollinger, N. and C. Coffey: Decision Logic for Organic Vapor Cartridge Respirators for Premanufacture Notification (PMN) Substances. DRAFT (May 25, 1988, unpublished).

${ }^{23}$ Nelson, G.O. and A.M. Correia.: Respirator Cartridge Efficiency Studies: VIII. Summary and Conclusions. American Industrial Hygiene Association Journal 37:514-525 (1976).

${ }^{24}$ Nelson, G.O. and C.A. Harder: Respirator Cartridge Efficiency Studies: IV. Effects of SteadyState and Pulsating Flow. American Industrial Hygiene Association Journal 33:797-805 (1972).

${ }^{25}$ Nelson, G.O., C.A. Harder, and B.E. Bigler: Respirator Cartridge Efficiency Studies: VI. Effect of Concentration. American Industrial Hygiene Association Journal 37:205 (1976).

${ }^{26}$ Nelson, G.O., A.M. Correia, and C.A. Harder: Respirator Cartridge Efficiency Studies: VII. Effect of Relative Humidity and Temperature. American Industrial Hygiene Association Journal 37:280 (1976).

${ }^{27}$ Yoon, Y.H. and J.H. Nelson: Application of Gas Adsorption Kinetics I. A Theoretical Model for Respirator Cartridge Service Life. American Industrial Hygiene Association Journal 45:509-516 (1984).

${ }^{28}$ Moyer, E. S.: Review of Influential Factors Affecting the Performance of Organic Vapor AirPurifying Respirator Cartridges. American Industrial Hygiene Association Journal 44:46-51(1983).

${ }^{29}$ Moyer, E.S.: Organic Vapor (OV) Respirator Cartridge Testing - Potential Jonas Model Applicability. American Industrial Hygiene Association Journal 48:791-97 (1987).

${ }^{30}$ Wood, G.O. and E.S. Moyer: A Review of the Wheeler Equation and Comparison of Its Applications to Organic Vapor Respirator Cartridge Breakthrough Data. American Industrial Hygiene Association Journal 50:400-407(1989).

${ }^{31}$ Wood, G.O. and E.S. Moyer: A Review and Comparison of Adsorption Isotherm Equations Used to Correlate and Predict Organic Vapor Cartridge Capacities. American Industrial Hygiene Association Journal 52:235-242(1991).

32 Wood, G.O. and J.F. Stampfer: Adsorption Rate Coefficients for Gases and Vapors on Activated Carbons. Carbon 31:195-200 (1993).

${ }^{33}$ Wheeler, A. and A.J. Robell: Performance of Fixed-Bed Catalytic Reactors with Poison in the Feed. J. Catal. 13:299-305 (1969). 
${ }^{34}$ Jonas, L.A. and W.J. Svirbely: The Kinetics of Adsorption of Carbon Tetrachloride and Chloroform from Air Mixtures by Activated Carbon. J. Catal. 24:446-459 (1972).

${ }^{35}$ Wood, G.O.: Estimating Service Lives of Organic Vapor Cartridges. American Industrial Hygiene Association Journal 55(1):11-15 (1994).

${ }^{36}$ Yoon, Y.H. and J.H. Nelson: Effects of humidity and contaminant concentration on respirator cartridge breakthrough. American Industrial Hygiene Association Journal 51(4):202-209(1990).

${ }^{37}$ Weast, R.C. (ed.): CRC Handbook of Chemistry and Physics. Boca Raton, FL: CRC Press, Inc. (1984).

${ }^{38}$ Wood, G.O.: A model for adsorption capacities of charcoal beds: I. Relative humidity effects. American Industrial Hygiene Association Journal 48:622-625(1987).

39 Lewis, W.K., E.R. Gilliland, B. Chertow, and W.P. Cadagon: Adsorption equilibria: hydrocarbon gas mixtures. Ind. Eng. Chem 42:1319-1326 (1950).

${ }^{40}$ Grant, R.J. and M. Mares: Adsorption of binary hydrocarbon gas mixtures on activated carbon. Ind. Eng. Chem. Fund. 5:490-498 (1966).

${ }^{41}$ Myers, A.L. and J.M. Prausnitz: Thermodynamics of mixed-gas adsorption. Am. Inst. Chem. Eng. J. 11:121-127 (1965).

${ }^{42}$ Jonas, L.A. and E.B. Sansone: Prediction of activated carbon performance for sequential adsorbates. American Industrial Hygiene Association Journal 47:509-511 (1986).

${ }^{43}$ Yoon, Y.H., J.H. Nelson, J. Lara, C. Kamel, and D. Fregeau.: A Theoretical Interpretation of the Service Life of Respirator Cartridges for the Binary Acetone/m-Xylene System. American Industrial Hygiene Association Journal, 52(2):65-74 (1991).

${ }^{44}$ Yoon, Y.H., J.H. Nelson, J. Lara: Respirator Cartridge Service-Life: Exposure to Mixtures. American Industrial Hygiene Association Journal, 57:809-819 (1996).

45 Leahy, H.F.: AL/OE-TR-1994-0075, Overview of the Vapor Generation and Analysis Parameters of the Petroleum- and Shale-Derived Fuel Studies Conducted in Thomas Dome Exposure Chambers at the Toxic Hazards Research Unit, Wright-Patterson AFB (Dayton), Ohio 1973-1983. United States Air Force Materiel Command, Armstrong Laboratory, Dayton, $\mathrm{OH}$ (May 1994).

${ }^{46}$ Potts, W.J. and E.C. Steiner: An apparatus for generation of vapors from liquids of low volatility for use in inhalation toxicity studies. American Industrial Hygiene Association Journal, 41:141-145 (1980).

${ }^{47}$ SAS Institute, Inc: SAS OnlineDoc ${ }^{\circledR}$, Version 8. http:// sasdocs.ats.ucla.edu/ (accessed $15 \mathrm{Jul} 00$ ).

${ }^{48}$ Levene, H. (1960): "Robust Tests for the Equality of Variance," in Contributions to Probability and Statistics, ed. I. Olkin, Palo Alto, CA: Stanford University Press, 278 -292.

${ }^{49}$ Keppel, G.: Design \& Analysis - A Researcher's Handbook, $2^{\text {nd }}$ edition. Englewood Cliffs, NJ: Prentice-Hall, Inc. (1973). 


\title{
APPENDIX A
}

\author{
Measured breakthrough concentration on the \\ exit side of cartridges during tests.
}

The following tables list the time elapsed (in minutes) in the left-hand column and the measured concentration (in parts per million, or ppm) in the neighboring columns underneath each cartridge number. Cartridges are grouped by treatment. 
Table A-1. Breakthrough concentrations (in parts per million, or ppm) per test time (in minutes) for cartridges tested at $300 \mathrm{ppm}$ and 50 percent relative humidity, with no prior exposure to fuel vapor.

\begin{tabular}{|c|c|c|c|c|c|}
\hline TIME & 46 & 49 & 55 & 56 & 74 \\
\hline 1 & 8.3 & 5.2 & 4.5 & 1.6 & 2.2 \\
\hline 2 & 6 & 3.9 & 3.9 & 1.2 & 2 \\
\hline 3 & 4.7 & 3.1 & 3.4 & 1 & 1.9 \\
\hline 4 & 3.8 & 2.6 & 3.1 & 0.9 & 1.7 \\
\hline 5 & 3.2 & \begin{tabular}{|l|}
2.3 \\
\end{tabular} & 2.8 & 0.8 & 1.6 \\
\hline 6 & 2.7 & 2 & 2.6 & 0.7 & 1.5 \\
\hline 7 & 2.4 & 1.7 & 2.3 & 0.6 & 1.4 \\
\hline 8 & 2.1 & 1.6 & 2.2 & 0.6 & 1.3 \\
\hline 9 & 1.9 & 1.5 & 2 & 0.5 & 1.2 \\
\hline 10 & 1.7 & 1.3 & 1.9 & 0.5 & 1.1 \\
\hline 11 & 1.5 & \begin{tabular}{|l|}
1.2 \\
\end{tabular} & 1.8 & 0.5 & 1.1 \\
\hline 12 & 1.4 & \begin{tabular}{|l|}
1.2 \\
\end{tabular} & & 0.4 & 1 \\
\hline 13 & 1.3 & 1.1 & & 0.4 & 1 \\
\hline 14 & 1.2 & 1 & & 0.3 & 1 \\
\hline 15 & 1.1 & 1 & & 0.4 & 0.9 \\
\hline 16 & 1 & 1 & & 0.3 & 0.9 \\
\hline 17 & 1 & 0.9 & & 0.3 & 0.8 \\
\hline 18 & 0.9 & 0.9 & & 0.3 & 0.8 \\
\hline 19 & 0.9 & 0.9 & & 0.3 & 0.8 \\
\hline 20 & 0.8 & 0.8 & & 0.3 & 0.7 \\
\hline 21 & 0.8 & 0.8 & & 0.3 & 0.7 \\
\hline 22 & 0.8 & 0.8 & & 0.3 & 0.7 \\
\hline 23 & 0.7 & 0.8 & & 0.2 & 0.7 \\
\hline 24 & 0.7 & 0.7 & 2.5 & 0.2 & 0.6 \\
\hline 25 & 0.7 & 0.7 & 2.2 & 0.2 & 0.6 \\
\hline 26 & 0.7 & 0.7 & 2 & 0.2 & 0.6 \\
\hline 27 & 0.6 & 0.7 & 1.8 & 0.2 & 0.6 \\
\hline 28 & 0.6 & 0.7 & 1.7 & 0.2 & 0.6 \\
\hline 29 & 0.6 & 0.7 & 1.6 & 0.2 & 0.5 \\
\hline 30 & 0.6 & 0.7 & 1.5 & 0.2 & \\
\hline 31 & 0.5 & 0.7 & 1.4 & 0.2 & \\
\hline 32 & 0.5 & 0.6 & 1.4 & 0.1 & \\
\hline 33 & 0.5 & 0.6 & 1.3 & 0.2 & \\
\hline 34 & 0.5 & 0.6 & 1.2 & 0.1 & \\
\hline 35 & 0.5 & \begin{tabular}{|c|}
0.6 \\
\end{tabular} & 1.2 & 0.1 & \\
\hline 36 & 0.5 & 0.6 & 1.1 & 0.1 & \\
\hline 37 & 0.5 & 0.6 & 1.1 & 0.1 & \\
\hline 38 & 0.4 & 0.6 & 1.1 & 0.1 & \\
\hline 39 & 0.4 & 0.6 & 1 & 0.1 & \\
\hline 40 & 0.4 & 0.6 & 1 & 0.1 & \\
\hline 41 & & 0.6 & 1 & 0.1 & \\
\hline 42 & & 0.6 & 1 & 0.1 & \\
\hline 43 & & 0.6 & 0.9 & 0.1 & \\
\hline 44 & & 0.6 & 0.9 & 0.1 & \\
\hline 45 & & 0.6 & 0.9 & 0.1 & \\
\hline 46 & & 0.6 & 0.9 & 0.1 & \\
\hline
\end{tabular}

\begin{tabular}{|r|r|r|r|r|r|}
\hline TIME & 46 & \multicolumn{1}{|c|}{$\mathbf{4 9}$} & \multicolumn{1}{|c|}{5} & \multicolumn{1}{l|}{56} & $\mathbf{7 4}$ \\
\hline 47 & & 0.6 & 0.8 & 0.1 & \\
\hline 48 & & 0.5 & 0.8 & 0.1 & \\
\hline 49 & & 0.6 & 0.8 & 0.1 & \\
\hline 50 & & 0.5 & 0.8 & 0.1 & \\
\hline 51 & & 0.5 & 0.8 & 0.1 & \\
\hline 52 & & 0.5 & 0.8 & 0.1 & \\
\hline 53 & & 0.5 & 0.7 & 0.1 & \\
\hline 54 & & 0.5 & 0.7 & 0.1 & \\
\hline 55 & & 0.5 & 0.7 & 0.1 & \\
\hline 56 & & 0.5 & 0.7 & 0.1 & \\
\hline 57 & & 0.5 & 0.7 & 0.1 & \\
\hline 58 & & 0.5 & 0.7 & 0.1 & \\
\hline 59 & & & 0.7 & 0.1 & \\
\hline 60 & & & 0.7 & & \\
\hline 61 & & & 0.6 & & \\
\hline 62 & & & 0.6 & & 3.2 \\
\hline 63 & & & 0.6 & & 2.8 \\
\hline 64 & & & 0.6 & & 2.6 \\
\hline 65 & & & 0.6 & & 2.3 \\
\hline 66 & & & 0.6 & & 2.1 \\
\hline 67 & & & 0.6 & & 1.9 \\
\hline 68 & 0.8 & & 0.6 & & 1.8 \\
\hline 69 & 0.8 & & 0.6 & & 1.6 \\
\hline 70 & 0.7 & & 0.6 & & 1.5 \\
\hline 71 & 0.7 & & 0.6 & & 1.4 \\
\hline 72 & 0.7 & & 0.6 & & 1.3 \\
\hline 73 & 0.6 & 2 & & & 1.3 \\
\hline 74 & 0.6 & 1.7 & & & 1.2 \\
\hline 75 & 0.6 & 1.5 & & & 1.2 \\
\hline 76 & 0.5 & 1.4 & & & 1.1 \\
\hline 77 & 0.5 & 1.3 & & & 1 \\
\hline 78 & 0.5 & 1.2 & & 1.3 & 1 \\
\hline 79 & 0.5 & 1.1 & & 1.1 & 0.9 \\
\hline 80 & 0.5 & 1 & & 1 & 0.9 \\
\hline 81 & 0.5 & 0.9 & & 0.9 & 0.9 \\
\hline 82 & 0.5 & 0.9 & & 0.8 & 0.9 \\
\hline 83 & 0.4 & 0.9 & & 0.7 & 0.8 \\
\hline 84 & 0.4 & 0.8 & & 0.7 & 0.8 \\
\hline 85 & 0.4 & 0.8 & & 0.6 & 0.8 \\
\hline 86 & 0.4 & 0.8 & & 0.6 & 0.8 \\
\hline 87 & 0.4 & 0.8 & & 0.5 & 0.8 \\
\hline 88 & 0.4 & 0.7 & & 0.5 & 0.8 \\
\hline 89 & 0.4 & 0.7 & & 0.4 & 0.7 \\
\hline 90 & 0.4 & 0.7 & & 0.4 & 0.7 \\
\hline 91 & 0.4 & 0.7 & & 0.4 & 0.7 \\
\hline 92 & 0.4 & 0.7 & & 0.4 & 0.7 \\
\hline & & & & & \\
\hline
\end{tabular}

\begin{tabular}{|r|r|r|r|r|r|}
\hline TIME & \multicolumn{1}{|l}{$\mathbf{4 6}$} & \multicolumn{1}{|c|}{$\mathbf{4 9}$} & $\mathbf{5 5}$ & $\mathbf{5 6}$ & $\mathbf{7 4}$ \\
\hline 93 & 0.4 & 0.6 & & 0.4 & 0.7 \\
\hline 94 & 0.4 & 0.7 & & 0.4 & 0.7 \\
\hline 95 & 0.4 & 0.6 & & 0.4 & 0.7 \\
\hline 96 & 0.4 & 0.6 & & 0.3 & 0.7 \\
\hline 97 & 0.4 & 0.6 & & 0.3 & 0.7 \\
\hline 98 & 0.4 & 0.6 & & 0.3 & 0.7 \\
\hline 99 & 0.4 & 0.6 & 4.2 & 0.3 & 0.7 \\
\hline 100 & 0.4 & 0.6 & 3.6 & 0.3 & 0.7 \\
\hline 101 & 0.4 & 0.6 & 3.1 & 0.3 & 0.7 \\
\hline 102 & 0.4 & 0.6 & 2.7 & 0.3 & 0.7 \\
\hline 103 & 0.4 & 0.6 & 2.4 & 0.3 & 0.7 \\
\hline 104 & 0.4 & 0.6 & 2.2 & 0.3 & 0.7 \\
\hline 105 & 0.4 & 0.6 & 2 & 0.3 & 0.7 \\
\hline 106 & 0.4 & 0.6 & 1.9 & 0.3 & 0.7 \\
\hline 107 & 0.4 & 0.6 & 1.7 & 0.3 & 0.7 \\
\hline 108 & & 0.6 & 1.6 & 0.3 & 0.7 \\
\hline 109 & & 0.6 & 1.5 & 0.3 & 0.7 \\
\hline 110 & & 0.6 & 1.5 & 0.3 & 0.7 \\
\hline 111 & & 0.6 & 1.4 & 0.3 & 0.7 \\
\hline 112 & & 0.6 & 1.3 & 0.3 & 0.7 \\
\hline 113 & & 0.6 & 1.3 & 0.3 & \\
\hline 114 & & 0.6 & 1.2 & 0.3 & \\
\hline 115 & & 0.6 & 1.2 & 0.3 & \\
\hline 116 & & 0.6 & 1.2 & 0.3 & \\
\hline 117 & & 0.6 & 1.2 & 0.3 & \\
\hline 118 & & 0.6 & 1.1 & 0.3 & \\
\hline 119 & & 0.6 & 1.1 & 0.3 & \\
\hline 120 & & 0.6 & 1.1 & 0.4 & \\
\hline 121 & & 0.6 & 1.1 & 0.4 & \\
\hline 122 & & & 1.1 & 0.4 & \\
\hline 123 & & & 1.1 & 0.4 & \\
\hline 124 & & & 1 & 0.4 & \\
\hline 125 & 2.5 & & 1 & 0.4 & \\
\hline 126 & 2.1 & & 1 & 0.4 & \\
\hline 127 & 1.9 & & 1 & 0.4 & 3.3 \\
\hline 128 & 1.7 & & 1 & 0.4 & 2.9 \\
\hline 129 & 1.6 & & 1 & 0.5 & 2.6 \\
\hline 130 & 1.5 & & 1 & 0.5 & 2.4 \\
\hline 131 & 1.4 & & 1 & 0.5 & 2.2 \\
\hline 132 & 1.3 & & 1 & 0.5 & 2.1 \\
\hline 133 & 1.3 & & 1 & 0.5 & 2 \\
\hline 134 & 1.2 & & 1 & 0.5 & 1.9 \\
\hline 135 & 1.2 & & 1 & 0.5 & 1.9 \\
\hline 136 & 1.2 & & 1 & 0.6 & 1.8 \\
\hline 137 & 1.2 & & 1 & 0.6 & 1.8 \\
\hline 138 & 1.2 & & 1.1 & 0.6 & 1.8 \\
\hline & & & & & \\
\hline
\end{tabular}




\begin{tabular}{|c|c|c|c|c|c|}
\hline TIME & 46 & 49 & 55 & 56 & 74 \\
\hline 139 & 1.2 & 2.3 & 1.1 & & 1.8 \\
\hline 140 & 1.3 & 2.1 & 1.1 & & 1.8 \\
\hline 141 & 1.2 & 1.9 & 1.1 & & 1.8 \\
\hline 142 & 1.3 & 1.8 & 1.1 & & 1.8 \\
\hline 143 & 1.3 & 1.7 & 1.1 & & 1.8 \\
\hline 144 & 1.3 & 1.6 & 1.1 & & 1.8 \\
\hline 145 & 1.3 & 1.5 & 1.1 & & 1.9 \\
\hline 146 & 1.3 & 1.4 & 1.2 & & 1.9 \\
\hline 147 & 1.3 & 1.4 & 1.2 & & 1.9 \\
\hline 148 & 1.4 & 1.4 & 1.2 & & 1.9 \\
\hline 149 & 1.4 & 1.4 & 1.2 & & 1.9 \\
\hline 150 & 1.5 & 1.4 & 1.3 & & 2 \\
\hline 151 & 1.5 & 1.3 & 1.3 & & 2 \\
\hline 152 & 1.5 & 1.3 & 1.3 & & 2 \\
\hline 153 & 1.6 & 1.4 & 1.4 & & 2.1 \\
\hline 154 & 1.7 & 1.4 & 1.4 & & 2.1 \\
\hline 155 & 1.7 & 1.4 & 1.4 & & 2.1 \\
\hline 156 & 1.8 & 1.4 & 1.5 & & 2.2 \\
\hline 157 & 1.9 & 1.4 & 1.5 & 1.9 & 2.2 \\
\hline 158 & 1.9 & 1.5 & 1.5 & 1.8 & 2.3 \\
\hline 159 & 2 & 1.5 & 1.6 & 1.8 & 2.2 \\
\hline 160 & 2 & 1.5 & 1.6 & 1.7 & 2.3 \\
\hline 161 & 2.1 & 1.5 & 1.6 & 1.7 & 2.4 \\
\hline 162 & 2.2 & 1.6 & 1.7 & 1.8 & 2.4 \\
\hline 163 & 2.3 & $\overline{1.6}$ & 1.8 & 1.8 & 2.5 \\
\hline 164 & 2.3 & 1.6 & 1.8 & 1.8 & 2.5 \\
\hline 165 & 2.4 & 1.7 & 1.9 & 1.8 & 2.6 \\
\hline 166 & 2.5 & 1.7 & 1.9 & 1.8 & 2.7 \\
\hline 167 & 2.6 & 1.7 & 2 & 1.9 & 2.7 \\
\hline 168 & 2.7 & 1.8 & 2 & 2 & 2.8 \\
\hline 169 & 2.8 & 1.8 & 2.1 & 2 & 2.9 \\
\hline 170 & 2.9 & 1.9 & & 2.1 & 2.9 \\
\hline 171 & 3 & 1.9 & & 2.1 & 3 \\
\hline 172 & 3.2 & 2 & & 2.2 & 3 \\
\hline 173 & 3.3 & 2.1 & & 2.3 & 3.1 \\
\hline 174 & 3.5 & 2.1 & & 2.4 & 3.2 \\
\hline 175 & 3.6 & 2.2 & & 2.4 & \\
\hline 176 & 3.8 & 2.2 & & 2.5 & \\
\hline 177 & 4 & 2.3 & & 2.6 & \\
\hline 178 & 4.1 & 2.4 & & & \\
\hline 179 & 4.4 & 2.5 & & & \\
\hline 180 & 4.6 & 2.6 & & & \\
\hline 181 & 4.8 & 2.7 & & & \\
\hline 182 & 5 & 2.8 & & & \\
\hline 183 & 5.1 & 2.8 & 4.4 & & \\
\hline
\end{tabular}

\begin{tabular}{|c|c|c|c|c|c|}
\hline TIME & 46 & 49 & 55 & 56 & 74 \\
\hline 184 & 5.3 & 3 & 4.4 & & \\
\hline 185 & 5.6 & 3.1 & 4.5 & & \\
\hline 186 & 5.9 & 3.2 & 4.5 & & \\
\hline 187 & 6.2 & 3.3 & 4.7 & & \\
\hline 188 & 6.5 & 7.5 & 4.8 & & 6.7 \\
\hline 189 & 6.8 & 7.4 & 4.9 & & 6.4 \\
\hline 190 & 7.3 & 7.5 & 5.1 & & 6.3 \\
\hline 191 & 7.5 & 7.6 & 5.2 & & 6.2 \\
\hline 192 & 8 & 7.9 & 5.4 & & 6.2 \\
\hline 193 & 8.3 & 8.1 & 5.6 & & 6.2 \\
\hline 194 & 8.8 & 8.4 & 5.8 & & 6.3 \\
\hline 195 & 9.2 & 8.8 & 6.1 & & 6.4 \\
\hline 196 & 9.6 & 9.1 & 6.3 & & 6.5 \\
\hline 197 & 10 & 9.6 & 6.6 & & 6.6 \\
\hline 198 & 11 & 10 & 6.9 & & 6.8 \\
\hline 199 & 11 & 11 & 7 & & 6.9 \\
\hline 200 & 12 & 11 & 7.2 & & 7.1 \\
\hline 201 & 13 & 12 & 7.6 & 8.7 & 7.2 \\
\hline 202 & 13 & 12 & 7.9 & 8.4 & 7.4 \\
\hline 203 & 14 & 13 & 8.2 & 8.4 & 7.6 \\
\hline 204 & 15 & 14 & 8.6 & 8.4 & 7.8 \\
\hline 205 & 16 & 14 & 9 & 8.5 & 8 \\
\hline 206 & 16 & 15 & 9.5 & 8.6 & 8.2 \\
\hline 207 & & 16 & 9.8 & 8.9 & 8.4 \\
\hline 208 & & 17 & 10 & 9.2 & 8.7 \\
\hline 209 & & 18 & 11 & 9.4 & 9 \\
\hline 210 & & 19 & 11 & 9.9 & 9.1 \\
\hline 211 & & 20 & 12 & 10 & 9.4 \\
\hline 212 & & 21 & 12 & 11 & 9.7 \\
\hline 213 & & 22 & 13 & 11 & 10 \\
\hline 214 & & 23 & 14 & 12 & 10 \\
\hline 215 & & 25 & 14 & 12 & 11 \\
\hline 216 & & 26 & 15 & 13 & 11 \\
\hline 217 & & 27 & 16 & 14 & 12 \\
\hline 218 & 27 & 29 & 17 & 14 & 12 \\
\hline 219 & 28 & 31 & 18 & 15 & 12 \\
\hline 220 & 29 & 32 & 19 & 16 & 12 \\
\hline 221 & 30 & 34 & 20 & 17 & 13 \\
\hline 222 & 32 & 36 & 21 & 18 & 13 \\
\hline 223 & 34 & 38 & 22 & 19 & 14 \\
\hline 224 & 35 & 41 & 23 & 20 & 14 \\
\hline 225 & 38 & 43 & 24 & 21 & 14 \\
\hline 226 & 40 & 46 & 25 & 22 & 15 \\
\hline 227 & 42 & 49 & 27 & 23 & 16 \\
\hline 228 & 44 & 51 & 29 & 24 & 16 \\
\hline
\end{tabular}

\begin{tabular}{|r|r|r|r|r|r|}
\hline TIME & \multicolumn{1}{|c|}{$\mathbf{4 6}$} & $\mathbf{4 9}$ & $\mathbf{5 5}$ & $\mathbf{5 6}$ & $\mathbf{7 4}$ \\
\hline 229 & 46 & 55 & 30 & 25 & 17 \\
\hline 230 & 49 & 58 & 32 & 27 & 18 \\
\hline 231 & 52 & 61 & 34 & 29 & 18 \\
\hline 232 & 54 & & 35 & 30 & 19 \\
\hline 233 & 57 & & 37 & 32 & 20 \\
\hline 234 & 61 & & 40 & 34 & 20 \\
\hline 235 & & & 42 & 35 & 21 \\
\hline 236 & & & 44 & 38 & 22 \\
\hline 237 & & & 47 & 39 & 23 \\
\hline 238 & & & 49 & 42 & 24 \\
\hline 239 & & & 52 & 44 & 25 \\
\hline 240 & & & 55 & 47 & 26 \\
\hline 241 & & & 58 & 49 & 27 \\
\hline 242 & & & 61 & 52 & 28 \\
\hline 243 & & & 64 & 53 & 29 \\
\hline 244 & & & 67 & 56 & 31 \\
\hline 245 & & & 72 & 59 & 32 \\
\hline 246 & & & 76 & 63 & 33 \\
\hline 247 & & & & & 35 \\
\hline 248 & & & & & 37 \\
\hline 249 & & & & & 38 \\
\hline 250 & & & & & 40 \\
\hline 251 & & & & & 41 \\
\hline 252 & & & & & 43 \\
\hline 253 & & & & & 46 \\
\hline 254 & & & & & 48 \\
\hline 255 & & & & & 50 \\
\hline 256 & & & & & 52 \\
\hline 257 & & & & & 54 \\
\hline 258 & & & & & 57 \\
\hline 259 & & & & & 59 \\
\hline 260 & & & & & 61 \\
\hline & & & &
\end{tabular}


Table A-2. Breakthrough concentrations (in parts per million, or ppm) per test time (in minutes) for cartridges tested at $600 \mathrm{ppm}$ and 50 percent relative humidity, with no prior exposure to fuel vapor.

\begin{tabular}{|r|r|r|r|r|r|}
\hline TIME & \multicolumn{1}{|l}{31} & $\mathbf{3 2}$ & $\mathbf{4 4}$ & $\mathbf{6 3}$ & $\mathbf{8 4}$ \\
\hline 1 & 3.2 & 4 & 3.3 & 3.2 & 3.7 \\
\hline 2 & 2.9 & 3.4 & 2.9 & 2.9 & 3.4 \\
\hline 3 & 2.8 & 3 & 2.5 & 2.7 & 3.2 \\
\hline 4 & 2.6 & 2.7 & 2.2 & 2.6 & 3 \\
\hline 5 & 2.5 & 2.4 & 2 & 2.4 & 2.8 \\
\hline 6 & 2.4 & 2.2 & 1.8 & 2.3 & 2.7 \\
\hline 7 & 2.2 & 2.1 & 1.7 & 2.2 & 2.5 \\
\hline 8 & 2.1 & 1.9 & 1.6 & 2.1 & 2.4 \\
\hline 9 & 2 & 1.8 & 1.4 & 2 & 2.3 \\
\hline 10 & 1.9 & 1.7 & 1.3 & 1.9 & 2.2 \\
\hline 11 & 1.9 & 1.6 & 1.2 & 1.8 & 2.1 \\
\hline 12 & 1.8 & 1.4 & 1.2 & 1.7 & 2 \\
\hline 13 & 1.7 & 1.4 & 1.1 & 1.6 & 1.9 \\
\hline 14 & 1.7 & 1.3 & 1 & & 1.9 \\
\hline 15 & 1.6 & 1.2 & 1 & & 1.8 \\
\hline 16 & 1.5 & 1.2 & 0.9 & & 1.7 \\
\hline 17 & 1.5 & 1.1 & 0.9 & & 1.7 \\
\hline 18 & 1.5 & 1.1 & 0.8 & & 1.6 \\
\hline 19 & 1.4 & 1 & & & 1.6 \\
\hline 20 & 1.4 & 1 & & & 1.5 \\
\hline 21 & 1.3 & 1 & & & 1.4 \\
\hline 22 & 1.3 & 0.9 & & & 1.4 \\
\hline 23 & 1.2 & 0.9 & & & 1.4 \\
\hline 24 & 1.2 & 0.9 & & & 1.4 \\
\hline 25 & 1.2 & 0.8 & & & 1.3 \\
\hline 26 & 1.2 & 0.8 & & & 1.3 \\
\hline 27 & 1.1 & 0.8 & & & 1.2 \\
\hline 28 & 1.1 & 0.8 & & & 1.2 \\
\hline 29 & 1.1 & 0.8 & & & 1.2 \\
\hline 30 & 1.1 & 0.7 & & & 1.2 \\
\hline 31 & & 0.7 & & & 1.1 \\
\hline 32 & & 0.7 & & & 1.1 \\
\hline 33 & & 0.7 & & & 1.1 \\
\hline 34 & & 0.7 & & & 1.1 \\
\hline 35 & & 0.7 & & & 1 \\
\hline 36 & & 0.7 & & & 1 \\
\hline 37 & & 0.7 & & & 1 \\
\hline 38 & & 0.7 & & 2.2 & 1 \\
\hline 39 & & 0.7 & & 2.1 & 0.9 \\
\hline 40 & & 0.7 & & 1.9 & 0.9 \\
\hline 41 & & & 1.5 & 1.8 & \\
\hline 42 & & & 1.4 & 1.7 & \\
\hline 46 & & & 1.3 & 1.6 & \\
\hline & & & 1.3 & 1.6 & \\
\hline 43 & & 1.2 & 1.5 & \\
\hline
\end{tabular}

\begin{tabular}{|c|c|c|c|c|c|}
\hline TIME & 31 & 32 & 44 & 63 & 84 \\
\hline 47 & 5.7 & & 1.2 & 1.4 & \\
\hline 48 & 4.8 & & 1.2 & 1.4 & \\
\hline 49 & 4.2 & & 1.1 & 1.3 & \\
\hline 50 & 3.7 & & 1.1 & 1.3 & \\
\hline 51 & 3.3 & & 1.1 & 1.3 & \\
\hline 52 & 3 & & 1.1 & 1.3 & \\
\hline 53 & 2.7 & & 1.2 & 1.3 & \\
\hline 54 & 2.5 & & 1.2 & 1.3 & \\
\hline 55 & 2.4 & & 1.2 & 1.4 & \\
\hline 56 & 2.3 & 5.3 & 1.3 & 1.4 & \\
\hline 57 & 2.2 & 4.5 & 1.3 & 1.4 & \\
\hline 58 & 2.2 & 4.1 & 1.4 & 1.4 & \\
\hline 59 & 2.1 & 3.7 & 1.5 & 1.5 & \\
\hline 60 & 2.1 & 3.5 & 1.6 & 1.6 & \\
\hline 61 & 2.1 & 3.3 & 1.7 & 1.6 & \\
\hline 62 & 2.1 & 3.2 & 1.8 & 1.7 & \\
\hline 63 & 2.2 & 3.2 & 2 & 1.8 & \\
\hline 64 & 2.2 & 3.2 & 2.2 & 1.9 & \\
\hline 65 & 2.3 & 3.3 & 2.4 & 2.1 & \\
\hline 66 & 2.4 & 3.4 & 2.6 & 2.2 & \\
\hline 67 & 2.5 & 3.5 & 2.8 & 2.4 & 5.8 \\
\hline 68 & 2.7 & 3.7 & 3.1 & 2.6 & 5.5 \\
\hline 69 & 2.8 & 3.9 & 3.4 & 2.8 & 5.4 \\
\hline 70 & 3 & 4.2 & 3.7 & 3.1 & 5.4 \\
\hline 71 & 3.3 & 4.5 & 4.1 & 3.4 & 5.5 \\
\hline 72 & 3.5 & 4.8 & 4.6 & & 5.7 \\
\hline 73 & 3.8 & 5.2 & 5.1 & & 5.9 \\
\hline 74 & 4.2 & 5.6 & 5.6 & & 6.2 \\
\hline 75 & 4.5 & 6.1 & & & 6.6 \\
\hline 76 & 4.9 & 6.7 & & & 7.1 \\
\hline 77 & 5.4 & & & & 7.6 \\
\hline 78 & 6 & & & & 8.3 \\
\hline 79 & 6.5 & & & & 9.1 \\
\hline 80 & 7.1 & & & & 10 \\
\hline 81 & 7.8 & & & & 11 \\
\hline 82 & 8.6 & & & & 12 \\
\hline 83 & 9.7 & & & & 13 \\
\hline 84 & 11 & & & & 15 \\
\hline 85 & 12 & & & & 16 \\
\hline 86 & 13 & & & 18 & $\overline{18}$ \\
\hline 87 & 14 & 23 & & 19 & 19 \\
\hline 88 & 16 & 24 & & 20 & 21 \\
\hline 89 & 17 & 24 & & 21 & 22 \\
\hline 90 & & 26 & 34 & 22 & 24 \\
\hline 91 & & 27 & 35 & 23 & 26 \\
\hline 92 & & 28 & 36 & 24 & 27 \\
\hline
\end{tabular}

\begin{tabular}{|r|r|r|r|r|r|}
\hline TIME & $\mathbf{3 1}$ & \multicolumn{1}{|c|}{$\mathbf{3 2}$} & \multicolumn{1}{|c|}{$\mathbf{4 4}$} & \multicolumn{1}{|c|}{$\mathbf{8 3}$} & $\mathbf{8 4}$ \\
\hline 93 & & 30 & 38 & 26 & 29 \\
\hline 94 & & 31 & 39 & 27 & 31 \\
\hline 95 & & 33 & 41 & 29 & 32 \\
\hline 96 & & 34 & 43 & 30 & 34 \\
\hline 97 & & 36 & 44 & 32 & 36 \\
\hline 98 & & 38 & 46 & 34 & 38 \\
\hline 99 & & 40 & 48 & 36 & 39 \\
\hline 100 & & 42 & 50 & 38 & 41 \\
\hline 101 & 49 & 44 & 52 & 39 & 43 \\
\hline 102 & 50 & 46 & 54 & 41 & 45 \\
\hline 103 & 50 & 48 & 57 & 43 & 47 \\
\hline 104 & 52 & 50 & 59 & 45 & 48 \\
\hline 105 & 54 & 52 & 61 & 47 & 50 \\
\hline 106 & 56 & 54 & 64 & 49 & 52 \\
\hline 107 & 57 & 55 & 67 & 52 & 55 \\
\hline 108 & 60 & 57 & 69 & 54 & 57 \\
\hline 109 & 62 & 60 & 73 & 56 & 59 \\
\hline 110 & 65 & 63 & 76 & 58 & 62 \\
\hline 111 & 69 & 65 & 79 & 61 & 63 \\
\hline 112 & 72 & 69 & 82 & & 65 \\
\hline 113 & 75 & 72 & 85 & & 67 \\
\hline 114 & 78 & 75 & 88 & & 71 \\
\hline 115 & 81 & 78 & 92 & & 74 \\
\hline 116 & 85 & 81 & 96 & & 77 \\
\hline 117 & 89 & 85 & 100 & & 80 \\
\hline 118 & 93 & 89 & 103 & & 83 \\
\hline 119 & 97 & 92 & 107 & & 87 \\
\hline 120 & 101 & 96 & 109 & & 91 \\
\hline 121 & 105 & 100 & 112 & & 94 \\
\hline 122 & 110 & 104 & 115 & 93 & 98 \\
\hline 123 & 115 & 107 & 119 & 97 & 102 \\
\hline 124 & 120 & 112 & & 100 & 106 \\
\hline 125 & & 117 & & 105 & 110 \\
\hline 126 & & 122 & & 109 & 115 \\
\hline 127 & & & & 114 & 120 \\
\hline 128 & & & & 119 & \\
\hline 129 & & & & 124 & \\
\hline
\end{tabular}


Table A-3. Breakthrough concentrations (in parts per million, or ppm) per test time (in minutes) for cartridges tested at $1200 \mathrm{ppm}$ and 50 percent relative humidity, with no prior exposure to fuel vapor.

\begin{tabular}{|c|c|c|c|c|c|}
\hline TIME & 36 & 39 & 54 & 72 & 73 \\
\hline 1 & 4.7 & 4.6 & 3.6 & 4.3 & 3.8 \\
\hline 2 & 4.3 & 4.1 & 3.2 & 3.8 & 3.3 \\
\hline 3 & 4.1 & 3.7 & 2.9 & 3.4 & 3 \\
\hline 4 & 3.8 & 3.4 & 2.7 & 3 & 2.7 \\
\hline 5 & 3.6 & 3.1 & 2.4 & 2.8 & 2.4 \\
\hline 6 & 3.4 & 2.9 & 2.3 & 2.6 & 2.2 \\
\hline 7 & 3.3 & 2.7 & 2.1 & 2.4 & 2 \\
\hline 8 & 3.2 & 2.5 & 2 & 2.2 & 1.9 \\
\hline 9 & 3.1 & 2.4 & 1.9 & 2.1 & 1.7 \\
\hline 10 & 2.9 & 2.2 & 1.8 & 2 & 1.6 \\
\hline 11 & 2.8 & 2.1 & 1.7 & 1.8 & 1.5 \\
\hline 12 & 2.7 & 2 & 1.6 & 1.8 & 1.5 \\
\hline 13 & 2.6 & 1.9 & 1.5 & 1.7 & 1.4 \\
\hline 14 & 2.6 & 1.8 & 1.5 & & \\
\hline 15 & 2.5 & 1.7 & 1.5 & & \\
\hline 16 & 2.5 & 1.6 & 1.4 & & \\
\hline 17 & 2.5 & 1.6 & 1.4 & & \\
\hline 18 & 2.5 & 1.5 & 1.4 & & \\
\hline 19 & 2.4 & 1.4 & 1.4 & & \\
\hline 20 & 2.4 & 1.4 & 1.4 & & \\
\hline 21 & 2.4 & 1.4 & 1.4 & & \\
\hline 22 & 2.5 & 1.4 & 1.4 & & \\
\hline 23 & 2.5 & 1.4 & 1.4 & & \\
\hline 24 & 2.6 & 1.4 & & & \\
\hline 25 & 2.7 & 1.5 & & 4.2 & \\
\hline 26 & 2.7 & 1.6 & & 3.9 & \\
\hline 27 & 2.9 & 1.7 & & 3.7 & \\
\hline 28 & 3 & 1.9 & & 3.7 & \\
\hline 29 & 3.2 & 2.1 & & 3.7 & \\
\hline 30 & 3.4 & 2.4 & & 3.9 & \\
\hline 31 & 3.7 & 2.8 & & 4.2 & \\
\hline 32 & 4.1 & 3.3 & & 4.5 & \\
\hline 33 & 4.5 & 3.8 & & 5.1 & \\
\hline 34 & 4.9 & 4.6 & & 5.8 & \\
\hline 35 & 5.5 & 5.5 & & 6.6 & \\
\hline 36 & 6.2 & 6.6 & & 7.7 & 7.3 \\
\hline 37 & 7 & 7.7 & & 8.9 & 7.2 \\
\hline 38 & 7.9 & 9.1 & 11 & 10 & 7.4 \\
\hline 39 & 9 & 11 & 12 & 12 & 7.7 \\
\hline 40 & 10 & 13 & 12 & 15 & 8.3 \\
\hline 41 & 12 & 16 & 14 & 18 & 8.9 \\
\hline 42 & 14 & 20 & 15 & 21 & 9.7 \\
\hline 43 & 16 & 24 & 17 & 25 & 11 \\
\hline 44 & 19 & 29 & 19 & 30 & 12 \\
\hline 45 & 21 & 35 & 21 & 36 & 14 \\
\hline 46 & 25 & 42 & 24 & 43 & 16 \\
\hline
\end{tabular}

\begin{tabular}{|r|r|r|r|r|r|}
\hline TIME & \multicolumn{1}{|c|}{36} & \multicolumn{1}{|c|}{$\mathbf{3 9}$} & \multicolumn{1}{|c|}{$\mathbf{7 2}$} & \multicolumn{1}{|c|}{$\mathbf{7 3}$} \\
\hline 47 & 29 & 50 & 28 & 50 & 19 \\
\hline 48 & 33 & 59 & 33 & 60 & 21 \\
\hline 49 & 38 & 72 & 39 & 72 & 25 \\
\hline 50 & 45 & 86 & 44 & 85 & 29 \\
\hline 51 & 52 & 103 & 50 & 99 & 34 \\
\hline 52 & 58 & 121 & 61 & 114 & 39 \\
\hline 53 & 63 & 143 & 71 & 127 & 45 \\
\hline 54 & 71 & 163 & 79 & 143 & 52 \\
\hline 55 & 79 & 193 & 90 & 160 & 61 \\
\hline 56 & 89 & 218 & 102 & 178 & 70 \\
\hline 57 & 97 & 248 & 116 & 196 & 80 \\
\hline 58 & 106 & & 131 & 217 & 91 \\
\hline 59 & 120 & & 144 & 237 & 103 \\
\hline 60 & 133 & & 156 & 260 & 115 \\
\hline 61 & 149 & & 169 & & 127 \\
\hline 62 & 161 & & 183 & & 141 \\
\hline 63 & 175 & & 199 & & 155 \\
\hline 64 & 189 & & 215 & & 171 \\
\hline 65 & 205 & & 233 & & 186 \\
\hline 66 & 223 & & 248 & & 204 \\
\hline 67 & 244 & & & & 220 \\
\hline 68 & & & & & 239 \\
\hline 69 & & & & & 259 \\
\hline
\end{tabular}


Table A-4. Breakthrough concentrations (in parts per million, or ppm) per test time (in minutes) for cartridges tested at $300 \mathrm{ppm}$ and 80 percent relative humidity, with no prior exposure to fuel vapor.

\begin{tabular}{|c|c|c|c|c|c|}
\hline TIME & 35 & 47 & 48 & 64 & 65 \\
\hline 1 & 3.7 & 2.9 & 6.8 & 5.2 & 3.7 \\
\hline 2 & 3.4 & \begin{tabular}{|l|}
2.5 \\
\end{tabular} & 4.9 & \begin{tabular}{|l|}
4.6 \\
\end{tabular} & 3 \\
\hline 3 & 2.9 & \begin{tabular}{|l|}
2.2 \\
\end{tabular} & 3.8 & \begin{tabular}{|l|}
4.1 \\
\end{tabular} & 2.6 \\
\hline 4 & 2.6 & 1.9 & 3 & \begin{tabular}{|c|}
3.7 \\
\end{tabular} & 2.3 \\
\hline 5 & 2.3 & \begin{tabular}{|l|}
1.7 \\
\end{tabular} & 2.5 & \begin{tabular}{|l|}
3.4 \\
\end{tabular} & 2 \\
\hline 6 & 2.1 & \begin{tabular}{l|}
1.5 \\
\end{tabular} & 2.1 & \begin{tabular}{|l|}
3.1 \\
\end{tabular} & 1.8 \\
\hline 7 & 1.9 & \begin{tabular}{|l|}
1.3 \\
\end{tabular} & 1.8 & \begin{tabular}{|l|}
2.8 \\
\end{tabular} & 1.7 \\
\hline 8 & $\begin{array}{ll}1.7 \\
\end{array}$ & \begin{tabular}{|l|}
1.2 \\
\end{tabular} & 1.5 & \begin{tabular}{|l|}
2.7 \\
\end{tabular} & 1.5 \\
\hline 9 & 1.6 & 1.1 & 1.3 & 2.5 & 1.4 \\
\hline 10 & 1.5 & 1 & 1.2 & \begin{tabular}{|l|}
2.3 \\
\end{tabular} & 1.3 \\
\hline 11 & 1.4 & 0.9 & 1 & 2.2 & 1.2 \\
\hline 12 & 1.3 & 0.9 & 0.9 & \begin{tabular}{|l|}
2.1 \\
\end{tabular} & 1.1 \\
\hline 13 & 1.2 & 0.8 & 0.8 & 1.9 & 1 \\
\hline 14 & 1.1 & \begin{tabular}{|l|}
0.8 \\
\end{tabular} & 0.8 & 1.8 & 1 \\
\hline 15 & 1.1 & 0.7 & 0.7 & \begin{tabular}{|l|}
1.8 \\
\end{tabular} & 0.9 \\
\hline 16 & 1 & 0.7 & & 1.7 & 0.9 \\
\hline 17 & 1 & 0.6 & & \begin{tabular}{|l|}
1.6 \\
\end{tabular} & 0.8 \\
\hline 18 & 0.9 & 0.6 & & 1.5 & 0.8 \\
\hline 19 & 0.9 & \begin{tabular}{l|l}
0.6 \\
\end{tabular} & & & 0.7 \\
\hline 20 & 0.9 & 0.5 & & & 0.7 \\
\hline 21 & 0.8 & \begin{tabular}{l|}
0.5 \\
\end{tabular} & & & \\
\hline 22 & 0.8 & 0.5 & & & \\
\hline 23 & 0.8 & 0.4 & & & \\
\hline 24 & 0.7 & 0.4 & & & \\
\hline 25 & $\begin{array}{l}0.7 \\
\end{array}$ & 0.4 & & & \\
\hline 26 & 0.7 & 0.4 & & & \\
\hline 27 & 0.6 & 0.4 & & & \\
\hline 28 & 0.6 & 0.4 & & & \\
\hline 29 & 0.6 & 0.4 & & & \\
\hline 30 & 0.6 & 0.4 & & & \\
\hline 31 & & 0.4 & & & \\
\hline 32 & & 0.4 & 2.7 & & \\
\hline 33 & & 0.4 & 2.2 & & \\
\hline 34 & & \begin{tabular}{|c|}
0.4 \\
\end{tabular} & 1.9 & & \\
\hline 35 & & 0.4 & 1.6 & & \\
\hline 36 & & 0.4 & 1.5 & & \\
\hline 37 & & 0.4 & 1.3 & & \\
\hline 38 & & \begin{tabular}{l|l}
0.4 \\
\end{tabular} & 1.2 & & \\
\hline 39 & & 0.4 & 1.1 & & \\
\hline 40 & & 0.4 & 1 & & \\
\hline 41 & & 0.4 & 0.9 & & \\
\hline 42 & & 0.4 & 0.9 & & \\
\hline 43 & & 0.4 & 0.8 & & \\
\hline 44 & & 0.4 & 0.8 & \begin{tabular}{|l|}
2.7 \\
\end{tabular} & \\
\hline 45 & & 0.4 & 0.7 & 2.4 & \\
\hline 46 & & \begin{tabular}{|l|}
0.4 \\
\end{tabular} & 0.7 & 2.2 & \\
\hline
\end{tabular}

\begin{tabular}{|r|r|r|r|r|r|}
\hline TIME & $\mathbf{3 5}$ & \multicolumn{1}{|c|}{$\mathbf{7 7}$} & \multicolumn{1}{|c|}{} & \multicolumn{1}{|c|}{$\mathbf{6 4}$} & $\mathbf{6 5}$ \\
\hline 47 & & 0.5 & 0.7 & 2.1 & \\
\hline 48 & & 0.5 & 0.7 & 2 & \\
\hline 49 & 1.4 & 0.5 & 0.7 & 1.9 & \\
\hline 50 & 1.3 & 0.6 & 0.7 & 1.8 & 2 \\
\hline 51 & 1.2 & 0.6 & 0.7 & 1.7 & 1.8 \\
\hline 52 & 1.2 & 0.7 & 0.7 & 1.7 & 1.7 \\
\hline 53 & 1.1 & 0.7 & 0.7 & 1.7 & 1.6 \\
\hline 54 & 1 & 0.8 & 0.7 & 1.6 & 1.6 \\
\hline 55 & 1.1 & 0.8 & 0.8 & 1.6 & 1.5 \\
\hline 56 & 1 & 0.9 & 0.8 & 1.6 & 1.5 \\
\hline 57 & 1 & 1 & 0.8 & 1.6 & 1.5 \\
\hline 58 & 1 & 1.1 & 0.9 & 1.6 & 1.5 \\
\hline 59 & 1 & 1.2 & 0.9 & 1.7 & 1.5 \\
\hline 60 & 1.1 & 1.3 & 1 & 1.7 & 1.6 \\
\hline 61 & 1.1 & & 1 & 1.8 & 1.7 \\
\hline 62 & 1.1 & & 1.1 & 1.9 & 1.8 \\
\hline 63 & 1.2 & & 1.2 & 2 & 1.9 \\
\hline 64 & 1.2 & & 1.3 & 2.1 & 2 \\
\hline 65 & 1.2 & & 1.4 & 2.2 & 2.1 \\
\hline 66 & 1.3 & & 1.5 & 2.3 & 2.3 \\
\hline 67 & 1.4 & & 1.7 & 2.5 & 2.5 \\
\hline 68 & 1.5 & & 1.8 & 2.6 & 2.6 \\
\hline 69 & 1.6 & & 2 & 2.8 & 2.9 \\
\hline 70 & 1.7 & & 2.2 & 3.1 & 3.1 \\
\hline 71 & 1.9 & & 2.4 & 3.3 & 3.4 \\
\hline 72 & 2 & & 2.6 & 3.6 & 3.7 \\
\hline 73 & 2.2 & & 2.8 & 3.9 & 4 \\
\hline 74 & 2.4 & 7.1 & 3.1 & 4.2 & 4.3 \\
\hline 75 & 2.5 & 7.2 & 3.4 & 4.6 & 4.7 \\
\hline 76 & 2.8 & 7.3 & 3.8 & 5 & 5.1 \\
\hline 77 & 3.1 & 7.6 & 4.2 & 5.4 & 5.6 \\
\hline 78 & 3.3 & 7.9 & 4.6 & 5.8 & 6 \\
\hline 79 & 3.7 & 8.3 & 5.1 & 6.3 & 6.5 \\
\hline 80 & 4 & 8.7 & 5.6 & 6.7 & 6.9 \\
\hline 81 & 4.4 & 9.1 & 6.1 & 6.9 & 7.2 \\
\hline 82 & 4.8 & 9.4 & 6.7 & 7.2 & 7.5 \\
\hline 83 & 5.7 & 9.8 & 7.3 & 7.7 & 7.9 \\
\hline 84 & 6 & 10 & 8 & 8 & 8.3 \\
\hline 85 & 6.5 & 11 & 8.7 & 8.4 & 8.6 \\
\hline 86 & 6.9 & 11 & 9.4 & 8.7 & 8.9 \\
\hline 87 & 7.4 & 11 & 10 & 9.1 & 9.2 \\
\hline 88 & 8 & 12 & 11 & 9.3 & 9.5 \\
\hline 89 & 8.7 & 12 & 11 & 9.6 & 9.8 \\
\hline 90 & & 12 & 12 & 9.9 & 10 \\
\hline 91 & & 13 & 12 & 10 & 10 \\
\hline 92 & & 13 & 13 & 11 & 11 \\
\hline & & & & \\
\hline
\end{tabular}

\begin{tabular}{|r|r|r|r|r|r|}
\hline TIME & 35 & $\mathbf{4 7}$ & $\mathbf{4 8}$ & $\mathbf{6 4}$ & $\mathbf{6 5}$ \\
\hline 93 & & 13 & 13 & 11 & 11 \\
\hline 94 & & 13 & 13 & 11 & 11 \\
\hline 95 & & 14 & 14 & 11 & 12 \\
\hline 96 & & 14 & 14 & 12 & 12 \\
\hline 97 & & 15 & 14 & 12 & 12 \\
\hline 98 & & 15 & 15 & 12 & 13 \\
\hline 99 & & 15 & 15 & 13 & 13 \\
\hline 100 & & 16 & 15 & 13 & 13 \\
\hline 101 & & 16 & 16 & 13 & 14 \\
\hline 102 & & 16 & & 14 & 14 \\
\hline 103 & & 17 & & 14 & 14 \\
\hline 104 & & 17 & & 14 & 15 \\
\hline 105 & & 17 & & 14 & 15 \\
\hline 106 & 19 & 18 & & 15 & 15 \\
\hline 107 & 18 & 18 & & & \\
\hline 108 & 18 & 19 & & & \\
\hline 109 & 18 & 19 & & & \\
\hline 110 & 19 & 19 & & & \\
\hline 111 & 19 & 20 & & & \\
\hline 112 & 19 & 20 & & & \\
\hline 113 & 19 & 21 & & & \\
\hline 114 & 19 & 21 & & & \\
\hline 115 & 20 & & & & \\
\hline 116 & 20 & & & & \\
\hline 117 & 20 & & & & \\
\hline 118 & 21 & & & & \\
\hline 119 & 21 & & & & \\
\hline 120 & 22 & & 25 & & \\
\hline 121 & 22 & & 24 & & 23 \\
\hline 122 & 23 & & 25 & & 23 \\
\hline 123 & 23 & & 25 & & 23 \\
\hline 124 & 23 & & 25 & 25 & 23 \\
\hline 125 & 25 & & 25 & 24 & 23 \\
\hline 126 & 26 & & 26 & 24 & 23 \\
\hline 127 & 27 & & 26 & 24 & 23 \\
\hline 128 & 29 & 29 & 26 & 24 & 24 \\
\hline 129 & 29 & 28 & 27 & 24 & 24 \\
\hline 130 & 29 & 28 & 27 & 24 & 24 \\
\hline 131 & 30 & 28 & 27 & 24 & 25 \\
\hline 132 & 29 & 28 & 28 & 24 & 25 \\
\hline 133 & 29 & 28 & 28 & 25 & 25 \\
\hline 134 & 30 & 28 & 29 & 25 & 26 \\
\hline 135 & 30 & 29 & 29 & 25 & 26 \\
\hline 136 & 30 & 29 & 29 & 25 & 27 \\
\hline 137 & 31 & 30 & 30 & 26 & 27 \\
\hline 138 & 31 & 30 & 30 & 26 & 27 \\
\hline & & & & \\
\hline
\end{tabular}




\begin{tabular}{|r|r|r|r|r|r|}
\hline TIME & \multicolumn{1}{|r|}{35} & 47 & \multicolumn{1}{|c|}{48} & 64 & 65 \\
\hline 139 & 31 & 30 & 31 & 26 & 28 \\
\hline 140 & 32 & 30 & 31 & 27 & 28 \\
\hline 141 & 32 & 31 & 32 & 27 & 29 \\
\hline 142 & 33 & 31 & 32 & 28 & 29 \\
\hline 143 & 33 & 32 & 33 & 28 & 30 \\
\hline 144 & 34 & 32 & 33 & 28 & 30 \\
\hline 145 & 34 & 32 & 34 & 29 & \\
\hline 146 & 35 & 33 & 34 & 29 & \\
\hline 147 & 35 & 33 & 34 & 29 & \\
\hline 148 & 35 & 33 & 35 & 30 & \\
\hline 149 & 36 & 34 & 35 & 30 & \\
\hline 150 & 36 & 34 & 36 & 30 & \\
\hline 151 & 36 & 34 & 36 & 31 & \\
\hline 152 & & 35 & 37 & 31 & \\
\hline 153 & & 35 & 37 & 32 & \\
\hline 154 & & 36 & 38 & 32 & \\
\hline 155 & & 36 & 38 & 32 & 38 \\
\hline 156 & & 37 & 39 & 33 & 37 \\
\hline 157 & & 37 & 39 & 33 & 36 \\
\hline 158 & & 38 & 40 & 34 & 37 \\
\hline 159 & & 38 & 40 & 34 & 37 \\
\hline 160 & & 39 & 41 & 34 & 37 \\
\hline 161 & & 39 & 41 & & 38 \\
\hline 162 & & 39 & 42 & & 38 \\
\hline 163 & & 40 & 42 & & 39 \\
\hline 164 & & 40 & 43 & & 39 \\
\hline 165 & & 41 & 43 & & 39 \\
\hline 166 & 48 & 41 & 44 & & 40 \\
\hline 167 & 52 & 41 & 45 & & 40 \\
\hline 168 & 51 & 42 & 45 & & 41 \\
\hline 169 & 52 & 43 & 45 & & 41 \\
\hline 170 & 51 & 43 & 46 & & 41 \\
\hline 171 & 52 & 43 & 46 & & 42 \\
\hline 172 & 52 & 43 & 47 & & 42 \\
\hline 173 & 53 & 43 & 48 & & 43 \\
\hline 174 & 52 & 43 & 48 & & 43 \\
\hline 175 & 51 & 43 & 48 & & 44 \\
\hline 176 & 51 & 44 & & 40 & 44 \\
\hline 177 & 50 & 44 & & 41 & 45 \\
\hline 178 & 51 & 45 & & 41 & 45 \\
\hline 179 & 52 & 45 & & 41 & 46 \\
\hline 180 & 52 & 46 & & 42 & 46 \\
\hline 181 & 52 & 46 & & 42 & 47 \\
\hline 183 & 53 & 47 & & 43 & 47 \\
\hline 184 & 54 & 48 & & 44 & 48 \\
\hline
\end{tabular}

\begin{tabular}{|r|r|r|r|r|r|}
\hline TIME & \multicolumn{1}{|l|}{$\mathbf{5 5}$} & $\mathbf{4 7}$ & $\mathbf{4 8}$ & \multicolumn{1}{|c|}{$\mathbf{6 4}$} & \multicolumn{1}{|c|}{} \\
\hline 185 & 54 & 49 & & 44 & 49 \\
\hline 186 & 56 & 49 & & 45 & 49 \\
\hline 187 & 57 & 50 & & 45 & 50 \\
\hline 188 & 58 & 50 & 57 & 46 & 50 \\
\hline 189 & 58 & 51 & 58 & 46 & 51 \\
\hline 190 & 58 & 51 & 59 & 47 & 51 \\
\hline 191 & & 52 & 59 & 48 & 52 \\
\hline 192 & & 53 & 60 & 48 & 52 \\
\hline 193 & & 53 & 60 & 49 & 53 \\
\hline 194 & & 54 & & 49 & 53 \\
\hline 195 & & 54 & & 50 & 53 \\
\hline 196 & & 55 & & 50 & 54 \\
\hline 197 & & 56 & & 51 & 55 \\
\hline 198 & & 57 & & 51 & 53 \\
\hline 199 & & 58 & & 51 & 54 \\
\hline 200 & & 58 & & 51 & 54 \\
\hline 201 & & 58 & & 51 & 55 \\
\hline 202 & & 59 & & 52 & 55 \\
\hline 203 & & 60 & & 53 & 56 \\
\hline 204 & & 60 & & 53 & 57 \\
\hline 205 & & & & 54 & 58 \\
\hline 206 & & & & 55 & 58 \\
\hline 207 & & & & 55 & 59 \\
\hline 208 & & & & 56 & 59 \\
\hline 209 & & & & 56 & 60 \\
\hline 210 & & & & 57 & 60 \\
\hline 211 & & & & 58 & \\
\hline 212 & & & & 58 & \\
\hline 213 & & & & 59 & \\
\hline 214 & & & & 60 & \\
\hline 215 & & & & 61 & \\
\hline
\end{tabular}


Table A-5. Breakthrough concentrations (in parts per million, or ppm) per test time (in minutes) for cartridges tested at $600 \mathrm{ppm}$ and 80 percent relative humidity, with no prior exposure to fuel vapor.

\begin{tabular}{|r|r|r|r|r|r|}
\hline TIME & \multicolumn{1}{|c|}{$\mathbf{4 4}$} & \multicolumn{1}{|c|}{} & $\mathbf{6 2}$ & $\mathbf{7 0}$ & $\mathbf{8 0}$ \\
\hline 1 & 0.2 & 1 & 3.3 & 3.4 & 3.5 \\
\hline 2 & 0.1 & 0.9 & 2.9 & 3 & 3.1 \\
\hline 3 & 0.1 & 0.9 & 2.5 & 2.8 & 2.8 \\
\hline 4 & 0 & 0.8 & 2.2 & 2.5 & 2.5 \\
\hline 5 & 0 & 0.7 & 2 & 2.3 & 2.3 \\
\hline 6 & -0.1 & 0.7 & 1.8 & 2.2 & 2.1 \\
\hline 7 & -0.1 & 0.7 & 1.6 & 2 & 1.9 \\
\hline 8 & -0.1 & 0.6 & 1.5 & 1.9 & 1.8 \\
\hline 9 & -0.1 & 0.6 & 1.4 & 1.8 & 1.7 \\
\hline 10 & -0.1 & 0.6 & 1.3 & 1.7 & 1.5 \\
\hline 11 & -0.2 & 0.5 & 1.2 & 1.6 & 1.4 \\
\hline 12 & -0.2 & 0.5 & 1.1 & 1.5 & 1.4 \\
\hline 13 & -0.2 & 0.5 & & 1.4 & 1.3 \\
\hline 14 & -0.2 & 0.5 & & 1.4 & 1.2 \\
\hline 15 & -0.2 & 0.4 & & 1.3 & 1.1 \\
\hline 16 & & 0.5 & & 1.2 & 1.1 \\
\hline 17 & & 0.4 & & 1.2 & 1 \\
\hline 18 & & 0.4 & & 1.2 & 1 \\
\hline 19 & & 0.4 & & 1.1 & 1 \\
\hline 20 & & 0.4 & & 1.1 & 0.9 \\
\hline 21 & & 0.4 & & 1.1 & \\
\hline 22 & & 0.4 & & 1 & \\
\hline 23 & & 0.4 & & 1 & \\
\hline 24 & & 0.5 & & 1 & \\
\hline 25 & & 0.5 & & 1 & \\
\hline 26 & & 0.5 & & 1 & \\
\hline 27 & & 0.5 & & 1 & \\
\hline 28 & & 0.5 & & 1 & \\
\hline 29 & & 0.6 & 4.4 & 1 & \\
\hline 30 & & 0.6 & 3.7 & 1.1 & \\
\hline 31 & 1.7 & 0.6 & 3.3 & 1.1 & \\
\hline 32 & 1.4 & 0.6 & 2.9 & 1.1 & \\
\hline 33 & 1.2 & 0.7 & 2.6 & 1.2 & \\
\hline 34 & 1 & 0.7 & 2.4 & 1.2 & \\
\hline 35 & 0.8 & 0.8 & 2.2 & 1.3 & \\
\hline 36 & 0.7 & 0.9 & 2.1 & 1.4 & \\
\hline 37 & 0.6 & 1 & 2 & 1.5 & \\
\hline 38 & 0.6 & 1.1 & 1.9 & 1.7 & \\
\hline 39 & 0.5 & 1.2 & 1.9 & 1.9 & \\
\hline 40 & 0.5 & 1.3 & 1.9 & 2.1 & \\
\hline 41 & 0.5 & & 1.9 & 2.3 & \\
\hline 42 & 0.5 & & 2 & 2.5 & \\
\hline 43 & 0.5 & & 2.1 & 2.8 & \\
\hline 44 & 0.6 & & 2.2 & 3.2 & \\
\hline 45 & 0.6 & & 2.3 & 3.6 & \\
\hline 46 & & & 2.5 & 3.9 & \\
\hline
\end{tabular}

\begin{tabular}{|r|r|r|r|r|r|}
\hline TIME & $\mathbf{3 4}$ & \multicolumn{1}{|c|}{$\mathbf{5 5}$} & \multicolumn{1}{|c|}{} & \multicolumn{1}{|c|}{} & $\mathbf{8 0}$ \\
\hline 47 & & & 2.7 & 4.3 & 4.9 \\
\hline 48 & & & 2.9 & 4.8 & 4.6 \\
\hline 49 & & & 3.2 & 5.4 & 4.3 \\
\hline 50 & & & 3.5 & 6.4 & 4.1 \\
\hline 51 & & & 3.9 & 6.9 & 4 \\
\hline 52 & & & 4.4 & 7.7 & 4 \\
\hline 53 & & & 4.9 & 8.8 & 4 \\
\hline 54 & & & 5.3 & 9.6 & 4.1 \\
\hline 55 & & & 6.1 & 11 & 4.4 \\
\hline 56 & & 13 & 6.9 & 12 & 4.6 \\
\hline 57 & & 14 & 7.7 & 14 & 4.9 \\
\hline 58 & & 15 & 8.8 & 14 & 5.2 \\
\hline 59 & & 16 & 9.8 & 16 & 5.6 \\
\hline 60 & 8.4 & 17 & 11 & 17 & 6.2 \\
\hline 61 & 8.3 & 19 & 12 & 19 & 6.8 \\
\hline 62 & 8.6 & 20 & 13 & 20 & 7.3 \\
\hline 63 & 9 & 22 & 14 & 22 & 8.1 \\
\hline 64 & 9.6 & 25 & 16 & 24 & 8.9 \\
\hline 65 & 10 & 27 & 17 & 24 & 9.9 \\
\hline 66 & 11 & 29 & 19 & 26 & 11 \\
\hline 67 & 13 & 31 & 21 & 27 & 12 \\
\hline 68 & 14 & 32 & 22 & 29 & 14 \\
\hline 69 & 16 & 34 & 24 & 30 & 15 \\
\hline 70 & 18 & 36 & 26 & 31 & 17 \\
\hline 71 & 20 & 38 & 28 & 32 & 19 \\
\hline 72 & 21 & 39 & 30 & 33 & 20 \\
\hline 73 & 24 & 41 & & & 22 \\
\hline 74 & 26 & 42 & & & 24 \\
\hline 75 & 27 & 44 & & & 25 \\
\hline 76 & 30 & 45 & & & 27 \\
\hline 77 & 31 & 47 & & & 28 \\
\hline 78 & 33 & 48 & & & 30 \\
\hline 79 & 36 & 50 & & & 31 \\
\hline 80 & 37 & 52 & & & 33 \\
\hline 81 & 39 & 53 & & & 34 \\
\hline 82 & 40 & 55 & & & 36 \\
\hline 83 & 42 & 56 & & & 37 \\
\hline 84 & 44 & 58 & & & 38 \\
\hline 85 & 45 & 60 & & 53 & 40 \\
\hline 86 & 47 & 61 & & 54 & 41 \\
\hline 87 & 48 & 63 & & 55 & 43 \\
\hline 88 & 50 & 65 & & 57 & 44 \\
\hline 89 & 52 & 67 & 56 & 59 & 46 \\
\hline 90 & 54 & 70 & 56 & 61 & 47 \\
\hline 91 & 56 & 72 & 58 & 62 & 49 \\
\hline 92 & 60 & 74 & 59 & 64 & 50 \\
\hline & & & & \\
\hline 52
\end{tabular}

\begin{tabular}{|r|r|r|r|r|r|}
\hline TIME & $\mathbf{3 4}$ & \multicolumn{1}{|c|}{$\mathbf{6 5}$} & \multicolumn{6}{|c|}{} & \multicolumn{1}{|c|}{$\mathbf{8 0}$} & \multicolumn{1}{|c|}{} \\
\hline 93 & 65 & 76 & 60 & 65 & 52 \\
\hline 94 & 70 & 78 & 62 & 67 & 54 \\
\hline 95 & 71 & 80 & 63 & 70 & 56 \\
\hline 96 & 72 & 82 & 65 & 73 & 58 \\
\hline 97 & 74 & 84 & 67 & 75 & 60 \\
\hline 98 & 75 & 87 & 68 & 77 & 90 \\
\hline 99 & 75 & 89 & 70 & 79 & 92 \\
\hline 100 & 77 & 90 & 73 & 82 & 95 \\
\hline 101 & 78 & 93 & 75 & 84 & 98 \\
\hline 102 & 81 & 96 & 75 & 87 & 101 \\
\hline 103 & 82 & 99 & 78 & 90 & 105 \\
\hline 104 & 84 & 102 & 79 & 93 & 108 \\
\hline 105 & 86 & 105 & 82 & 95 & 112 \\
\hline 106 & 89 & 109 & 85 & 99 & 115 \\
\hline 107 & 92 & 112 & 87 & 102 & 119 \\
\hline 108 & 94 & 116 & 90 & 106 & 122 \\
\hline 109 & 97 & 120 & 93 & 109 & \\
\hline 110 & 100 & & 97 & 112 & \\
\hline 111 & 103 & & 100 & 116 & \\
\hline 112 & 106 & & 102 & 120 & \\
\hline 113 & 109 & & 106 & & \\
\hline 114 & 112 & & 109 & & \\
\hline 115 & 115 & & 113 & & \\
\hline 116 & 119 & & 116 & & \\
\hline 117 & & & 119 & & \\
\hline & & & & \\
\hline
\end{tabular}


Table A-6. Breakthrough concentrations (in parts per million, or ppm) per test time (in minutes) for cartridges tested at $1200 \mathrm{ppm}$ and 80 percent relative humidity, with no prior exposure to fuel vapor.

\begin{tabular}{|c|c|c|c|c|c|}
\hline TIME & 37 & 38 & 71 & 81 & 82 \\
\hline 1 & 4.4 & 4.8 & 4.1 & 3.7 & 2.2 \\
\hline 2 & 4.1 & 4.4 & 7.1 & 3.3 & 2.1 \\
\hline 3 & 3.8 & 4 & 5.1 & 3 & 1.9 \\
\hline 4 & 3.5 & 3.6 & 4.6 & 2.7 & 1.7 \\
\hline 5 & 3.3 & 3.4 & 4.2 & 2.4 & 1.6 \\
\hline 6 & 3.1 & 3.1 & 3.9 & 2.3 & 1.5 \\
\hline 7 & 2.9 & 2.9 & 3.6 & 2.1 & 1.4 \\
\hline 8 & 2.8 & 2.7 & 3.4 & 2 & 1.3 \\
\hline 9 & 2.6 & 2.6 & 3.3 & 1.8 & 1.2 \\
\hline 10 & 2.5 & 2.5 & 3.1 & 1.7 & 1.1 \\
\hline 11 & 2.5 & 2.4 & 3 & & 1.1 \\
\hline 12 & 2.4 & 2.3 & 2.9 & & 1.1 \\
\hline 13 & 2.4 & 2.2 & 2.8 & & 1 \\
\hline 14 & 2.3 & 2.1 & 2.7 & & 1 \\
\hline 15 & 2.3 & 2.1 & & & 1 \\
\hline 16 & 2.4 & 2 & & & 1 \\
\hline 17 & 2.4 & 2 & & & 1 \\
\hline 18 & 2.5 & 1.9 & & & 1 \\
\hline 19 & 2.5 & 1.9 & & & 1.1 \\
\hline 20 & 2.5 & 1.9 & & & 1.1 \\
\hline 21 & 2.6 & 1.9 & & & 1.2 \\
\hline 22 & 2.7 & 1.9 & & & 1.4 \\
\hline 23 & 3 & 1.9 & & & 1.5 \\
\hline 24 & 3.1 & 1.9 & & & 1.7 \\
\hline 25 & 3.3 & 2 & & & 2 \\
\hline 26 & 3.7 & 2 & & & 2.3 \\
\hline 27 & 4.3 & 2.1 & & & 2.7 \\
\hline 28 & 4.9 & 2.1 & & & 3.1 \\
\hline 29 & 5.6 & 2.3 & 9.4 & 8.4 & 3.7 \\
\hline 30 & 6.5 & 2.5 & 10 & 8.6 & 4.4 \\
\hline 31 & 7.6 & 2.7 & 11 & 9.1 & 5.2 \\
\hline 32 & 8.7 & 3 & 13 & 9.7 & 6.1 \\
\hline 33 & 10 & 3.3 & 15 & 11 & 7.2 \\
\hline 34 & 11 & 3.7 & 17 & 12 & 8.7 \\
\hline 35 & 13 & 4.2 & 20 & 14 & 11 \\
\hline 36 & 16 & 4.8 & 24 & 17 & 13 \\
\hline 37 & 19 & 5.6 & 28 & 20 & 15 \\
\hline 38 & 21 & 6.4 & 33 & 23 & 18 \\
\hline 39 & 24 & 7.3 & 40 & 27 & 22 \\
\hline 40 & 29 & 8.3 & 48 & 32 & 27 \\
\hline 41 & 33 & 9.9 & 54 & 38 & 33 \\
\hline 42 & 39 & 12 & 61 & 44 & 39 \\
\hline 43 & 44 & 14 & 72 & 52 & 47 \\
\hline 44 & 50 & 16 & 80 & 62 & 54 \\
\hline 45 & 56 & 20 & 90 & 74 & 62 \\
\hline 46 & 66 & 24 & 103 & 85 & 73 \\
\hline
\end{tabular}

\begin{tabular}{|r|r|r|r|r|r|}
\hline TIME & \multicolumn{1}{|c|}{$\mathbf{3 7}$} & \multicolumn{1}{|c|}{$\mathbf{3 8}$} & $\mathbf{7 1}$ & $\mathbf{8 1}$ & $\mathbf{8 2}$ \\
\hline 47 & 74 & 28 & 116 & 96 & 83 \\
\hline 48 & 83 & 33 & 128 & 109 & 95 \\
\hline 49 & 93 & 39 & 140 & 120 & 107 \\
\hline 50 & 103 & 46 & 153 & 135 & 119 \\
\hline 51 & 118 & 54 & 168 & 149 & 134 \\
\hline 52 & 128 & 66 & 183 & 164 & 148 \\
\hline 53 & 145 & 75 & 199 & 180 & 162 \\
\hline 54 & 159 & 89 & 217 & 196 & 178 \\
\hline 55 & 168 & 99 & 237 & 216 & 194 \\
\hline 56 & 178 & 113 & 257 & 235 & 214 \\
\hline 57 & 201 & 125 & & 255 & 233 \\
\hline 58 & 219 & 140 & & & 254 \\
\hline 59 & 227 & 155 & & & \\
\hline 60 & 250 & 175 & & & \\
\hline 61 & & 193 & & & \\
\hline 62 & & 201 & & & \\
\hline 63 & & 217 & & & \\
\hline 64 & & 237 & & & \\
\hline 65 & & 253 & & & \\
\hline
\end{tabular}


Table A-7. Breakthrough concentrations (in parts per million, or ppm) per test time (in minutes) for cartridges tested at $300 \mathrm{ppm}$ and 80 percent relative humidity, with prior static exposure to fuel vapor.

\begin{tabular}{|r|r|r|r|r|r|}
\hline TIME & \multicolumn{6}{|c|}{} & $\mathbf{6 1}$ & $\mathbf{6 6}$ & $\mathbf{6 7}$ & $\mathbf{7 5}$ \\
\hline 1 & 3.7 & 4.4 & 3 & 2.8 & \\
\hline 2 & 3.2 & 3.6 & 2.6 & 2.1 & \\
\hline 3 & 2.7 & 3 & 2.3 & 1.8 & \\
\hline 4 & 2.4 & 2.6 & 2.1 & 1.5 & \\
\hline 5 & 2.1 & 2.3 & 1.8 & 1.4 & \\
\hline 6 & 1.8 & 2 & 1.7 & 1.2 & \\
\hline 7 & 1.7 & 1.8 & 1.5 & 1.1 & \\
\hline 8 & 1.5 & 1.6 & 1.4 & 1 & \\
\hline 9 & 1.4 & 1.5 & 1.3 & 0.9 & \\
\hline 10 & 1.3 & 1.3 & 1.2 & 0.8 & \\
\hline 11 & 1.2 & 1.2 & 1.1 & 0.8 & \\
\hline 12 & 1.1 & 1.1 & & 0.7 & \\
\hline 13 & 1 & 1 & & 0.6 & \\
\hline 14 & 1 & 1 & & 0.6 & \\
\hline 15 & 0.9 & 0.9 & & 0.5 & \\
\hline 16 & & 0.8 & & 0.5 & \\
\hline 17 & & 0.8 & & 0.5 & \\
\hline 18 & & 0.8 & & 0.5 & \\
\hline 19 & & 0.7 & & 0.4 & \\
\hline 20 & & 0.7 & & 0.4 & \\
\hline 21 & & 0.6 & & 0.4 & \\
\hline 22 & & 0.6 & & 0.4 & \\
\hline 23 & & 0.6 & & 0.4 & \\
\hline 24 & & 0.5 & & 0.3 & \\
\hline 25 & & 0.5 & & 0.4 & \\
\hline 26 & & 0.5 & & 0.3 & \\
\hline 27 & & 0.5 & & 0.3 & \\
\hline 28 & & 0.5 & & 0.3 & \\
\hline 29 & & 0.5 & & 0.3 & \\
\hline 30 & & 0.5 & & 0.3 & \\
\hline 31 & & 0.5 & & 0.3 & \\
\hline 32 & & 0.4 & & 0.3 & \\
\hline 33 & & 0.4 & & 0.3 & \\
\hline 34 & & 0.4 & & 0.3 & \\
\hline 35 & & 0.4 & & 0.3 & \\
\hline 36 & & 0.5 & & 0.3 & \\
\hline 37 & & & 1.3 & 0.3 & \\
\hline 38 & 2.3 & & 1.2 & 0.3 & \\
\hline 39 & 2.1 & & 1.2 & 0.3 & \\
\hline 40 & 1.9 & & 1.2 & 0.3 & \\
\hline 41 & 1.8 & & 1.2 & 0.4 & \\
\hline 42 & 1.7 & & 1.2 & 0.4 & 1.2 \\
\hline 43 & 1.6 & & 1.2 & & 1.3 \\
\hline 44 & 1.6 & & 1.2 & & \\
\hline 45 & 1.5 & & 1.3 & & \\
\hline 46 & 1.3 & & 1.3 & & \\
\hline
\end{tabular}

\begin{tabular}{|c|c|c|c|c|c|}
\hline TIME & 60 & 61 & 66 & 67 & 75 \\
\hline 47 & 1.1 & & \begin{tabular}{|l|}
1.4 \\
\end{tabular} & & \\
\hline 48 & 0.8 & & 1.5 & & \\
\hline 49 & 0.6 & & 1.6 & & \\
\hline 50 & 0.4 & & 1.7 & & \\
\hline 51 & & & 1.8 & & \\
\hline 52 & & & 2 & & \\
\hline 53 & & & \begin{tabular}{|l|}
2.2 \\
\end{tabular} & & \\
\hline 54 & & & 2.4 & & \\
\hline 55 & & & 2.6 & & \\
\hline 56 & & & 2.8 & & \\
\hline 57 & & & 3.1 & 3.6 & \\
\hline 58 & & & 3.4 & 3.5 & \\
\hline 59 & & & 3.8 & 3.6 & \\
\hline 60 & & & 4.1 & 3.7 & \\
\hline 61 & & & \begin{tabular}{|l|}
4.5 \\
\end{tabular} & \begin{tabular}{|l|}
3.8 \\
\end{tabular} & \\
\hline 62 & & & 4.9 & 4 & 7.8 \\
\hline 63 & & & \begin{tabular}{|l|}
5.3 \\
\end{tabular} & 4.3 & 7.6 \\
\hline 64 & & 4.6 & 5.7 & 4.6 & 7.7 \\
\hline 65 & & 4.9 & \begin{tabular}{l|l}
6.2 \\
\end{tabular} & 5 & 7.7 \\
\hline 66 & & 5.3 & \begin{tabular}{|c|}
6.6 \\
\end{tabular} & \begin{tabular}{|l|}
5.4 \\
\end{tabular} & 7.8 \\
\hline 67 & & 5.6 & 7 & 5.8 & 7.9 \\
\hline 68 & & 6 & \begin{tabular}{|l|}
7.4 \\
\end{tabular} & \begin{tabular}{|l|}
6.2 \\
\end{tabular} & 8.1 \\
\hline 69 & & 6.4 & 7.8 & $\begin{array}{ll}6.6 \\
\end{array}$ & 8.3 \\
\hline 70 & 4.3 & 6.8 & 8 & \begin{tabular}{|l|}
7.1 \\
\end{tabular} & 8.3 \\
\hline 71 & 4.9 & 7.3 & 8.2 & 7.3 & 8.5 \\
\hline 72 & 5.4 & 7.8 & 8.6 & 7.8 & 8.7 \\
\hline 73 & 5.9 & 8.4 & \begin{tabular}{|c|}
8.9 \\
\end{tabular} & 8.2 & 9 \\
\hline 74 & 6.3 & 9.1 & \begin{tabular}{|l|}
9.2 \\
\end{tabular} & \begin{tabular}{|l|}
8.6 \\
\end{tabular} & 9.3 \\
\hline 75 & 6.7 & 9.6 & \begin{tabular}{|l|}
9.6 \\
\end{tabular} & 8.9 & 9.5 \\
\hline 76 & 7 & 10 & 9.9 & 9.3 & 9.8 \\
\hline 77 & 7.3 & 11 & 10 & \begin{tabular}{|l|}
9.7 \\
\end{tabular} & 10 \\
\hline 78 & 7.7 & 11 & & 10 & 10 \\
\hline 79 & 8 & 11 & & 10 & 11 \\
\hline 80 & 8.3 & 12 & & 11 & 11 \\
\hline 81 & 8.5 & 12 & & 11 & 11 \\
\hline 82 & 8.8 & 12 & & 11 & 11 \\
\hline 83 & 9 & 13 & & 12 & 12 \\
\hline 84 & 9.3 & 13 & & 12 & 12 \\
\hline 85 & 9.6 & 13 & & 12 & 12 \\
\hline 86 & 9.9 & 14 & & 13 & 13 \\
\hline 87 & 10 & 14 & & 13 & 13 \\
\hline 88 & 10 & 15 & & 13 & 13 \\
\hline 89 & 11 & 15 & & \begin{tabular}{|l|}
14 \\
\end{tabular} & 14 \\
\hline 90 & 11 & 15 & 18 & 14 & 14 \\
\hline 91 & 11 & & 18 & 15 & 14 \\
\hline 92 & 12 & & 18 & 15 & 15 \\
\hline
\end{tabular}

\begin{tabular}{|r|r|r|r|r|r|}
\hline TIME & $\mathbf{6 0}$ & $\mathbf{6 1}$ & \multicolumn{1}{c|}{$\mathbf{6 6}$} & $\mathbf{6 7}$ & \multicolumn{1}{l|}{} \\
\hline 93 & 12 & & 18 & 15 & 15 \\
\hline 94 & 12 & & 18 & 15 & 15 \\
\hline 95 & 12 & & 18 & 16 & 16 \\
\hline 96 & 13 & & 18 & 16 & 16 \\
\hline 97 & 13 & & 19 & 16 & 17 \\
\hline 98 & 13 & & 19 & 16 & 17 \\
\hline 99 & 14 & & 19 & 17 & 17 \\
\hline 100 & 14 & & 20 & 17 & 17 \\
\hline 101 & 15 & & 20 & 17 & 18 \\
\hline 102 & 15 & & 20 & 17 & 18 \\
\hline 103 & & 21 & 21 & 17 & 19 \\
\hline 104 & & 21 & 21 & 17 & 19 \\
\hline 105 & & 21 & 21 & 17 & 20 \\
\hline 106 & & 21 & 22 & 18 & 20 \\
\hline 107 & & 21 & 22 & 18 & 20 \\
\hline 108 & & 21 & 22 & 18 & 21 \\
\hline 109 & & 21 & 23 & 18 & 21 \\
\hline 110 & & 22 & 23 & 18 & 22 \\
\hline 111 & & 22 & 24 & 19 & 22 \\
\hline 112 & & 22 & 24 & 19 & 22 \\
\hline 113 & & 23 & 25 & 19 & 23 \\
\hline 114 & & 23 & 25 & 20 & 23 \\
\hline 115 & & 24 & 26 & 20 & 24 \\
\hline 116 & & 24 & 26 & 21 & 24 \\
\hline 117 & & 25 & 27 & & 24 \\
\hline 118 & & 25 & 27 & & 25 \\
\hline 119 & & 25 & 28 & & 25 \\
\hline 120 & & 26 & 28 & & 26 \\
\hline 121 & 26 & 26 & 28 & & 26 \\
\hline 122 & 26 & 27 & 29 & & 26 \\
\hline 123 & 26 & 27 & 29 & & 26 \\
\hline 124 & 26 & 27 & 30 & & 27 \\
\hline 125 & 26 & 28 & 30 & & 27 \\
\hline 126 & 26 & 28 & & & 27 \\
\hline 127 & 27 & 29 & & & 28 \\
\hline 128 & 27 & 29 & & & 28 \\
\hline 129 & 27 & 30 & & & 28 \\
\hline 130 & 28 & 30 & & 30 & 28 \\
\hline 131 & 28 & 30 & & 30 & 29 \\
\hline 132 & 29 & & & 30 & 29 \\
\hline 133 & 29 & & & 30 & 30 \\
\hline 134 & 29 & & & 30 & 30 \\
\hline 135 & 29 & & & 31 & 39 \\
\hline 136 & 30 & & & 31 & 39 \\
\hline 137 & & & & 31 & 39 \\
\hline 138 & & & & 32 & 40 \\
\hline
\end{tabular}




\begin{tabular}{|c|c|c|c|c|c|}
\hline TIME & 60 & 61 & 66 & 67 & 75 \\
\hline 139 & & & 38 & 32 & 40 \\
\hline 140 & & & 38 & 32 & 40 \\
\hline 141 & & & 38 & 33 & 41 \\
\hline 142 & & & 38 & 33 & 41 \\
\hline 143 & & & 38 & 34 & 42 \\
\hline 144 & & & 39 & 33 & 42 \\
\hline 145 & & & 38 & 33 & 43 \\
\hline 146 & & & 38 & 34 & 43 \\
\hline 147 & & 39 & 39 & 34 & 44 \\
\hline 148 & & 39 & 39 & 35 & 44 \\
\hline 149 & & 40 & 40 & 35 & 44 \\
\hline 150 & & 40 & 40 & 36 & 44 \\
\hline 151 & & 41 & 41 & 36 & 45 \\
\hline 152 & 41 & 41 & 41 & 37 & 46 \\
\hline 153 & 41 & 41 & 41 & 37 & 46 \\
\hline 154 & 42 & 42 & 42 & 37 & 47 \\
\hline 155 & 42 & 42 & 42 & 38 & 48 \\
\hline 156 & 42 & 43 & 43 & 38 & 48 \\
\hline 157 & 42 & 43 & 43 & 39 & 49 \\
\hline 158 & 43 & 44 & 44 & 39 & 49 \\
\hline 159 & 43 & 44 & 44 & 40 & 50 \\
\hline 160 & 44 & 44 & 43 & 40 & 51 \\
\hline 161 & 44 & 44 & 44 & 41 & 51 \\
\hline 162 & 45 & 45 & 42 & 41 & 52 \\
\hline 163 & 45 & 45 & 46 & 41 & 52 \\
\hline 164 & 46 & 46 & 47 & 41 & 53 \\
\hline 165 & 47 & 46 & 47 & 42 & 54 \\
\hline 166 & 47 & 47 & 48 & 42 & 54 \\
\hline 167 & 48 & 47 & 48 & 43 & 55 \\
\hline 168 & 49 & 48 & 49 & 43 & 55 \\
\hline 169 & 49 & 48 & 49 & 44 & 56 \\
\hline 170 & 50 & 49 & 50 & 44 & 57 \\
\hline 171 & 51 & 50 & 50 & 45 & 57 \\
\hline 172 & 51 & 50 & 51 & 45 & 58 \\
\hline 173 & 52 & 50 & 51 & 46 & 59 \\
\hline 174 & 53 & 51 & 52 & 46 & 59 \\
\hline 175 & 53 & 52 & 52 & 46 & 60 \\
\hline 176 & 53 & 52 & 53 & 47 & \\
\hline 177 & 54 & 53 & 53 & 48 & \\
\hline 178 & 55 & 54 & 54 & 48 & \\
\hline 179 & 56 & 54 & 54 & & \\
\hline 180 & 57 & 55 & 55 & & \\
\hline 181 & 57 & 55 & 55 & & \\
\hline 182 & 58 & 56 & 55 & & \\
\hline 183 & 59 & 57 & 55 & & \\
\hline 184 & 60 & 57 & 55 & & \\
\hline
\end{tabular}

\begin{tabular}{|c|c|c|c|c|c|}
\hline TIME & 60 & 61 & 66 & 67 & 75 \\
\hline 185 & 63 & 58 & 55 & & \\
\hline 186 & & 58 & 55 & & \\
\hline 187 & & 58 & 56 & & \\
\hline 188 & & 58 & 56 & & \\
\hline 189 & & 59 & 57 & & \\
\hline 190 & & 60 & 57 & 54 & \\
\hline 191 & & 61 & 58 & 54 & \\
\hline 192 & & & 58 & 54 & \\
\hline 193 & & & 59 & 54 & \\
\hline 194 & & & 60 & 54 & \\
\hline 195 & & & 61 & 55 & \\
\hline 196 & & & & 55 & \\
\hline 197 & & & & 56 & \\
\hline 198 & & & & 56 & \\
\hline 199 & & & & 57 & \\
\hline 200 & & & & 57 & \\
\hline 201 & & & & 58 & \\
\hline 202 & & & & 58 & \\
\hline 203 & & & & 59 & \\
\hline 204 & & & & 59 & \\
\hline 205 & & & & 60 & \\
\hline 206 & & & & 60 & \\
\hline
\end{tabular}


Table A-8. Breakthrough concentrations (in parts per million, or ppm) per test time (in minutes) for cartridges tested at $600 \mathrm{ppm}$ and 80 percent relative humidity, with prior static exposure to fuel vapor.

\begin{tabular}{|c|c|c|c|c|c|}
\hline TIME & 57 & 58 & 59 & 68 & 69 \\
\hline 1 & 4.1 & 3.6 & 2.8 & & 4.4 \\
\hline 2 & 3.8 & 3.2 & 2.4 & 5.5 & 3.8 \\
\hline 3 & 3.5 & 2.9 & 2.2 & 4.8 & 3.2 \\
\hline 4 & 3.3 & 2.6 & 1.9 & 4.4 & 2.8 \\
\hline 5 & 3.1 & 2.4 & 1.8 & 4 & 2.5 \\
\hline 6 & & 2.2 & 1.6 & 3.7 & 2.2 \\
\hline 7 & & 2 & 1.5 & 3.5 & 2 \\
\hline 8 & & 1.9 & 1.4 & 3.3 & 1.8 \\
\hline 9 & & 1.8 & 1.3 & 3.1 & 1.7 \\
\hline 10 & & 1.7 & 1.2 & 3 & 1.5 \\
\hline 11 & & 1.6 & 1.1 & 2.8 & 1.4 \\
\hline 12 & & 1.5 & 1 & 2.7 & 1.3 \\
\hline 13 & & 1.4 & 1 & 2.6 & 1.2 \\
\hline 14 & & 1.4 & 0.9 & 2.6 & 1.1 \\
\hline 15 & & 1.3 & 0.9 & 2.5 & 1.1 \\
\hline 16 & & & 0.9 & 2.5 & 1 \\
\hline 17 & & & 0.8 & 2.4 & 0.9 \\
\hline 18 & & & 0.8 & & 0.9 \\
\hline 19 & & & 0.8 & & 0.8 \\
\hline 20 & & & 0.8 & & 0.8 \\
\hline 21 & & & 0.8 & & 0.8 \\
\hline 22 & & & 0.8 & & 0.8 \\
\hline 23 & & & 0.8 & & 0.7 \\
\hline 24 & & & 0.8 & & 0.7 \\
\hline 25 & & & 0.8 & & 0.7 \\
\hline 26 & & 4.3 & 0.8 & & \\
\hline 27 & & 3.7 & 0.9 & & \\
\hline 28 & & 3.3 & 0.9 & & \\
\hline 29 & & 3 & 1 & & \\
\hline 30 & & 2.8 & 1 & & \\
\hline 31 & 3.7 & 2.7 & 1.1 & & \\
\hline 32 & 3.5 & 2.6 & 1.2 & & \\
\hline 33 & 3.5 & 2.6 & 1.3 & & \\
\hline 34 & 3.4 & 2.6 & 1.5 & & \\
\hline 35 & 3.5 & 2.8 & 1.7 & & \\
\hline 36 & 3.6 & 2.9 & 1.8 & & \\
\hline 37 & 3.7 & 3 & 2 & & \\
\hline 38 & 3.9 & 3.2 & 2.3 & 6.3 & 4.5 \\
\hline 39 & 4.1 & 3.5 & 2.6 & 5.9 & 4.1 \\
\hline 40 & 4.4 & 3.8 & 2.9 & 5.6 & 3.8 \\
\hline 41 & 4.8 & 4.2 & 3.2 & 5.6 & 3.7 \\
\hline 42 & 5.2 & 4.6 & 3.7 & 5.5 & 3.7 \\
\hline 43 & 5.7 & 5.1 & 4.2 & 5.6 & 3.8 \\
\hline 44 & & 5.7 & 4.7 & 5.8 & 4 \\
\hline 45 & & 6.3 & 5.3 & 6 & 4.2 \\
\hline 46 & & & 6.1 & 6.4 & 4.5 \\
\hline
\end{tabular}

\begin{tabular}{|c|c|c|c|c|c|}
\hline TIME & 57 & 58 & 59 & 68 & 69 \\
\hline 47 & & & 7 & 6.8 & 4.9 \\
\hline 48 & & & & 7.4 & 5.4 \\
\hline 49 & & & & 8 & 5.9 \\
\hline 50 & & & & 8.7 & 6.6 \\
\hline 51 & & & & 9.5 & 7.4 \\
\hline 52 & & & & 11 & 8.2 \\
\hline 53 & & & & 12 & 9.3 \\
\hline 54 & & & & 13 & 10 \\
\hline 55 & & & & 15 & 12 \\
\hline 56 & 26 & & & 16 & 13 \\
\hline 57 & 27 & & & 18 & 15 \\
\hline 58 & 29 & & & 20 & 17 \\
\hline 59 & 30 & 25 & 26 & 22 & 18 \\
\hline 60 & 31 & 26 & 27 & 24 & 20 \\
\hline 61 & 32 & 28 & 28 & 26 & 22 \\
\hline 62 & 33 & 29 & 29 & 28 & 24 \\
\hline 63 & 34 & 30 & 30 & 30 & 26 \\
\hline 64 & 36 & 31 & 31 & 32 & 27 \\
\hline 65 & 37 & 33 & 32 & & 29 \\
\hline 66 & 39 & 34 & 34 & & 31 \\
\hline 67 & & 35 & 35 & & \\
\hline 68 & & 36 & 36 & & \\
\hline 69 & & 38 & 38 & & \\
\hline 70 & & 39 & 39 & & \\
\hline 71 & & 40 & 41 & & \\
\hline 72 & & 41 & 42 & & \\
\hline 73 & & 43 & 43 & & \\
\hline 74 & & 44 & 44 & & \\
\hline 75 & & 46 & 45 & & \\
\hline 76 & 59 & 48 & 47 & & \\
\hline 77 & 60 & 49 & 49 & 57 & \\
\hline 78 & 61 & 51 & 51 & 58 & \\
\hline 79 & 63 & 52 & 52 & 60 & 52 \\
\hline 80 & 64 & 54 & 54 & 61 & 53 \\
\hline 81 & 66 & 55 & 55 & 63 & 54 \\
\hline 82 & 68 & 56 & 57 & 65 & 55 \\
\hline 83 & 70 & 58 & 59 & 67 & 57 \\
\hline 84 & 73 & 59 & 62 & 70 & 58 \\
\hline 85 & 75 & 61 & 64 & 72 & 60 \\
\hline 86 & 77 & 63 & 66 & 74 & 61 \\
\hline 87 & 79 & 65 & 68 & 76 & 63 \\
\hline 88 & 81 & 66 & 72 & 79 & 65 \\
\hline 89 & 84 & 68 & 74 & 82 & 67 \\
\hline 90 & 87 & 70 & 75 & 84 & 68 \\
\hline 91 & 89 & 72 & 78 & 87 & 72 \\
\hline 92 & 92 & 73 & 80 & 90 & 74 \\
\hline
\end{tabular}

\begin{tabular}{|c|c|c|c|c|c|}
\hline TIME & 57 & 58 & 59 & 68 & 69 \\
\hline 93 & 94 & 75 & 83 & 93 & 76 \\
\hline 94 & 97 & 76 & 85 & $\overline{96}$ & 78 \\
\hline 95 & 99 & 78 & 88 & 99 & 80 \\
\hline 96 & 102 & 80 & 90 & 102 & 82 \\
\hline 97 & 106 & 82 & 92 & 106 & 84 \\
\hline 98 & 110 & 84 & 95 & 109 & 87 \\
\hline 99 & 113 & 86 & 98 & 112 & 89 \\
\hline 100 & 117 & 88 & 101 & 116 & 90 \\
\hline 101 & 121 & 91 & 104 & 120 & 93 \\
\hline 102 & & 93 & 107 & & 96 \\
\hline 103 & & 96 & 110 & & 99 \\
\hline 104 & & 99 & 113 & & 102 \\
\hline 105 & & 102 & 117 & & 105 \\
\hline 106 & & 104 & 119 & & 108 \\
\hline 107 & & 107 & & & 111 \\
\hline 108 & & 110 & & & 115 \\
\hline 109 & & 114 & & & $\overline{118}$ \\
\hline 110 & & 117 & & & 122 \\
\hline 111 & & 121 & & & \\
\hline
\end{tabular}


Table A-9. Breakthrough concentrations (in parts per million, or ppm) per test time (in minutes) for cartridges tested at $1200 \mathrm{ppm}$ and 80 percent relative humidity, with prior static exposure to fuel vapor.

\begin{tabular}{|c|c|c|c|c|c|}
\hline TIME & 51 & 52 & 76 & 77 & 78 \\
\hline 1 & 4.3 & 3.7 & 4.4 & 2.7 & 1.3 \\
\hline 2 & 4.1 & 3.5 & 4.2 & 2.5 & 1.3 \\
\hline 3 & 3.8 & 3.3 & 3.9 & 2.3 & 1.2 \\
\hline 4 & 3.5 & 3.1 & 3.7 & 2.2 & 1.1 \\
\hline 5 & 3.3 & 2.9 & 3.4 & 2.1 & 1.1 \\
\hline 6 & 3.1 & 2.8 & 3.2 & 2 & 1 \\
\hline 7 & 3 & 2.7 & 3 & 1.9 & 1 \\
\hline 8 & 2.9 & 2.6 & 2.9 & 1.8 & 1 \\
\hline 9 & 2.8 & 2.5 & 2.8 & 1.8 & 0.9 \\
\hline 10 & 2.7 & 2.4 & & 1.8 & 0.9 \\
\hline 11 & 2.7 & 2.4 & & & 0.9 \\
\hline 12 & 2.6 & 2.4 & & & 0.9 \\
\hline 13 & 2.6 & 2.4 & & & 0.9 \\
\hline 14 & 2.6 & 2.4 & & & 0.9 \\
\hline 15 & 2.6 & 2.4 & & & 0.9 \\
\hline 16 & 2.7 & 2.5 & & & 1 \\
\hline 17 & 2.8 & 2.6 & & & 1 \\
\hline 18 & 2.9 & 2.7 & & & 1.1 \\
\hline 19 & 3 & 2.8 & & & 1.2 \\
\hline 20 & 3.2 & 2.9 & & & 1.4 \\
\hline 21 & 3.5 & 3.2 & & & 1.5 \\
\hline 22 & 3.8 & 3.4 & & & 1.7 \\
\hline 23 & 4.1 & 3.8 & & & 2 \\
\hline 24 & 4.5 & 4.2 & & & 2.3 \\
\hline 25 & 5.1 & 4.7 & & & 2.7 \\
\hline 26 & & & 20 & & 3.1 \\
\hline 27 & & & 23 & & 3.7 \\
\hline 28 & & & 26 & 34 & 4.4 \\
\hline 29 & & & 30 & 37 & 5.2 \\
\hline 30 & & & 35 & 42 & 6.3 \\
\hline 31 & & & 39 & 46 & 7.5 \\
\hline 32 & & & 44 & 50 & 9.1 \\
\hline 33 & & & 50 & 55 & 11 \\
\hline 34 & & & 55 & 60 & 13 \\
\hline 35 & & & 61 & 65 & 16 \\
\hline 36 & & & 68 & 71 & 19 \\
\hline 37 & & & 76 & 76 & 23 \\
\hline 38 & & & 83 & 82 & 28 \\
\hline 39 & & & 92 & 89 & 33 \\
\hline 40 & & & 101 & 96 & 38 \\
\hline 41 & 59 & 61 & 111 & 104 & 46 \\
\hline 42 & 69 & 69 & 120 & 112 & 54 \\
\hline 43 & 77 & 79 & 132 & 120 & 65 \\
\hline 44 & 86 & 87 & 144 & 130 & 77 \\
\hline 45 & 93 & 96 & 158 & 141 & 90 \\
\hline 46 & 100 & 105 & 172 & 151 & 100 \\
\hline
\end{tabular}

\begin{tabular}{|r|c|c|c|c|c|}
\hline TIME & $\mathbf{5 1}$ & $\mathbf{5 2}$ & $\mathbf{7 6}$ & $\mathbf{7 7}$ & $\mathbf{7 8}$ \\
\hline 47 & 108 & 114 & 187 & 163 & 110 \\
\hline 48 & 116 & 123 & 206 & 176 & 118 \\
\hline 49 & 123 & 132 & 223 & 190 & 128 \\
\hline 50 & 132 & 143 & 245 & 204 & 141 \\
\hline 51 & 141 & 154 & & 220 & 154 \\
\hline 52 & 152 & 167 & & 237 & 170 \\
\hline 53 & 162 & 179 & & 255 & 185 \\
\hline 54 & 173 & 190 & & & 201 \\
\hline 55 & 185 & 205 & & & 218 \\
\hline 56 & 199 & 220 & & & 236 \\
\hline 57 & 213 & 236 & & & 257 \\
\hline 58 & 227 & & & & \\
\hline 59 & 240 & & & & \\
\hline
\end{tabular}




\title{
APPENDIX B
}

\author{
Modified NIOSH 1550 Method Sampling Results
}

Results from sampling of JP-8 fuel vapors within the respirator chamber, using the modified $\mathrm{NIOSH} 1550$ Method for naphthas, are presented in the following table. 
Table B-1. Modified NIOSH 1550 Method charcoal tube sampling results. Target concentration was measured with the Foxboro TVA-1000B. Conversion of measured concentration charcoal tube sampling results to parts per million (ppm) was accomplished using an average molecular weight of $170 \mathrm{~g} / \mathrm{mol}$ and a molar gas volume of 24.45 liters.

\begin{tabular}{|c|c|c|c|c|c|c|}
\hline $\begin{array}{l}\text { Sample } \\
\text { number }\end{array}$ & $\begin{array}{l}\text { Cartridge } \\
\text { number }\end{array}$ & $\begin{array}{c}\text { Target } \\
\text { concentration } \\
\text { (measured } \\
\text { w/TVA-1000B) }\end{array}$ & $\begin{array}{c}\text { Mass } \\
\text { collected } \\
(\mathrm{mg})\end{array}$ & $\begin{array}{c}\text { Air } \\
\text { volume } \\
\text { collected } \\
\text { (L) }\end{array}$ & $\begin{array}{c}\text { Measured } \\
\text { concentration } \\
\text { via NIOSH 1550 } \\
\left(\mathrm{mg} / \mathrm{m}^{3}\right)\end{array}$ & $\begin{array}{c}\text { Measured } \\
\text { concentration, } \\
\text { converted to } \\
\text { ppm }\end{array}$ \\
\hline 9388-КС30 & 31 & 600 & 15 & 3.706 & 4004 & 582 \\
\hline 9388-KC31 & 32 & 600 & 15 & 3.933 & 3824 & 549 \\
\hline 9388-КС33 & 34 & 600 & 14 & 3.545 & 3879 & 568 \\
\hline 9388-КС34 & 35 & 300 & 12 & 5.855 & 2096 & 295 \\
\hline 9388-KC35 & 36 & 1200 & 12 & 1.591 & 7247 & 1085 \\
\hline 9388-КС36 & 37 & 1200 & 14 & 1.807 & 7737 & 1114 \\
\hline 9388-KC37 & 38 & 1200 & 14 & 1.966 & 7162 & 1024 \\
\hline 9388-KC38 & 39 & 1200 & 15 & 1.719 & 8540 & 1255 \\
\hline 9388-KC42 & 44 & 600 & 13 & 3.640 & 3676 & 514 \\
\hline 9388-KC43 & 45 & 600 & 13 & 3.370 & 3843 & 555 \\
\hline 9388-KC44 & 46 & 300 & 13 & 6.135 & 2039 & 305 \\
\hline 9388-KC45 & 47 & 300 & 13 & 6.229 & 2057 & 300 \\
\hline 9388-KC46 & 48 & 300 & 12 & 5.875 & 2089 & 294 \\
\hline 9388-KC47 & 49 & 300 & 14 & 7.411 & 1845 & 272 \\
\hline 9388-KC49 & 51 & 1200 & 14 & 1.833 & 7430 & 1098 \\
\hline 9388-KC50 & 52 & 1200 & 13 & 1.765 & 7592 & 1059 \\
\hline 9388-KC52 & 54 & 1200 & 15 & 2.020 & 7540 & 1068 \\
\hline 9388-KC53 & 55 & 300 & 16 & 7.619 & 2103 & 302 \\
\hline 9388-KC54 & 56 & 300 & 16 & 7.578 & 2138 & 304 \\
\hline 9388-KC55 & 57 & 600 & 13 & 3.159 & 4204 & 592 \\
\hline 9388-KC56 & 58 & 600 & 14 & 3.436 & 3981 & 586 \\
\hline 9388-KC57 & 59 & 600 & 13 & 3.306 & 3878 & 566 \\
\hline 9388-KC58 & 62 & 600 & 14 & 3.619 & 3736 & 556 \\
\hline 9388-KC59 & 60 & 300 & 12 & 5.652 & 2173 & 305 \\
\hline 9388-KC60 & 61 & 300 & 13 & 5.895 & 2146 & 317 \\
\hline 9388-KC61 & 63 & 600 & 13 & 3.547 & 3651 & 527 \\
\hline 9388-KC62 & 64 & 300 & 9.6 & 5.419 & 1770 & 255 \\
\hline 9388-KC63 & 65 & 300 & 12 & 6.424 & 1865 & 269 \\
\hline 9388-KC64 & 66 & 300 & 11 & 5.882 & 1824 & 269 \\
\hline 9388-KC65 & 67 & 300 & 11 & 6.271 & 1727 & 252 \\
\hline 9388-KC66 & 68 & 600 & 12 & 3.152 & 3791 & 548 \\
\hline 9388-KC67 & 70 & 600 & 13 & 3.508 & 3606 & 533 \\
\hline 9388-KC68 & 69 & 600 & 12 & 3.422 & 3407 & 504 \\
\hline
\end{tabular}


Table B-1 (continued). Modified NIOSH 1550 Method charcoal tube sampling results.

\begin{tabular}{ccccccc}
\hline $\begin{array}{c}\text { Sample } \\
\text { number }\end{array}$ & $\begin{array}{c}\text { Cartridge } \\
\text { number }\end{array}$ & $\begin{array}{c}\text { Target } \\
\text { concentration } \\
\text { (measured } \\
\text { w/TVA-1000B) }\end{array}$ & $\begin{array}{c}\text { Mass } \\
\text { collected } \\
\text { (mg) }\end{array}$ & $\begin{array}{c}\text { Air } \\
\text { volume } \\
\text { collected } \\
\text { (L) }\end{array}$ & $\begin{array}{c}\text { Measured } \\
\text { concentration } \\
\text { via NIOSH 1550 } \\
\left.\text { (mg/. } \mathbf{m}^{\mathbf{3}}\right)\end{array}$ & $\begin{array}{c}\text { Measured } \\
\text { concentration, } \\
\text { converted to } \\
\text { ppm }\end{array}$ \\
\hline $9388-K C 69$ & 71 & 1200 & 13 & 1.733 & 7513 & 1079 \\
$9388-K C 70$ & 72 & 1200 & 15 & 1.858 & 7815 & 1161 \\
$9388-K C 71$ & 73 & 1200 & 15 & 2.109 & 7117 & 1024 \\
$9388-K C 72$ & 74 & 300 & 15 & 7.959 & 1882 & 271 \\
$9388-K C 73$ & 75 & 300 & 11 & 5.840 & 1880 & 270 \\
$9388-K C 74$ & 80 & 600 & 11 & 3.638 & 3576 & 514 \\
$9388-K C 75$ & 76 & 1200 & 12 & 1.532 & 7983 & 1148 \\
$9388-K C 76$ & 77 & 1200 & 12 & 1.601 & 7564 & 1088 \\
$9388-K C 77$ & 81 & 1200 & 13 & 1.766 & 7469 & 1074 \\
$9388-K C 78$ & 78 & 1200 & 13 & 1.731 & 7250 & 1043 \\
$9388-K C 79$ & 82 & 1200 & 14 & 1.767 & 7651 & 1100 \\
$9388-K C 80$ & 84 & 600 & 14 & 3.937 & 3622 & 521 \\
\hline
\end{tabular}




\title{
APPENDIX C
}

\author{
Cartridge weight change summary
}

The attached table lists the changes in cartridge weight that resulted from each stage preparation and testing. All weights are reported in grams. 
Table C-1. Cartridge weight gains during pre-conditioning at 80 percent relative humidity, prior exposure to $1200 \mathrm{ppm}$ JP-8 fuel and $80 \%$ relative humidity, and breakthrough tests at challenge conditions. (Tests were terminated at 20 percent breakthrough of the challenge concentration.)

\begin{tabular}{|c|c|c|c|c|c|c|c|c|}
\hline $\begin{array}{l}\text { Crtdg } \\
\text { num }\end{array}$ & Conc & $R H$ & Prior & $\begin{array}{l}P k g w t \\
\text { (g) }\end{array}$ & $\begin{array}{l}\text { Pre-conditioning } \\
\text { wt gain }(g)\end{array}$ & $\begin{array}{c}\text { Prior exposure } \\
\text { wt gain }(g)\end{array}$ & $\begin{array}{c}\text { Breakthrough test } \\
\text { wt gain }(g)\end{array}$ & $\begin{array}{l}\text { Total gain } \\
\text { (g) }\end{array}$ \\
\hline 46 & 300 & 50 & No & 76.267 & 14.372 & $\mathrm{~N} / \mathrm{A}$ & 2.804 & 17.176 \\
\hline 49 & 300 & 50 & No & 76.058 & 13.732 & $\mathrm{~N} / \mathrm{A}$ & 3.054 & 16.786 \\
\hline 55 & 300 & 50 & No & 76.015 & 14.456 & $\mathrm{~N} / \mathrm{A}$ & 2.954 & 17.410 \\
\hline 56 & 300 & 50 & No & 76.344 & 14.313 & $\mathrm{~N} / \mathrm{A}$ & 3.251 & 17.564 \\
\hline 74 & 300 & 50 & No & 76.147 & 14.577 & $\mathrm{~N} / \mathrm{A}$ & 3.214 & 17.791 \\
\hline 31 & 600 & 50 & No & 76.333 & 13.898 & $\mathrm{~N} / \mathrm{A}$ & 5.124 & 19.022 \\
\hline 32 & 600 & 50 & No & 76.659 & 13.902 & $\mathrm{~N} / \mathrm{A}$ & 5.121 & 19.023 \\
\hline 44 & 600 & 50 & No & 76.743 & 14.114 & $\mathrm{~N} / \mathrm{A}$ & 5.249 & 19.363 \\
\hline 63 & 600 & 50 & No & 76.296 & 14.455 & $\mathrm{~N} / \mathrm{A}$ & 4.728 & 19.183 \\
\hline 84 & 600 & 50 & No & 76.396 & 14.166 & $\mathrm{~N} / \mathrm{A}$ & 5.362 & 19.528 \\
\hline 36 & 1200 & 50 & No & 76.721 & 15.800 & $\mathrm{~N} / \mathrm{A}$ & 8.024 & 23.824 \\
\hline 39 & 1200 & 50 & No & 76.659 & 13.337 & $\mathrm{~N} / \mathrm{A}$ & 8.971 & 23.308 \\
\hline 54 & 1200 & 50 & No & 76.087 & 14.738 & $\mathrm{~N} / \mathrm{A}$ & 8.535 & 23.273 \\
\hline 72 & 1200 & 50 & No & 76.160 & 14.313 & $\mathrm{~N} / \mathrm{A}$ & 10.217 & 24.530 \\
\hline 73 & 1200 & 50 & No & 76.261 & 14.208 & $\mathrm{~N} / \mathrm{A}$ & 10.558 & 24.766 \\
\hline 35 & 300 & 80 & No & 76.204 & 13.533 & $\mathrm{~N} / \mathrm{A}$ & 7.251 & 20.784 \\
\hline 47 & 300 & 80 & No & 76.497 & 14.513 & $\mathrm{~N} / \mathrm{A}$ & 7.401 & 21.914 \\
\hline 48 & 300 & 80 & No & 76.826 & 13.779 & $\mathrm{~N} / \mathrm{A}$ & 7.457 & 21.236 \\
\hline 64 & 300 & 80 & No & 75.984 & 14.578 & $\mathrm{~N} / \mathrm{A}$ & 5.477 & 20.055 \\
\hline 65 & 300 & 80 & No & 76.113 & 14.808 & $\mathrm{~N} / \mathrm{A}$ & 6.088 & 20.896 \\
\hline 34 & 600 & 80 & No & 76.747 & 13.497 & $\mathrm{~N} / \mathrm{A}$ & 11.207 & 24.704 \\
\hline 45 & 600 & 80 & No & 76.812 & 14.276 & $\mathrm{~N} / \mathrm{A}$ & 11.643 & 25.919 \\
\hline 62 & 600 & 80 & No & 75.980 & 14.601 & $\mathrm{~N} / \mathrm{A}$ & 11.739 & 26.340 \\
\hline 70 & 600 & 80 & No & 75.970 & 14.614 & $\mathrm{~N} / \mathrm{A}$ & 11.145 & 25.759 \\
\hline 80 & 600 & 80 & No & 76.059 & 14.387 & $\mathrm{~N} / \mathrm{A}$ & 11.629 & 26.016 \\
\hline 37 & 1200 & 80 & No & 76.281 & 15.367 & $\mathrm{~N} / \mathrm{A}$ & 12.286 & 27.653 \\
\hline 38 & 1200 & 80 & No & 76.625 & 13.867 & $\mathrm{~N} / \mathrm{A}$ & 12.900 & 26.767 \\
\hline 71 & 1200 & 80 & No & 75.947 & 14.368 & $\mathrm{~N} / \mathrm{A}$ & 13.354 & 27.722 \\
\hline 81 & 1200 & 80 & No & 76.186 & 14.271 & $\mathrm{~N} / \mathrm{A}$ & 12.451 & 26.722 \\
\hline 82 & 1200 & 80 & No & 75.928 & 14.697 & $\mathrm{~N} / \mathrm{A}$ & 13.169 & 27.866 \\
\hline 60 & 300 & 80 & Yes & 76.383 & 14.682 & 0.980 & 5.977 & 21.639 \\
\hline 61 & 300 & 80 & Yes & 76.045 & 14.385 & 0.729 & 6.175 & 21.289 \\
\hline 66 & 300 & 80 & Yes & 76.107 & 14.351 & 1.590 & 5.078 & 21.019 \\
\hline 67 & 300 & 80 & Yes & 75.895 & 14.312 & 1.713 & 5.067 & 21.092 \\
\hline 75 & 300 & 80 & Yes & 76.029 & 14.226 & 1.809 & 5.344 & 21.379 \\
\hline 57 & 600 & 80 & Yes & 76.119 & 14.526 & 0.880 & 10.457 & 25.863 \\
\hline 58 & 600 & 80 & Yes & 76.037 & 14.399 & 1.031 & 10.562 & 25.992 \\
\hline 59 & 600 & 80 & Yes & 76.171 & 14.722 & 0.959 & 10.546 & 26.227 \\
\hline 68 & 600 & 80 & Yes & 76.465 & 13.842 & 0.767 & 10.848 & 25.457 \\
\hline 69 & 600 & 80 & Yes & 76.369 & 14.109 & 0.856 & 10.477 & 25.442 \\
\hline 51 & 1200 & 80 & Yes & 76.074 & 14.372 & 1.015 & 11.195 & 26.582 \\
\hline 52 & 1200 & 80 & Yes & 76.128 & 14.575 & 0.810 & 11.708 & 27.093 \\
\hline 76 & 1200 & 80 & Yes & 76.291 & 14.231 & 1.609 & 10.817 & 26.657 \\
\hline 77 & 1200 & 80 & Yes & 76.141 & 14.098 & 1.821 & 11.529 & 27.448 \\
\hline 78 & 1200 & 80 & Yes & 76.070 & 14.344 & 1.000 & 11.778 & 27.122 \\
\hline
\end{tabular}




\section{APPENDIX D}

\section{Statistical Assessment of Results: SAS/STAT ${ }^{\circledR}$ Output}

SAS programs and output for the Analysis of Variance (ANOVA), means tests, homogeneity of variance, and normality assessments are enclosed in this Appendix for hypotheses 1 and 2. 


\section{ANOVA and means tests for first hypothesis (RELATIVE HUMIDITY and CONCENTRATION)}

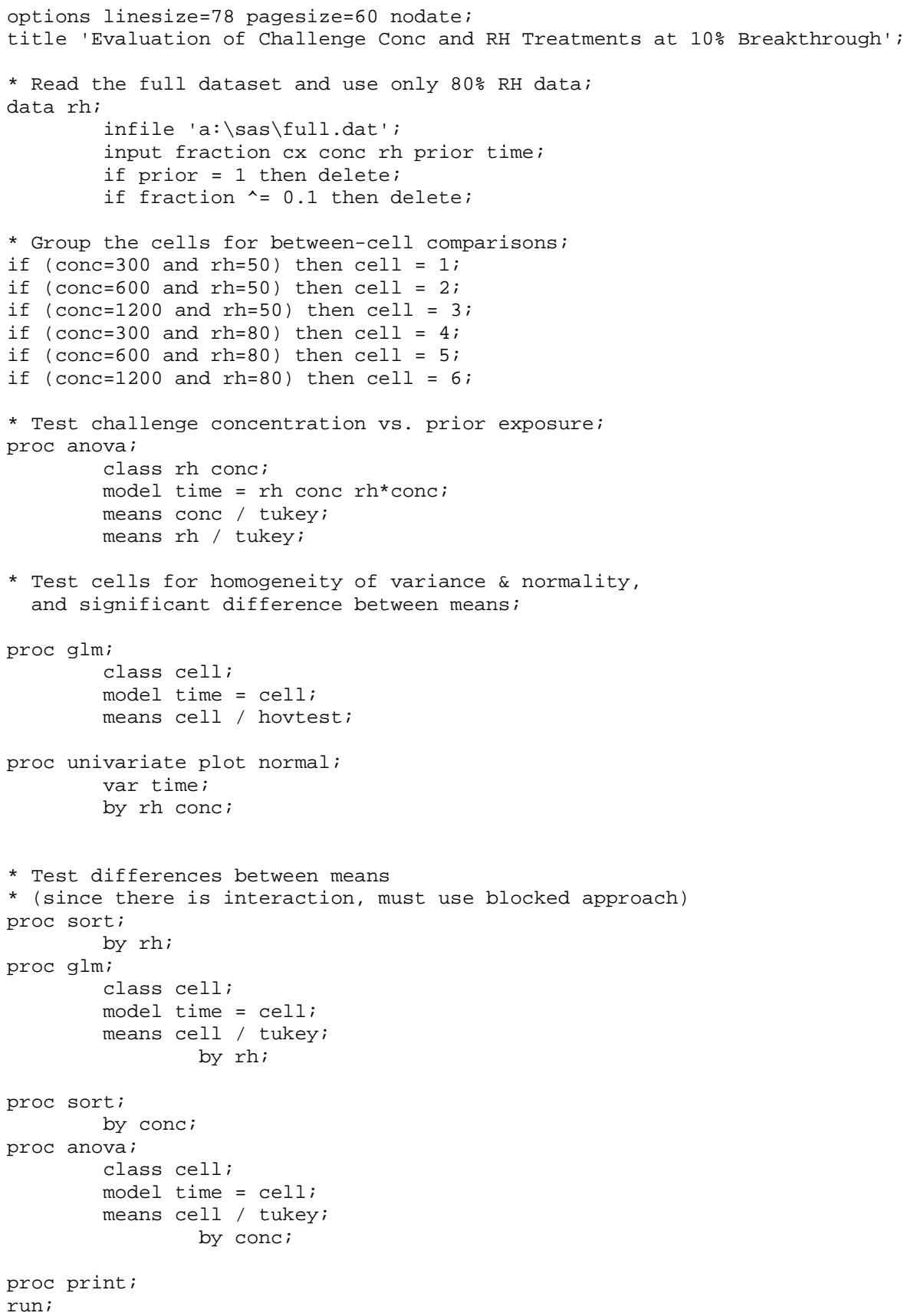


Evaluation of Challenge Conc and RH Treatments at 10\% Breakthrough

Analysis of Variance Procedure

Class Level Information

Class Levels Values

$\mathrm{RH} \quad 2 \quad 50 \quad 80$

CONC $\quad 3 \quad 300600 \quad 1200$

Number of observations in data set $=30$

\section{Analysis of Variance Procedure}

Dependent Variable: TIME

\begin{tabular}{|c|c|c|c|c|c|}
\hline & & Sum of & Mean & & \\
\hline Source & $\mathrm{DF}$ & Squares & Square & F Value & $\operatorname{Pr}>\mathrm{F}$ \\
\hline Model & 5 & 109011.8667 & 21802.3733 & 742.42 & 0.0001 \\
\hline Error & 24 & 704.8000 & 29.3667 & & \\
\hline \multirow[t]{3}{*}{ Corrected Total } & 29 & 109716.6667 & & & \\
\hline & R-Square & $\mathrm{C} \cdot \mathrm{V}$. & Root MSE & & TIME Mean \\
\hline & 0.993576 & 4.809854 & 5.419102 & & 112.6667 \\
\hline Source & $\mathrm{DF}$ & Anova SS & Mean Square & F Value & $\operatorname{Pr}>\mathrm{F}$ \\
\hline $\mathrm{RH}$ & 1 & 10010.13333 & 10010.13333 & 340.87 & 0.0001 \\
\hline CONC & 2 & 88983.26667 & 44491.63333 & 1515.04 & 0.0001 \\
\hline $\mathrm{RH}{ }^{*} \mathrm{CONC}$ & 2 & 10018.46667 & 5009.23333 & 170.58 & 0.0001 \\
\hline
\end{tabular}

Analysis of Variance Procedure

Tukey's Studentized Range (HSD) Test for variable: TIME

NOTE: This test controls the type I experimentwise error rate, but generally has a higher type II error rate than REGWQ.

Alpha $=0.05 \quad \mathrm{df}=24 \quad \mathrm{MSE}=29.36667$

Critical Value of Studentized Range $=3.532$

Minimum Significant Difference $=6.0522$

Means with the same letter are not significantly different.

$\begin{array}{rrrr}\text { Tukey Grouping } & \text { Mean } & \text { N } & \text { CONC } \\ \text { A } & 184.900 & 10 & 300 \\ \text { B } & 99.700 & 10 & 600 \\ \text { C } & 53.400 & 10 & 1200\end{array}$


Analysis of Variance Procedure

Tukey's Studentized Range (HSD) Test for variable: TIME

NOTE: This test controls the type I experimentwise error rate, but generally has a higher type II error rate than REGWQ.

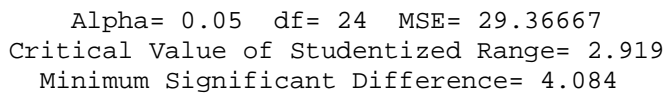

Number of observations in data set $=30$

General Linear Models Procedure

Dependent Variable: TIME

Source

Mode 1

Error

Corrected Total

$$
\begin{aligned}
& \text { R-Square } \\
& 0.993576
\end{aligned}
$$

Source

CELL

Source

CELL

DF

DF
DF

5

24

29

C.V.

4.809854

Type I SS

109011.8667

Type III SS

109011.8667

5

5

Mean
Square

21802.3733

29.3667

Root MSE

5. 419102

F Value

742.42

0.0001

$\begin{array}{rr}\text { Mean Square } & \text { F Value } \\ 21802.3733 & 742.42 \\ \text { Mean Square } & \text { F Value } \\ 21802.3733 & 742.42\end{array}$

TIME Mean

112.6667

$\operatorname{Pr}>\mathrm{F}$

0.0001

$\operatorname{Pr}>\mathrm{F}$

0.0001 
General Linear Models Procedure

Levene's Test for Equality of TIME Variance ANOVA of Squared Deviations from Group Means

$\begin{array}{lrcccc}\text { Source } & \text { DF } & \begin{array}{l}\text { Sum of } \\ \text { Squares }\end{array} & \begin{array}{c}\text { Mean } \\ \text { Square }\end{array} & \text { F Value } & \text { Pr }>\text { F } \\ \text { CELL } & 5 & 16228.2 & 3245.6 & 2.4369 & 0.0638 \\ \text { Error } & 24 & 31965.2 & 1331.9 & & \end{array}$

General Linear Models Procedure

\begin{tabular}{lrrc} 
Level of & \multicolumn{3}{c}{-1} \\
CELL & $\mathrm{N}$ & Mean & SD \\
& & & \\
1 & 5 & 228.800000 & 9.60208311 \\
2 & 5 & 108.000000 & 2.34520788 \\
3 & 5 & 56.000000 & 3.80788655 \\
4 & 5 & 141.000000 & 5.52268051 \\
5 & 5 & 91.400000 & 4.39317653 \\
6 & 5 & 50.800000 & 3.76828874
\end{tabular}

Evaluation of Challenge Conc and RH Treatments at $10 \%$ Breakthrough 


\section{Univariate Procedure}

\section{Variable $=$ TIME}

Moments

$\begin{array}{lrlr}\text { N } & 15 & \text { Sum Wgts } & 15 \\ \text { Mean } & 130.9333 & \text { Sum } & 1964 \\ \text { Std Dev } & 75.13936 & \text { Variance } & 5645.924 \\ \text { Skewness } & 0.50858 & \text { Kurtosis } & -1.55749 \\ \text { USS } & 336196 & \text { CSS } & 79042.93 \\ \text { CV } & 57.3875 & \text { Std Mean } & 19.4009 \\ \text { T : Mean=0 } & 6.748828 & \text { Pr }>|\mathrm{T}| & 0.0001 \\ \text { Num ^=0 } & 15 & \text { Num }>0 & 15 \\ \text { M(Sign) } & 7.5 & \text { Pr }>=|\mathrm{M}| & 0.0001 \\ \text { Sgn Rank } & 60 & \text { Pr }>=|\mathrm{S}| & 0.0001 \\ \text { W:Normal } & 0.814914 & \text { Pr }<W & 0.0053\end{array}$

Quantiles (Def $=5$ )

$\begin{array}{rrrr}100 \% \text { Max } & 243 & 99 \% & 243 \\ 75 \% \text { Q3 } & 221 & 95 \% & 243 \\ 50 \% \text { Med } & 109 & 90 \% & 232 \\ 25 \% \text { Q1 } & 59 & 10 \% & 52 \\ 0 \% \text { Min } & 52 & 5 \% & 52 \\ & & 1 \% & 52\end{array}$

$\begin{array}{ll}\text { Range } & 191 \\ \text { Q3-Q1 } & 162\end{array}$

Mode 52

Extremes

$\begin{array}{rrrr}\text { Lowest } & \text { Obs } & \text { Highest } & \text { Obs } \\ 52( & 14) & 219( & 2) \\ 52( & 12) & 221( & 1) \\ 57( & 13) & 229( & 3) \\ 59( & 11) & 232( & 4) \\ 60( & 15) & 243( & 5)\end{array}$

Stem Leaf

222334

1

101111

055666

-----+----+----+-----+

Multiply stem. Leaf by $10 * \star+2$
15

64

45.924

9042.93

.4009

15

0.0001

0.0053 


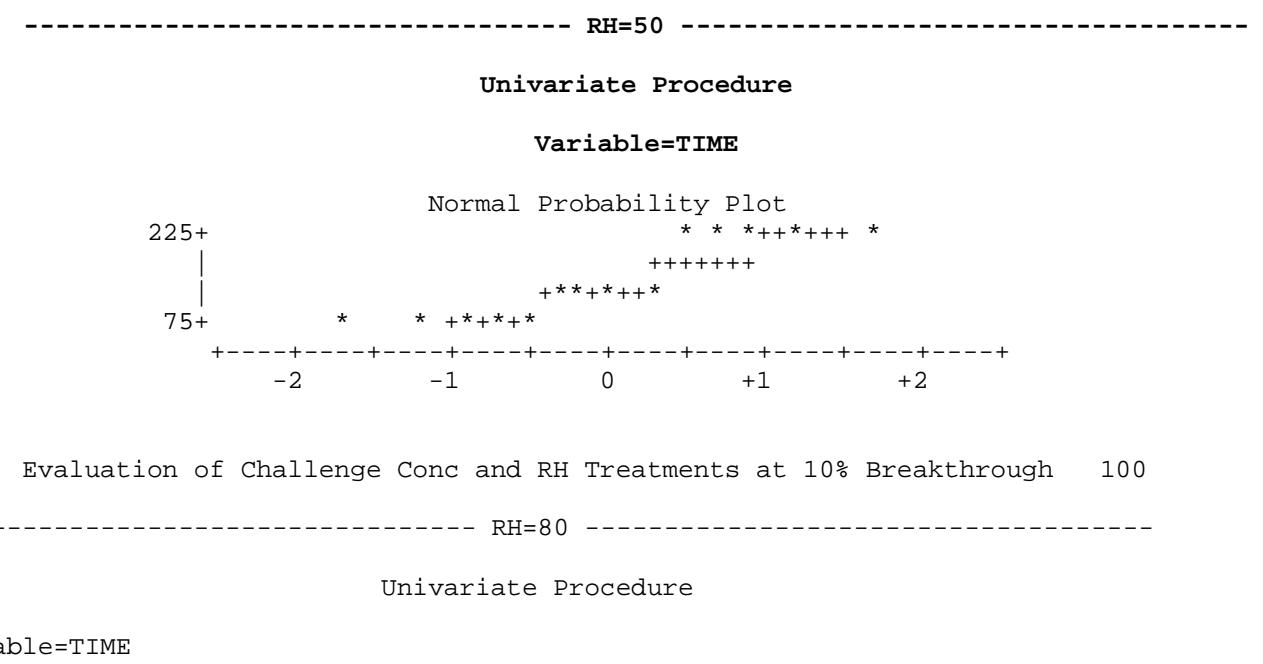

Variable $=$ TIME

Moments

\begin{tabular}{|c|c|c|c|}
\hline $\mathrm{N}$ & 15 & Sum Wgts & 15 \\
\hline Mean & 94.4 & Sum & 1416 \\
\hline Std Dev & 38.41837 & Variance & 1475.971 \\
\hline Skewness & 0.146423 & Kurtosis & -1.55365 \\
\hline USS & 154334 & CSS & 20663.6 \\
\hline $\mathrm{CV}$ & 40.69743 & Std Mean & 9.919581 \\
\hline $\mathrm{T}: \mathrm{Mean}=0$ & 9.516531 & $\operatorname{Pr}>|\mathrm{T}|$ & 0.0001 \\
\hline Num $\wedge=0$ & 15 & Num $>0$ & 15 \\
\hline M (Sign) & 7.5 & $\operatorname{Pr}>=|M|$ & 0.0001 \\
\hline Sgn Rank & 60 & $\operatorname{Pr}>=|S|$ & 0.0001 \\
\hline W: Normal & 0.87524 & $\operatorname{Pr}<W$ & 0.0405 \\
\hline \multicolumn{4}{|c|}{ Quantiles (Def $=5$ ) } \\
\hline $100 \% \operatorname{Max}$ & 149 & $99 \%$ & 149 \\
\hline $75 \% \mathrm{Q} 3$ & 138 & $95 \%$ & 149 \\
\hline $50 \% \mathrm{Med}$ & 92 & $90 \%$ & 144 \\
\hline $25 \% \mathrm{Q} 1$ & 51 & $10 \%$ & 49 \\
\hline \multirow[t]{2}{*}{$0 \% \operatorname{Min}$} & 47 & $5 \%$ & 47 \\
\hline & & $1 \%$ & 47 \\
\hline Range & 102 & & \\
\hline Q3-Q1 & 87 & & \\
\hline Mode & 47 & & \\
\hline
\end{tabular}




$\begin{array}{rrrr}\text { Lowest } & \text { Obs } & \text { Highest } & \text { Obs } \\ 47( & 13) & 135( & 1) \\ 49( & 14) & 138( & 3) \\ 50( & 15) & 139( & 2) \\ 51( & 11) & 144( & 5) \\ 57( & 12) & 149( & 4)\end{array}$

Stem Leaf

1449

12589

10

$8 \quad 50237$

479017 ----+----+----+----+

Multiply Stem. Leaf by $10 * *+1$

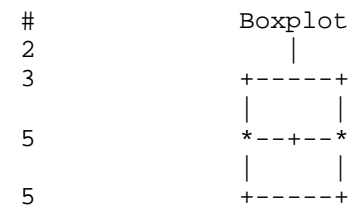

$\mathrm{RH}=80$

Univariate Procedure

Variable=TIME

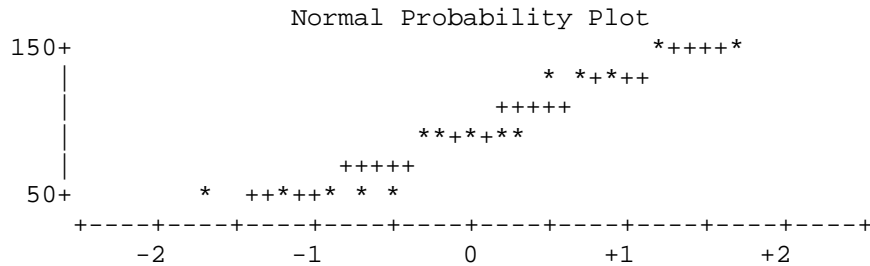


Univariate Procedure

Schematic Plots

Variable $=$ TIME

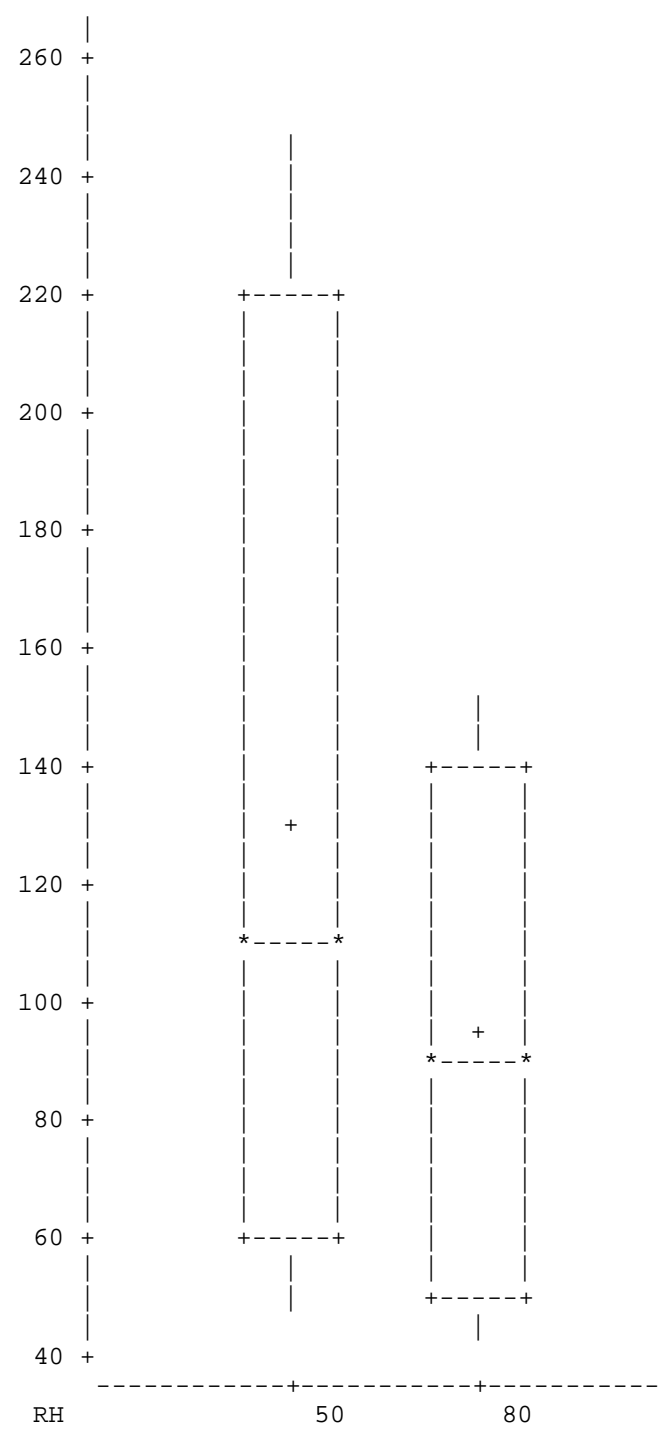




\begin{tabular}{crr}
\multicolumn{2}{c}{$\begin{array}{c}\text { General Linear Models } \\
\text { Class Level Inform }\end{array}$} \\
Class & Levels & Values \\
CELL & 3 & 123
\end{tabular}

Number of observations in by group $=15$

$\mathrm{RH}=50$

General Linear Models Procedure

\begin{tabular}{|c|c|c|c|c|c|}
\hline r & & Sum of & Mean & & \\
\hline Source & $\mathrm{DF}$ & Squares & Square & F Value & $\operatorname{Pr}>\mathrm{F}$ \\
\hline Model & 2 & 78594.13333 & 39297.06667 & 1050.72 & 0.0001 \\
\hline Error & 12 & 448.80000 & 37.40000 & & \\
\hline \multirow[t]{3}{*}{ Corrected Total } & 14 & 79042.93333 & & & \\
\hline & R-Square & C.V. & Root MSE & & TIME Mean \\
\hline & 0.994322 & 4.670739 & 6.115554 & & 130.9333 \\
\hline Source & $\mathrm{DF}$ & Type I SS & Mean Square & F Value & $\operatorname{Pr}>\mathrm{F}$ \\
\hline CELL & 2 & 78594.13333 & 39297.06667 & 1050.72 & 0.0001 \\
\hline Source & $\mathrm{DF}$ & Type III SS & Mean Square & F Value & $\operatorname{Pr}>\mathrm{F}$ \\
\hline CELL & 2 & 78594.13333 & 39297.06667 & 1050.72 & 0.0001 \\
\hline
\end{tabular}

General Linear Models Procedure

Tukey's Studentized Range (HSD) Test for variable: TIME

NOTE: This test controls the type I experimentwise error rate, but generally has a higher type II error rate than REGWQ.

Alpha $=0.05 \quad \mathrm{df}=12 \mathrm{MSE}=37.4$

Critical Value of Studentized Range $=3.773$

Minimum Significant Difference $=10.318$

Means with the same letter are not significantly different.

$\begin{array}{rrrr}\text { Tukey Grouping } & \text { Mean } & \text { N } & \text { CELL } \\ \text { A } & 228.800 & 5 & 1 \\ \text { B } & 108.000 & 5 & 2 \\ \text { C } & 56.000 & 5 & 3\end{array}$




\begin{tabular}{|c|c|c|c|c|c|}
\hline \multicolumn{6}{|c|}{$\begin{array}{c}\text { General Linear Models Procedure } \\
\text { Class Level Information }\end{array}$} \\
\hline & Class & Levels & Values & & \\
\hline & CELL & 3 & 456 & & \\
\hline \multicolumn{6}{|c|}{ Number of observations in by group $=15$} \\
\hline & \multicolumn{5}{|c|}{ General Linear Models Procedure } \\
\hline & \multicolumn{5}{|c|}{$\begin{array}{c}\text { Dependent Variable: TIME } \\
\text { Sum of } \\
\text { Mean }\end{array}$} \\
\hline Source & $\mathrm{DF}$ & Squares & Square & F Value & $\operatorname{Pr}>\mathrm{F}$ \\
\hline Model & 2 & 20407.60000 & 10203.80000 & 478.30 & 0.0001 \\
\hline Error & 12 & 256.00000 & 21.33333 & & \\
\hline \multirow[t]{3}{*}{ Corrected Total } & 14 & 20663.60000 & & & \\
\hline & R-Square & C.V. & Root MSE & & TIME Mean \\
\hline & 0.987611 & 4.892799 & 4.618802 & & 94.40000 \\
\hline Source & $\mathrm{DF}$ & Type I SS & Mean Square & F Value & $\operatorname{Pr}>\mathrm{F}$ \\
\hline CELL & 2 & 20407.60000 & 10203.80000 & 478.30 & 0.0001 \\
\hline Source & $\mathrm{DF}$ & Type III SS & Mean Square & F Value & $\operatorname{Pr}>\mathrm{F}$ \\
\hline CELL & 2 & 20407.60000 & 10203.80000 & 478.30 & 0.0001 \\
\hline
\end{tabular}

General Linear Models Procedure

Tukey's Studentized Range (HSD) Test for variable: TIME

NOTE: This test controls the type I experimentwise error rate, but generally has a higher type II error rate than REGWQ.

Alpha $=0.05 \quad \mathrm{df}=12 \mathrm{MSE}=21.33333$

Critical Value of Studentized Range $=3.773$

Minimum Significant Difference $=7.793$

Means with the same letter are not significantly different.

$\begin{array}{rrrr}\text { Tukey Grouping } & \text { Mean } & \text { N } & \text { CELL } \\ \text { A } & 141.000 & 5 & 4 \\ \text { B } & 91.400 & 5 & 5 \\ \text { C } & 50.800 & 5 & 6\end{array}$




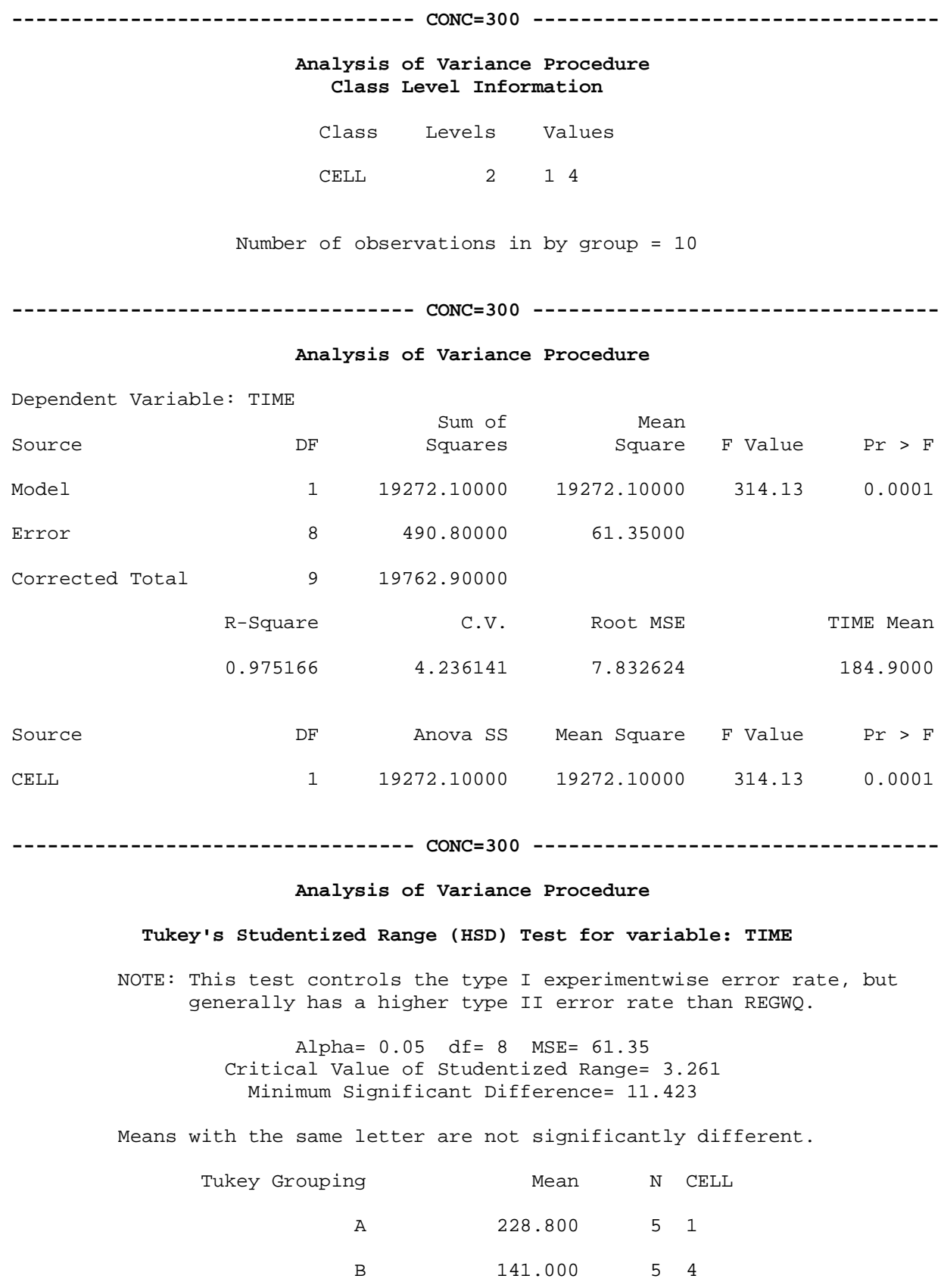




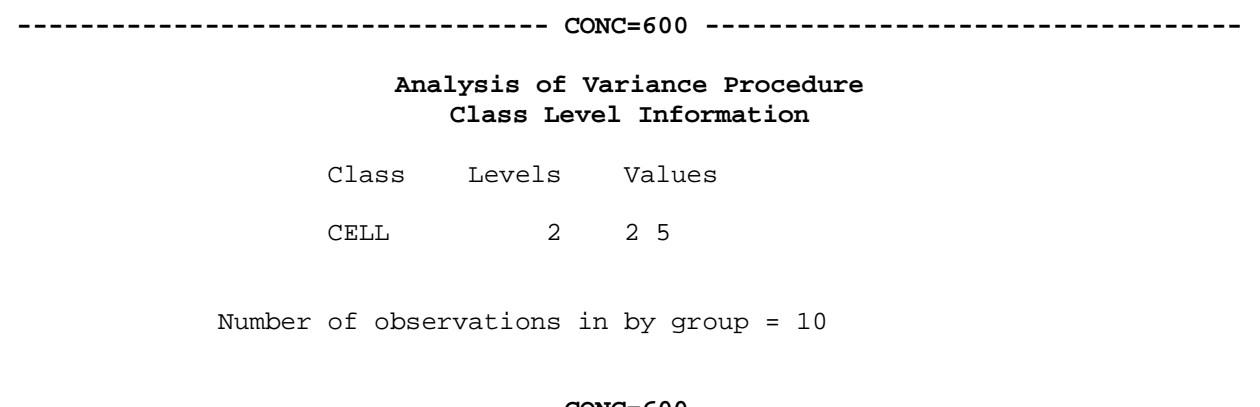

$\mathrm{CONC}=600$

Analysis of Variance Procedure

\begin{tabular}{|c|c|c|c|c|c|c|c|}
\hline & & & Sum of & Mean & & & \\
\hline Source & & $\mathrm{DF}$ & Squares & Square & $\mathrm{F}$ & Value & $\operatorname{Pr}>\mathrm{F}$ \\
\hline Model & & 1 & 688.9000000 & 688.9000000 & & 55.56 & 0.0001 \\
\hline Error & & 8 & 99.2000000 & 12.4000000 & & & \\
\hline \multirow[t]{3}{*}{ Corrected } & Total & 9 & 788.1000000 & & & & \\
\hline & & R-Square & C.V. & Root MSE & & & TIME Mean \\
\hline & & 0.874128 & 3.531959 & 3.521363 & & & 99.70000 \\
\hline Source & & $\mathrm{DF}$ & Anova SS & Mean Square & $\mathrm{F}$ & Value & $\operatorname{Pr}>\mathrm{F}$ \\
\hline CELL & & 1 & 688.9000000 & 688.9000000 & & 55.56 & 0.0001 \\
\hline
\end{tabular}

Analysis of Variance Procedure

Tukey's Studentized Range (HSD) Test for variable: TIME

NOTE: This test controls the type I experimentwise error rate, but generally has a higher type II error rate than REGWQ.

$$
\begin{gathered}
\text { Alpha= } 0.05 \quad \mathrm{df}=8 \mathrm{MSE}=12.4 \\
\text { Critical Value of Studentized Range= } 3.261 \\
\text { Minimum Significant Difference= } 5.1357
\end{gathered}
$$

Means with the same letter are not significantly different.

$\begin{array}{rrrr}\text { Tukey Grouping } & \text { Mean } & \text { N } & \text { CELL } \\ \text { A } & 108.000 & 5 & 2 \\ \text { B } & 91.400 & 5 & 5\end{array}$




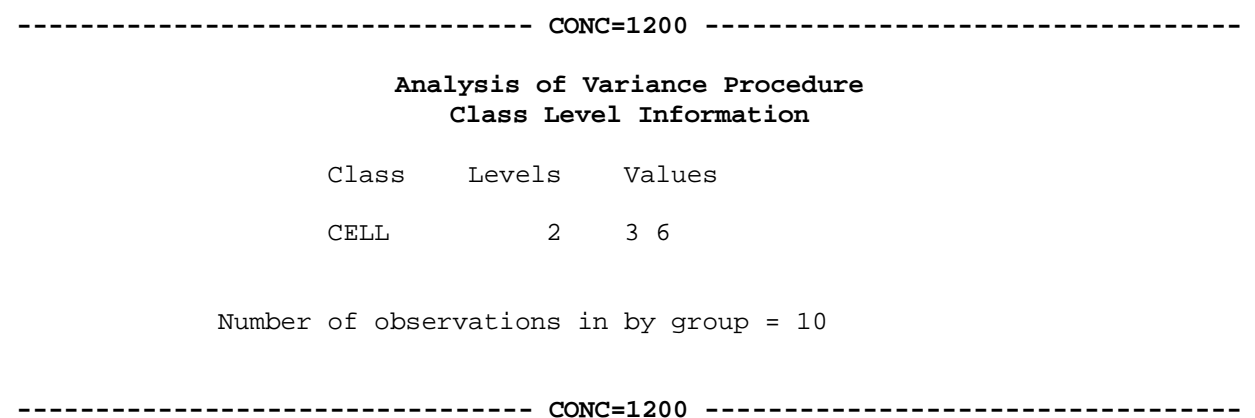

Analysis of Variance Procedure

\begin{tabular}{|c|c|c|c|c|c|c|c|}
\hline 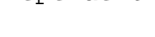 & & & Sum of & Mean & & & \\
\hline Source & & $\mathrm{DF}$ & Squares & Square & $\mathrm{F}$ & Value & $\operatorname{Pr}>\mathrm{F}$ \\
\hline Model & & 1 & 67.60000000 & 67.60000000 & & 4.71 & 0.0618 \\
\hline Error & & 8 & 114.80000000 & 14.35000000 & & & \\
\hline \multirow[t]{3}{*}{ Corrected } & Total & 9 & 182.40000000 & & & & \\
\hline & & R-Square & C.V. & Root MSE & & & TIME Mean \\
\hline & & 0.370614 & 7.093894 & 3.788139 & & & 53.40000 \\
\hline Source & & $\mathrm{DF}$ & Anova SS & Mean Square & $\mathrm{F}$ & Value & $\operatorname{Pr}>\mathrm{F}$ \\
\hline CELL & & 1 & 67.60000000 & 67.60000000 & & 4.71 & 0.0618 \\
\hline
\end{tabular}

Analysis of Variance Procedure

Tukey's Studentized Range (HSD) Test for variable: TIME

NOTE: This test controls the type I experimentwise error rate, but generally has a higher type II error rate than REGWQ.

$$
\begin{gathered}
\text { Alpha= } 0.05 \quad \mathrm{df}=8 \mathrm{MSE}=14.35 \\
\text { Critical Value of Studentized Range= } 3.261 \\
\text { Minimum Significant Difference= 5.5247 }
\end{gathered}
$$

Means with the same letter are not significantly different.

$\begin{array}{rrrr}\text { Tukey Grouping } & \text { Mean } & \text { N } & \text { CELL } \\ \text { A } & 56.000 & 5 & 3 \\ \text { A } & 50.800 & 5 & 6\end{array}$




$\begin{array}{rrrrrrrr}\text { OBS } & \text { FRACTION } & \text { CX } & \text { CONC } & \text { RH } & \text { PRIOR } & \text { TIME } & \text { CELL } \\ 1 & 0.1 & 30 & 300 & 50 & 0 & 221 & 1 \\ 2 & 0.1 & 30 & 300 & 50 & 0 & 219 & 1 \\ 3 & 0.1 & 30 & 300 & 50 & 0 & 229 & 1 \\ 4 & 0.1 & 30 & 300 & 50 & 0 & 232 & 1 \\ 5 & 0.1 & 30 & 300 & 50 & 0 & 243 & 1 \\ 6 & 0.1 & 30 & 300 & 80 & 0 & 135 & 4 \\ 7 & 0.1 & 30 & 300 & 80 & 0 & 139 & 4 \\ 8 & 0.1 & 30 & 300 & 80 & 0 & 138 & 4 \\ 9 & 0.1 & 30 & 300 & 80 & 0 & 149 & 4 \\ 10 & 0.1 & 30 & 300 & 80 & 0 & 144 & 4 \\ 11 & 0.1 & 60 & 600 & 50 & 0 & 108 & 2 \\ 12 & 0.1 & 60 & 600 & 50 & 0 & 109 & 2 \\ 13 & 0.1 & 60 & 600 & 50 & 0 & 104 & 2 \\ 14 & 0.1 & 60 & 600 & 50 & 0 & 110 & 2 \\ 15 & 0.1 & 60 & 600 & 50 & 0 & 109 & 2 \\ 16 & 0.1 & 60 & 600 & 80 & 0 & 92 & 5 \\ 17 & 0.1 & 60 & 600 & 80 & 0 & 85 & 5 \\ 18 & 0.1 & 60 & 600 & 80 & 0 & 93 & 5 \\ 19 & 0.1 & 60 & 600 & 80 & 0 & 90 & 5 \\ 20 & 0.1 & 60 & 600 & 80 & 0 & 97 & 5 \\ 21 & 0.1 & 120 & 1200 & 50 & 0 & 59 & 3 \\ 22 & 0.1 & 120 & 1200 & 50 & 0 & 52 & 3 \\ 23 & 0.1 & 120 & 1200 & 50 & 0 & 57 & 3 \\ 24 & 0.1 & 120 & 1200 & 50 & 0 & 52 & 3 \\ 25 & 0.1 & 120 & 1200 & 50 & 0 & 60 & 3 \\ 26 & 0.1 & 120 & 1200 & 80 & 0 & 51 & 6 \\ 27 & 0.1 & 120 & 1200 & 80 & 0 & 57 & 6 \\ 28 & 0.1 & 120 & 1200 & 80 & 0 & 47 & 6 \\ 29 & 0.1 & 120 & 1200 & 80 & 0 & 49 & 6 \\ 30 & 0.1 & 120 & 1200 & 80 & 0 & 50 & 6\end{array}$




\section{ANOVA and means tests for second hypothesis (PRIOR EXPOSURE and CONCENTRATION)}

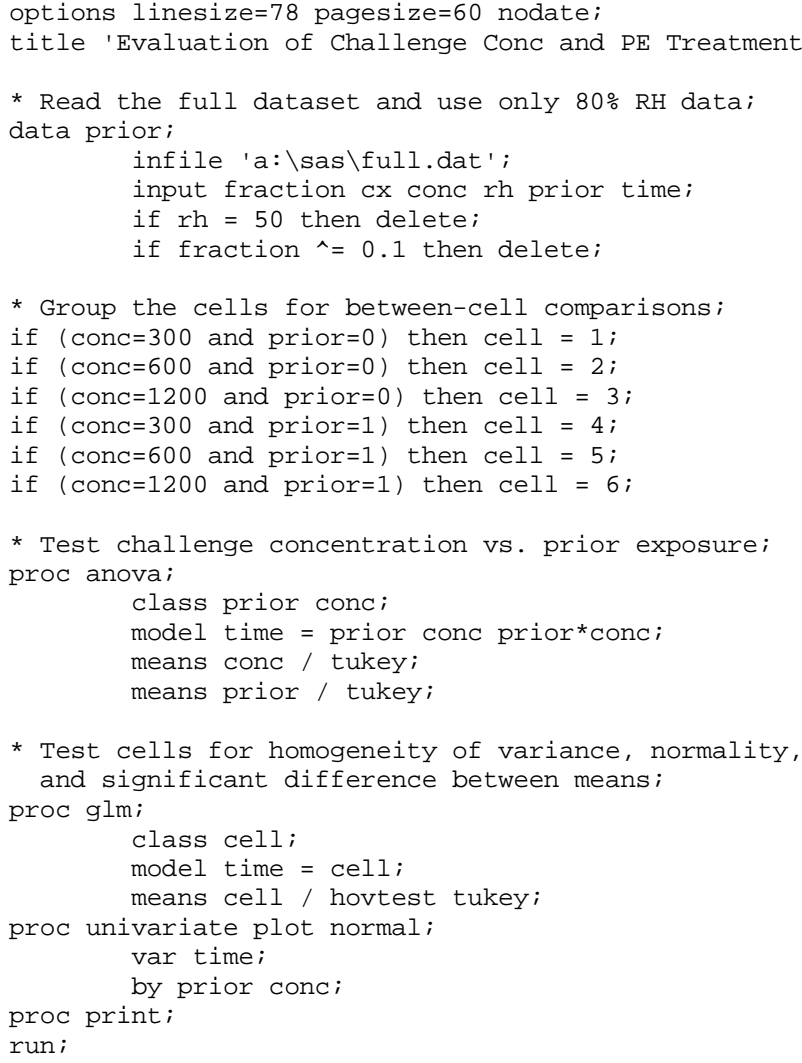


Evaluation of Challenge Conc and PE Treatment at 10\% Breakthrough

\section{Analysis of Variance Procedure}

Class Level Information

Class Levels Values

PRIOR $20 \quad 0 \quad 1$

CONC $\quad 3 \quad 300 \quad 600 \quad 1200$

Number of observations in data set $=30$

\section{Analysis of Variance Procedure}

Dependent Variable: TIME

\begin{tabular}{|c|c|c|c|c|c|}
\hline & & Sum of & Mean & & \\
\hline Source & $\mathrm{DF}$ & Squares & Square & F Value & $\operatorname{Pr}>\mathrm{F}$ \\
\hline Model & 5 & 39296.56667 & 7859.31333 & 452.99 & 0.0001 \\
\hline Error & 24 & 416.40000 & 17.35000 & & \\
\hline \multirow[t]{3}{*}{ Corrected Total } & 29 & 39712.96667 & & & \\
\hline & R-Square & C.V. & Root MSE & & TIME Mean \\
\hline & 0.989515 & 4.609369 & 4.165333 & & 90.36667 \\
\hline Source & $\mathrm{DF}$ & Anova SS & Mean Square & F Value & $\operatorname{Pr}>\mathrm{F}$ \\
\hline PRIOR & 1 & 488.03333 & 488.03333 & 28.13 & 0.0001 \\
\hline CONC & 2 & 38768.46667 & 19384.23333 & 1117.25 & 0.0001 \\
\hline $\mathrm{PRIOR} * \mathrm{CONC}$ & 2 & 40.06667 & 20.03333 & 1.15 & 0.3321 \\
\hline
\end{tabular}

Analysis of Variance Procedure

Tukey's Studentized Range (HSD) Test for variable: TIME

NOTE: This test controls the type I experimentwise error rate, but generally has a higher type II error rate than REGWQ.

Alpha $=0.05 \quad \mathrm{df}=24 \quad \mathrm{MSE}=17.35$

Critical Value of Studentized Range= 3.532

Minimum Significant Difference $=4.6519$

Means with the same letter are not significantly different.

$\begin{array}{rrrr}\text { Tukey Grouping } & \text { Mean } & \text { N } & \text { CONC } \\ \text { A } & 136.200 & 10 & 300 \\ \text { B } & 86.500 & 10 & 600 \\ \text { C } & 48.400 & 10 & 1200\end{array}$




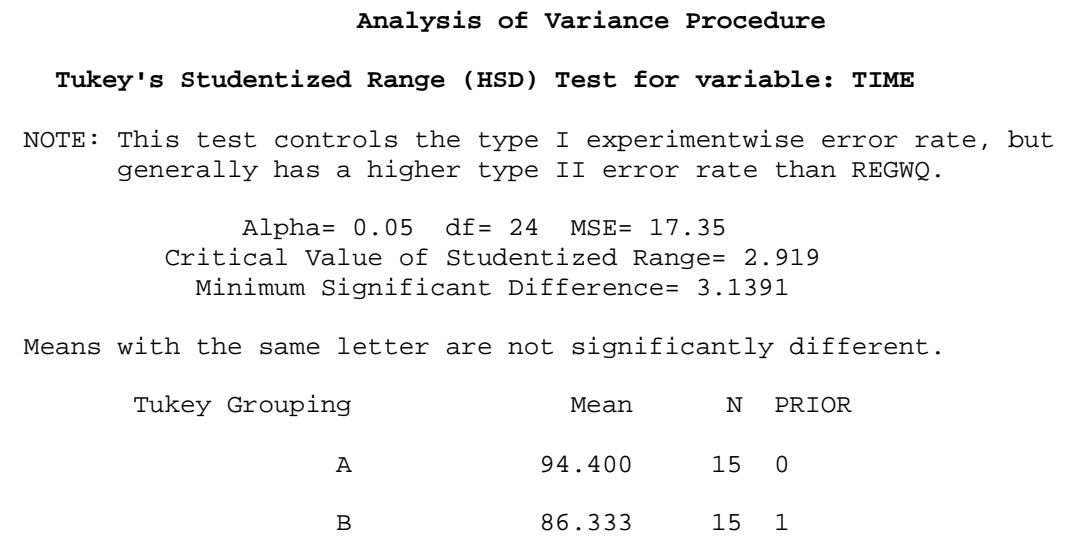

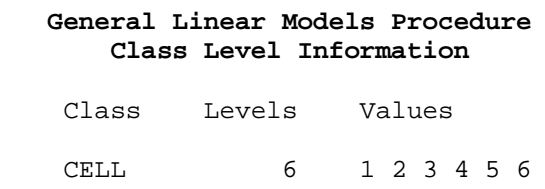

Number of observations in data set $=30$

\section{General Linear Models Procedure}

\begin{tabular}{|c|c|c|c|c|c|}
\hline & & Sum of & Mean & & \\
\hline Source & $\mathrm{DF}$ & Squares & Square & F Value & $\operatorname{Pr}>\mathrm{F}$ \\
\hline Model & 5 & 39296.56667 & 7859.31333 & 452.99 & 0.0001 \\
\hline Error & 24 & 416.40000 & 17.35000 & & \\
\hline \multirow[t]{3}{*}{ Corrected Total } & 29 & 39712.96667 & & & \\
\hline & R-Square & C.V. & Root MSE & & TIME Mean \\
\hline & 0.989515 & 4.609369 & 4.165333 & & 90.36667 \\
\hline Source & $\mathrm{DF}$ & Type I SS & Mean Square & F Value & $\operatorname{Pr}>\mathrm{F}$ \\
\hline CELL & 5 & 39296.56667 & 7859.31333 & 452.99 & 0.0001 \\
\hline Source & $\mathrm{DF}$ & Type III SS & Mean Square & F Value & $\operatorname{Pr}>\mathrm{F}$ \\
\hline CELL & 5 & 39296.56667 & 7859.31333 & 452.99 & 0.0001 \\
\hline
\end{tabular}


General Linear Models Procedure

Levene's Test for Equality of TIME Variance ANOVA of Squared Deviations from Group Means

$\begin{array}{lrrrrr}\text { Source } & \text { DF } & \begin{array}{c}\text { Sum of } \\ \text { Squares }\end{array} & \begin{array}{c}\text { Mean } \\ \text { Square }\end{array} & \text { F Value } & \text { Pr }>\text { F } \\ \text { CELL } & 5 & 846.6 & 169.3 & 0.6156 & 0.6890 \\ \text { Error } & 24 & 6601.7 & 275.1 & & \end{array}$

General Linear Models Procedure

Tukey's Studentized Range (HSD) Test for variable: TIME

NOTE: This test controls the type I experimentwise error rate, but generally has a higher type II error rate than REGWQ.

Alpha $=0.05 \quad \mathrm{df}=24 \quad \mathrm{MSE}=17.35$

Critical Value of Studentized Range $=4.373$

Minimum Significant Difference $=8.1454$

Means with the same letter are not significantly different.

$\begin{array}{rrrr}\text { Tukey Grouping } & \text { Mean } & \text { N } & \text { CELL } \\ \text { A } & 141.000 & 5 & 1 \\ \text { B } & 131.400 & 5 & 4 \\ \text { C } & 91.400 & 5 & 2 \\ \text { D } & 81.600 & 5 & 5 \\ \text { E } & 50.800 & 5 & 3 \\ \text { E } & 46.000 & 5 & 6 \\ \text { E } & & & \end{array}$


PRIOR $=0 \quad$ CONC $=300$

\section{Univariate Procedure}

\section{Variable $=$ TIME}

Moments$$
\mathrm{N}
$$

Mean

Std Dev

Skewness

USS

$\mathrm{CV}$

$\mathrm{T}: \mathrm{Mean}=0$

Num $\wedge=0$

M (Sign)

Sgn Rank

W: Normal

$\begin{aligned} 5 & \text { Sum Wgts } \\ 141 & \text { Sum } \\ 5.522681 & \text { Variance } \\ 0.712412 & \text { Kurtosis } \\ 99527 & \text { CSS } \\ 3.916795 & \text { Std Mean } \\ 57.08923 & \text { Pr }>|\mathrm{T}| \\ 5 & \text { Num }>0 \\ 2.5 & \text { Pr }>=|\mathrm{M}| \\ 7.5 & \text { Pr }>=|\mathrm{S}| \\ 0.947621 & \text { Pr }<\mathrm{W}\end{aligned}$

$0.947621 \quad$ Pr $<W$

Quantiles (Def $=5$ )

$\begin{array}{rrrr}100 \% \text { Max } & 149 & 99 \% & 149 \\ 75 \% \text { Q3 } & 144 & 95 \% & 149 \\ 50 \% \text { Med } & 139 & 90 \% & 149 \\ 25 \% \text { Q1 } & 138 & 10 \% & 135 \\ 0 \% \text { Min } & 135 & 5 \% & 135 \\ & & 1 \% & 135 \\ \text { Range } & 14 & & \end{array}$

Q3-Q1

Mode

Lowest
135(
$138 i$
$139 i$
144(
149(

$\begin{array}{rrr}\text { Obs } & \text { Highest } & \text { Obs } \\ \text { 1) } & 135( & 1) \\ 3) & 138( & 3) \\ 2) & 139( & 2) \\ 5) & 144( & 5) \\ 4) & 149( & 4)\end{array}$

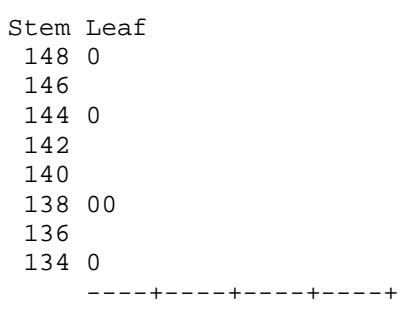

\#

1

2

1

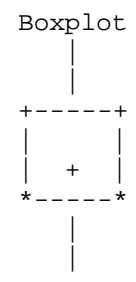


PRIOR $=0 \quad \mathrm{CONC}=300$

Univariate Procedure

\section{Variable $=$ TIME}

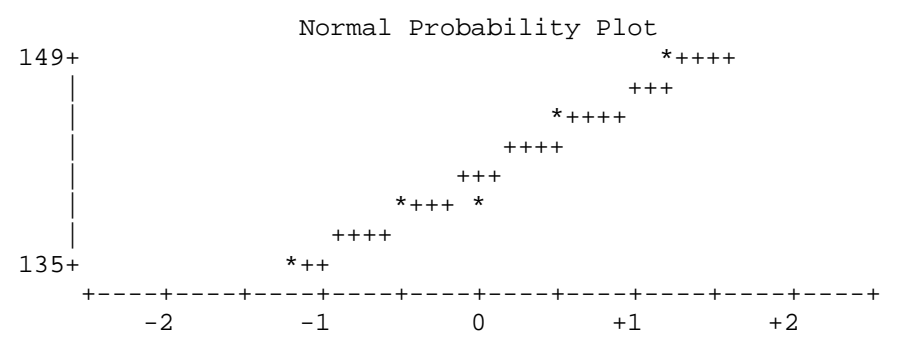


PRIOR $=0 \quad \mathrm{CONC}=600$

\section{Univariate Procedure}

\section{Variable $=$ TIME}

Moments

$\begin{array}{lrlr}\text { N } & 5 & \text { Sum Wgts } & 5 \\ \text { Mean } & 91.4 & \text { Sum } & 457 \\ \text { Std Dev } & 4.393177 & \text { Variance } & 19.3 \\ \text { Skewness } & -0.41751 & \text { Kurtosis } & 0.965664 \\ \text { USS } & 41847 & \text { CSS } & 77.2 \\ \text { CV } & 4.806539 & \text { Std Mean } & 1.964688 \\ \text { T }: \text { Mean=0 } & 46.52138 & \text { Pr }>|\mathrm{T}| & 0.0001 \\ \text { Num } \wedge=0 & 5 & \text { Num }>0 & 5 \\ \text { M(Sign) } & 2.5 & \text { Pr }>=|M| & 0.0625 \\ \text { Sgn Rank } & 7.5 & \text { Pr }>=|\mathrm{S}| & 0.0625 \\ \text { W:Normal } & 0.980238 & \text { Pr }<W & 0.9224\end{array}$

Quantiles (Def=5)

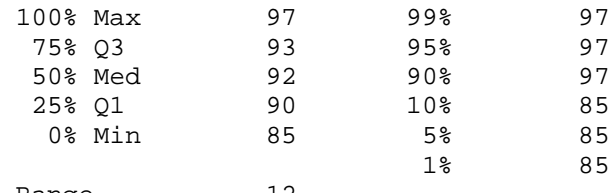

$\begin{array}{lr}\text { Range } & 12 \\ \text { Q3-Q1 } & 3\end{array}$

Mode 85

Extremes

$\begin{array}{rrrr}\text { Lowest } & \text { Obs } & \text { Highest } & \text { Obs } \\ 85( & 2) & 85( & 2) \\ 90( & 4) & 90( & 4) \\ 92( & 1) & 92( & 1) \\ 93( & 3) & 93( & 3) \\ 97( & 5) & 97( & 5)\end{array}$

$\begin{array}{rlcc}\text { Stem Leaf } & \# & \text { Boxplot } \\ 96 & 0 & 1 & \\ 94 & & & +----+ \\ 92 & 00 & 2 & +-+-+ \\ 90 & 0 & 1 & 0 \\ 88 & & \\ 86 & & 1 & \\ 84 & 0 & & \end{array}$




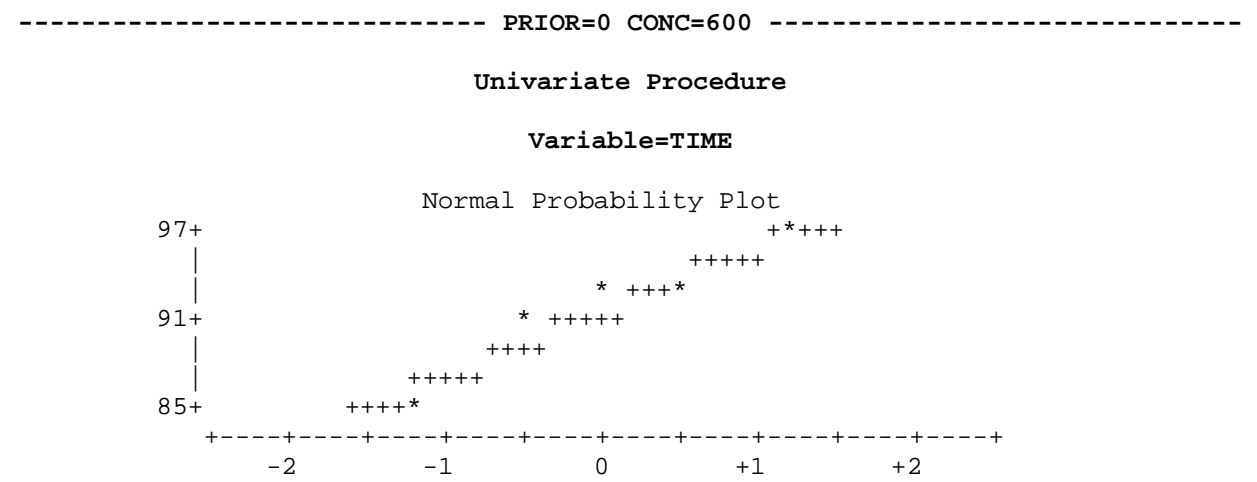


PRIOR $=0 \quad \mathrm{CONC}=1200$

Univariate Procedure

\section{Variable=TIME}

Moments

$\begin{array}{lrlr}\text { N } & 5 & \text { Sum Wgts } & 5 \\ \text { Mean } & 50.8 & \text { Sum } & 254 \\ \text { Std Dev } & 3.768289 & \text { Variance } & 14.2 \\ \text { Skewness } & 1.379189 & \text { Kurtosis } & 2.520333 \\ \text { USS } & 12960 & \text { CSS } & 56.8 \\ \text { CV } & 7.417891 & \text { Std Mean } & 1.68523 \\ \text { T :Mean=0 } & 30.14425 & \text { Pr }>|\mathrm{T}| & 0.0001 \\ \text { Num ^=0 } & 5 & \text { Num }>0 & 5 \\ \text { M(Sign) } & 2.5 & \text { Pr }>=|\mathrm{M}| & 0.0625 \\ \text { Sgn Rank } & 7.5 & \text { Pr }>=|\mathrm{S}| & 0.0625 \\ \text { W:Normal } & 0.894664 & \text { Pr }<W & 0.3786\end{array}$

Quantiles $($ Def $=5)$

$\begin{array}{cccc}100 \% \text { Max } & 57 & 99 \% & 57 \\ 75 \% \mathrm{Q} 3 & 51 & 95 \% & 57 \\ 50 \% \text { Med } & 50 & 90 \% & 57 \\ 25 \% \text { Q1 } & 49 & 10 \% & 47 \\ 0 \% \text { Min } & 47 & 5 \% & 47 \\ & & 1 \% & 47\end{array}$

$\begin{array}{lr}\text { Range } & 10 \\ \text { Q3-Q1 } & 2\end{array}$

Mode 47

Extremes

$\begin{array}{rrrr}\text { Lowest } & \text { Obs } & \text { Highest } & \text { Obs } \\ 47( & 3) & 47( & 3) \\ 49( & 4) & 49( & 4) \\ 50( & 5) & 50( & 5) \\ 51( & 1) & 51( & 1) \\ 57( & 2) & 57( & 2)\end{array}$

\begin{tabular}{|c|c|c|c|}
\hline Stem & Leaf & \# & Boxplot \\
\hline 56 & 0 & 1 & 0 \\
\hline 54 & & & \\
\hline 52 & & & \\
\hline 50 & 00 & 2 & +--+--+ \\
\hline 48 & 0 & 1 & +-----+ \\
\hline 46 & 0 & 1 & $\mid$ \\
\hline
\end{tabular}




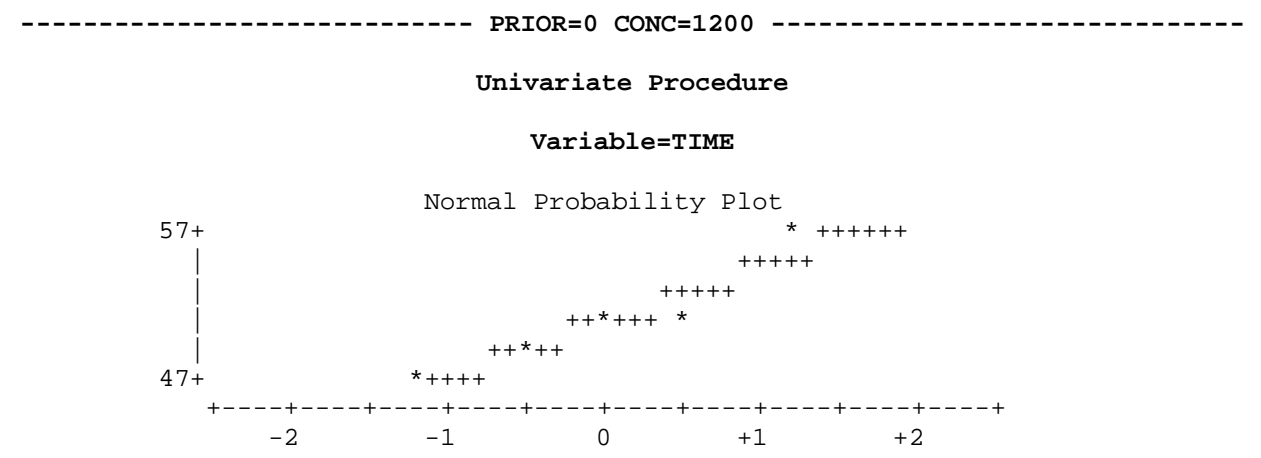


PRIOR $=1 \quad \mathrm{CONC}=300$

Univariate Procedure

\section{Variable $=$ TIME}

Moments

$\begin{array}{lrlr}\text { N } & 5 & \text { Sum Wgts } & 5 \\ \text { Mean } & 131.4 & \text { Sum } & 657 \\ \text { Std Dev } & 4.219005 & \text { Variance } & 17.8 \\ \text { Skewness } & -0.83091 & \text { Kurtosis } & 0.581366 \\ \text { USS } & 86401 & \text { CSS } & 71.2 \\ \text { CV } & 3.21081 & \text { Std Mean } & 1.886796 \\ \text { T:Mean=0 } & 69.64186 & \text { Pr }>|\mathrm{T}| & 0.0001 \\ \text { Num ^=0 } & 5 & \text { Num }>0 & 5 \\ \text { M(Sign) } & 2.5 & \text { Pr }>=|M| & 0.0625 \\ \text { Sgn Rank } & 7.5 & \text { Pr }>=|\mathrm{S}| & 0.0625 \\ \text { W:Normal } & 0.961922 & \operatorname{Pr}<W & 0.8204\end{array}$

Quantiles (Def=5)

\begin{tabular}{|c|c|c|c|c|}
\hline $100 \%$ & Max & 136 & $99 \%$ & 136 \\
\hline $75 \%$ & Q3 & 134 & $95 \%$ & 136 \\
\hline $50 \%$ & Med & 132 & $90 \%$ & 136 \\
\hline $25 \%$ & Q1 & 130 & $10 \%$ & 125 \\
\hline $0 \%$ & Min & 125 & $5 \%$ & 125 \\
\hline
\end{tabular}

Range

Q3-Q1

11

125

Extremes

$\begin{array}{rrrr}\text { Lowest } & \text { Obs } & \text { Highest } & \text { Obs } \\ 125( & 3) & 125( & 3) \\ 130( & 2) & 130( & 2) \\ 132( & 4) & 132( & 4) \\ 134( & 5) & 134( & 5) \\ 136( & 1) & 136( & 1)\end{array}$

$\begin{array}{rllc}\text { Stem } & \text { Leaf } & \# & \text { Boxplot } \\ 136 & 0 & 1 & +---++ \\ 134 & 0 & 1 & \star----\star \\ 132 & 0 & 1 & +-+-+ \\ 130 & 0 & 1 & \\ 128 & & & \\ 126 & & & \\ 124 & 0 & 1 & \end{array}$




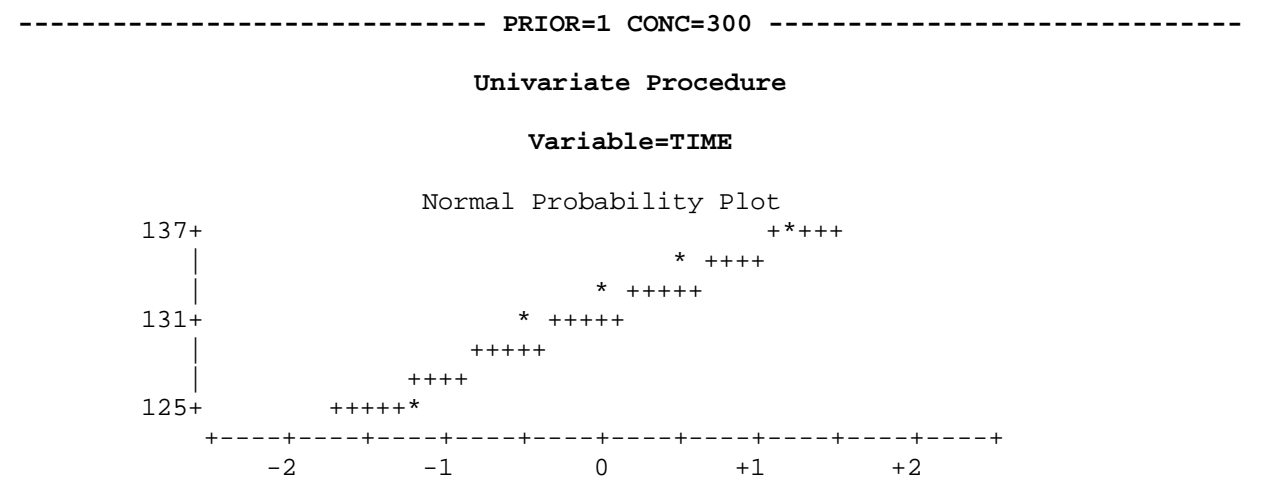


PRIOR $=1 \quad \mathrm{CONC}=600$

Univariate Procedure

\section{Variable $=$ TIME}

Moments

$\begin{array}{lrlr}\text { N } & 5 & \text { Sum Wgts } & 5 \\ \text { Mean } & 81.6 & \text { Sum } & 408 \\ \text { Std Dev } & 3.435113 & \text { Variance } & 11.8 \\ \text { Skewness } & -0.60689 & \text { Kurtosis } & -2.03821 \\ \text { USS } & 33340 & \text { CSS } & 47.2 \\ \text { CV } & 4.209697 & \text { Std Mean } & 1.536229 \\ \text { T }: \text { Mean=0 } & 53.11708 & \text { Pr }>|\mathrm{T}| & 0.0001 \\ \text { Num } \wedge=0 & 5 & \text { Num }>0 & 5 \\ \text { M(Sign) } & 2.5 & \text { Pr }>=|M| & 0.0625 \\ \text { Sgn Rank } & 7.5 & \text { Pr }>=|\mathrm{S}| & 0.0625 \\ \text { W: Normal } & 0.901556 & \text { Pr }<\text { W } & 0.4155\end{array}$

Quantiles $($ Def $=5)$

$\begin{array}{ccrl}100 \% \text { Max } & 85 & 99 \% & 85 \\ 75 \% \mathrm{Q} 3 & 84 & 95 \% & 85 \\ 50 \% \text { Med } & 83 & 90 \% & 85 \\ 25 \% \mathrm{Q} 1 & 79 & 10 \% & 77 \\ 0 \% \text { Min } & 77 & 5 \% & 77 \\ & & 1 \% & 77\end{array}$

$\begin{array}{lr}\text { Range } & 8 \\ \text { Q3-Q1 } & 5\end{array}$

Mode 77

Extremes

$\begin{array}{rrrr}\text { Lowest } & \text { Obs } & \text { Highest } & \text { Obs } \\ 77( & 1) & 77( & 1) \\ 79( & 4) & 79( & 4) \\ 83( & 3) & 83( & 3) \\ 84( & 2) & 84( & 2) \\ 85( & 5) & 85( & 5)\end{array}$

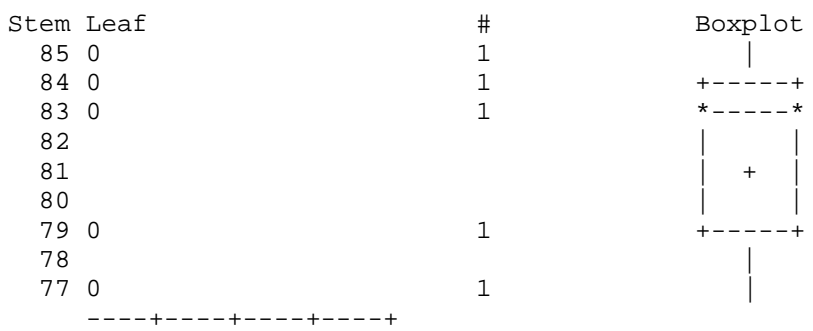


PRIOR $=1 \quad \mathrm{CONC}=600$

Univariate Procedure

Variable $=$ TIME

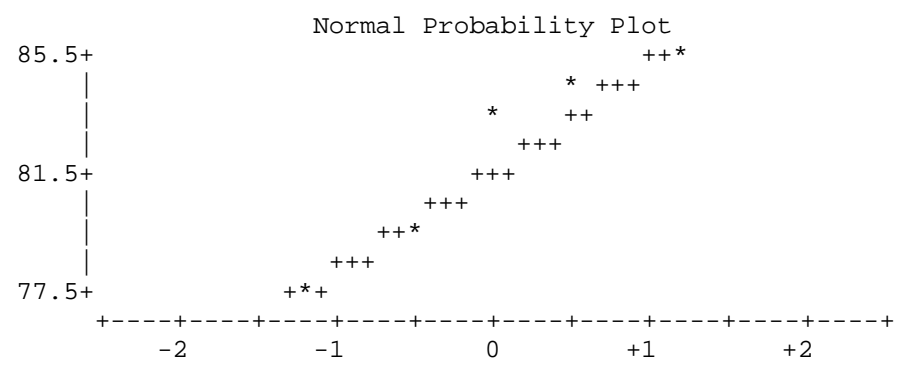


PRIOR=1 CONC $=1200$

Univariate Procedure

\section{Variable=TIME}

Moments

$\begin{array}{lrlr}\text { N } & 5 & \text { Sum Wgts } & 5 \\ \text { Mean } & 46 & \text { Sum } & 230 \\ \text { Std Dev } & 3.24037 & \text { Variance } & 10.5 \\ \text { Skewness } & -0.58782 & \text { Kurtosis } & -2.89796 \\ \text { USS } & 10622 & \text { CSS } & 42 \\ \text { CV } & 7.044283 & \text { Std Mean } & 1.449138 \\ \text { T:Mean=0 } & 31.74302 & \text { Pr }>|\mathrm{T}| & 0.0001 \\ \text { Num ^=0 } & 5 & \text { Num }>0 & 5 \\ \text { M(Sign) } & 2.5 & \text { Pr }>=|\mathrm{M}| & 0.0625 \\ \text { Sgn Rank } & 7.5 & \text { Pr }>=|\mathrm{S}| & 0.0625 \\ \text { W: Normal } & 0.817247 & \text { Pr }<\text { W } & 0.1095\end{array}$

Quantiles $($ Def $=5)$

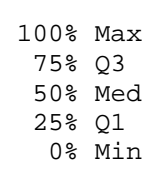

$49 \quad 99 \%$

$99 \% \quad 49$

$48 \quad 95 \% \quad 49$

$48 \quad 90 \% \quad 49$

$43 \quad 10 \% \quad 42$

$42 \quad 5 \%$

Range

Q3-Q1

Mode

7

5
48

Extremes

$\begin{array}{rrrr}\text { Lowest } & \text { Obs } & \text { Highest } & \text { Obs } \\ 42( & 3) & 42( & 3) \\ 43( & 4) & 43( & 4) \\ 48( & 5) & 48( & 2) \\ 48( & 2) & 48( & 5) \\ 49( & 1) & 49( & 1)\end{array}$
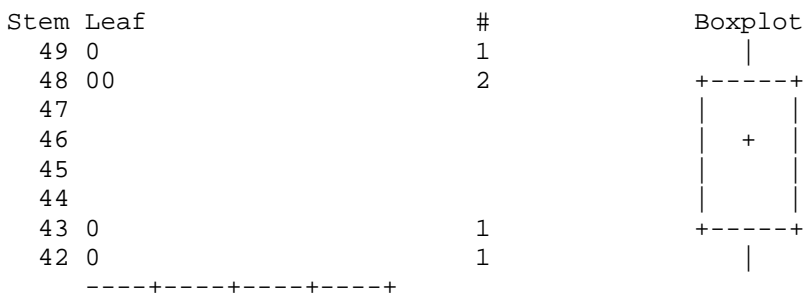
PRIOR=1 CONC $=1200$

Univariate Procedure

Variable $=$ TIME

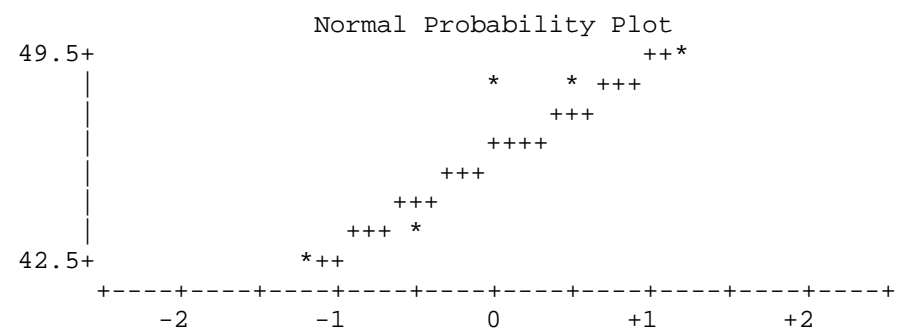


Univariate Procedure

Schematic Plots

Variable $=$ TIME

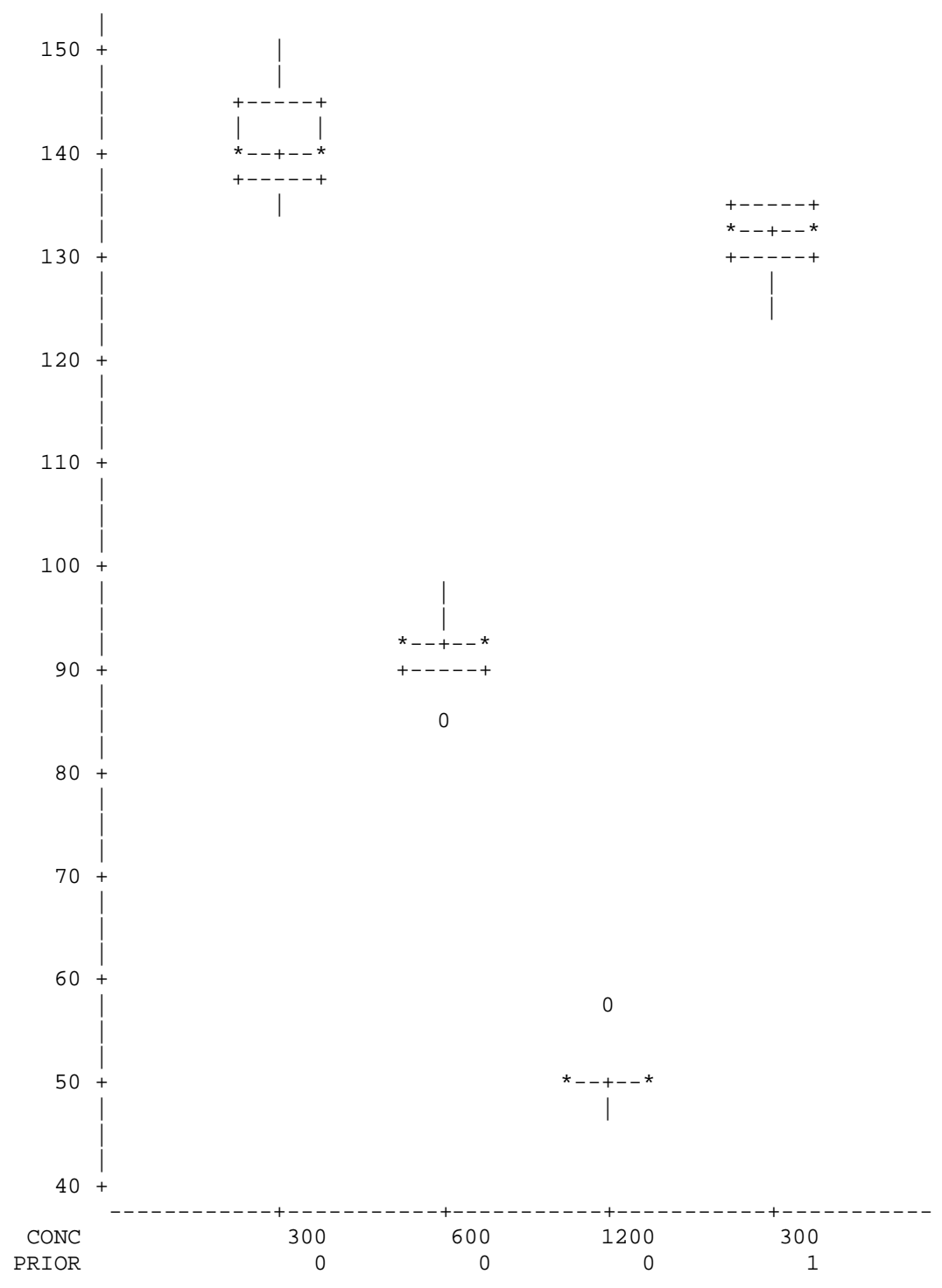


Univariate Procedure

Schematic Plots

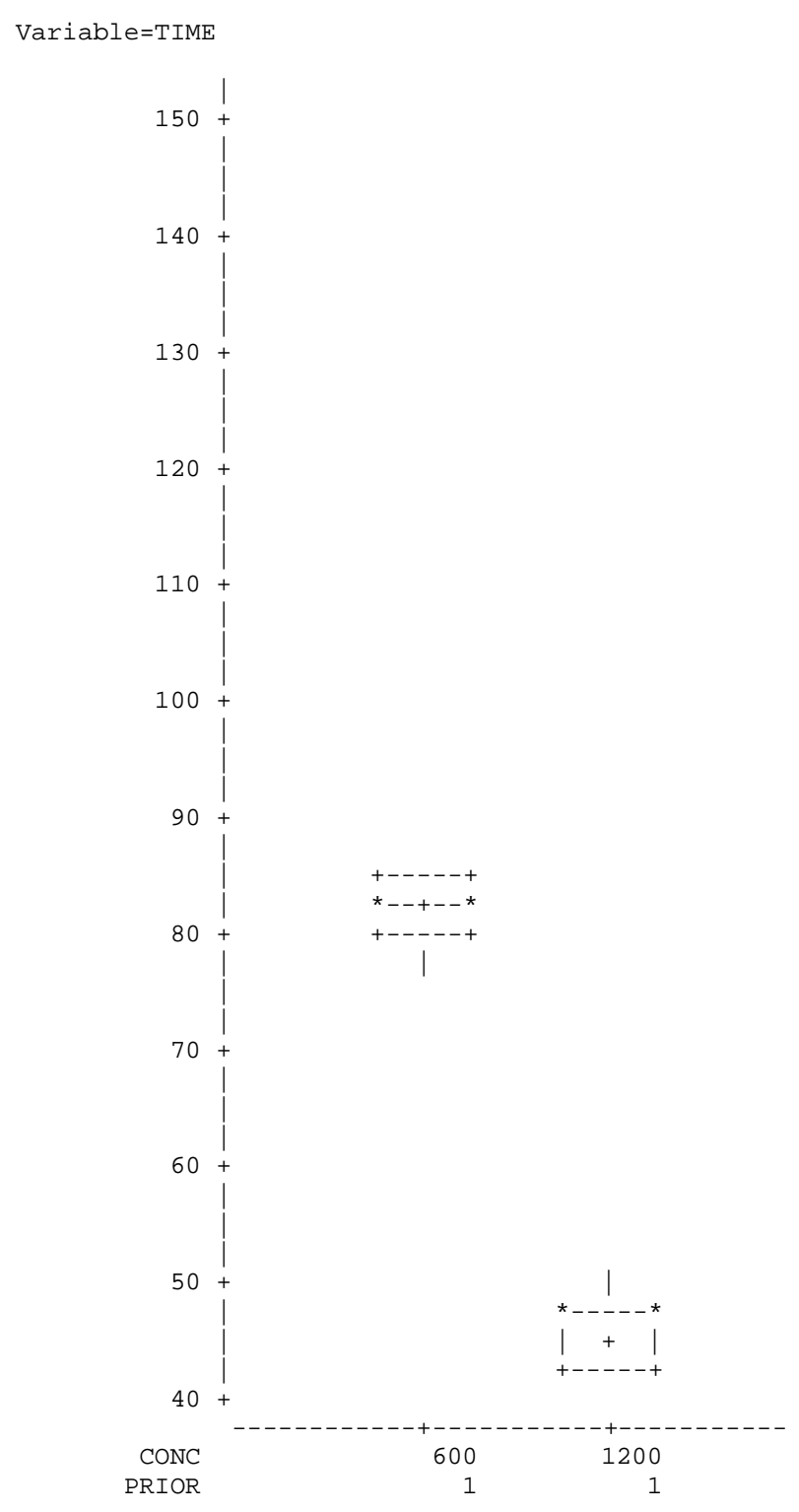




$\begin{array}{rrrrrrrr}\text { OBS } & \text { FRACTION } & \text { CX } & \text { CONC } & \text { RH } & \text { PRIOR } & \text { TIME } & \text { CELL } \\ 1 & 0.1 & 30 & 300 & 80 & 0 & 135 & 1 \\ 2 & 0.1 & 30 & 300 & 80 & 0 & 139 & 1 \\ 3 & 0.1 & 30 & 300 & 80 & 0 & 138 & 1 \\ 4 & 0.1 & 30 & 300 & 80 & 0 & 149 & 1 \\ 5 & 0.1 & 30 & 300 & 80 & 0 & 144 & 1 \\ 6 & 0.1 & 60 & 600 & 80 & 0 & 92 & 2 \\ 7 & 0.1 & 60 & 600 & 80 & 0 & 85 & 2 \\ 8 & 0.1 & 60 & 600 & 80 & 0 & 93 & 2 \\ 9 & 0.1 & 60 & 600 & 80 & 0 & 90 & 2 \\ 10 & 0.1 & 60 & 600 & 80 & 0 & 97 & 2 \\ 11 & 0.1 & 120 & 1200 & 80 & 0 & 51 & 3 \\ 12 & 0.1 & 120 & 1200 & 80 & 0 & 57 & 3 \\ 13 & 0.1 & 120 & 1200 & 80 & 0 & 47 & 3 \\ 14 & 0.1 & 120 & 1200 & 80 & 0 & 49 & 3 \\ 15 & 0.1 & 120 & 1200 & 80 & 0 & 50 & 3 \\ 16 & 0.1 & 30 & 300 & 80 & 1 & 136 & 4 \\ 17 & 0.1 & 30 & 300 & 80 & 1 & 130 & 4 \\ 18 & 0.1 & 30 & 300 & 80 & 1 & 125 & 4 \\ 19 & 0.1 & 30 & 300 & 80 & 1 & 132 & 4 \\ 20 & 0.1 & 30 & 300 & 80 & 1 & 134 & 4 \\ 21 & 0.1 & 60 & 600 & 80 & 1 & 77 & 5 \\ 22 & 0.1 & 60 & 600 & 80 & 1 & 84 & 5 \\ 23 & 0.1 & 60 & 600 & 80 & 1 & 83 & 5 \\ 24 & 0.1 & 60 & 600 & 80 & 1 & 79 & 5 \\ 25 & 0.1 & 60 & 600 & 80 & 1 & 85 & 5 \\ 26 & 0.1 & 120 & 1200 & 80 & 1 & 49 & 6 \\ 27 & 0.1 & 120 & 1200 & 80 & 1 & 48 & 6 \\ 28 & 0.1 & 120 & 1200 & 80 & 1 & 42 & 6 \\ 29 & 0.1 & 120 & 1200 & 80 & 1 & 43 & 6 \\ 30 & 0.1 & 120 & 1200 & 80 & 1 & 48 & 6\end{array}$




\section{APPENDIX E}

\section{Curve-Fitting Analysis of Generalized Yoon and Nelson Equation}

This appendix presents the results of Oakdale Engineering's DataFit software analysis of a generalized form of the Yoon and Nelson equation for each of the nine treatment combinations. 
Table E-1. Generalized Yoon and Nelson equation curve fit results for 50 percent relative humidity and $300 \mathrm{ppm}$ fuel vapor test conditions, using breatkthrough times at $1 \%, 5 \%, 10 \%$, and $20 \%$ of challenge concentration.

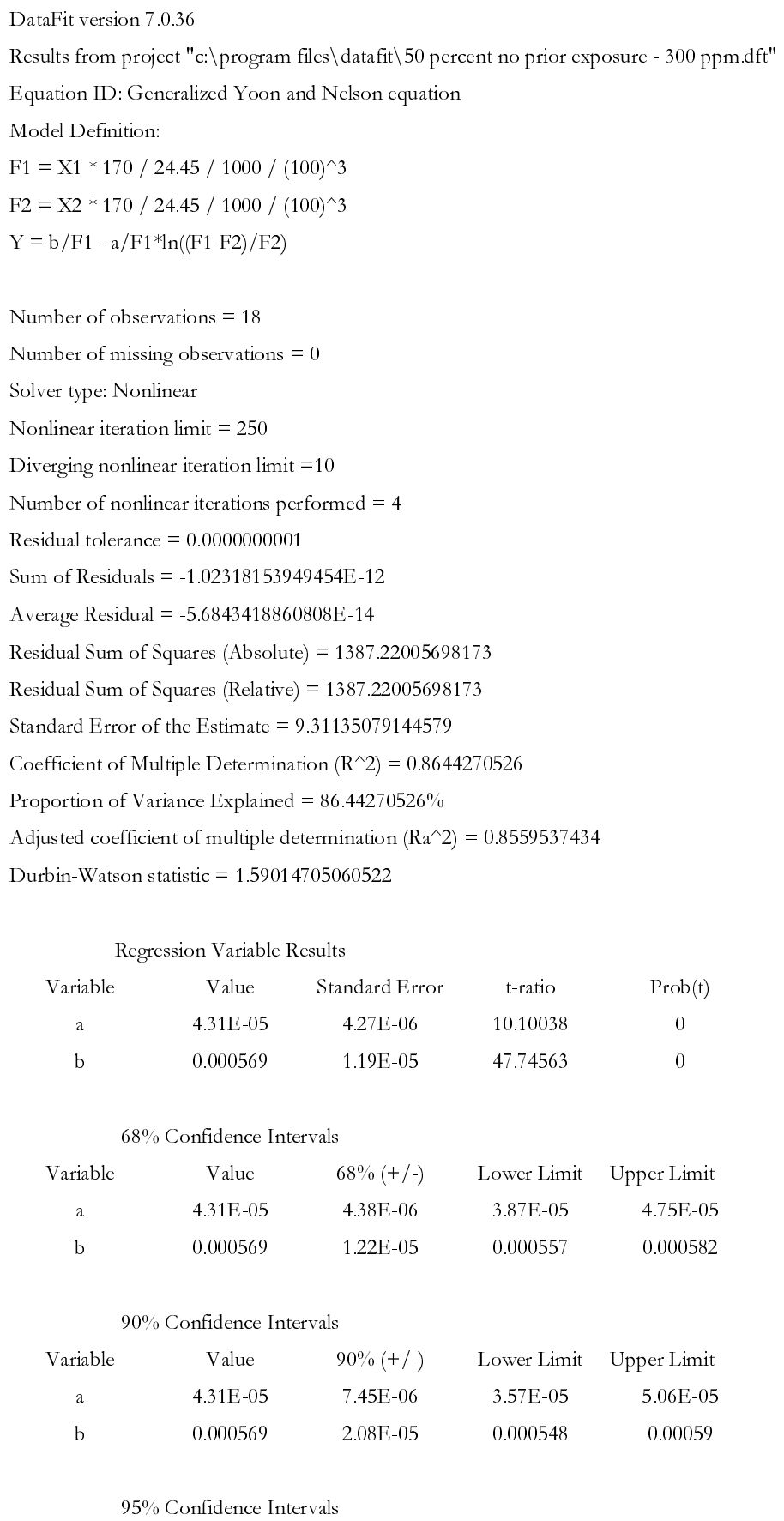

\begin{tabular}{|c|c|c|c|c|}
\hline \multicolumn{5}{|c|}{ Regression Variable Results } \\
\hline Variable & Value & Standard Frror & t-ratio & $\operatorname{Prob}(\mathrm{t})$ \\
\hline a & $4.31 \mathrm{E}-05$ & $4.27 \mathrm{E}-06$ & 10.10038 & 0 \\
\hline $\mathrm{b}$ & 0.000569 & $1.19 \mathrm{E}-05$ & 47.74563 & 0 \\
\hline \multicolumn{5}{|c|}{$68 \%$ Confidence Intervals } \\
\hline Variable & Value & $68 \%(+/-)$ & Lower Limit & Upper Iimit \\
\hline a & $4.31 \mathrm{E}-05$ & $4.38 \mathrm{E}-06$ & $3.87 \mathrm{E}-05$ & $4.75 \mathrm{E}-05$ \\
\hline $\mathrm{b}$ & 0.000569 & $1.22 \mathrm{E}-05$ & 0.000557 & 0.000582 \\
\hline \multicolumn{5}{|c|}{$90 \%$ Confidence Intervals } \\
\hline Variable & Value & $90 \%(+/-)$ & Lower Limit & Upper Limit \\
\hline a & $4.31 \mathrm{E}-05$ & $7.45 \mathrm{E}-06$ & $3.57 \mathrm{E}-05$ & $5.06 \mathrm{E}-05$ \\
\hline$b$ & 0.000569 & $2.08 \mathrm{E}-05$ & 0.000548 & 0.00059 \\
\hline
\end{tabular}

$95 \%$ Confidence Intervals 


\begin{tabular}{|c|c|c|c|c|c|}
\hline Variable & Value & $95 \%(+/-)$ & Lower Limit & Upper Limit & \\
\hline $\mathrm{a}$ & $4.31 \mathrm{E}-05$ & $9.05 \mathrm{E}-06$ & $3.41 \mathrm{E}-05$ & $5.22 \mathrm{E}-05$ & \\
\hline $\mathrm{b}$ & 0.000569 & $2.53 \mathrm{E}-05$ & 0.000544 & 0.000595 & \\
\hline \multicolumn{6}{|c|}{$99 \%$ Confidence Intervals } \\
\hline Variable & Value & $99 \%(+/-)$ & Lower Limit & Upper Limit & \\
\hline $\mathrm{a}$ & $4.31 \mathrm{E}-05$ & $1.25 \mathrm{E}-05$ & $3.06 \mathrm{E}-05$ & $5.56 \mathrm{E}-05$ & \\
\hline $\mathrm{b}$ & 0.000569 & $3.48 \mathrm{E}-05$ & 0.000534 & 0.000604 & \\
\hline \multicolumn{6}{|c|}{ Variance Analysis } \\
\hline Source & DF & Sum of Squares & Mean Square & F Ratio & $\operatorname{Prob}(F)$ \\
\hline Regression & 1 & 8845.058 & 8845.058 & 102.0176 & 0 \\
\hline Error & 16 & 1387.22 & 86.70125 & & \\
\hline Total & 17 & 10232.28 & & & \\
\hline
\end{tabular}


Table E-2. Generalized Yoon and Nelson equation curve fit results for 50 percent relative humidity and $600 \mathrm{ppm}$ fuel vapor test conditions, using breatkthrough times at $1 \%, 5 \%, 10 \%$, and $20 \%$ of challenge concentration.

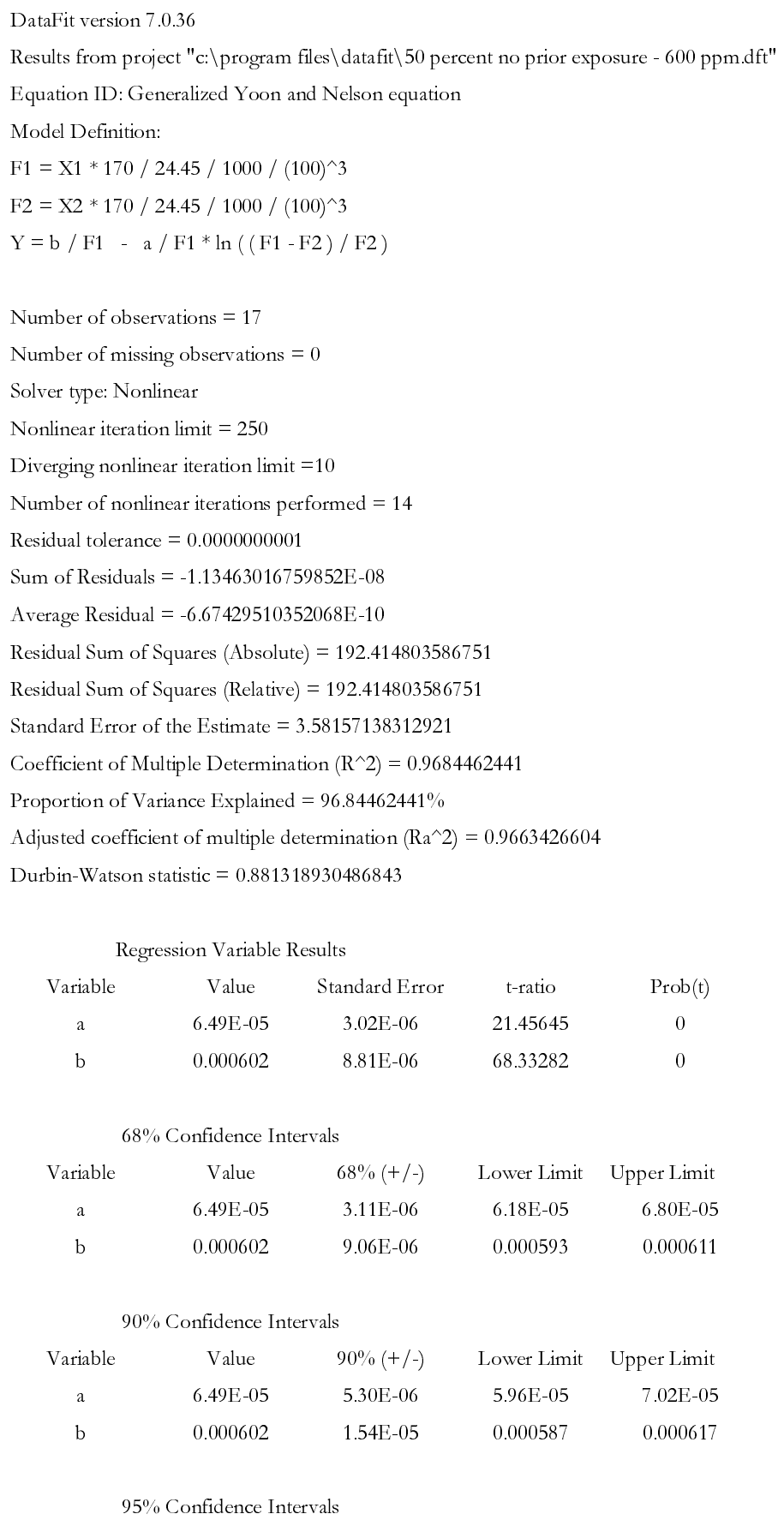

\begin{tabular}{|c|c|c|c|c|}
\hline \multicolumn{5}{|c|}{ Regression Variable Results } \\
\hline Variable & Value & Standard Frror & t-ratio & $\operatorname{Prob}(\mathrm{t})$ \\
\hline a & $6.49 \mathrm{E}-05$ & $3.02 \mathrm{E}-06$ & 21.45645 & 0 \\
\hline $\mathrm{b}$ & 0.000602 & $8.81 \mathrm{E}-06$ & 68.33282 & 0 \\
\hline \multicolumn{5}{|c|}{$68 \%$ Confidence Intervals } \\
\hline Variable & Value & $68 \%(+/-)$ & Lower Limit & Upper Iimit \\
\hline a & $6.49 \mathrm{E}-05$ & $3.11 \mathrm{E}-06$ & $6.18 \mathrm{E}-05$ & $6.80 \mathrm{E}-05$ \\
\hline $\mathrm{b}$ & 0.000602 & $9.06 \mathrm{E}-06$ & 0.000593 & 0.000611 \\
\hline \multicolumn{5}{|c|}{$90 \%$ Confidence Intervals } \\
\hline Variable & Value & $90 \%(+/-)$ & Lower Limit & Upper Limit \\
\hline a & $6.49 \mathrm{E}-05$ & $5.30 \mathrm{E}-06$ & $5.96 \mathrm{E}-05$ & $7.02 \mathrm{E}-05$ \\
\hline $\mathrm{b}$ & 0.000602 & $1.54 \mathrm{E}-05$ & 0.000587 & 0.000617 \\
\hline
\end{tabular}

$95 \%$ Confidence Intervals 


\begin{tabular}{|c|c|c|c|c|c|}
\hline Variable & Value & $95 \%(+/-)$ & Lower Limit & Upper Limit & \\
\hline a & $6.49 \mathrm{E}-05$ & $6.45 \mathrm{E}-06$ & $5.85 \mathrm{E}-05$ & 7.13E-05 & \\
\hline $\mathrm{b}$ & 0.000602 & $1.88 \mathrm{E}-05$ & 0.000583 & 0.000621 & \\
\hline \multicolumn{6}{|c|}{$99 \%$ Confidence Intervals } \\
\hline Variable & Value & $99 \%(+/-)$ & Lower Limit & Upper Limit & \\
\hline $\mathrm{a}$ & $6.49 \mathrm{E}-05$ & $8.91 \mathrm{E}-06$ & $5.60 \mathrm{E}-05$ & $7.38 \mathrm{E}-05$ & \\
\hline $\mathrm{b}$ & 0.000602 & $2.60 \mathrm{E}-05$ & 0.000576 & 0.000628 & \\
\hline \multicolumn{6}{|c|}{ Variance Analysis } \\
\hline Source & DF & Sum of Squares & Mean Square & F Ratio & $\operatorname{Prob}(F)$ \\
\hline Regression & 1 & 5905.585 & 5905.585 & 460.3792 & 0 \\
\hline Error & 15 & 192.4148 & 12.82765 & & \\
\hline Total & 16 & 6098 & & & \\
\hline
\end{tabular}


Table E-3. Generalized Yoon and Nelson equation curve fit results for 50 percent relative humidity and $1200 \mathrm{ppm}$ fuel vapor test conditions, using breatkthrough times at $1 \%, 5 \%, 10 \%$, and $20 \%$ of challenge concentration.

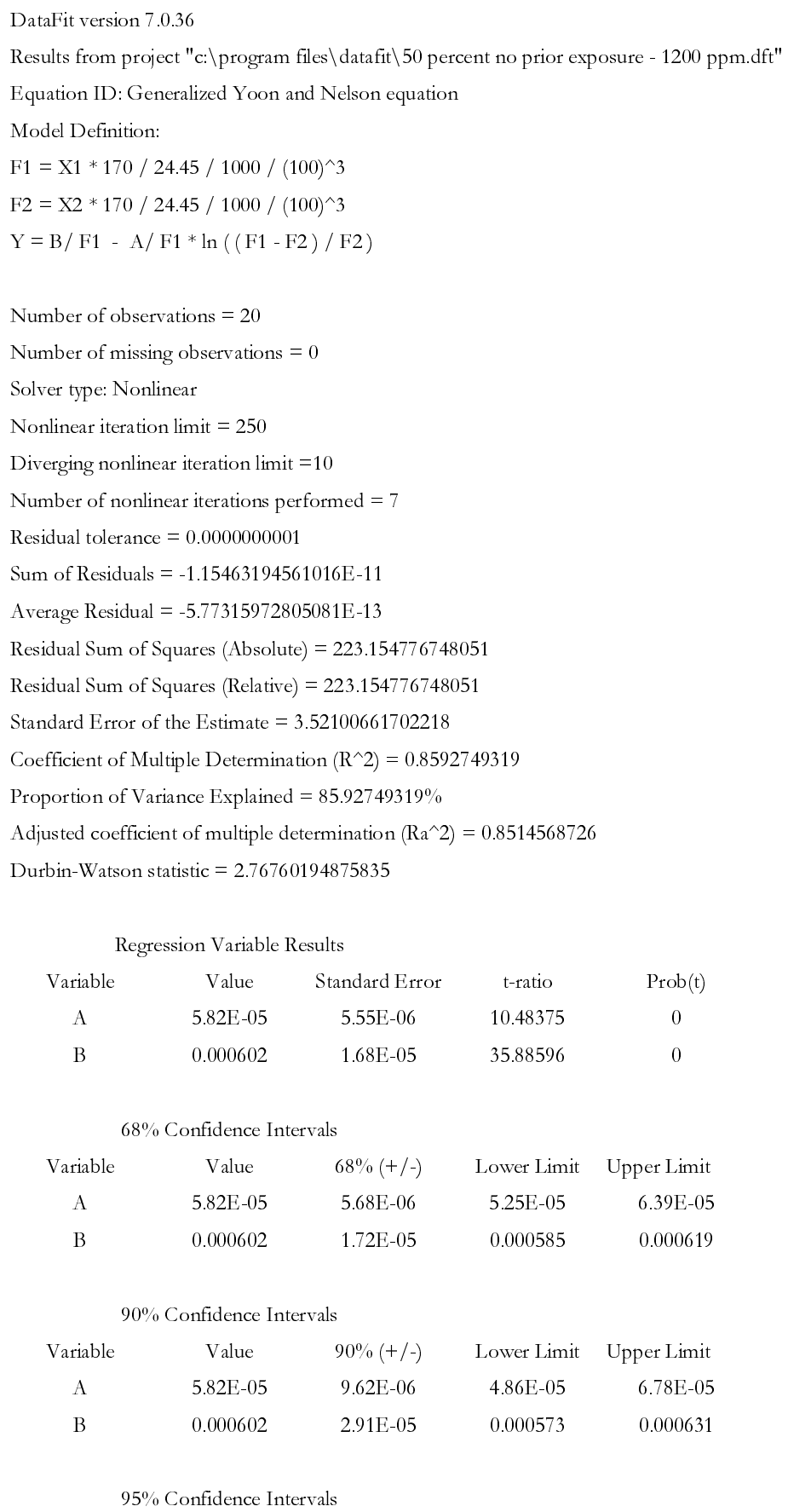

\begin{tabular}{|c|c|c|c|c|}
\hline \multicolumn{3}{|c|}{ Regression Variable Results } & \multirow[b]{2}{*}{ t-ratio } & \multirow[b]{2}{*}{$\operatorname{Prob}(\mathrm{t})$} \\
\hline Variable & Value & Standard Error & & \\
\hline A & $5.82 \mathrm{E}-05$ & $5.55 \mathrm{E}-06$ & 10.48375 & 0 \\
\hline $\mathrm{B}$ & 0.000602 & $1.68 \mathrm{E}-05$ & 35.88596 & 0 \\
\hline \multicolumn{3}{|c|}{$68 \%$ Confidence Intervals } & & \\
\hline Variable & Value & $68 \%(+/-)$ & Lower Limit & Upper Iimit \\
\hline A & $5.82 \mathrm{E}-05$ & $5.68 \mathrm{E}-06$ & $5.25 \mathrm{E}-05$ & $6.39 \mathrm{E}-05$ \\
\hline $\mathrm{B}$ & 0.000602 & $1.72 \mathrm{E}-05$ & 0.000585 & 0.000619 \\
\hline \multicolumn{3}{|c|}{$90 \%$ Confidence Intervals } & & \\
\hline Variable & Value & $90 \%(+/-)$ & Lower Limit & Upper Limit \\
\hline A & $5.82 \mathrm{E}-05$ & $9.62 \mathrm{E}-06$ & $4.86 \mathrm{E}-05$ & $6.78 \mathrm{E}-05$ \\
\hline $\mathrm{B}$ & 0.000602 & $2.91 \mathrm{E}-05$ & 0.000573 & 0.000631 \\
\hline
\end{tabular}

$95 \%$ Confidence Intervals 


\begin{tabular}{|c|c|c|c|c|c|}
\hline Variable & Value & $95 \%(+/-)$ & Lower Limit & Upper Limit & \\
\hline A & $5.82 \mathrm{E}-05$ & $1.17 \mathrm{E}-05$ & 4. $65 \mathrm{E}-05$ & $6.98 \mathrm{E}-05$ & \\
\hline B & 0.000602 & $3.52 \mathrm{E}-05$ & 0.000567 & 0.000637 & \\
\hline \multicolumn{6}{|c|}{$99 \%$ Confidence Intervals } \\
\hline Variable & Value & $99 \%(+/-)$ & Lower Limit & Upper Limit & \\
\hline A & $5.82 \mathrm{E}-05$ & $1.60 \mathrm{E}-05$ & $4.22 \mathrm{E}-05$ & 7.42E-05 & \\
\hline B & 0.000602 & 4.83E-05 & 0.000554 & 0.00065 & \\
\hline \multicolumn{6}{|c|}{ Variance Analysis } \\
\hline Source & $\mathrm{DF}$ & Sum of Squares & Mean Square & F Ratio & $\operatorname{Prob}(\mathrm{F})$ \\
\hline Regression & 1 & 1362.595 & 1362.595 & 109.909 & 0 \\
\hline Error & 18 & 223.1548 & 12.39749 & & \\
\hline Total & 19 & 1585.75 & & & \\
\hline
\end{tabular}


Table E-4. Generalized Yoon and Nelson equation curve fit results for 80 percent relative humidity and $300 \mathrm{ppm}$ fuel vapor test condition (no prior exposure to fuel), using breatkthrough times at $1 \%, 5 \%, 10 \%$, and $20 \%$ of challenge concentration.

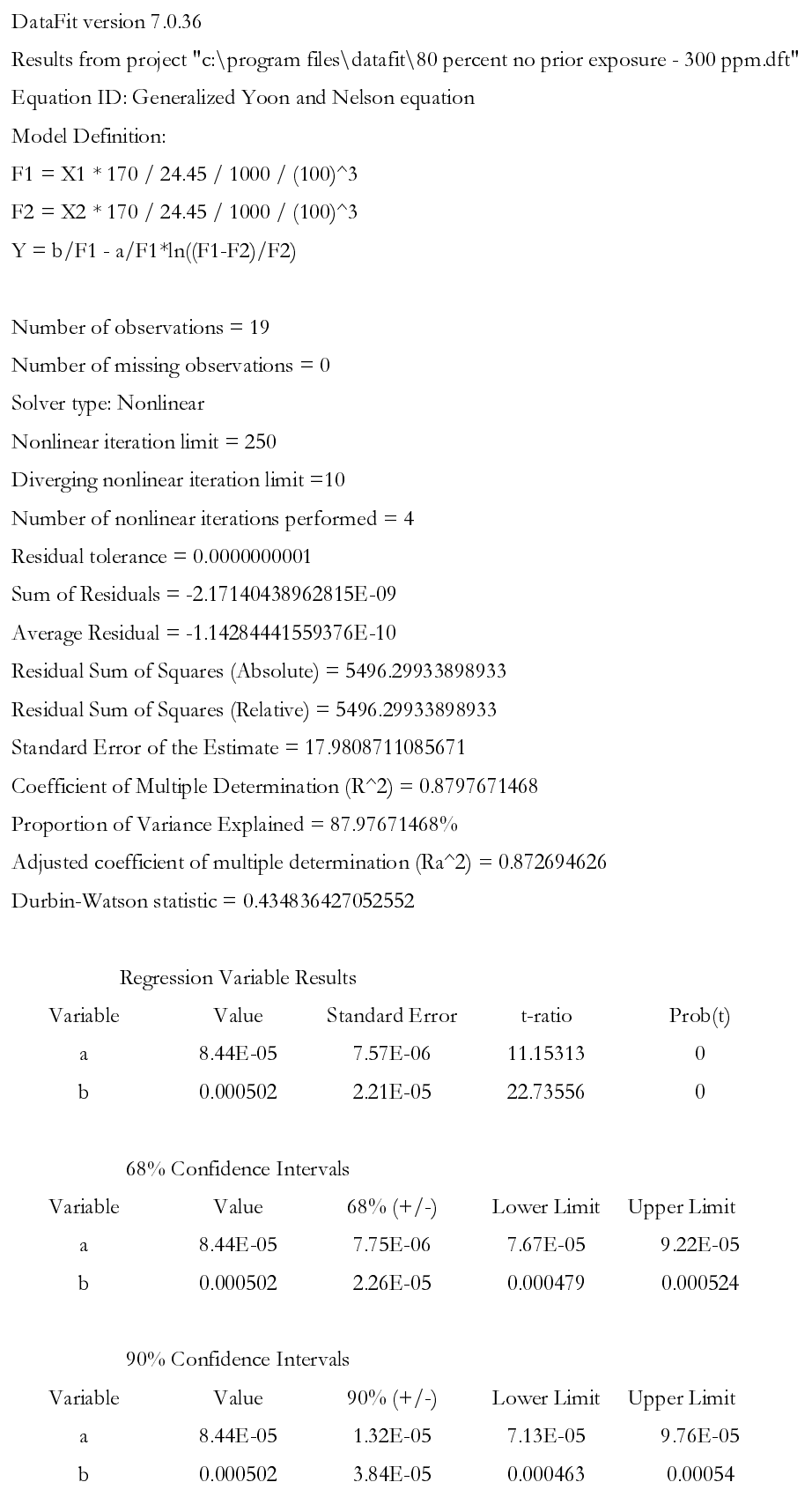

\begin{tabular}{|c|c|c|c|c|}
\hline \multicolumn{5}{|c|}{ Regression Variable Results } \\
\hline Variable & Value & Standard Error & t-ratio & Prob(t) \\
\hline $\mathrm{a}$ & $8.44 \mathrm{E}-05$ & $7.57 \mathrm{E}-06$ & 11.15313 & 0 \\
\hline $\mathrm{b}$ & 0.000502 & $2.21 \mathrm{E}-05$ & 22.73556 & 0 \\
\hline \multicolumn{5}{|c|}{$68 \%$ Confidence Intervals } \\
\hline Variable & Value & $68 \%(+/-)$ & Lower Limit & Upper Limit \\
\hline $\mathrm{a}$ & $8.44 \mathrm{E}-05$ & $7.75 \mathrm{E}-06$ & $7.67 \mathrm{E}-05$ & $9.22 \mathrm{E}-05$ \\
\hline $\mathrm{b}$ & 0.000502 & $2.26 \mathrm{E}-05$ & 0.000479 & 0.000524 \\
\hline \multicolumn{5}{|c|}{$90 \%$ Confidence Intervals } \\
\hline Variable & Value & $90 \%(+/-)$ & Lower Limit & Upper Limit \\
\hline $\mathrm{a}$ & $8.44 \mathrm{E}-05$ & $1.32 \mathrm{E}-05$ & $7.13 \mathrm{E}-05$ & $9.76 \mathrm{E}-05$ \\
\hline $\mathrm{b}$ & 0.000502 & $3.84 \mathrm{E}-05$ & 0.000463 & 0.00054 \\
\hline
\end{tabular}




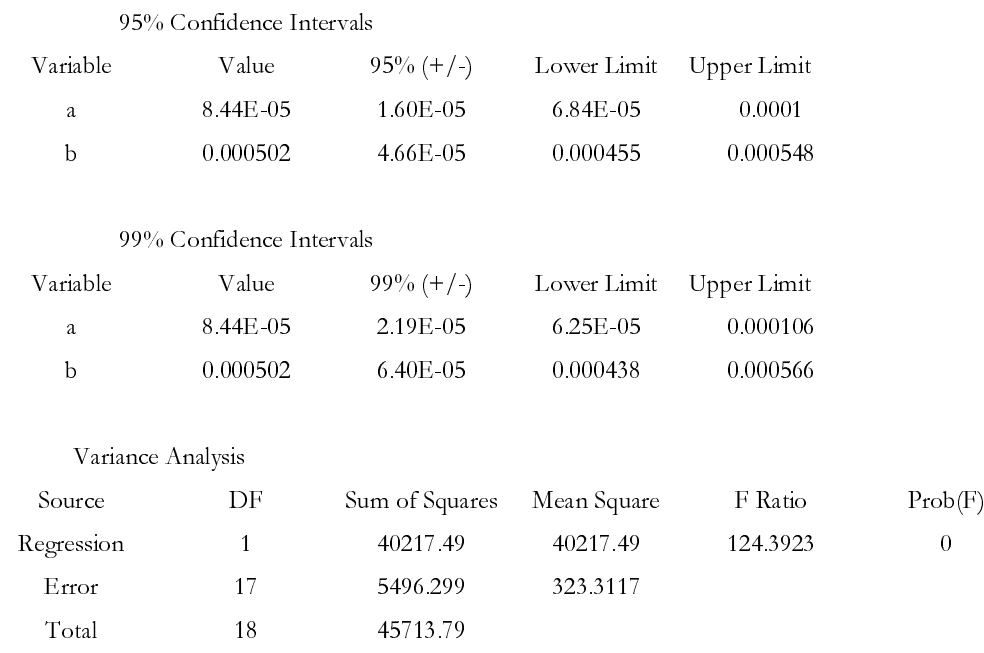


Table E-5. Generalized Yoon and Nelson equation curve fit results for 80 percent relative humidity and $600 \mathrm{ppm}$ fuel vapor test condition (no prior exposure to fuel), using breatkthrough times at $1 \%, 5 \%, 10 \%$, and $20 \%$ of challenge concentration.

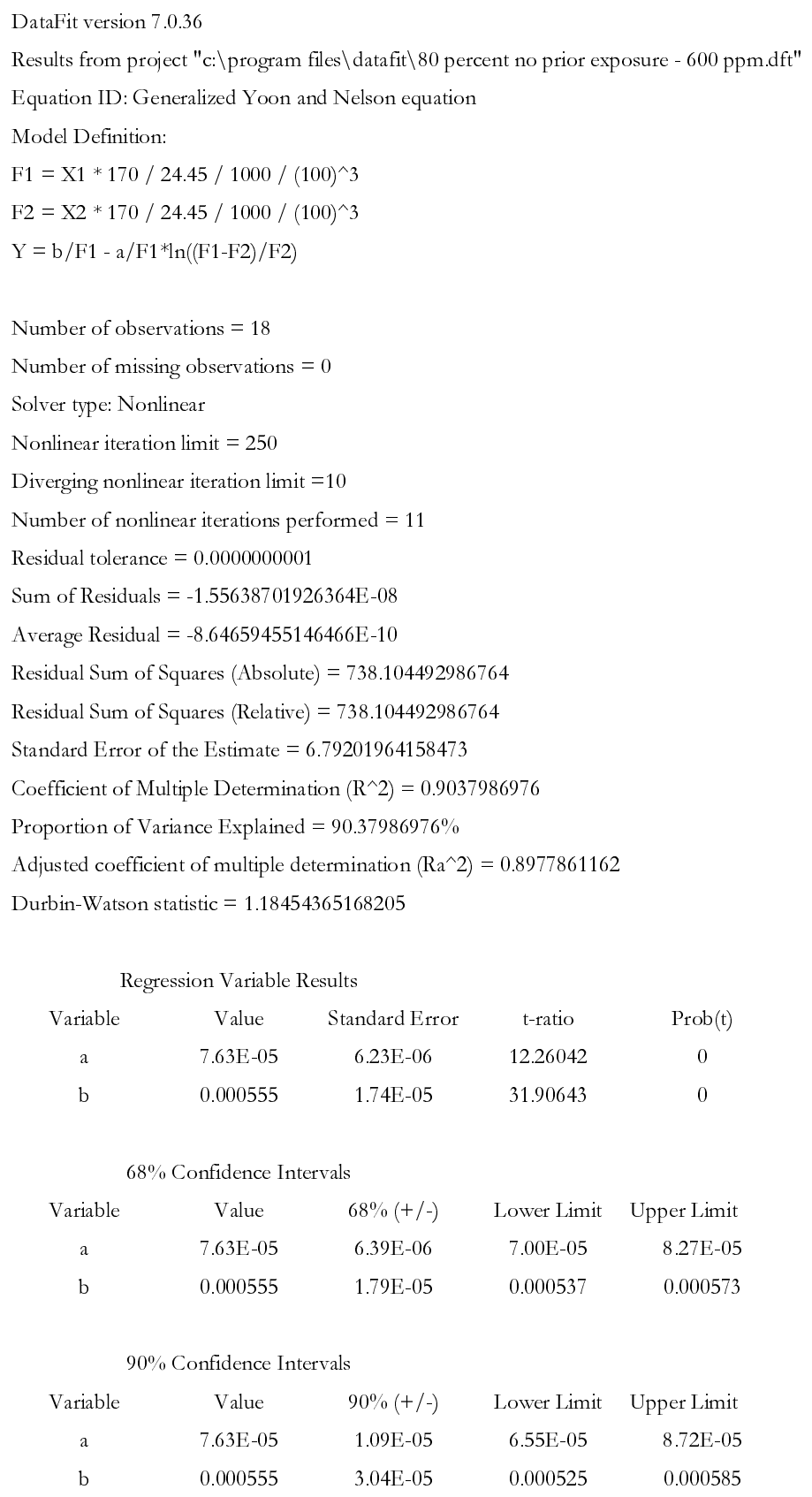

\begin{tabular}{|c|c|c|c|c|}
\hline \multicolumn{5}{|c|}{ Regression Variable Results } \\
\hline Variable & Value & Standard Error & t-ratio & $\operatorname{Prob}(t)$ \\
\hline a & $7.63 \mathrm{E}-05$ & $6.23 \mathrm{E}-06$ & 12.26042 & 0 \\
\hline $\mathrm{b}$ & 0.000555 & $1.74 \mathrm{E}-05$ & 31.90643 & 0 \\
\hline \multicolumn{5}{|c|}{$68 \%$ Confidence Intervals } \\
\hline Variable & Value & $68 \%(+/-)$ & Lower Limit & Upper Iimit \\
\hline a & $7.63 \mathrm{E}-05$ & $6.39 \mathrm{E}-06$ & $7.00 \mathrm{E}-05$ & $8.27 \mathrm{E}-05$ \\
\hline $\mathrm{b}$ & 0.000555 & $1.79 \mathrm{E}-05$ & 0.000537 & 0.000573 \\
\hline \multicolumn{5}{|c|}{$90 \%$ Confidence Intervals } \\
\hline Variable & Value & $90 \%(+/-)$ & Lower Limit & Upper Limit \\
\hline a & $7.63 \mathrm{E}-05$ & $1.09 \mathrm{E}-05$ & $6.55 \mathrm{E}-05$ & $8.72 \mathrm{E}-05$ \\
\hline $\mathrm{b}$ & 0.000555 & $3.04 \mathrm{E}-05$ & 0.000525 & 0.000585 \\
\hline
\end{tabular}




\begin{tabular}{|c|c|c|c|c|c|}
\hline \multicolumn{6}{|c|}{$95 \%$ Confidence Intervals } \\
\hline Variable & Value & $95 \%(+/-)$ & Lower Limit & Upper Limit & \\
\hline a & 7.63E-05 & $1.32 \mathrm{E}-05$ & $6.31 \mathrm{E}-05$ & $8.96 \mathrm{E}-05$ & \\
\hline $\mathrm{b}$ & 0.000555 & $3.69 \mathrm{E}-05$ & 0.000518 & 0.000592 & \\
\hline \multicolumn{6}{|c|}{$99 \%$ Confidence Intervals } \\
\hline Variable & Value & $99 \%(+/-)$ & Lower Limit & Upper Limit & \\
\hline $\mathrm{a}$ & 7.63E-05 & $1.82 \mathrm{E}-05$ & $5.82 \mathrm{E}-05$ & $9.45 \mathrm{E}-05$ & \\
\hline $\mathrm{b}$ & 0.000555 & $5.08 \mathrm{E}-05$ & 0.000504 & 0.000606 & \\
\hline \multicolumn{6}{|c|}{ Variance Analysis } \\
\hline Source & $\mathrm{DF}$ & Sum of Squares & Mean Square & F Ratio & $\operatorname{Prob}(\mathrm{F})$ \\
\hline Regression & 1 & 6934.396 & 6934.396 & 150.3179 & 0 \\
\hline Error & 16 & 738.1045 & 46.13153 & & \\
\hline Total & 17 & 7672.5 & & & \\
\hline
\end{tabular}


Table E-6. Generalized Yoon and Nelson equation curve fit results for 80 percent relative humidity and $1200 \mathrm{ppm}$ fuel vapor test condition (no prior exposure to fuel), using breatkthrough times at $1 \%, 5 \%, 10 \%$, and $20 \%$ of challenge concentration.

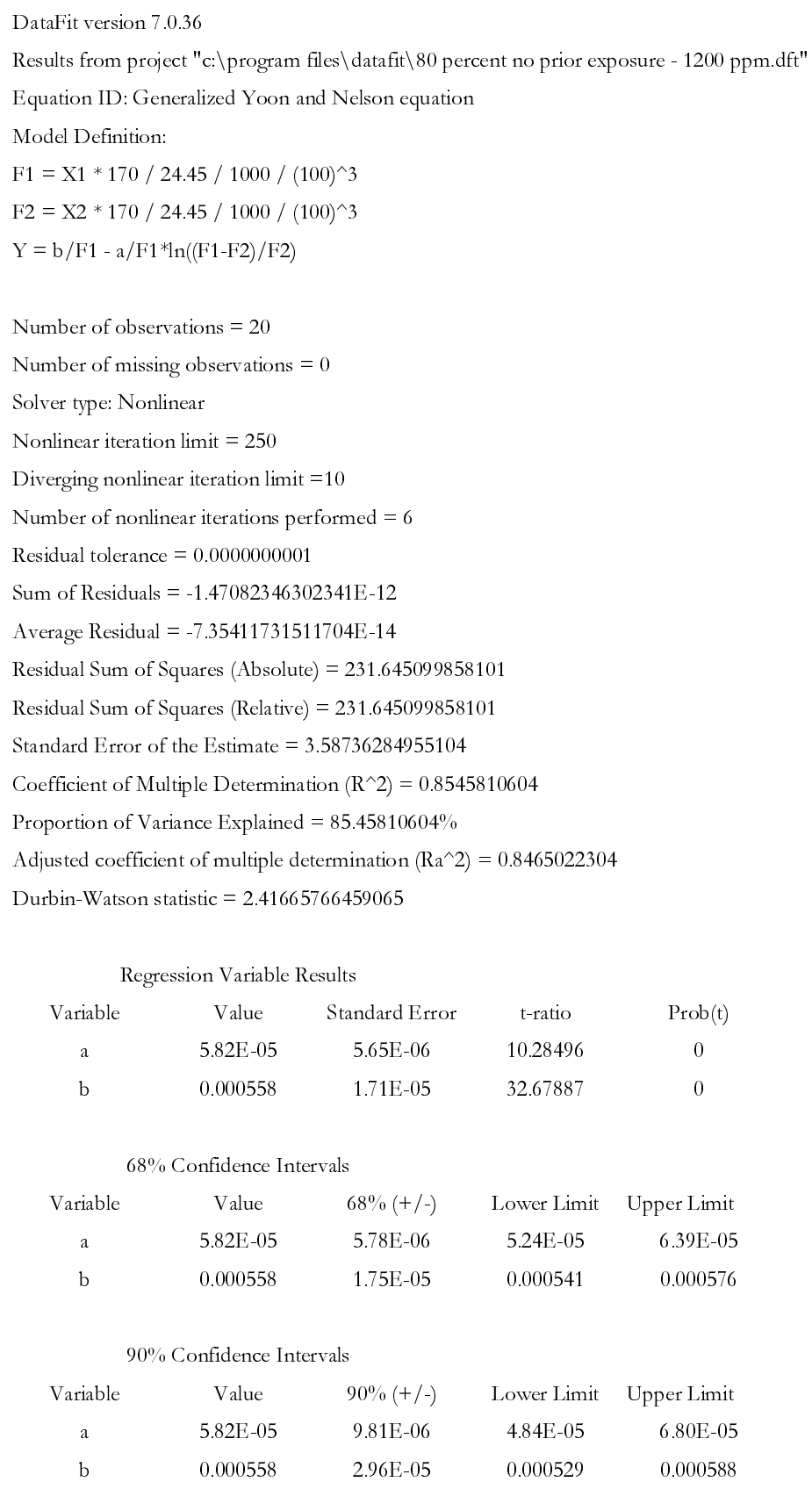

\begin{tabular}{ccccc}
\multicolumn{5}{c}{ Regression Variable Results } \\
Variable & Value & Standard Error & t-ratio & Prob(t) \\
a & $5.82 \mathrm{E}-05$ & $5.65 \mathrm{E}-06$ & 10.28496 & 0 \\
$\mathrm{~b}$ & 0.000558 & $1.71 \mathrm{E}-05$ & 32.67887 & 0 \\
\multicolumn{5}{c}{} \\
\multicolumn{5}{c}{ 68\% Confidence Intervals } \\
Variable & Value & $68 \%(+/-)$ & Lower Limit & Upper Limit \\
a & $5.82 \mathrm{E}-05$ & $5.78 \mathrm{E}-06$ & $5.24 \mathrm{E}-05$ & $6.39 \mathrm{E}-05$ \\
$\mathrm{~b}$ & 0.000558 & $1.75 \mathrm{E}-05$ & 0.000541 & 0.000576 \\
\multicolumn{5}{c}{} \\
Variable & $90 \%$ Confidence Intervals & & \\
a & Value & $90 \%(+/-)$ & Lower Limit & Upper Limit \\
b & $5.82 \mathrm{E}-05$ & $9.81 \mathrm{E}-06$ & $4.84 \mathrm{E}-05$ & $6.80 \mathrm{E}-05$ \\
& 0.000558 & $2.96 \mathrm{E}-05$ & 0.000529 & 0.000588
\end{tabular}




\begin{tabular}{|c|c|c|c|c|c|}
\hline \multicolumn{6}{|c|}{$95 \%$ Confidence Intervals } \\
\hline Variable & Value & $95 \%(+/-)$ & Lower Limit & Upper Limit & \\
\hline a & $5.82 \mathrm{E}-05$ & 1.19E-05 & 4.63E- -05 & $7.00 \mathrm{E}-05$ & \\
\hline $\mathrm{b}$ & 0.000558 & $3.59 \mathrm{E}-05$ & 0.000523 & 0.000594 & \\
\hline \multicolumn{6}{|c|}{$99 \%$ Confidence Intervals } \\
\hline Variable & Value & $99 \%(+/-)$ & Lower Limit & Upper Limit & \\
\hline a & $5.82 \mathrm{E}-05$ & $1.63 \mathrm{E}-05$ & $4.19 \mathrm{E}-05$ & 7.44E-05 & \\
\hline $\mathrm{b}$ & 0.000558 & $4.92 \mathrm{E}-05$ & 0.000509 & 0.000608 & \\
\hline \multicolumn{6}{|c|}{ Variance Analysis } \\
\hline Source & $\mathrm{DF}$ & Sum of Squares & Mean Square & F Ratio & $\operatorname{Prob}(F)$ \\
\hline Regression & 1 & 1361.305 & 1361.305 & 105.7803 & 0 \\
\hline Error & 18 & 231.6451 & 12.86917 & & \\
\hline Total & 19 & 1592.95 & & & \\
\hline
\end{tabular}


Table E-7. Generalized Yoon and Nelson equation curve fit results for 80 percent relative humidity and $300 \mathrm{ppm}$ fuel vapor test condition (with prior exposure to fuel), using breatkthrough times at $1 \%, 5 \%, 10 \%$, and $20 \%$ of challenge concentration.

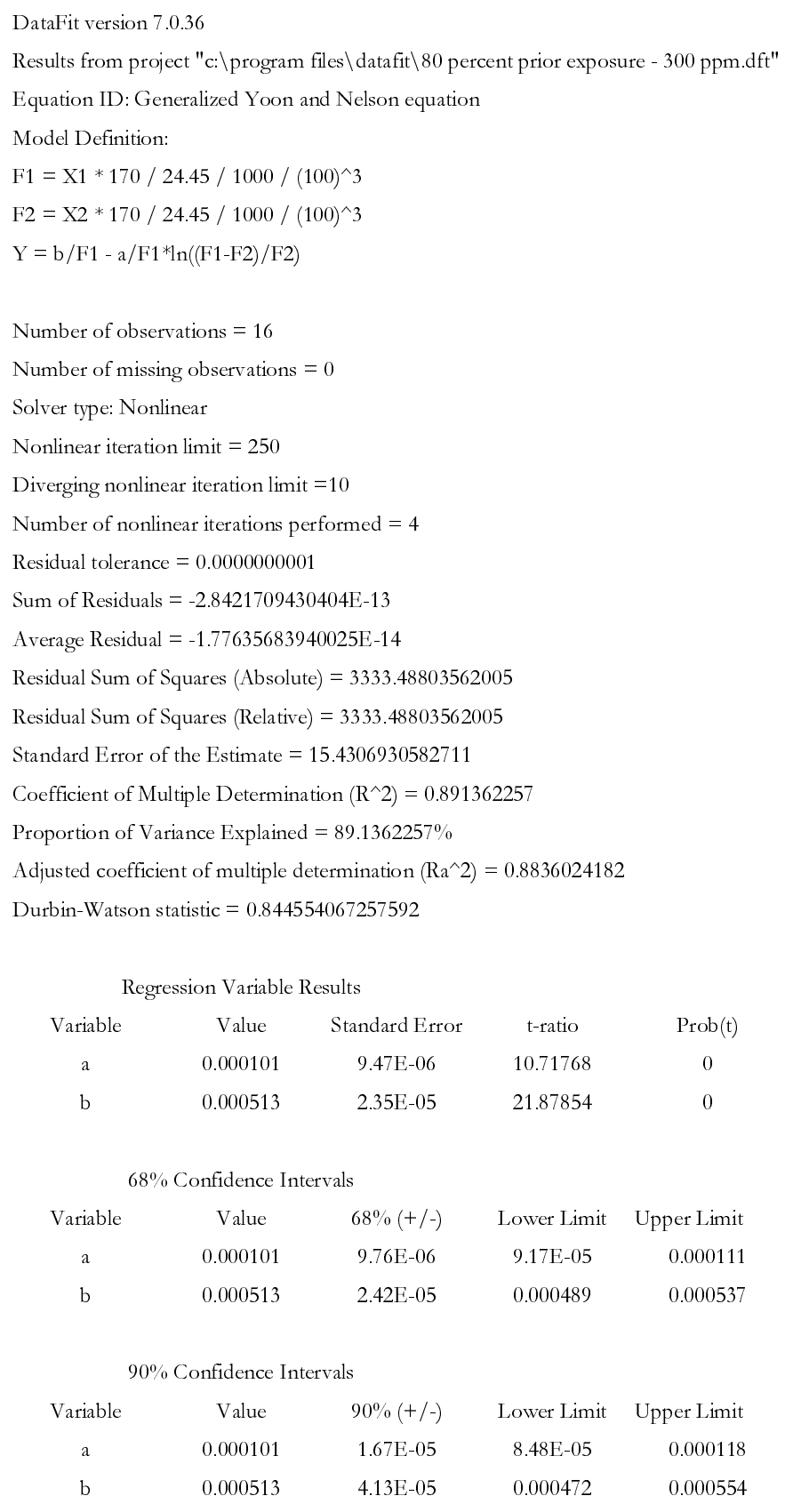

\begin{tabular}{|c|c|c|c|c|}
\hline \multicolumn{5}{|c|}{ Regression Variable Results } \\
\hline Variable & Value & Standard Error & t-ratio & $\operatorname{Prob}(t)$ \\
\hline $\mathrm{a}$ & 0.000101 & $9.47 \mathrm{E}-06$ & 10.71768 & 0 \\
\hline $\mathrm{b}$ & 0.000513 & $2.35 \mathrm{E}-05$ & 21.87854 & 0 \\
\hline \multicolumn{5}{|c|}{$68 \%$ Confidence Intervals } \\
\hline Variable & Value & $68 \%(+/-)$ & Lower Limit & Upper Limit \\
\hline $\mathrm{a}$ & 0.000101 & $9.76 \mathrm{E}-06$ & $9.17 \mathrm{E}-05$ & 0.000111 \\
\hline $\mathrm{b}$ & 0.000513 & $2.42 \mathrm{E}-05$ & 0.000489 & 0.000537 \\
\hline \multicolumn{5}{|c|}{$90 \%$ Confidence Intervals } \\
\hline Variable & Value & $90 \%(+/-)$ & Lower Limit & Upper Limit \\
\hline $\mathrm{a}$ & 0.000101 & $1.67 \mathrm{E}-05$ & $8.48 \mathrm{E}-05$ & 0.000118 \\
\hline b & 0.000513 & 4.13E- -05 & 0.000472 & 0.000554 \\
\hline
\end{tabular}




\begin{tabular}{|c|c|c|c|c|c|}
\hline \multicolumn{6}{|c|}{$95 \%$ Confidence Intervals } \\
\hline Variable & Value & $95 \%(+/-)$ & Lower Limit & Upper Limit & \\
\hline a & 0.000101 & $2.03 \mathrm{E}-05$ & $8.12 \mathrm{E}-05$ & 0.000122 & \\
\hline $\mathrm{b}$ & 0.000513 & $5.03 \mathrm{E}-05$ & 0.000463 & 0.000563 & \\
\hline \multicolumn{6}{|c|}{$99 \%$ Confidence Intervals } \\
\hline Variable & Value & $99 \%(+/-)$ & Lower Limit & Upper Limit & \\
\hline a & 0.000101 & $2.82 \mathrm{E}-05$ & $7.33 \mathrm{E}-05$ & 0.00013 & \\
\hline $\mathrm{b}$ & 0.000513 & $6.98 \mathrm{E}-05$ & 0.000443 & 0.000583 & \\
\hline \multicolumn{6}{|c|}{ Variance Analysis } \\
\hline Source & DF & Sum of Squares & Mean Square & F Ratio & $\operatorname{Prob}(F)$ \\
\hline Regression & 1 & 27350.95 & 27350.95 & 114.8687 & 0 \\
\hline Error & 14 & 3333.488 & 238.1063 & & \\
\hline Total & 15 & 30684.44 & & & \\
\hline
\end{tabular}


Table E-8. Generalized Yoon and Nelson equation curve fit results for 80 percent relative humidity and $600 \mathrm{ppm}$ fuel vapor test condition (with prior exposure to fuel), using breatkthrough times at $1 \%, 5 \%, 10 \%$, and $20 \%$ of challenge concentration.

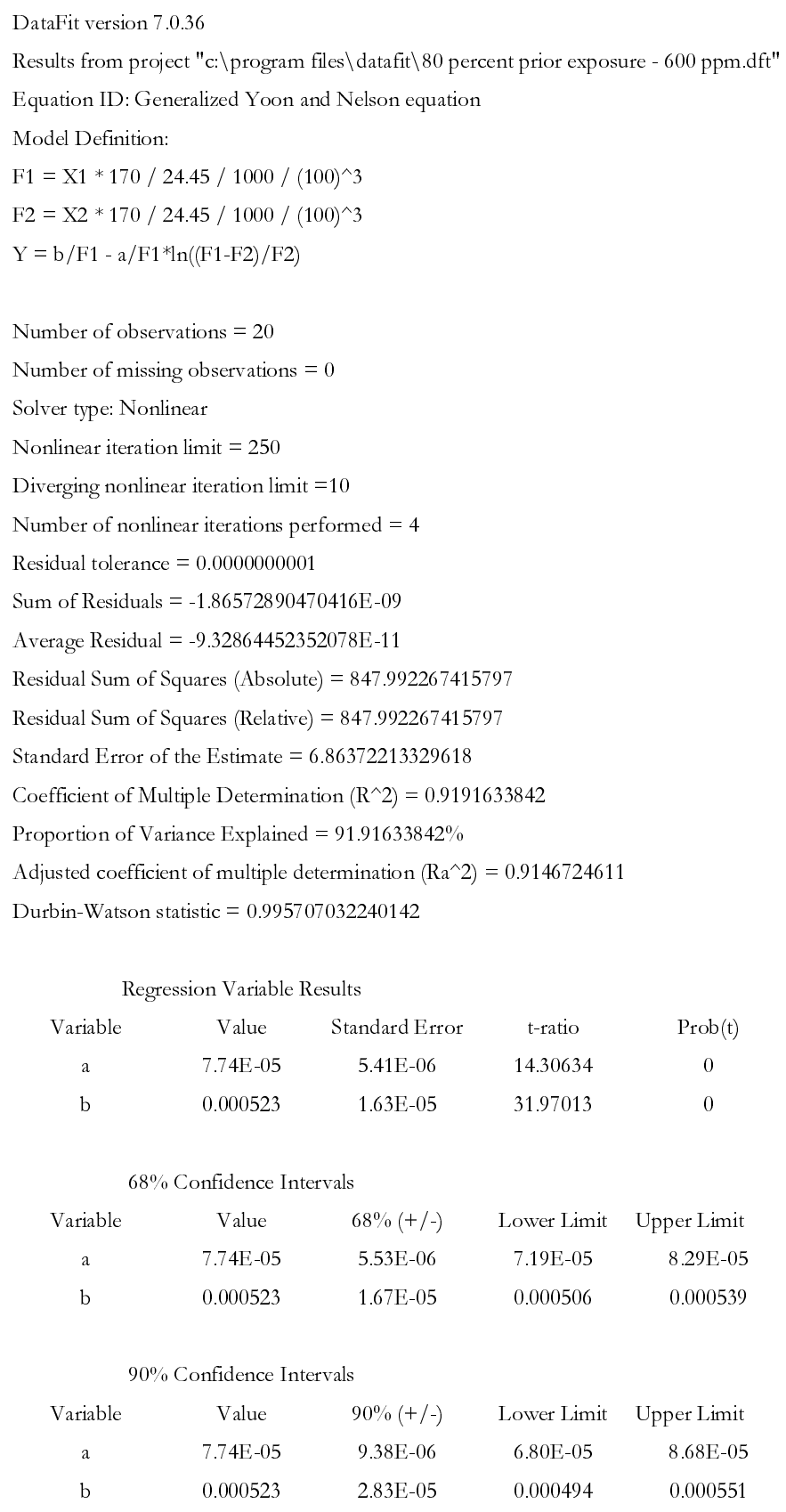

\begin{tabular}{|c|c|c|c|c|}
\hline \multicolumn{5}{|c|}{ Regression Variable Results } \\
\hline Variable & Value & Standard Error & t-ratio & $\operatorname{Prob}(\mathrm{t})$ \\
\hline $\mathrm{a}$ & 7.74E-05 & $5.41 \mathrm{E}-06$ & 14.30634 & 0 \\
\hline $\mathrm{b}$ & 0.000523 & $1.63 \mathrm{E}-05$ & 31.97013 & 0 \\
\hline \multicolumn{5}{|c|}{$68 \%$ Confidence Intervals } \\
\hline Variable & Value & $68 \%(+/-)$ & Lower Limit & Upper Limit \\
\hline $\mathrm{a}$ & $7.74 \mathrm{E}-05$ & $5.53 \mathrm{E}-06$ & $7.19 \mathrm{E}-05$ & $8.29 \mathrm{E}-05$ \\
\hline $\mathrm{b}$ & 0.000523 & $1.67 \mathrm{E}-05$ & 0.000506 & 0.000539 \\
\hline \multicolumn{5}{|c|}{$90 \%$ Confidence Intervals } \\
\hline Variable & Value & $90 \%(+/-)$ & Lower Limit & Upper Limit \\
\hline $\mathrm{a}$ & 7.74E-05 & $9.38 \mathrm{E}-06$ & $6.80 \mathrm{E}-05$ & $8.68 \mathrm{E}-05$ \\
\hline $\mathrm{b}$ & 0.000523 & $2.83 \mathrm{E}-05$ & 0.000494 & 0.000551 \\
\hline
\end{tabular}




\begin{tabular}{|c|c|c|c|c|c|}
\hline \multicolumn{6}{|c|}{$95 \%$ Confidence Intervals } \\
\hline Variable & Value & $95 \%(+/-)$ & Lower Limit & Upper Limit & \\
\hline a & $7.74 \mathrm{E}-05$ & $1.14 \mathrm{E}-05$ & $6.60 \mathrm{E}-05$ & $8.88 \mathrm{E}-05$ & \\
\hline $\mathrm{b}$ & 0.000523 & $3.43 \mathrm{E}-05$ & 0.000488 & 0.000557 & \\
\hline \multicolumn{6}{|c|}{$99 \%$ Confidence Intervals } \\
\hline Variable & Value & $99 \%(+/-)$ & Lower Limit & Upper Limit & \\
\hline a & $7.74 \mathrm{E}-05$ & $1.56 \mathrm{E}-05$ & $6.18 \mathrm{E}-05$ & $9.30 \mathrm{E}-05$ & \\
\hline $\mathrm{b}$ & 0.000523 & $4.71 \mathrm{E}-05$ & 0.000476 & 0.00057 & \\
\hline \multicolumn{6}{|c|}{ Variance Analysis } \\
\hline Source & $\mathrm{DF}$ & Sum of Squares & Mean Square & F Ratio & $\operatorname{Prob}(F)$ \\
\hline Regression & 1 & 9642.208 & 9642.208 & 204.6714 & 0 \\
\hline Error & 18 & 847.9923 & 47.11068 & & \\
\hline Total & 19 & 10490.2 & & & \\
\hline
\end{tabular}


Table E-9. Generalized Yoon and Nelson equation curve fit results for 80 percent relative humidity and $1200 \mathrm{ppm}$ fuel vapor test condition (with prior exposure to fuel), using breatkthrough times at $1 \%, 5 \%, 10 \%$, and $20 \%$ of challenge concentration.

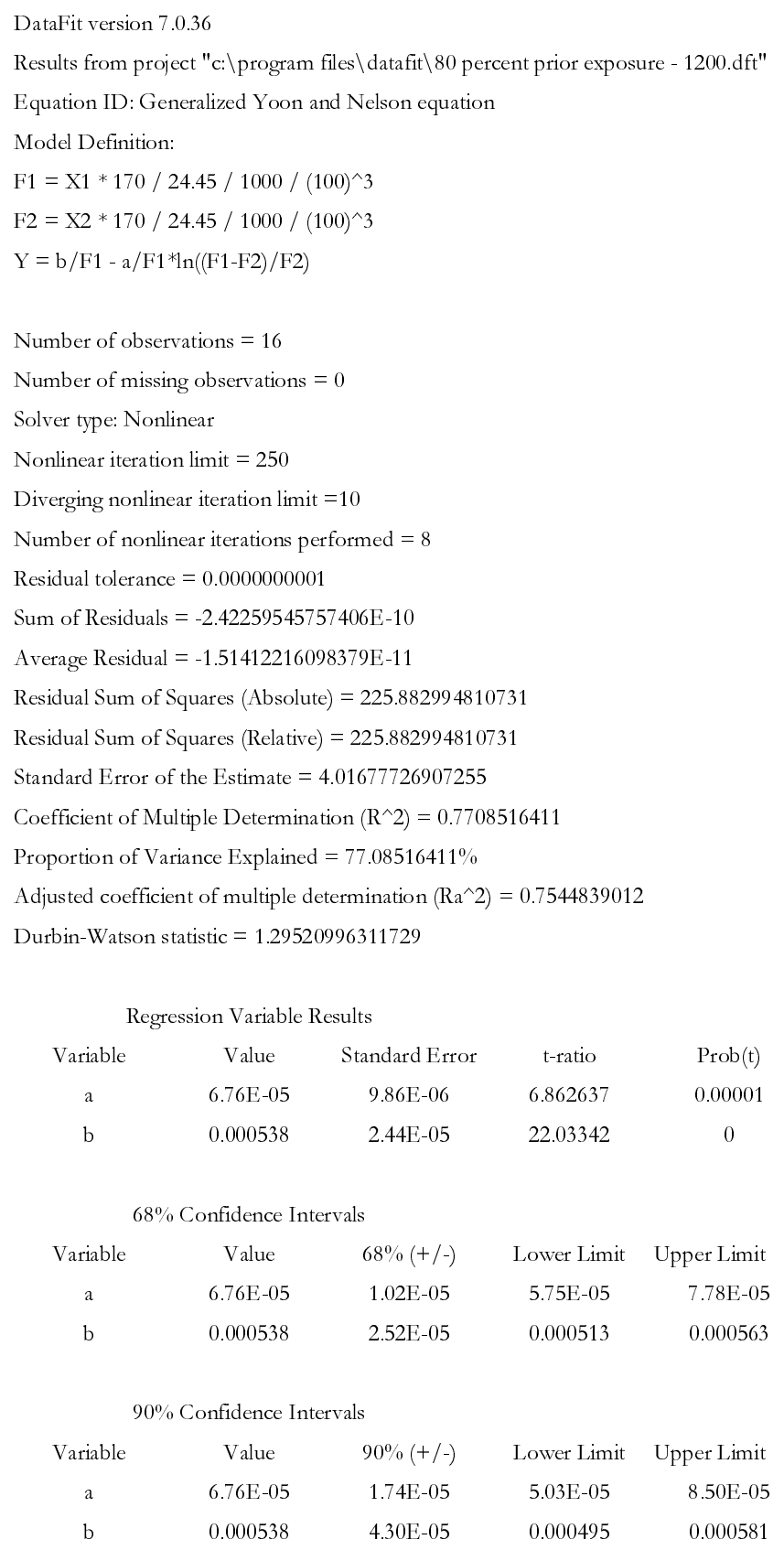




\begin{tabular}{|c|c|c|c|c|c|}
\hline \multicolumn{6}{|c|}{$95 \%$ Confidence Intervals } \\
\hline Variable & Value & $95 \%(+/-)$ & Lower Limit & Upper Limit & \\
\hline a & $6.76 \mathrm{E}-05$ & $2.11 \mathrm{E}-05$ & 4.65E-05 & $8.88 \mathrm{E}-05$ & \\
\hline $\mathrm{b}$ & 0.000538 & $5.24 \mathrm{E}-05$ & 0.000486 & 0.00059 & \\
\hline \multicolumn{6}{|c|}{$99 \%$ Confidence Intervals } \\
\hline Variable & Value & $99 \%(+/-)$ & Lower Limit & Upper Limit & \\
\hline $\mathrm{a}$ & $6.76 \mathrm{E}-05$ & $2.93 \mathrm{E}-05$ & $3.83 \mathrm{E}-05$ & $9.70 \mathrm{E}-05$ & \\
\hline $\mathrm{b}$ & 0.000538 & $7.27 \mathrm{E}-05$ & 0.000465 & 0.000611 & \\
\hline \multicolumn{6}{|c|}{ Variance Analysis } \\
\hline Source & $\mathrm{DF}$ & Sum of Squares & Mean Square & F Ratio & $\operatorname{Prob}(\mathrm{F})$ \\
\hline Regression & 1 & 759.867 & 759.867 & 47.09579 & $1.00 \mathrm{E}-05$ \\
\hline Error & 14 & 225.883 & 16.1345 & & \\
\hline Total & 15 & 985.75 & & & \\
\hline
\end{tabular}

